\title{
Effect of enzyme additions, microaeration and grinding on septic tank performance and sludge accumulation rates
}

\author{
By \\ James Diak, B.Eng.
}

A thesis submitted to the Faculty of Graduate Studies and Research

in partial fulfillment of the requirements for the degree of

\author{
Master of Applied Science \\ in \\ Environmental Engineering*
}
Department of Civil and Environmental Engineering
Carleton University
Ottawa, Ontario
Canada
*The Master of Applied Science in Environmental Engineering program is a joint program with the University of Ottawa administered by the
Ottawa-Carleton Institute for Environmental Engineering

(C) Copyright, 2008 


$\begin{array}{ll}\begin{array}{l}\text { Library and } \\ \text { Archives Canada }\end{array} & \begin{array}{l}\text { Bibliothèque et } \\ \text { Archives Canada }\end{array} \\ \begin{array}{l}\text { Published Heritage } \\ \text { Branch }\end{array} & \begin{array}{l}\text { Direction du } \\ \text { Patrimoine de l'édition }\end{array} \\ \begin{array}{l}\text { 395 Wellington Street } \\ \text { Ottawa ON K1A ON4 } \\ \text { Canada }\end{array} & \begin{array}{l}\text { 395, rue Wellington } \\ \text { Ottawa ON K1A 0N4 } \\ \text { Canada }\end{array}\end{array}$

Your file Votre référence ISBN: 978-0-494-44037-7

Our file Notre référence

ISBN: 978-0-494-44037-7

NOTICE:

The author has granted a nonexclusive license allowing Library and Archives Canada to reproduce, publish, archive, preserve, conserve, communicate to the public by telecommunication or on the Internet, loan, distribute and sell theses worldwide, for commercial or noncommercial purposes, in microform, paper, electronic and/or any other formats.

The author retains copyright ownership and moral rights in this thesis. Neither the thesis nor substantial extracts from it may be printed or otherwise reproduced without the author's permission.
AVIS:

L'auteur a accordé une licence non exclusive permettant à la Bibliothèque et Archives Canada de reproduire, publier, archiver, sauvegarder, conserver, transmettre au public par télécommunication ou par l'Internet, prêter, distribuer et vendre des thèses partout dans le monde, à des fins commerciales ou autres, sur support microforme, papier, électronique et/ou autres formats.

L'auteur conserve la propriété du droit d'auteur et des droits moraux qui protège cette thèse. $\mathrm{Ni}$ la thèse ni des extraits substantiels de celle-ci ne doivent être imprimés ou autrement reproduits sans son autorisation.
In compliance with the Canadian

Privacy Act some supporting forms may have been removed from this thesis.

While these forms may be included in the document page count, their removal does not represent any loss of content from the thesis.
Conformément à la loi canadienne sur la protection de la vie privée, quelques formulaires secondaires ont été enlevés de cette thèse.

Bien que ces formulaires aient inclus dans la pagination, il n'y aura aucun contenu manquant.

\section{Canada}




\begin{abstract}
The purpose of the study was to evaluate and compare simple and inexpensive treatment techniques to enhance digestion rates in septic tanks, improve effluent quality and maximise the pump-out interval. Four enzyme doses, three grinding cycles and microaeration were evaluated in batch reactor stabilisation tests, at two solids concentrations: $4.2 \%$ solids (undiluted primary sludge) and $2.1 \%$ solids (diluted primary sludge). After an initial solubilisation period, microaeration effectively degraded the soluble chemical oxygen demand (sCOD). Enzyme additions increased the COD and carbohydrates of the system, but resulted in high reaction rates. Grinding did not result in any appreciable changes relative to the control tests. The second phase tested two enzyme doses and two microaeration rates using five $40 \mathrm{~L}$ continuous flow reactors seeded with $8 \mathrm{~L}$ of primary sludge and fed a synthetic wastewater. The largest net reduction in COD was achieved through microaeration. Enzyme additions did not result in a significant improvement in the effluent COD relative to the control reactor.
\end{abstract}




\section{Acknowledgements}

First and foremost, I would like to thank my supervisor, Dr. Banu Örmeci for her exceptional dedication and support, her countless guidance and insights, and her gracious generosity throughout this entire process. I would also like to thank my co-supervisor, Dr. Kevin Kennedy, who provided an expertise that was priceless to the design and operation of my experiments, and helped to make this report of higher quality. To all of the committee members who examined this work: Thank You for Your time and contributions. I would also like to thank the laboratory staff at Carleton University, in particular Dr. Marie-Josée Tudoret Chow, who was always so quick and reliable for all of my laboratory needs. To the maintenance staff, who were so quick to repair mishaps in the lab that occurred either directly or indirectly as a result of my experiments, and to my colleagues in the laboratory who put up with my odorous experiments and always respected my space and instruments. I'd also like to thank all of the people from Clearford Industries Inc., in particular Jill Hass, Bruce Linton and Rod Bryden, for their financial support and luxurious trips to the Senators games. I would also like to thank Duane Smith, who helped to initiate my role at Clearford Industries Inc., and the staff at the National Research Council Biotechnology Research Institute (NRC-BRI), in particular Boris Tartakovsky, who accepted random phone calls to his office to share some of his experience and knowledge with me. To the Natural Sciences and Engineering Research Council of Canada (NSERC), thank you for your financial support. It helped to provide me with the ability to focus on my research. And finally, I'd like to thank my family and close friends for their tolerance and unconditional support. 


\section{Table of Contents}

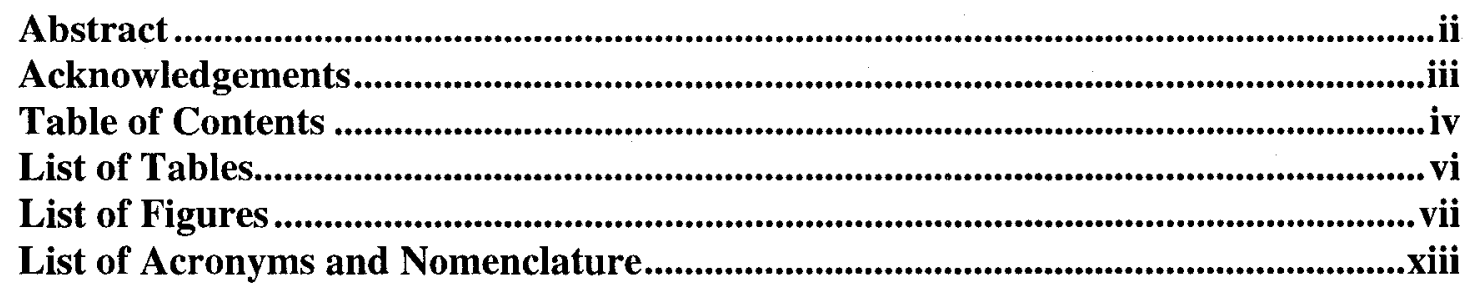

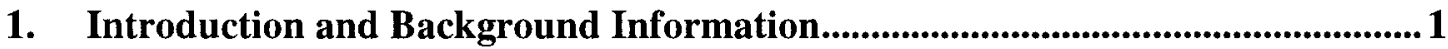

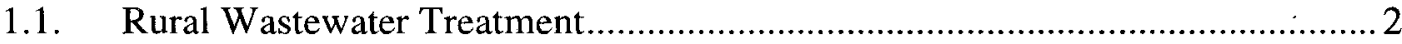

1.1.1. Septic Tank and Soil Absorption System............................................. 3

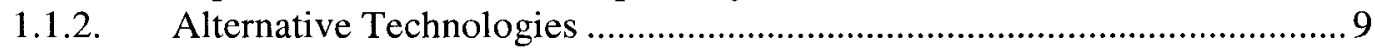

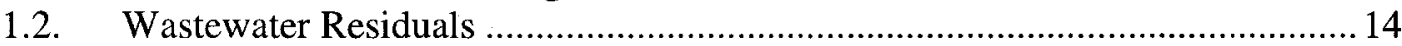

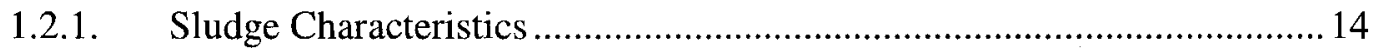

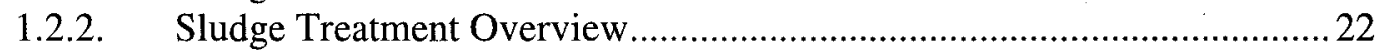

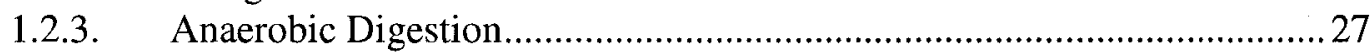

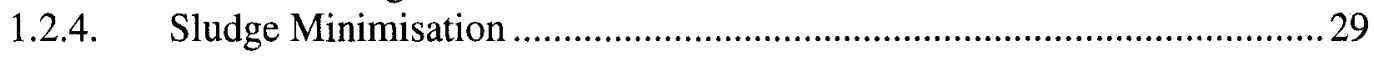

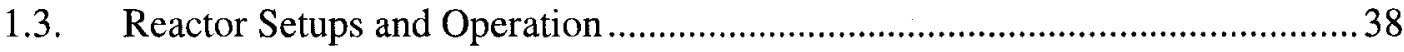

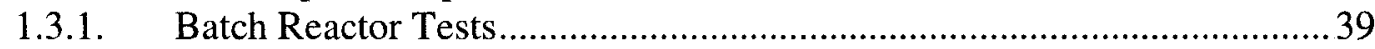

1.3.2. Continuous Flow Reactor Tests ........................................................ 41

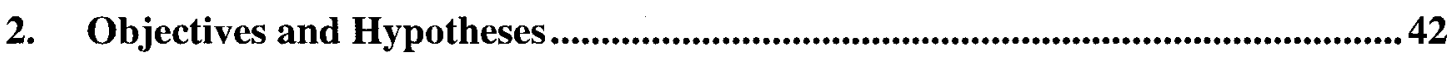

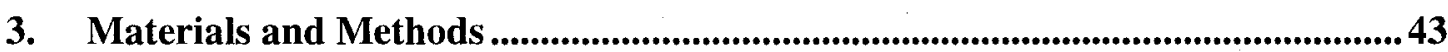

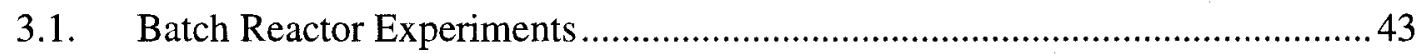

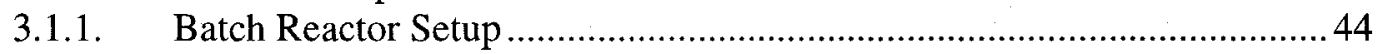

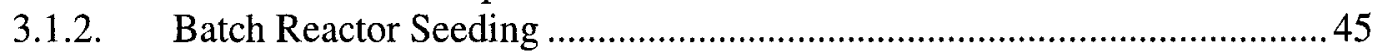

3.1.3. Sludge Minimization Techniques....................................................... 45

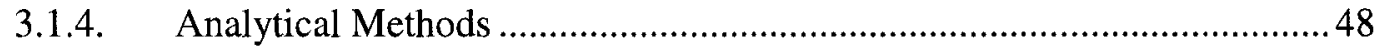

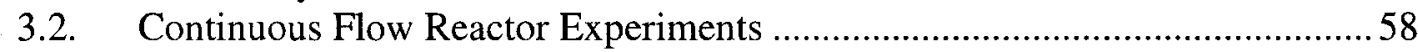

3.2.1. Continuous Flow Reactor Setup ............................................................5 58

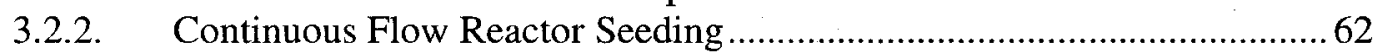

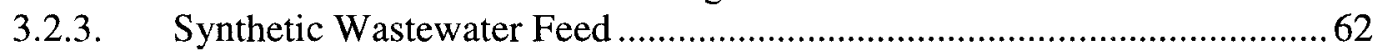

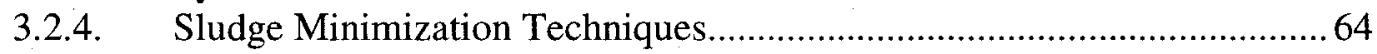

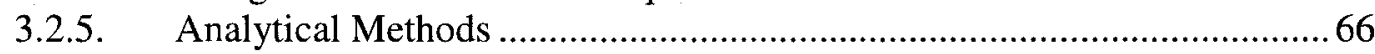

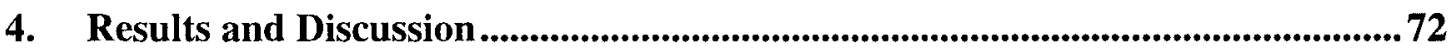

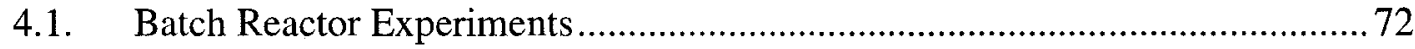

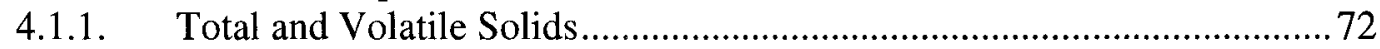

4.1.2. Total Suspended and Volatile Suspended Solids .................................... 80

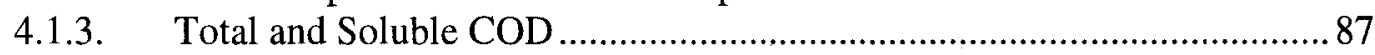

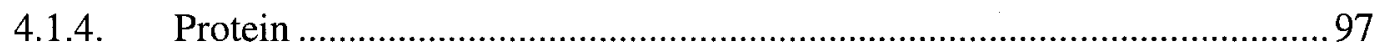

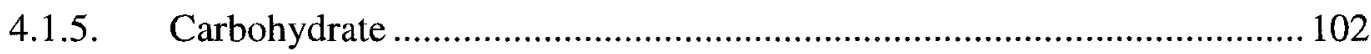

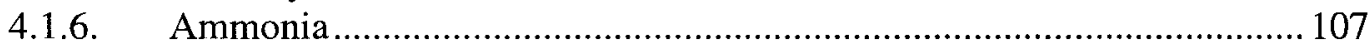




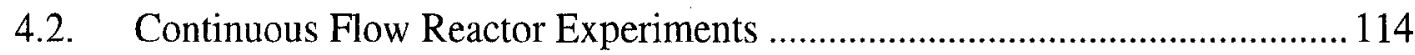

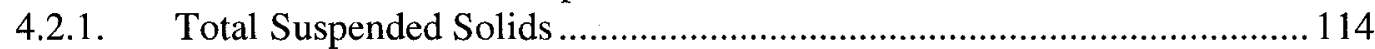

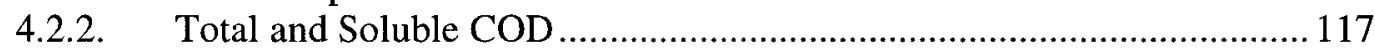

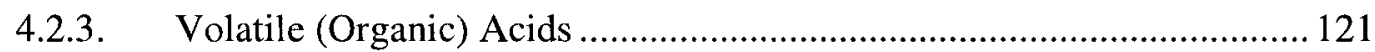

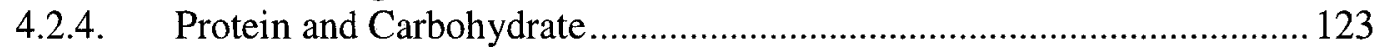

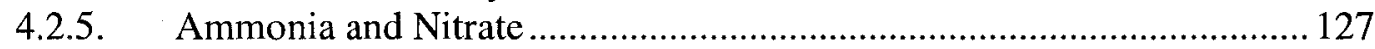

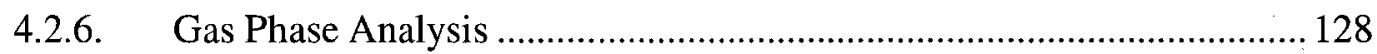

4.2.7. Oxygen Reduction Potential, $\mathrm{pH}$ and Dissolved Oxygen ...................... 130

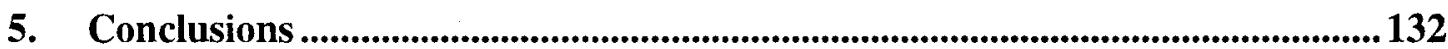

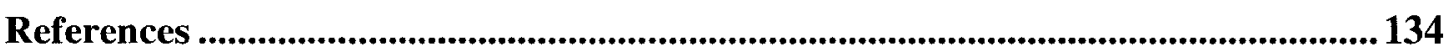

Appendix A: Particle Size Distribution (PSD) Analysis ........................................ 139

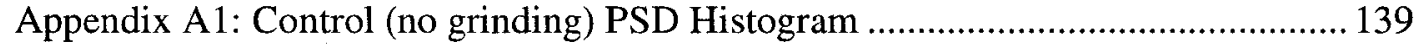

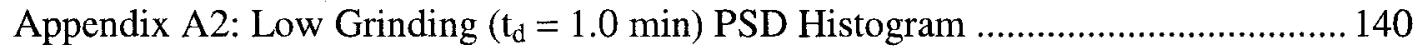

Appendix A3: Moderate Grinding $\left(t_{d}=2.0 \mathrm{~min}\right)$ PSD Histogram ......................... 141

Appendix A4: High Grinding $\left(t_{d}=5.0 \mathrm{~min}\right)$ PSD Histogram ................................ 142

Appendix B: Raw Data - Batch Reactor Tests..................................................143

Appendix B1: Total and Volatile Solids ......................................................... 143

Appendix B2: Total Suspended \& Volatile Suspended Solids .................................. 145

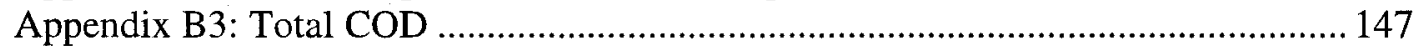

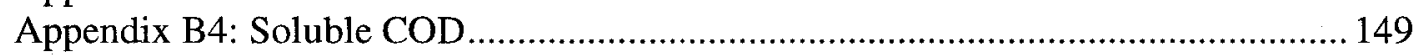

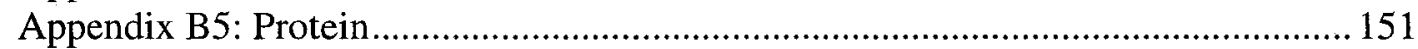

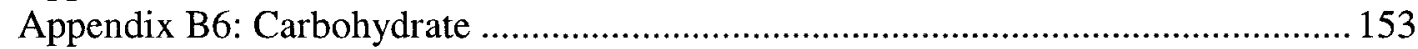

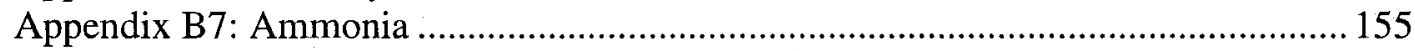

Appendix C: Figures with 95\% C.I. - Batch Reactor Tests................................... 157

Appendix D: Volatile/Total Solids Analysis - Batch Reactor Tests ......................... 174

Appendix E: Raw Data - Continuous Flow Reactor Tests...................................176

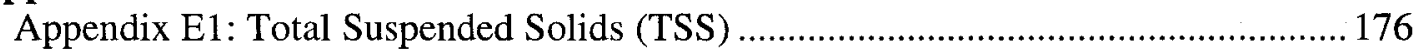

Appendix E2: Total Chemical Oxygen Demand (tCOD) ........................................ 178

Appendix E3: Soluble Chemical Oxygen Demand (sCOD) ...................................... 181

Appendix E4: Volatile (Organic) Acids ................................................................ 184

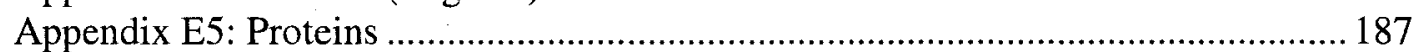

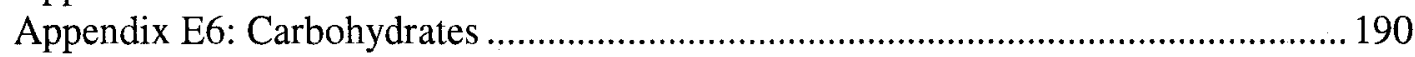

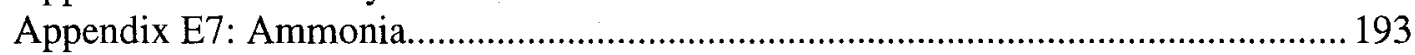

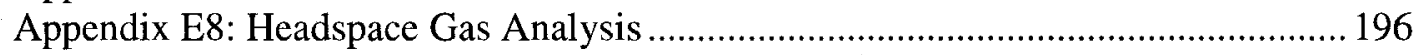

Appendix F: Figures with 95\% C.I. - Continuous Flow Reactor Tests...................197 


\section{List of Tables}

Table 1: List of Substances that are undesirable or detrimental to the Septic Tank and Soil Absorption System (City of Ottawa, 2001, CMHC, 2008) .................................... 8

Table 2: Effluent Quality Criteria for Alternative Treatment Units to the Septic Tank and Soil Absorption System for Ontario (OBC, 1996).

Table 3: Initial characteristics of the raw primary sludges used in the batch reactor experiments

Table 4: Characteristics of the Septaid Powder ${ }^{\mathrm{TM}}$ used as an enzyme additive for the batch reactor tests and for the first 3 months of the continuous flow reactor experiments

Table 5: Initial characteristics of: the raw primary sludge used to seed the continuous flow reactors,

Table 6: Characteristics of the synthetic wastewater used to feed the continuous flow reactors

Table 7: Characteristics of the pure-powder enzyme additive mixture used after 3 months of reactor operation to the end of the experiments.... 65 


\section{List of Figures}

Figure 1-1: Conventional Septic Tank and Soil Absorption System (Thurston County

Public Health and Social Services Department, 2007) 4

Figure 1-2: Conventional 2-Compartment Septic Tank with an Effluent Filter (Sheldon

Farm Septic Tank Service, Inc., 2008) ................................................................ 6

Figure 1-3: Micrograph of WAS (a) prior to and (b) following HPH treatment (Nah et al., 2000) 31

Figure 1-4: Organic (volatile) and mineral matter solubilisation for different thermal pretreatment temperatures (Valo et al., 2004).

Figure 3-1: Diagram of the setup used for the (a) enzyme, grinding and control flasks, and the (b) microaeration flasks (courtesy B. Lynch, Carleton University)...............44

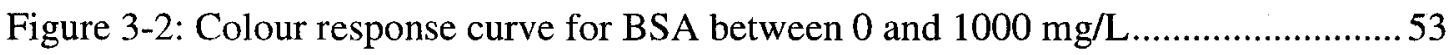

Figure 3-3: Colour response curve for galactose between 0 and $200 \mathrm{mg} / \mathrm{L} \ldots \ldots \ldots \ldots \ldots \ldots . . . . . . . . .55$

Figure 3-4: Picture and diagram of the setup used for the enzyme and control tanks ......60

Figure 3-5: Picture and diagram of the setup used for the microaeration tank with two air diffusers

Figure 3-6: Microaeration rates delivered to the two continuous flow reactors equipped with coarse grained diffusing stones.

Figure 4-1: Profiles of the total and volatile solids concentrations during the batch reactor tests with raw sludge treated with an enzyme and bacterial additive. 74

Figure 4-2: Profiles of the total and volatile solids concentrations during the batch reactor tests with diluted sludge treated with an enzyme and bacterial additive

Figure 4-3: Profiles of the total and volatile solids concentrations during the batch reactor tests with raw primary sludge treated with microaeration .76

Figure 4-4: Profiles of the total and volatile solids concentrations during the batch reactor tests with diluted primary sludge treated with microaeration .77

Figure 4-5: Profiles of the total and volatile solids concentrations during the batch reactor tests with raw primary sludge treated with an initial grinding cycle .78 
Figure 4-6: Profiles of the total and volatile solids concentrations during the batch reactor tests with diluted primary sludge treated with an initial grinding cycle

Figure 4-7: Profiles of the total suspended and volatile suspended solids concentrations during the batch reactor tests with raw sludge treated with an enzyme and bacterial additive.

Figure 4-8: Profiles of the total suspended and volatile suspended solids concentrations during the batch reactor tests with diluted sludge treated with an enzyme and bacterial additive

Figure 4-9: Profiles of the total suspended and volatile suspended solids concentrations during the batch reactor tests with raw primary sludge treated with microaeration .83

Figure 4-10: Profiles of the total suspended and volatile suspended solids concentrations during the batch reactor tests with diluted primary sludge treated with microaeration

Figure 4-11: Profiles of the total suspended and volatile suspended solids concentrations during the batch reactor tests with raw primary sludge treated with an initial grinding cycle.

Figure 4-12: Profiles of the total suspended and volatile suspended solids concentrations during the batch reactor tests with diluted primary sludge treated with an initial grinding cycle.

Figure 4-13: Profiles of the total and soluble COD during the batch reactor tests with raw sludge treated with an enzyme and bacterial additive.

Figure 4-14: Profiles of the total and soluble COD during the batch reactor tests with diluted sludge treated with an enzyme and bacterial additive.

Figure 4-15: Profiles of the total and soluble COD during the batch reactor tests with raw primary sludge treated with microaeration.

Figure 4-16: Profiles of the total and soluble COD during the batch reactor tests with diluted primary sludge treated with microaeration

Figure 4-17: Profiles of the total and soluble COD during the batch reactor tests with raw primary sludge treated with an initial grinding cycle.....

Figure 4-18: Profiles of the total and soluble COD during the batch reactor tests with diluted primary sludge treated with an initial grinding cycle

Figure 4-19: Profiles of the protein concentrations during the batch reactor tests with raw primary sludge samples treated with an enzyme and bacterial additive 
Figure 4-20: Profiles of the protein concentrations during the batch reactor tests with diluted primary sludge samples treated with an enzyme and bacterial additive

Figure 4-21: Profiles of the protein concentrations during the batch reactor tests with raw primary sludge treated with microaeration and an initial grinding cycle 101

Figure 4-22: Profiles of the protein concentrations during the batch reactor tests with diluted primary sludge treated with microaeration and an initial grinding cycle.... 102

Figure 4-23: Profiles of the carbohydrates concentrations during the batch reactor tests with raw primary sludge samples treated with an enzyme and bacterial additive... 104

Figure 4-24: Profiles of the carbohydrates concentrations during the batch reactor tests with diluted primary sludge samples treated with an enzyme and bacterial additive

Figure 4-25: Profiles of the carbohydrate concentrations during the batch reactor tests with raw primary sludge treated with microaeration and an initial grinding cycle. 106

Figure 4-26: Profiles of the carbohydrate concentrations during the batch reactor tests with diluted primary sludge treated with microaeration and an initial grinding cycle

Figure 4-27: Profiles of the ammonia concentrations during the batch reactor tests with raw primary sludge samples treated with an enzyme and bacterial additive

Figure 4-28: Profiles of the ammonia concentrations during the batch reactor tests with diluted primary sludge samples treated with an enzyme and bacterial additive ..... 110

Figure 4-29: Profiles of the ammonia concentrations during the batch reactor tests with raw primary sludge treated with microaeration and an initial grinding cycle.....

Figure 4-30: Profiles of the ammonia concentrations during the batch reactor tests with diluted primary sludge treated with microaeration and an initial grinding cycle.... 113

Figure 4-31: Profiles of the total suspended solids of the influent and the effluents from the continuous flow reactors

Figure 4-32: Profiles of the total and soluble COD of the influent and the effluents from the microaeration and control continuous flow reactors

Figure 4-33: Profiles of the total and soluble COD of the influent and effluents from the enzyme and control continuous flow reactors

Figure 4-34: Profiles of the volatile (organic) acids concentrations in the influent and effluents from the continuous flow reactors. 
Figure 4-35: Profiles of the protein concentrations in the influent and effluents from the continuous flow reactors

Figure 4-36: Profiles of the carbohydrates concentration in the influent and effluents from the continuous flow reactors

Figure 4-37: Profiles of the ammonia concentrations in the influent and effluents from the continuous flow reactors

Figure 4-38: Gas phase analysis of the headspace gas collected from the two enzyme and bacterial additive reactors, and the control reactor

Figure 4-39: Dissolved oxygen measurements on the sample of air-saturated water to show how wastewater reduces the sensitivity of the DO probe

\section{Extra Figures with $95 \%$ Confidence Interval $( \pm 1.96 \sigma)$}

Figure 4-1(b): Profiles of the total and volatile solids concentrations during the batch reactor experiments with raw sludge treated with an enzyme and bacterial additive

Figure 4-2 (b): Profiles of the total and volatile solids concentrations during the batch reactor experiments with diluted sludge treated with an enzyme and bacterial additive

Figure 4-3(b): Profiles of the total and volatile solids concentrations during the batch reactor experiments with raw primary sludge treated with microaeration.

Figure 4-4(b): Profiles of the total and volatile solids concentrations during the batch reactor experiments with diluted primary sludge treated with microaeration.

Figure 4-5(b): Profiles of the total and volatile solids concentrations during the batch reactor experiments with raw primary sludge treated with an initial grinding cycle

Figure 4-6(b): Profiles of the total and volatile solids concentrations during the batch reactor experiments with diluted primary sludge treated with an initial grinding cycle

Figure 4-7(b): Profiles of the TSS and VSS concentrations during the batch reactor experiments with raw sludge treated with an enzyme and bacterial additive

Figure 4-8(b): Profiles of the TSS and VSS concentrations during the batch reactor experiments with diluted sludge treated with an enzyme and bacterial additive .... 162 
Figure 4-9(b): Profiles of the TSS and VSS concentrations during the batch reactor experiments with raw primary sludge treated with microaeration

Figure 4-10(b): Profiles of the TSS and VSS concentrations during the batch reactor experiments with diluted primary sludge treated with microaeration....

Figure 4-11(b): Profiles of the TSS and VSS concentrations during the batch reactor experiments with raw primary sludge treated with an initial grinding cycle

Figure 4-12(b): Profiles of the TSS and VSS concentrations during the batch reactor experiments with diluted primary sludge treated with an initial grinding cycle.... 164

Figure 4-13(b): Profiles of the total and soluble COD during the batch reactor experiments with raw sludge treated with an enzyme and bacterial additive

Figure 4-14(b): Profiles of the total and soluble COD during the batch reactor experiments with diluted sludge treated with an enzyme and bacterial additive .... 165

Figure 4-15(b): Profiles of the total and soluble COD during the batch reactor experiments with raw primary sludge treated with microaeration.

Figure 4-16(b): Profiles of the total and soluble COD during the batch reactor experiments with diluted primary sludge treated with microaeration

Figure 4-17(b): Profiles of the total and soluble COD during the batch reactor experiments with raw primary sludge treated with an initial grinding cycle

Figure 4-18(b): Profiles of the total and soluble COD during the batch reactor experiments with diluted primary sludge treated with an initial grinding cycle..... 167

Figure 4-19(b): Profiles of the protein concentrations during the batch reactor tests with raw primary sludge samples treated with an enzyme and bacterial additive 168

Figure 4-20(b): Profiles of the protein concentrations during the batch reactor tests with diluted primary sludge samples treated with an enzyme and bacterial additive ..... 168

Figure 4-21(b): Profiles of the protein concentrations during the batch reactor tests with raw primary sludge treated with microaeration and an initial grinding cycle

Figure 4-22(b): Profiles of the protein concentrations during the batch reactor tests with diluted primary sludge treated with microaeration and an initial grinding cycle.... 169

Figure 4-23(b): Profiles of the carbohydrates concentrations during the batch reactor tests with raw primary sludge samples treated with an enzyme and bacterial additive .. 170 
Figure 4-24(b): Profiles of the carbohydrates concentrations during the batch reactor tests with diluted primary sludge samples treated with an enzyme and bacterial additive

Figure 4-25(b): Profiles of the carbohydrate concentrations during the batch reactor tests with raw primary sludge treated with microaeration and an initial grinding cycle. 171

Figure 4-26(b): Profiles of the carbohydrate concentrations during the batch reactor tests with diluted primary sludge treated with microaeration and an initial grinding cycle

Figure 4-27(b): Profiles of the ammonia concentrations during the batch reactor tests with raw primary sludge samples treated with an enzyme and bacterial additive

Figure 4-28(b): Profiles of the ammonia concentrations during the batch reactor tests with diluted primary sludge samples treated with an enzyme and bacterial additive ..... 172

Figure 4-29(b): Profiles of the ammonia concentrations during the batch reactor tests with raw primary sludge treated with microaeration and an initial grinding cycle

Figure 4-30(b): Profiles of the ammonia concentrations during the batch reactor tests with diluted primary sludge treated with microaeration and an initial grinding cycle.... 173

Figure 4-31(b): Profiles of the total suspended solids of the influent and effluents from the continuous flow reactors

Figure 4-32(b): Profiles of the total and soluble COD of the influent and effluents from the microaeration and control continuous flow reactors

Figure 4-33(b): Profiles of the total and soluble COD of the influent and effluents from the enzyme and the control continuous flow reactors

Figure 4-34(b): Profiles of the volatile (organic) acids concentrations in the influent and effluents from the continuous flow reactors

Figure 4-35(b): Profiles of the protein concentrations in the influent and effluents from the continuous flow reactors

Figure 4-36(b): Profiles of the carbohydrates concentration in the influent and effluents from the continuous flow reactors.

Figure 4-37(b): Profiles of the ammonia concentrations in the influent and effluents from the continuous flow reactors

Figure 4-38(b): Gas phase analysis of the headspace gas collected from the two enzyme and bacterial additive reactors, and the control reactor. 


\section{List of Acronyms and Nomenclature}

\begin{tabular}{|l|l|}
\hline BOD & Biological Oxygen Demand, expressed as 5-day BOD \\
\hline CBOD & Carbonaceous component of the BOD \\
\hline CMHC & Canada Mortgage and Housing Corporation \\
\hline COD & Chemical Oxygen Demand \\
\hline sCOD & Soluble component of the COD $\left(\mathrm{d}_{\mathrm{p}}<0.45 \mu \mathrm{m}\right)$ \\
\hline tCOD & Total COD \\
\hline CSA & Canadian Standards Association \\
\hline CSTR & Completely Stirred Tank Reactor \\
\hline CWWA & Canadian Water and Wastewater Association \\
\hline EPS & Extracellular Polymeric Substances \\
\hline HOAc & Acetic Acid \\
\hline HPH & High Pressure Homogeniser \\
\hline MBR & Membrane Bioreactor \\
\hline NRC-BRI & National Research Council Biotechnology Research Institute \\
\hline OBC & Ontario Building Code \\
\hline TDS & Total dissolved solids \\
\hline ThOD & Theoretical Oxygen Demand \\
\hline TOC & Total Organic Carbon \\
\hline TS & Total Solids \\
\hline TSS & Total Suspended Solids \\
\hline TVS & Total Volatile Solids \\
\hline US EPA & United States Environmental Protection Agency \\
\hline VFAs & Volatile Fatty Acids \\
\hline VS & Volatile Solids \\
\hline VSS & Volatile Suspended Solids \\
\hline WWTP & Wastewater Treatment Plant \\
\hline
\end{tabular}




\section{Introduction and Background Information}

The septic tank and soil absorption system is an elegantly passive on-site wastewater treatment system that remains to be one of the most common methods of treating household wastewater in rural areas. Where limitations exist, such as land restrictions, modifications to the conventional system have been used. Nowadays, with the desire to alleviate some of the environmental demands of conventional systems, particularly where high density installations exist, newer alternative technologies have been used. Each of these alternative technologies brings added cost and complication, and as with the conventional septic tank, regular system pump-outs are required to remove the accumulated solids within the tank. The purpose of this study was to investigate and compare the effects of three treatment techniques (enzyme and bacterial additives, microaeration and grinding) on septic tank performance and sludge accumulation rates. The research intends to see if the treatments enhance biodegradation rates and eventually maximise pump-out intervals, and improve effluent quality using simple means that do not require expensive or complex modification to septic tanks.

This chapter will describe the conventional septic tank and soil absorption system, as well as some of the alternative technologies used to treat rural wastewater. It will also describe various features of wastewater and sludge that will be used in the experiments to characterise the effectiveness of the various sludge minimisation techniques. To better understand how the various treatment techniques can be used to improve degradation and reduce sludge volumes, a brief review of some of the commonly used sludge minimisation technologies is also included. 


\subsection{Rural Wastewater Treatment}

In cities and large communities throughout North America, the wastewater generated is collected in municipal sanitary sewers and sent to a wastewater treatment plant with little worry to the homeowner. In rural areas however, where a complex sewage piping infrastructure is economically unfeasible, a septic tank and soil absorption system remains the predominant method for household wastewater treatment. The invention of the septic tank was credited to Louis Mouras of Vesoul, France in 1881 (Hammond and Tyson, 1991). Shortly after, baffles were added to the tank to regulate the flow and promote settling conditions. Nowadays, although the system is over century old, very few changes have been made, and according to the Canada Mortgage and Housing Corporation (CMHC, 2008), the system is still used by $25 \%$ of Canadians. Septic systems are suitable for on-site wastewater treatment due to their low energy requirements, small space requirements and simple reactor design (Luostarinen et al., 2006). In Ontario, septic systems are regulated by the Ministry of Municipal Affairs and Housing, and must be built in accordance with Part 8 , Sections 8.6 and 8.7 of the Ontario Building Code (OBC) (CMHC, 2008). Although variations to the system exist, the fundamentals are the same. The following sections will describe the septic tank and soil absorption system, and some of the variations or alternative technologies to the classic technology. 


\subsubsection{Septic Tank and Soil Absorption System}

The conventional septic tank and soil absorption system consists of a large wastewater retention unit called a septic tank, a distribution box, a series of distribution pipes and a drain field (Figure 1-1). Wastewater from the house enters the septic tank, where the flow is dampened and partially retained. This allows time for the large solids to settle, forming the sludge bed, and the fats, oils and grease to float to the surface, forming the scum layer. The sludge layer and scum layer are retained in the tank, where they accumulate and partially degrade. The middle layer is a conditioned and nearly solidsfree liquid layer which leaves the tank and enters a distribution box, where it is evenly distributed throughout the drainage tiles. The drainage tiles distribute the effluent evenly throughout the drain field, and into the underlying soils, where the remaining biological treatments take place. If solids escape the septic tank, they will quickly clog the distribution pipes and the leaching tiles, and cause wastewater to seep up to the soil surface, or potentially backup into the house. Septic system failures are expensive to fix, and pose a significant health hazard for people and the environment. To ensure good and reliable performance, septic tanks must be operated and maintained properly. 


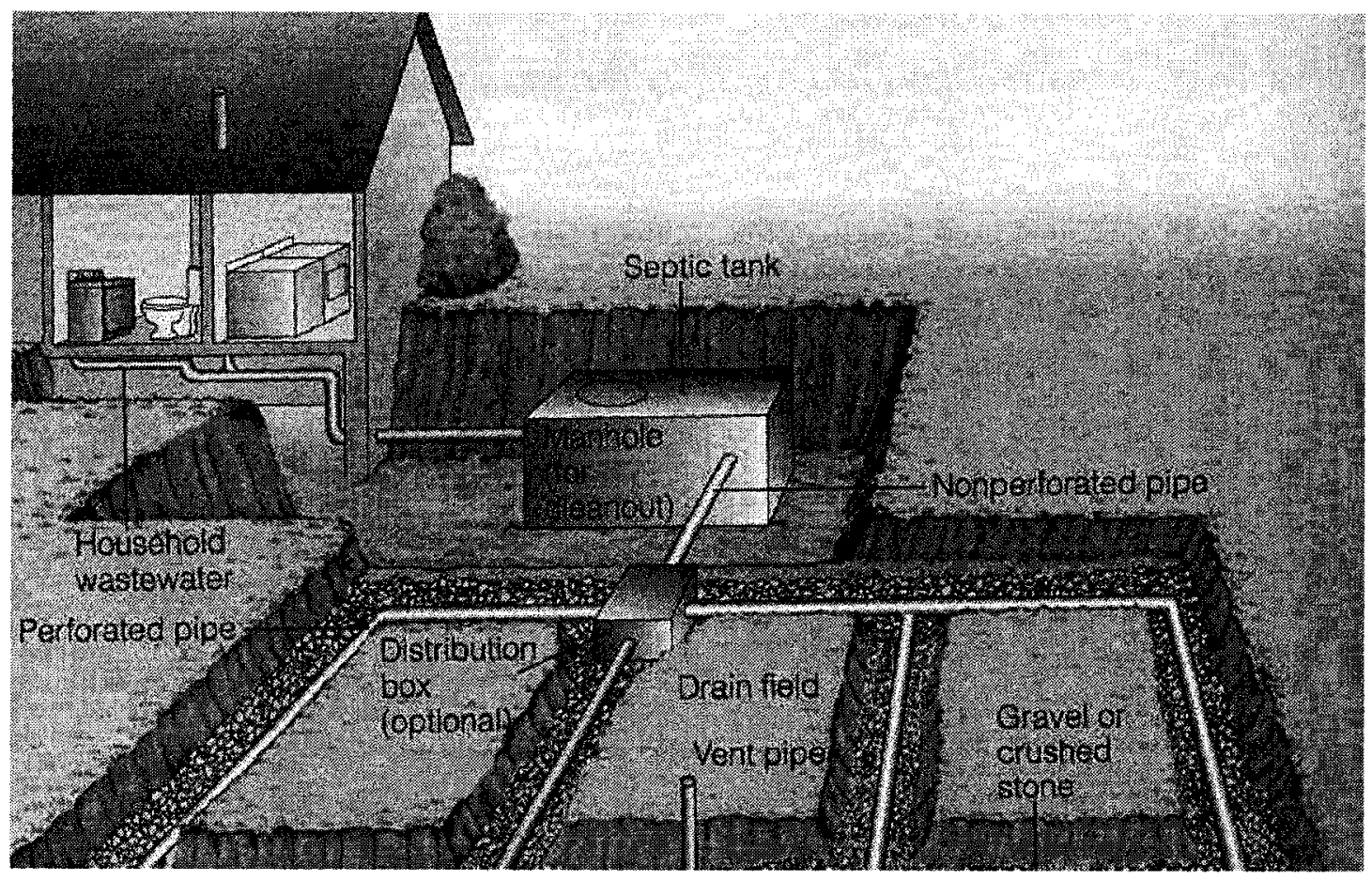

Figure 1-1: Conventional Septic Tank and Soil Absorption System (Thurston County Public Health and Social Services Department, 2007)

\subsubsection{Septic Tanks}

Septic tanks may have one or two-compartments and are typically made of concrete, polyethylene or fibreglass, although some older septic tanks were made of steel or wood (CMHC, 2008). OBC requires the septic tank to meet the requirements of a CSA B66 "Prefabricated Septic Tanks and Sewage Holding Tanks" (OBC, 1997). When installed, the capacity of the septic tank for a house is usually based on the number of bedrooms in a house, which reflects the liveable capacity. Newer household septic tanks usually have a capacity of 3600 to $4500 \mathrm{~L}$, while schools and businesses require larger tanks. Some community developments have large communal septic tanks. This idea was first performed in Saratoga, NY, in 1903, where four septic tanks were installed with a total capacity of almost $5000 \mathrm{~m}^{3}$ (Hammond and Cecil, 1991). 
Septic tanks serve to dampen the flow which allows the heavier solids to settle to the bottom of the tank and the lighter solids to float to the surface, and also to provide time for the partial degradation of some of the organic material. In the United States, septic tanks must be large enough to retain the wastewater flow for at least 24 hours (Hammond and Tyson, 1991). The wastewater retention time is known as the hydraulic retention time (HRT), and is determined by dividing the volume of the septic tank by the average expected flow rate to the septic tank as shown by Equation 1-1.

$$
H R T(\text { days })=\frac{V\left(m^{3}\right)}{Q\left(m^{3} / \text { day }\right)} \quad \text { Equation 1-1 }
$$

where:

HRT: hydraulic retention time of the septic tank (days)

$\mathrm{V}$ : volume of the septic tank $\left(\mathrm{m}^{3}\right)$

$\mathrm{Q}$ : wastewater flow rate into the septic tank $\left(\mathrm{m}^{3} /\right.$ day $)$

Over time, the heavier solids in the wastewater gradually accumulate in the septic tank, forming a distinct sludge layer at the bottom, similarly the lighter substances such as fats, oils and greases are retained to form a scum layer at the surface of the tank (Figure 1-2). Inside the tank conditions are anaerobic, often referred to as "septic", which allows the anaerobic bacteria present in wastewater to flourish. After an initial acclimatisation period, the bacterial populations in the septic tank condition the wastewater and digest some of the organic solids in the sludge. Some of the solids in the wastewater feed stream are not easily biodegradable and remain in the tank. These solids must be removed periodically be pumping out the tank, or they may escape the septic tank and 
clog the drainage tiles. To prevent the latter, more recent septic tanks have an effluent filter at the outlet of the tank (Figure 1-2). The effluent filter is cheap to replace and can save the drain field from clogging.

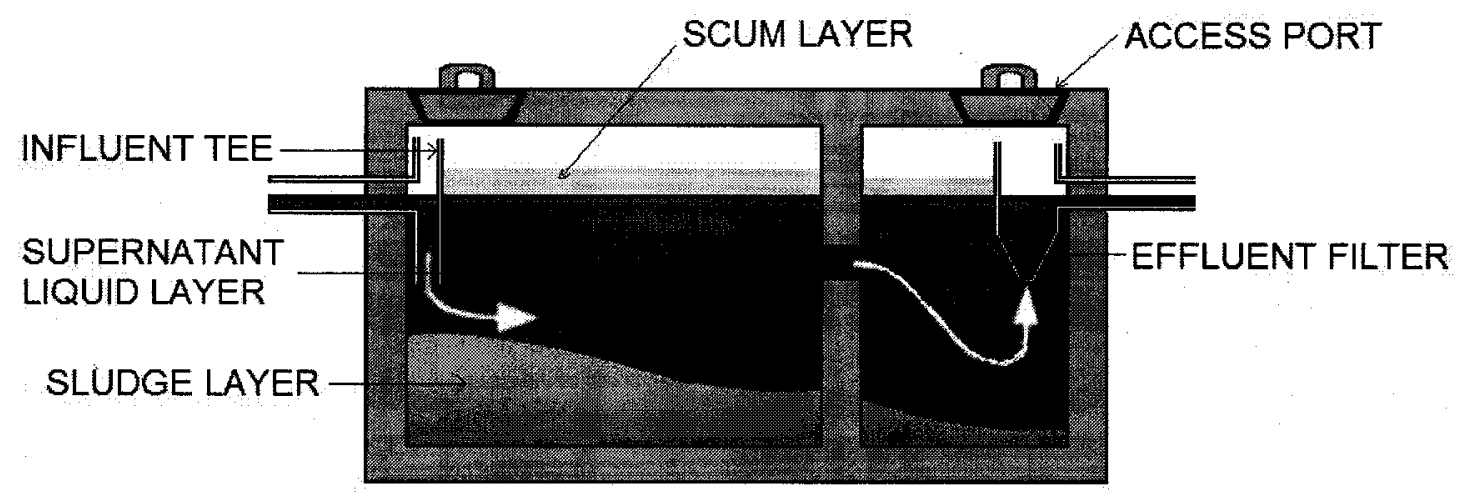

Figure 1-2: Conventional 2-Compartment Septic Tank with an Effluent Filter (Sheldon Farm Septic Tank Service, Inc., 2008)

\subsubsection{Drain Field}

A drain field is commonly referred to as a drainage bed, leaching bed or absorption bed. The drain field consists of a network of perforated plastic pipes (distribution pipes), in gravel trenches (distribution trenches) on top of a layer of soil (drainage bed). Older systems used clay tiles to disperse the effluent into the native soil. The gravel distribution trenches surrounding the distribution pipes help to move the septic effluent away from the pipes where it percolates into the underlying soil. The gravel distribution trenches also provide a site for bacteria to grow, which help to treat the effluent. In Ontario, the construction and placement of leaching beds is strictly regulated. The drain field must not be placed within 30 metres of a well $(15 \mathrm{~m}$ for well with a water tight casing), 15 meters of an open water body (stream, lake, pond, reservoir, river, spring), 5 
meters of a structure and 2 meters of the property line. Also, there must be at least $0.9 \mathrm{~m}$ of soil above the underlying bedrock or the high-level water table for effluent absorption. The actual size of the drainage network depends on the amount of wastewater generated and the hydraulic conductivity of the underlying soils. The hydraulic conductivity of the underlying soils must be sufficient to retain the effluent long enough for treatment to occur, while allowing the effluent to percolate into the underlying soils fast enough to avoid saturating the surrounding soils in the drain field. As the effluent percolates down through the drain field and into the underlying soils, the remaining biological treatment takes place. In the past it was believed that septic tanks removed most of the bacteria from the wastewater, but it is now understood that the supernatant liquid portion of the wastewater leaving the tank has high amounts of bacteria, nutrients and organic matter. As a result, drain fields must be properly constructed and maintained to ensure safe and reliable onsite wastewater treatment.

A good drain field provides an optimal site for a slime layer of bacteria, known as a "biomat", to form. The biomat typically exists on the bottom and sidewalls of the gravel distribution trenches. The biomat is capable of breaking down some of the organic matter and converting some nutrients in the wastewater to other forms. In particular, ammonia nitrogen, which is harmful to many aquatic species, is converted to nitrate nitrogen, which is less harmful. Other harmful bacteria and viruses are removed from the wastewater in the leaching bed as it percolates down through the various layers of soil and rock through filtration, predation and environmental exposure (CHMC, 2008). 


\subsubsection{System Care and Maintenance}

Most rural wastewater treatment systems are entirely biological, which means diligent use and care are imperative. The biological activity of the system is susceptible to variations such as temperature, organic load and most importantly toxins. Many things like cleaners, dyes and other detergents are poisonous to the microbes in the septic tank and drain field or could contaminate the surface or groundwater. Even small amounts of nail polish remover or excessive amounts of kitchen grease can be detrimental to the system (Hammond and Tyson, 1991, CHMC, 2008). Other things may not necessarily kill the microbes but are not easily broken down by bacteria and will accumulate in the tank, or may lead to the formation of undesirable end products. Matches for instance, will add sulphur to the system, which will contribute to the formation of hydrogen sulphide, which is a toxic and flammable gas with an offensive odour of rotten eggs. Table 1 lists a variety of substances that should not be flushed down the toilet or drain because they are undesirable or harmful for the septic tank system, or because they are detrimental to the groundwater and surface water.

Table 1: List of Substances that are undesirable or detrimental to the Septic Tank and Soil Absorption System (City of Ottawa, 2001, CMHC, 2008)

\begin{tabular}{|l|l|l|l|}
\hline \multicolumn{2}{|c|}{ Undesirable or Harmful Substances } & \multicolumn{2}{c|}{ Groundwater/Surface Water } \\
\hline Loose hair, & Disposable diapers & Paints & Nail polish \\
Dental floss & Tampons, condoms & Varnishes & remover \\
Coffee grounds, & Gauze bandages & Thinners & Pesticides or \\
Cigarette buts, & Paper towels, & Waste oils & herbicides \\
Fats, oils and greases & Facial tissues, & Photographic & \\
Egg shells, bones and & Sanitary napkins & solutions & \\
vegetable scraps & Kitty litter & & \\
\hline
\end{tabular}


Diligent use of your septic system will minimise the amount of non-degradable components entering the tank, and will sustain healthy bacterial populations within the tank to help degrade some of the organic solids. Regardless, the accumulation of sludge is inevitable and will necessitate periodic tank pump-outs. In Virginia and many other states, septic tank inspections and pump-outs are performed annually by the region and the associated pump-out and disposal fees are incorporated into the homeowners' property taxes. In Quebec, many communities have bi-annual pump-out cycles which are regulated in a similar fashion, whereas in Ontario, the $\mathrm{OBC}$ guidelines recommend a pump-out every three to five years, and also require that the tank be pumped out once the sludge level has reached one third of the liquid operating depth. Periodic inspections by qualified personnel will help to determine if a pump-out is required. A study by Philip et al., 1993, suggested a 5-year pump-out interval since digestive activities within the tank are only effective after 2 years of operation.

\subsubsection{Alternative Technologies}

The following sections will discuss some of the most common alternative technologies to the conventional septic tank and soil absorption system. Most of these technologies are simply minor variations or additions to the conventional system to achieve desirable performance under undesirable conditions, namely soil or landscape/property conditions. In cases where the design requirements stipulated by the local regulations cannot be met, alternative treatment technologies can be used as long as the treatment system is proven to be effective. In Ontario, alternative treatment technologies must meet the effluent quality criteria in Table 2. 
Table 2: Effluent Quality Criteria for Alternative Treatment Units to the Septic Tank and Soil Absorption System for Ontario (OBC, 1996)

\begin{tabular}{|l|c|c|}
\hline \multicolumn{1}{|c|}{ Parameter } & Secondary Effluent $(\mathrm{mg} / \mathrm{L})$ & Tertiary Effluent (mg/L) \\
\hline BOD & 40 & 15 \\
\hline CBOD & 30 & 10 \\
\hline Suspended Solids & 20 & 10 \\
\hline
\end{tabular}

1. Based on 30 day averages $(\mathrm{mg} / \mathrm{L})$

\subsubsection{Pressure Distribution System}

A pressure distribution system has a pump and pump chamber in the distribution box following the septic tank. The pump ensures a uniform distribution of the effluent throughout the leaching bed, and can be used to provide intermittent doses of effluent over the drainage. Intermittent dosing cycles can be used when the hydraulic conductivity of the drainage soils is too low to percolate effluent continuously. However, most often if the drainage capacity of the underlying soils is insufficient, the drain field is expanded over a larger area, or some more appropriate soils are imported. If none of these cheaper alternatives are feasible, then a pressure distribution system may be required. A pressure distribution system may also be used when the distribution pipe network is longer than normal. In Ontario, the $\mathrm{OBC}$ requires a pump or siphon system to be used if the total length of the distribution pipe network exceeds $150 \mathrm{~m}$ to ensure a uniform dispersion of effluent over the drain field. 


\subsubsection{Raised Bed System}

A raised bed system is also known as a mound system. It is used when the soil overlying the bedrock is too shallow, or the groundwater table is too close to the surface. A raised leaching bed system assures that there is consistently unsaturated soil surrounding the leaching tiles, capable of absorbing and treating the septic tank effluent. The soil used in the raised bed must be supported and protected from erosion, excessive evaporation and drainage or runoff. Furthermore, raised beds must not be covered with anything such as a driveway or a patio, which would limit the amount of air available to soil. A raised bed system also requires a pump and pump chamber, which is often incorporated into the distribution box as with a pressure distribution system.

\subsubsection{Small Diameter Gravity Sewer System}

Small diameter gravity sewer (SDGS) systems have been used in Australia since the 1960's and the United States since the 1970's (United States Environmental Protection Agency (US EPA, 2000a). SDGS systems are used to convey the effluent from household septic tanks by gravity to a pumping reservoir or directly to a semidecentralised wastewater treatment facility. These systems have typically been used in excessively hilly terrain where conventional concrete sewers would require deep excavations, although some installations have been used in newly constructed subdevelopments to convey septic tank effluent to smaller, semi-decentralised wastewater facilities. The SDGS system is very attractive for several reasons. Many of the advantages of the system are the result of the existing septic tank technology. As describes in section 1.1.1, septic tanks remove most of the solids from the wastewater, 
which enables the use of small diameter sewers. The SDGS system is easier, faster and cheaper to install than conventional sewers because the trenches for the pipelines are shallower and narrower, as well the material costs are significantly reduced because the SDGS pipelines are much smaller than conventional sewers. Furthermore, the final treatment costs for the semi-decentralised wastewater treatment facility are reduced because the large amount of rain water infiltration that is typical with conventional concrete sewer systems is minimised, and more substantially, the effluent has been partially treated by the septic tank to remove solids and some of the organic content. Concerns of the system that must be addressed include: proper sewer depth to prevent freezing, corrosion of pipes, odour control and similarly to conventional septic tanks, periodic pump-outs are required to remove the accumulation of solids.

A partner in this research was Clearford Industries, Ottawa ON. The Wastewater Systems Division of Clearford Industries Inc., designs and implements a patented Small Bore Sewer ${ }^{\mathrm{TM}}\left(\mathrm{SBS}^{\mathrm{TM}}\right)$ technology. The system uses small diameter sewers to collect the effluent from household Clarifiers ${ }^{\mathrm{TM}}$ or septic tanks, primarily via gravity. The system has successfully been installed in several locations in Canada and the United States (Clearford Industries Inc., 2008). Although previous installations have pertained to the treatment and collection of wastewater from new sub-developments, the small diameter sewer trend will likely move towards the rehabilitation of the current aging septic tank and soil absorption systems in rural communities throughout North America. 


\subsubsection{Aerobic Treatment Units}

Aerobic treatment units (ATUs) treat the effluent from a settling chamber or septic tank using oxygen to promote the growth of aerobic microorganisms. The effluent leaving the ATU is treated to a higher level than conventional septic tanks, and can be released over smaller drain fields, or nearer to surface waters, and in some cases, directly into surface waters. ATUs are most commonly used when conventional septic systems are inadequate due to the soil conditions, property location or property size, and/or proximity of the drain field to underlying bedrock or water table. Household ATUs have been used in the United States since the 1950's, however these earlier systems were noisy, released foul odours, were prone to failure and required routine maintenance (US EPA, 2000b). By the 1970's, proven ATUs were all over the market, with successful installations all across North America (CHMC, 2008). In the United States, the National Sanitation Federation (NSF) created a program to certify the various models of ATUs, and by June 2000, 100 models from 15 manufacturers were certified to meet the NSF Class I effluent performance limits (US EPA, 2000b). Class I effluent meets the US EPA Secondary Treatment Guidelines for BOD, suspended solids and $\mathrm{pH}$, which are very similar to the effluent quality criteria for the province of Ontario, presented in Table 1. Colour, such as oily films, foaming, odour and noise are also addressed in the NSF certification program. The improved effluent quality from ATUs comes with added cost. These systems require electricity and more frequent maintenance than conventional septic systems. Furthermore, ATUs require mechanical parts which can fail, rendering the units nonfunctional. As a precaution ATUs are rigged with an alarm to notify the homeowner in the event of a system failure. 


\subsection{Wastewater Residuals}

The components removed from the wastewater, which accumulate in the tank are commonly referred to as septage. Septage is a combination of sludge and scum that must be removed from the tank periodically to prevent solids from escaping the septic tank and clogging the distribution pipes. When septage is pumped out of the septic tank, it is typically hauled to the nearest WWTP and treated along with the wastewater residuals generated from the WWTP processes.

\subsubsection{Sludge Characteristics}

The characteristics of sludge depend on the type of sludge and the age of the sludge. Primary sludge is considered young sludge. It is readily biodegradable, and since it has not undergone any sort of treatment, it can contain all pathogenic organisms and worm eggs present in human and animal faeces (Kropp and Dichtl, 2001). The following sections will present some of the physical characteristics used to describe sludge, such as the solids and water content, the density and the particle size distributions. Some of the common inorganic, non-metallic constituents, such as the $\mathrm{pH}$, alkalinity, chlorides, nitrogen, phosphorous, sulphur, gasses and odours will be also presented. The common metallic constituents found in domestic wastewater are not particularly relevant in these experiments and will not be addressed in any real detail. The organic constituents, namely chemical oxygen demand (COD), carbohydrates, proteins and lipids, will be presented. 


\subsubsection{Physical Characteristics}

The physical characteristics which are used to describe sludge in this report include the solids and water contents, the particle size distribution, and the density. Total solids (TS) and volatile solids (VS) are often used in sludge applications, where the TS content is typically greater than $10,000 \mathrm{mg} / \mathrm{L}$, or $1 \%$ solids. For primary sludge, the TS is typically around 5\% solids, where 60 to $80 \%$ of this is volatile. TS and VS values for sludge are often quoted in percentages, since the suspension is slightly denser than water. The TS is determined by drying a known mass in an oven at around $105^{\circ} \mathrm{C}$ for 24 hours, or until the sample is completely dry. The VS is determined by igniting the dry sample in a muffle furnace at $550^{\circ} \mathrm{C}$ for 1 to 2 hours, or until there are no further changes in the mass with longer ignition periods. Detailed procedures for the determination of TS and VS concentrations for the batch reactor experiments are presented in section 3.1.4.3.

Total suspended solids (TSS) and volatile suspended solids (VSS) are commonly used parameters to assess the strength and age of wastewater and sludge. They are commonly used in wastewater applications since they allow one to quantify the organic solids content of dilute solutions by retaining the solids from a large sample volume on a filter paper, using a common vacuum filtration apparatus. The term suspended refers to the portion of solids that are retained on a filter with a $1.5 \mu \mathrm{m}$ pore size. The detailed methods for the determination of TSS and VSS, including sampling procedures and methods of calculation, are presented in section 3.1.4.4. 
The distribution of water in sludge can be categorised into four groups: free water, interstitial water, surface water and intracellular or bound water. Free water accounts for $70-75 \%$ of the total water in sludge. This water is not bound or absorbed, it moves freely, unaffected by capillary forces amongst the particles. Interstitial water is physically bound to the sludge particles through capillary forces. It is termed interstitial water because it is bound within the interstice of the sludge particles and microorganisms within the floc (Kropp and Dichtl, 2001). This water can only be removed when the sludge floc is broken (Yin et al., 2004). Surface or vicinal water is the water that covers the entire surface of the sludge particles, often several layers of water molecules thick. This water is physically bound by adhesive and absorptive forces and cannot move freely. Intracellular or bound water is chemically bound to the particle (Kropp et al., 2004).

Particle size distributions of sludge are used to assess the degree of sludge disintegration with the various grinding cycles. Histograms of the particle size distributions provide a visual representation of the colloidal fractions in the sludge and also provide an overall estimate of the average particle size in the sample. For these experiments, the specific methods used to quantify the distribution of particles and the average particle size will be discussed in detail in section 3.1.4.10. The density of the sludge depends on the organic and inorganic solids contents since the density of organic solids are around $1.0 \mathrm{~g} / \mathrm{mL}$, whereas the density of the inorganic solids is around $2.3 \mathrm{~g} / \mathrm{mL}$ (Kropp and Dichtl, 2001). Primary sludge contains high amounts of both organic and inorganic solids. 


\subsubsection{Inorganic Non-Metallic Constituents}

The $\mathrm{pH}$ and alkalinity of sludge are useful indicators of the digestion conditions. The $\mathrm{pH}$ of primary sludge is generally between 6 and 7, and the alkalinity of the sludge is normally around $600 \mathrm{mg} / \mathrm{L}$ as $\mathrm{CaCO}_{3}$ (Metcalf and Eddy, 2003). During anaerobic digestion, the breakdown of proteins produce ammonium bicarbonate, which acts as a buffering substance, however, the accumulation of VFAs may create a slightly below neutral $\mathrm{pH}$. In such cases, $\mathrm{pH}$ and alkalinity adjustments can be made. In many cases with anaerobic digesters, alkali agents are required to keep the $\mathrm{pH}$ in the neutral region (Mukherjee and Levine, 1992). Generally, an alkalinity concentration that is several hundred times higher, in $\mathrm{mg} / \mathrm{L}$ of $\mathrm{CaCO}_{3}$, than the concentration of VFAs is generally an indication that the digestion process is not endangered (Kropp and Dichtl, 2001).

The oxidation-reduction potential (ORP) of a solution is a measure of its potential to either gain or lose electrons when a new species is added. Solutions with higher ORP values are more likely to gain electrons, and to be reduced, by oxidising the new species. These solutions are often referred to as oxidisers. Solutions with a lower ORP are more likely to lose electrons to the new species, and to be oxidised, by reducing the new species. The solutions are called reducers, or referred to as reduced conditions. An anaerobic system has reducing conditions, and a low ORP. In these experiments a measure of the ORP will help to assess the level of microaeration, along dissolved oxygen measurements. It will also help to assess the effect of the increased acids that would be expected as a result of the enzyme and bacterial additives used in these experiments. 
Nitrogen typically represents 1.5 to $4 \%$ of the total solids in sludge (Metcalf and Eddy, 2003). Under anaerobic conditions, the degradation of nitrogen containing compounds will lead to an increase in ammonia. Ammonia nitrogen $\left(\mathrm{NH}_{3}\right)$ in sludge is in equilibrium with the ammonium ion $\left(\mathrm{NH}_{4}{ }^{+}\right)$. The dissociation occurs at a $\mathrm{pH}$ of 9.3 , which means that in wastewater and sludge applications $(\mathrm{pH}=6-7)$ essentially all of the ammonia is actually in the form of the ammonium ion $\left(\mathrm{NH}_{4}{ }^{+}\right)$. In this report, the term ammonia is used when to referring to the ammonium ion.

The gasses generated during anaerobic digestion, called biogas, typically contain 65 to $70 \%$ methane, 25 to $30 \%$ carbon dioxide, and small amounts of nitrogen, hydrogen and hydrogen sulphide (Metcalf and Eddy, 2003). The volume of gas produced can be related to the destruction of volatile solids (VS). Normal gas generation is about 0.75 to 1.12 $\mathrm{m}^{3} / \mathrm{kg}$ of VS destroyed (Metcalf and Eddy, 2003), although these values can vary widely depending on the health of the anaerobic system, particularly the methanogens.

\subsubsection{Metallic Constituents}

A variety of metallic constituents such as iron, copper, manganese, nickel, lead, chromium and zinc are present in sludge. The term heavy metals is often used to quantify the total concentration of the trace metallic elements in wastewater. The total heavy metals content in sludge is generally around 0.5 to $2 \%$ of the TS (Wong and Henry, 1999). High concentrations of heavy metals in sludge can limit the use of the digested biosolids in land applications (Wong and Selvam, 2006). 


\subsubsection{Organic Constituents}

The chemical oxygen demand (COD) of a substance is a measure of the oxygen demand required for the complete chemical oxidation of all organic material using dichromate in an acidic solution (Metcalf and Eddy, 2003). The value is very similar to the commonly used biological oxygen demand (BOD), however COD is a theoretical value and can never be achieved in nature, since the complete oxidation of all organic material cannot be achieved through biological means alone. Furthermore, COD values tend to be even higher than the BOD values due to the chemical oxidation of certain inorganic species present. In any case, COD measurements are a very useful tool to assess the amount of organic material present in wastewater and sludge. The measurement of COD becomes even more useful by fractionating the total COD (tCOD) from the soluble COD (sCOD). The soluble component of the tCOD is that component within the soluble phase, that is particle sizes less than $0.45 \mu \mathrm{m}$. As will be discussed in the material and methods chapter, the samples of the soluble phase is separated from the particulate phase by first centrifuging the sample, then filtering the centrate through a $0.45 \mu \mathrm{m}$ filter paper using a typical vacuum apparatus. The soluble component of the COD provides an ability to assess the health and performance of the digestion process. As will be discussed in section 1.2.3, the first phase, and often the limiting phase, of anaerobic digestion process is the hydrolysis phase during which time particulate-phase organics are solubilised, and complex organics are broken down into simpler more digestible components. 
Volatile Fatty Acids (VFAs) are low molecular weight carbonic acids. They are produced as an early intermediate during digestion. Most often, acetic and propionic acid are used to characterise the concentration of VFAs. The VFAs are subsequently transformed into acetate, carbon dioxide and hydrogen. This is followed by the methanogenic phase which splits acetate $(\sim 70 \%)$, and utilises carbon dioxide and hydrogen $(\sim 30 \%)$ to form methane. Therefore, high VFA concentrations can be used as an indicator of a disturbance or over load in the digestion process (Kropp and Dichtl, 2001). High concentrations of fatty acids will decrease the buffering capacity of the system and may lead to a reduced $\mathrm{pH}$. This can lead to the inhibition of the methanogens, and ultimately cause system failure (Noyola and Tinajero, 2005).

Proteins typically represent 20 to $30 \%$ of the total solids in sludge, which is equivalent to about $40 \%$ of the organic solids (Metcalf and Eddy, 2003). Proteins are large organic compounds made up of amino acids. Many proteins are enzymes, which are critical to the digestion process. Other proteins have structural and mechanical roles. These large biological macromolecules must be broken down into simpler organic compounds as a preliminary to the digestion process. In the study by Schmitz et al., 2000, the increase in protein concentration was used to assess the level of cell disintegration during sludge pretreatment/minimisation tests prior to anaerobic digestion. During digestion, proteins are released through microbial and enzymatic activities, then they are broken down into amino acids, which are subsequently converted to short chain VFAs. The anaerobic digestion process is discussed in more detail later in section 1.2.3. 
Carbohydrates typically represent 25 to $50 \%$ of the organic content in wastewater (Metcalf and Eddy, 2003). The simplest carbohydrates are called monosaccharides, they include glucose, fructose and galactose. Complex carbohydrates, called polysaccharides, are made up of numerous monosaccharides joined together. Starch and glycogen are examples of food storage carbohydrates. For these experiments, the carbohydrate measurements will be used to assess the amount of sugar, or food, that is available for the microorganisms.

Lipids such as fats, oils, greases and waxes represent 8 to $12 \%$ of organic matter in wastewater, and up to $30 \%$ of the total solids in sludge (Metcalf and Eddy, 2003). Lipids in wastewater result in the formation of the scum layer, and when present in large quantities in sludge can lead to high VFA concentrations, which can have inhibitory effects on the methanogens.

\subsubsection{Biological Characteristics}

The biological characteristics of sludge refer to the organisms present. Such organisms include bacteria, fungi, algae, protozoa, plants, animals and viruses. Bacteria in sludge lead to the degradation of the organic constituents through a series of biochemical processes involving a variety of microbially secreted, exocellular enzymes. The health of these bacteria are vital for the health of the digestive system. Biological stability is a term used to describe the level of digestion related to the destruction of volatile solids and the generation of methane. 


\subsubsection{Sludge Treatment Overview}

Sludge treatment refers to the thickening, stabilisation, conditioning and dewatering of sludge. In the United States, depending on the quality of the treated sludge, it can be used as a fertiliser for land applications. The highest quality, Class A biosolids, can be sold in bags as fertiliser and used on lawns, gardens and golf courses. Class B biosolids are lower in quality and have restrictions regarding their use or disposal. The quality of the treated sludge or biosolids depends on the level of disinfection achieved and the concentration of nutrients and heavy metals among other things (Metcalf \& Eddy Inc., 2003).

\subsubsection{Preliminary Operations}

Most treatment plants employ preliminary operations to improve the performance of the subsequent sludge treatment processes. Screening and grit removal help to remove nuisance material such as rags and inorganic solids. Blending is used to homogenize primary sludge and waste activated sludge (WAS) streams so they can be treated together. Grinding is sometimes used to reduce the average particle size of the sludge to improve sludge stabilisation.

\subsubsection{Thickening}

Sludge thickening reduces the volume of sludge that must be treated in the subsequent processes by removing some of the liquid portion of the sludge. Primary and waste activated sludges typically have between $2-6 \%$ and $0.5-1.5 \%$ solids respectively. 
Thickened sludges can have a solids content up to $7 \%$ solids. By increasing the solids concentration of sludge by 1 or $2 \%$, the volume of sludge can be cut in half, which provides major savings during the subsequent treatment and disposal processes. Gravity settling thickeners are some of the most common methods used, and are very effective for primary sludge streams which have readily settleable solids. WAS has lighter, larger bacterial flocs which are tougher to thicken using gravity. For WAS, some larger plants use more active methods like dissolved air-flotation, centrifuge thickeners, gravity-belt thickeners and rotary-drum thickeners to thicken or dewater sludges.

\subsubsection{Stabilisation}

Sludge stabilisation refers to the reduction of pathogens, the elimination of offensive odours, and the inhibition, reduction or elimination of the potential for putrefaction (Metcalf \& Eddy Inc., 2003). Sludge stabilisation can be achieved many ways such as lime treatments, aerobic digestion, anaerobic digestion, composting, pasteurisation, incineration, irradiation and drying. The principal methods of sludge stabilisation are lime treatments, composting, aerobic digestion and anaerobic digestion.

Lime stabilisation is a technique where lime additions are used to maintain a $\mathrm{pH}$ of 12 for about 2 hours to destroy pathogens. Both dewatered and pre-dewatered sludge can be treated with lime and used as a fertilizer for agricultural land. In some cases, Class A or Class B sludge or biosolids can be produced. 
Composting is the biological degradation of solid organic matter into a stable end product. Efficient composting is able to convert $20-30 \%$ of the volatile solids into carbon dioxide and water (Metcalf \& Eddy Inc., 2003). Furthermore, the metabolic heat generated during the thermophilic stage of the decomposition process heats up the compost temperature to between $50-70^{\circ} \mathrm{C}$, which is capable of destroying pathogens (Gea et al., 2007). Depending on the level of disinfection and the quantity of heavy metals in the compost, the end product can be used as a fertiliser or soil conditioner (Wong and Fang, 2000).

Aerobic digestion is the biological conversion of organic matter in the presence of oxygen. Aerobic digestion processes have been widely used by wastewater treatment facilities to stabilise sludge, however the process is very energy intensive, and the excessive aeration required to maintain high dissolved oxygen levels reduces the temperature and the effectiveness of the disinfection process.

Anaerobic digestion is the biological conversion of organic matter, in the absence of oxygen. It is one of the oldest and most dominant sludge stabilisation techniques, primarily because anaerobic digestion produces methane gas, which can be used for the generation of heat or electricity. In many cases, the amount of methane gas produced is able to meet most of the energy requirements of the treatment plant (Metcalf \& Eddy Inc., 2003). Septic tanks can be considered anaerobic digesters, used for the partial degradation of organic material present in the household wastewater feed stream. The process fundamentals of anaerobic digestion are discussed in more detail in section 1.2.3. 


\subsubsection{Conditioning}

Sludge conditioning is used to improve the dewaterability of the sludge. Most often, chemical conditioners are added to the sludge to improve the agglomeration of the negatively charged sludge solid particles through charge neutralisation and interparticle bridging (Bohm and Kulicke, 1997). Other forms of sludge conditioning include heat treatments and freeze-thaw treatments. Sludge conditioning is discussed in more detail later, in the sludge minimisation section (section 1.2.4).

\subsubsection{Dewatering}

Sludge dewatering has been one of the most expensive and least understood processes at the wastewater treatment plant (Bruus et al., 1992). Generally, mechanical dewatering processes such as vacuum filtration, pressure filtration, belt-press filtration and centrifugation are used. Drying beds such as sand drying beds, solar drying beds, artificial-media drying beds and vacuum-assisted drying beds have also been used (Metcalf \& Eddy Inc., 2003). However, drying beds require a large footprint, and may not be an effective use of space for certain WWTPs. Heat drying is capable of reducing the moisture content of the sludge below that achievable through conventional mechanical dewatering process, however this method is very energy intensive and can result in odour problems unless odour control devices are used. The cost of dewatering is offset by the reduced transportation and disposal costs of the dewatered sludge. The type of dewatering method used is generally based on the final disposal method for the sludge. 


\subsubsection{Disposal}

Disposal costs can amount to $50 \%$ of the operating costs for the wastewater treatment plant (Vesilind and Spinosa, 2001). Disposal methods include incineration, disposal in landfills, and land-applications. In Ontario, wastewater residuals are classified as waste, and require an appropriate Waste Disposal Site Approval for all methods of disposal. Recycling options such as land application are encouraged (Lewis, 2006). Land application of treated sludges, called biosolids, takes place in most Canadian Provinces and Territories. It is a beneficial way to promote the growth of agricultural crops, fertilize gardens and parks and for reclamation of mining sites (Canadian Water and Wastewater Association, 2003), and is one of the most economical methods of sludge treatment and disposal, by combining material recycling and sludge disposal (Fang et al., 1999). Canadian regulatory frameworks exist for the application of biosolids to agricultural lands although these frameworks are based on the regulations set out by the US EPA (Oleszkiewicz and Mavinic, 2001). The US EPA has two classes of sludge suitable for land disposal. Class A sludge is a high quality product which can be sold in bags as fertilizer and applied in moderation to home lawns and gardens in the United States (United States Environmental Protection Agency (US EPA)). Class A sludge is classified in terms of fecal coliforms and Salmonella sp. bacteria. Class A sludge must have a coliform density less than 1000 most probable number (MPN) per gram of total dried solids (1000 MPN/g TS), or Salmonella sp. bacteria less than 3 MPN/4 g TS (US EPA, 1999). Class B sludge is a lower quality product which faces certain restrictions. Class B sludge must have less than 2,000,000 MPN/g TS. 


\subsubsection{Anaerobic Digestion}

Anaerobic digestion is the decomposition of organic matter and inorganic matter (principally sulphate) in the absence of free oxygen (Metcalf \& Eddy Inc., 2003). During anaerobic sludge digestion, complex organic substances are converted to water, carbon dioxide and methane in a series of biological processes known as hydrolysis, acidogenesis and acetogenesis (collectively referred to as fermentation), and finally methanogenesis. The process involves a number of different bacterial groups working in harmony, which makes the system very sensitive to variations, such as temperature, $\mathrm{pH}$ and of course biologically toxic substances.

\subsubsection{Hydrolysis}

Sludge hydrolysis refers to the solubilisation of particulate matter into soluble compounds, and the conversion of complex substances into simple monomers which can then be consumed by the fermentative bacteria. (Metcalf \& Eddy Inc., 2003). During the hydrolysis process, extracellular enzymes break down complex organic substances such as carbohydrates, proteins, lipids and phosphorylated organics into simpler substances such as glucose, amino acids, fatty acids, phosphorous, alcohols, carbon dioxide and ammonia. The simpler soluble organics generated in the hydrolysis phase are then consumed in the second phase of digestion known as acidogenesis 


\subsubsection{Acidogenesis}

During acidogenesis the fatty acids, amino acids and sugars are fermented, resulting in the production of short-chain organic acids, known as volatile fatty acids (VFAs) and other fermentation products such as ethanol and $\mathrm{CO}_{2}$. Acetic acid, propionic acid and butyric acid are commonly used to characterise the VFAs. In some cases, excessive amounts of organic acids may build up and lower the $\mathrm{pH}$ towards the acidic region, which can hinder the methanogenic bacteria in the reactor (Vlyssides and Karlis, 2004).

\subsubsection{Acetogenesis}

During the acetogenesis phase, the volatile fatty acids produced by the acidogenic bacteria are consumed by a group of bacteria called acetogens, which produce acetate, carbon dioxide and hydrogen. The health and stability of the acetogens are vital to ensure a stable, near-neutral $\mathrm{pH}$ and a continuous supply of methanogenic substrates, namely acetate (Kropp and Dicht1, 2001).

\subsubsection{Methanogenesis}

In the final stage of anaerobic digestion, methanogenic bacteria convert acetate, $\mathrm{CO}_{2}$ and $\mathrm{H}_{2}$ into methane and carbon dioxide by either splitting acetate (acetoclastic methanogens $\sim 70 \%$ ) or utilizing $\mathrm{CO}_{2}$ and $\mathrm{H}_{2}$ (hydrogenophilic methanogens $\sim 30 \%$ ). The former pathway is critical for the stability of the process, since it maintains low hydrogen concentrations, which is required for the production of acetate. Kropp and Dichtl, 2001 found that high hydrogen partial pressures caused fermentative bacteria to produce acids 
other than acetic acid. More of a concern however, are the sensitive and slow growing methanogens. These bacteria are very sensitive to variations such as $\mathrm{pH}$ and temperature. As well, because methanogens grow much slower than the fermentative acidogens, an increased load will result in more acidogens, and higher VFA concentrations which can lower the $\mathrm{pH}$ below 6.0, at which point methanogenic activity is inhibited. Many researchers believe that the accumulation of acids, particularly long-chain fatty acids, is the primary cause of failure in anaerobic digesters. Therefore, under certain circumstances the methanogenesis phase can also be viewed as a rate limiting step (Puchajda and Oleszkiewicz, 2006). The effects of acids accumulation can be reduced by the presence of bicarbonates, which are in equilibrium with soluble $\mathrm{CO}_{2}$ at neutral $\mathrm{pH}$ (buffering capacity), but in some cases, an alkali in the form of lime, sodium hydroxide or potassium hydroxide is added to maintain a near-neutral $\mathrm{pH}$, and healthy population of methanogens (Vlyssides and Karlis, 2004, Mukherjee and Levine, 1992).

\subsubsection{Sludge Minimisation}

Sludge minimisation refers to the reduction of sludge volume. Water is the primary component of sludge, therefore sludge minimisation is most effectively achieved by reducing the moisture content of the sludge through dewatering, although sludge minimisation is also achieved through digestion. Sludge dewatering and sludge digestion can be improved using various sludge pretreatment techniques. As a result, various sludge pretreatment techniques, both pre-digestion (digestion aide) and pre-dewatering (dewatering aide), are considered sludge minimisation techniques. For the purposes of 
this research however, only those sludge minimisation techniques related to improving digestion, particularly anaerobic digestion, will be discussed in the following sections.

Countless pretreatment techniques and modifications to anaerobic digesters have been designed and tested to improve sludge digestion and ultimately reduce disposal costs. Conventional pretreatments include:

- Mechanical disintegration techniques

- High pressure homogenizer, ball mill processes, ultrasonic disintegration, colloid mills and grinding pumps,

- Thermal treatment techniques,

- Microwave heating, conventional heating

- Chemical oxidation techniques

- Ozonation and hydrogen peroxide additions.

- Enzyme and bacterial additives

In the following sections, the various mechanical, thermal, and chemical pretreatment techniques, and some other digestion aides will be discussed. While some of the methods are intended to be used at centralised wastewater treatment plants, the surrounding topics will provide a clear understanding of the conceptual approach to designing the experimental phases of the research. 


\subsubsection{Mechanical Disintegration Techniques}

Mechanical treatments disintegrate the sludge using shear stress without denaturing the cell components through chemical reactions (Barjenbruch and Kopplow, 2003). One of the most common methods of mechanical sludge disintegration is the high pressure homogeniser, where sludge is compressed then ejected through a high speed valve onto an impaction ring. The process disintegrates sludge through turbulence, cavitation and shear stresses (Weemaes and Verstraete, 1998). Cavitation collapse can cause local pressures of 500 bar and hundreds of degrees Celsius (Müller, 2003). Figure 1-3 is a micrograph of WAS before and after treatment with a high pressure homogeniser.

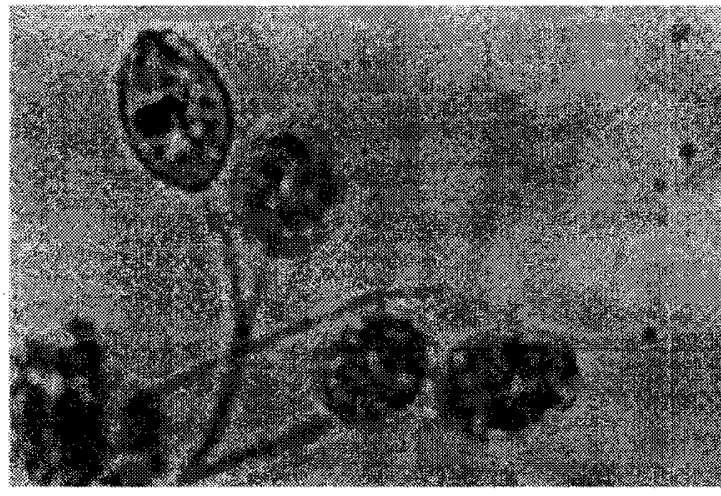

(a)

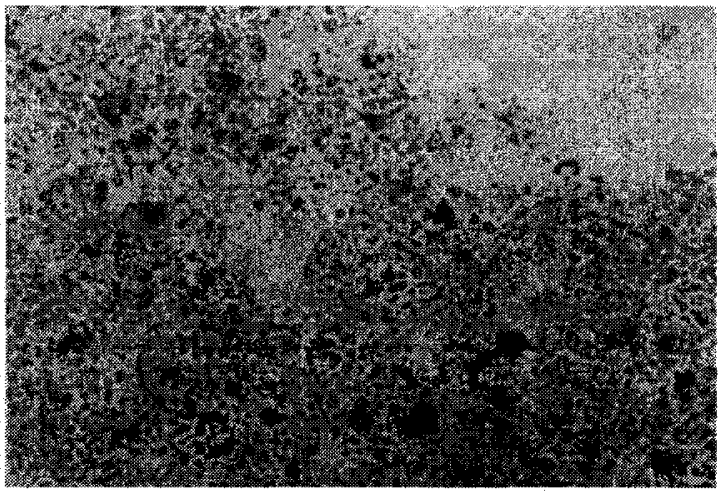

(b)

Figure 1-3: Micrograph of WAS (a) prior to and (b) following a HPH (Nah et al., 2000)

Ball mill processes, such as stirred ball mills, the high speed shaker and rotating ball mills are common mechanical cell disintegration techniques. Sludge is mixed with dense spheres of glass, steel or ceramic and agitated. Sludge flocs are pulverized, and the spheres are reclaimed at the end of the process. These processes are quite energy intensive, however properly designed and operated ball mills create shear-stresses and pressure forces which can break bacterial cell walls (Weemaes and Verstraete, 1998). 
Ultrasonic treatments generally utilize low frequency sound waves which result in the formation of cavitation bubbles. When the bubbles reach their critical size, they violently collapse, forming extreme localised heat and pressure (Bougrier et al., 2006a), which promotes chemical reactions from the formation of highly reactive $\mathrm{H}^{*}$ and $\mathrm{OH}^{*}$ radicals (Dewil et al., 2006).

The Seber Colloid mill was developed by Aquadec Ltd (London, UK). Sludge is pumped through an aperture at the centre of a stationary disk. A second disk located close to the opening, spins at high speed. As sludge passes, roughly $50 \%$ of the sludge is ruptured, and the cell suspension is heated through energy dissipation (Weemaes and Verstraete, 1998). A similar line of colloid mills have been developed by Greerco, a registered trademark of Chemineer Inc. (OH, USA). A colloid mill or variation of a sludge grinding pump, is a fairly simple method which achieves efficient cell disintegration. A method similar to these could potentially be implemented in the piping infrastructure, prior to the septic tank, which would reduce modifications required to implement the technology, and provide easy access to the unit in the event of a failure.

\subsubsection{Thermal Pretreatment Techniques}

Thermal treatments are some of the most widely used methods to improve anaerobic digestion. They involve heating the sludge, generally under pressure, for short time periods. As the sludge heats, the gel-like structure of the floc breaks down, and the solids have a lower affinity for water, which causes the solid particles to coagulate (Tchobanoglous et al., 2003). Even in the mesophillic temperature range $\left(25-40^{\circ} \mathrm{C}\right)$, 
thermal treatments are capable of disturbing the filamentous bacteria (Dohányos et al., 2003). At higher temperatures, thermal treatments can also lead to cell destruction as a result of pressure differences (Bougrier et al., 2006b).

Thermal treatment of thickened WAS (TWAS) at a temperature of $96^{\circ} \mathrm{C}$ was seen to disrupt the flocs, causing the release of extra- and intra-cellular material (Eskicioglu et al., 2006). The disruption was marked by an increase in sugars and proteins in the soluble phase, and a very significant increase in the soluble COD. Bougrier et al., 2006, recorded COD solubilisations between 40 and $45 \%$ with heating temperatures of 170 and $190^{\circ} \mathrm{C}$. The latter was coupled by a $51 \%$ decrease in the organic solids content, with no effect on the mineral matter, as shown in Figure 1-4.

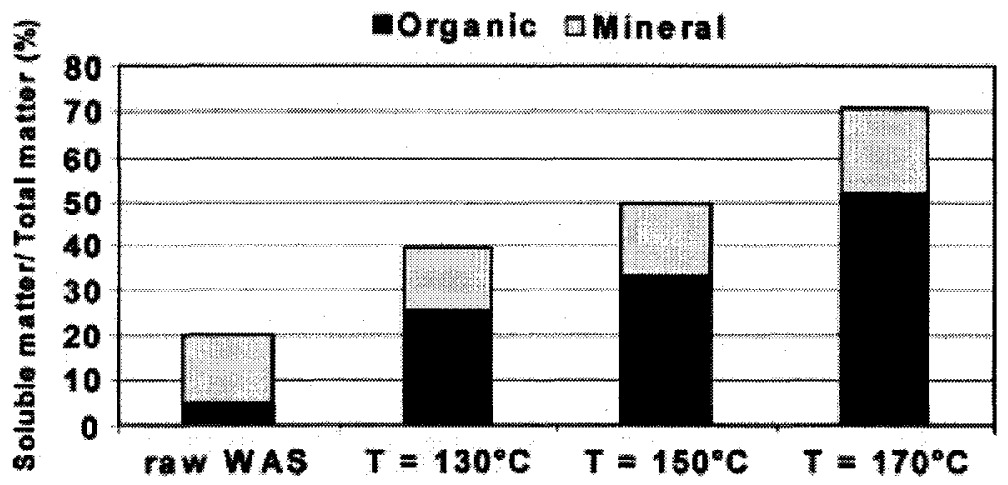

Figure 1-4: Organic (volatile) and mineral matter solubilisation for different thermal pretreatment temperatures (Valo et al., 2004)

In the study by Bougrier et al, 2006, relatively high thermal treatment temperatures of 170 and $190^{\circ} \mathrm{C}$ were used. Following treatment, the $\mathrm{pH}$ had dropped to a value of 5.8. The latter was explained by the formation of acidic compounds. For example, lipids were seen to degrade at the elevated temperature, and form into volatile fatty acids. This was 
also seen in the experiment by Eskicioglu et al., 2006, where a heating temperature of $96^{\circ} \mathrm{C}$ resulted in an increase of acetic acid from 0 to $778 \mathrm{mg} / \mathrm{L}$.

\subsubsection{Chemical Oxidation Techniques}

Ozone and hydrogen peroxide have been widely used as a chemical oxidant in wastewater applications due to their highly oxidative and destructive properties. Recent investigations with ozone have been coupled with anaerobic digestion, either as a pre- or post-treatment, and also in membrane bioreactors (MBRs) (Weemaes et al., 2000). Hydrogen peroxide is a strong oxidant, however it is not effective when used alone due to the high concentrations of certain refractory components which reduce reaction rates (Neyens and Baeyens, 2003a). Most often, metal salts are used with hydrogen peroxide called Fenton's reagent, to improve reaction rates (Valo et al., 2004).

In the presence of the wide variety of complexes from wastewater, ozone decomposes itself into highly reactive radicals. These highly reactive radicals are capable of reacting with all components of the wastewater sludge, soluble and particulate, organic and mineral (Bougrier et al., 2006b). Ozonation results in the destruction of cell walls, and the release of intracellular material, which are solubilised into soluble organic products (Saktaywin et al., 2005). The latter is marked by an increase in the sCOD, a decrease in the particulate COD, and a reduction in TSS. 
When using hydrogen peroxide as an oxidant, reactions rates can be increased through the formation of hydroxyl radicals, often with ozone, UV light or metal salts such as iron salts. In the presence of a metal ion, one hydrogen peroxide molecule reacts to form one hydroxyl radical and one hydroxide ion. In the presence of ozone, one hydroxyl radical, one oxygen molecule and one hydroperoxyl radical form. In the presence of UV light, hydrogen peroxide breaks into two hydroxyl radicals, which effectively destroy cell walls, and solubilize cell contents (Neyens and Baeyens, 2003a). Hydrogen peroxide has also been coupled with thermal treatments (microwave and conventional) as an advanced oxidation process (AOP) for sludge treatment (Wong et al., 2006).

Supercritical water oxidation of excess sewage sludge using hydrogen peroxide and temperatures between $450-550^{\circ} \mathrm{C}$ was performed by Goto et al., 1999 , similar to the many patented processes employing elevated temperatures and pressures to achieve oxidative conditions. The German Bayer- ${ }^{\mathrm{R}}$ Loprox process operates under acidic conditions, at temperatures below $200^{\circ} \mathrm{C}$, pressures between $500-200 \mathrm{kPa}$, a retention time of 1-3 hr, and use $\mathrm{Fe}^{2+}$ ions and chinon-forming organic substances as a catalyst. In Japan, a catalyst consisting of a variety of metals in solution is used with hydrogen peroxide to treat sewage sludge at $270^{\circ} \mathrm{C}$ and $86 \mathrm{~Pa}$. As a pretreatment for anaerobic digestion, the same catalytic oxidation was used in a UASB reactor, achieving roughly 93\% COD removal (Song et al., 1992). 


\subsubsection{Microaeration}

Microaeration refers to the addition of very small amounts of air (oxygen) to the system. A large amount of research has focussed on completely aerobic or anaerobic biological treatment systems, but less research has focussed on the transition region between these two extremities (Johansen and Bakke, 2006). Alternate anaerobic-aerobic cycling is used to minimise sludge yield in activated sludge processes (Pérez-Elvira et al., 2006). The cycling process is used to uncouple the catabolic and anabolic processes by limiting the amount of energy supplied to anabolism, thereby reducing biomass yield. Subsequently, catabolism and hydrolysis are improved, and ultimately digestion is improved. On the other hand, increased biomass and carbon dioxide production, and reduced methane yield are expected when oxygen is introduced as an electron acceptor in an anaerobic system (Johansen and Bakke, 2006). Limiting amounts of oxygen to improve hydrolysis, without excessive biomass production must be achieved for microaeration to be effective.

In the experiments by Johansen and Bakke, 2006, four day batch reactor tests with 300 $\mathrm{mL}$ samples of chemically-precipitated sludge were used to examine the effects of microaeration on sludge hydrolysis. The accumulation of VFAs and methane generation for the samples under microaerobic conditions were roughly half of those of the anaerobic samples. Furthermore the amount of biomass generated under microaerobic conditions was more than five time higher than the anaerobic reactors. However, under microaerobic conditions a $50 \%$ increase in hydrolysis was estimated based on carbon, nitrogen and COD balancing. 


\subsubsection{Enzyme and Bacterial Additives}

Enzymes catalyse the bacterial conversion of complex organic matter, primarily proteins, carbohydrates and lipids, into low molecular weight compounds (Barjenbruch and Kopplow, 2003, Nybroe et al., 1992). A variety of hydrolysing enzymes are synthesized and secreted by the microorganisms (Goel et al., 1998), however it is thought that during digestion, certain enzymatic activities cease, in particular glucosidase activity which is responsible for the degradation of extracellular polymeric substances (EPS) like starch (Ayol, 2005a). EPS are highly hydrated substances, capable of confining hydrolytic enzymes and protecting cells from degradation. Likewise, the rate of degradation of proteins and polysaccharides also declined during the later stages of digestion. In well understood systems, specialized enzyme additions to target the degradation of specific constituents are becoming an economically viable method to minimise excess sludge. In many other applications, such as food processing, relatively pure enzyme extracts are required which make the cost of the additive very expensive. In wastewater applications however, cheaper less purified enzyme products are sufficient (Ayol, 2005a). Enzyme additions (cellulase and lipase) were used to enhance the anaerobic degradation of the cellulosic and the oil- and grease- rich fractions of municipal wastewater sludge (Higgins and Swartzbaugh, 1985). Enzyme and bacterial additives have also been used to increase the activity and growth of methanogenic bacteria during anaerobic digestion. In the experiments by Noyola and Tinajero, 2005, lyophilised bacteria (Thuringiensis sp., Subtilis sp., Licheniformes sp.) and a mixture of enzymes (lipase, protease and cellulase), and a combination of micronutrients $(\mathrm{Fe}, \mathrm{Co}, \mathrm{Ni}, \mathrm{Mo})$ were used separately and together, in a series of batch reactor tests. Bacilli additions alone increased methane production by 
$95 \%$ and decreased the concentration of VFAs by $40 \%$. Enzyme additions without any bacterial additives however, decreased the amount of methane generation.

In thermophilic reactors $\left(50-60^{\circ} \mathrm{C}\right)$, particular types of microbes develop, which produce enzymes to attack the outer membrane of the bacteria present in the sludge. A variety of patented processes, both aerobic and anaerobic, stimulate and utilise biological processes to reduce sludge volumes and improve degradation (Pérez-Elvira et al., 2006). Biolysis $E$, originally developed by Shinko Pantec, Japan, is one such process which draws heats samples of mixed liquor from the activated sludge basin to between 50 to $60^{\circ} \mathrm{C}$, which stimulates particular enzymes which secrete hydrolytic enzymes. The process has demonstrated up to an $80 \%$ reduction in sludge.

Lipids can form a physical barrier which protects the lipid surface from the digestive bacteria. Enzyme additions which help to hydrolyse complex organics, such as lipids, will help improve this rate limiting step. Enzyme and bacterial additives can also be used to help promote the health and productivity of the sensitive methanogens.

\subsection{Reactor Setups and Operation}

To help with this project, several experimental studies related to anaerobic digestion of primary sludge and sludge minimisation were reviewed. The studies were reviewed in terms of the materials and methods used, such as reactor design, sampling procedures and analytical methods, and also in terms of the results and conclusions obtained for a comparative analysis. 


\subsubsection{Batch Reactor Tests}

In the study by Gömeç, 2006, 2.0 L completely stirred tank reactors (CSTR) operating as . batch systems for 18 days at $35^{\circ} \mathrm{C}$ were used to monitor and compare the anaerobic digestion of primary sludge and a mixture of $85 \%$ primary sludge and $15 \%$ scum, both with and without $\mathrm{pH}$ control ( $\mathrm{pH}$ controlled at 6.5). $20 \mathrm{~mL}$ fresh samples were used for the determination of total suspended solids (TSS), volatile suspended solids (VSS), soluble chemical oxygen demand (sCOD) and volatile fatty acids (VFAs). Samples for sCOD and VFAs measurements were centrifuged at $4000 \mathrm{rpm}$ for $20 \mathrm{~min}$, then the supernatants were filtered through $25 \mathrm{~mm}$ Whatman GF/F glass microfibre filters, centrifuged again at $4000 \mathrm{rpm}$ for 5 min and then filtered through $0.45 \mathrm{~mm}$ MSI MicronSep nitrocellulose disc filters. TSS and VSS determinations were performed on the pellets collected at the bottom of the centrifuge tubes. In the reactor with primary sludge and no $\mathrm{pH}$ control, the TSS and VSS were reduced by roughly $12 \%$ in the first two days, which was coupled with a dramatic $300 \%$ increase in the sCOD concentrations. The solubilisation period ceased after five days, at which point the SCOD began to gradually decrease during the methanogenesis period. In the presence of scum however, the SCOD continued to increase to about 1.5 times higher, suggesting that the methanogenesis phase was hindered by the presence of scum, without $\mathrm{pH}$ control. In the experiments with $\mathrm{pH}$ control however, TSS and VSS reductions were improved and the hindering effects of the scum on methanogenesis (sCOD destruction) were reduced. 
In the study by Ortega et al., 2007, 2.0 L Erlenmeyer flasks were used in 14 day and 25 day batch reactor experiments at room temperature $\left(18-19^{\circ} \mathrm{C}\right)$, with a working volume of $1.8 \mathrm{~L}$, to test the effects of electrolysis on anaerobic digestion of primary sludge. Each flask was sealed with a rubber stopper which housed a $20 \mathrm{~mL}$ sampling syringe, a gas exit line attached to a u-tube, and electrical wires when necessary. A magnetic stirrer was used to stir the flasks either poorly or intensively. Electrical power between 0 and $0.4 \mathrm{~W}$ were supplied to the electrolysis-assisted batch reactors, with electrodes placed in either the middle of the flask or at the bottom of the flask, depending on the test. Nitrogen compounds $\left(\mathrm{NH}_{4}{ }^{+}, \mathrm{NO}_{3}{ }^{-}, \mathrm{NO}_{2}^{-}\right)$, phosphorous $\left(\mathrm{HPO}_{4}{ }^{-}\right)$, VFAs and sCOD were measured once per week, and TSS, VSS and tCOD were measured twice per week. Gas samples were collected and analysed for hydrogen, nitrogen, oxygen, methane and carbon dioxide concentrations. Results from the study demonstrated that the anaerobic control reactors had an accumulation of hydrolysis products (SCOD, VFAs), whereas microaeration of sludge samples, through low power electrolysis, improved biodegradation of the soluble constituents such as SCOD and VFAs, and thus improved the COD removal efficiency of the system, relative to the control reactors. The study also demonstrated that while the anaerobic control reactors were completely anaerobic after the first day the operation, the microaerobic reactors took seven days to reach completely anaerobic conditions. However, the delayed anaerobic acclimatisation period did not affect biodegradation during this time, and may have led to the improved overall performance in the later stages of digestion. 


\subsubsection{Continuous Flow Reactor Tests}

Zaveri and Flora, 2002, investigated the effects of electrolytic stimulation on the performance of $27.0 \mathrm{~L}$ two-compartment septic tanks operating under intermittent-flow conditions. The tanks were seeded with activated sludge and fed $4.0 \mathrm{~L} /$ day (hydraulic retention time, HRT $=6$ days) of synthetic wastewater containing $350 \mathrm{mg} / \mathrm{L}$ peptone trypticase, $140 \mathrm{mg} / \mathrm{L}$ beef extract, $50 \mathrm{mg} / \mathrm{L}\left(\mathrm{NH}_{4}\right)_{2} \mathrm{CO}_{3}, 40 \mathrm{mg} / \mathrm{L}$ urea, $35 \mathrm{mg} / \mathrm{L} \mathrm{NaCl}, 20$ $\mathrm{mg} / \mathrm{L} \mathrm{CaCl} 22 \mathrm{H}_{2} \mathrm{O}, 20 \mathrm{mg} / \mathrm{L} \mathrm{K} \mathrm{K}_{2} \mathrm{HPO}_{4}$, and $10 \mathrm{mg} / \mathrm{L} \mathrm{MgSO}{ }_{4} 2 \mathrm{H}_{2} \mathrm{O}$ in distilled water. Results from the study indicated that electrolytic stimulation of the wastewater resulted in an improved COD degradation proportional to the applied current.

In the study by Ortega et al., 2007, 15 L two-compartment septic tanks, operating under continuous-flow conditions were used to test the effects of electrolysis on the hydrolysis and biodegradation of septic tank sludge. The tanks were seeded with primary sludge, and fed 4.0 L/day (HRT $=3.8$ days) of synthetic wastewater using two peristaltic pumps. One of the pumps was used to deliver concentrated synthetic wastewater, and the other pump was used to deliver tap water for dilution. Once combined, the concentrations of the components in the influent wastewater were the same as those used in the studies by Zaveri and Flora, 2002, mentioned in the previous paragraph. 


\section{Objectives and Hypotheses}

The purpose of this study was to improve anaerobic digestion rates in septic tanks using simple means that do not require expensive or complicated design changes. Enhanced biodegradation rates would improve effluent quality and reduce sludge accumulation rates. This would help to alleviate some of the environmental demands of septic tank and soil absorption system, and help to ensure public health and safety.

It was hypothesised that enzyme and bacterial additives, microaeration and grinding could be used to improve septic tank performance.

The following hypotheses were the starting point of the research.

- Enzyme and bacterial additives promote the degradation of lipids, proteins, polysaccharides and cellulose in sludge

- Microaeration increases the hydrolysis rate and solubilisation of particulates

- Grinding reduces the average particle size and increases the surface area of the organic material available to the digestive bacteria

Enhanced biodegradation rates will reduce the concentration of organic materials in the effluents, and improve the conversion of the nutrients to more-tolerable forms. This will help maintain effective and reliable on-site wastewater treatment systems. 


\section{Materials and Methods}

This project was split into two phases. The first phase was a set of forty $2.0 \mathrm{~L}$ batch reactor experiments to evaluate the effects of an enzyme and bacterial additive, microaeration and grinding on primary sludge over a five week period. The second phase used a set of five continuous flow reactors to evaluate the ability of enzyme and bacterial additions and microaeration to enhance septic tank performance by improving effluent quality and reducing sludge accumulation rates. This chapter will describe the materials and methods used in the batch reactor and the continuous flow reactor experiments. It will describe the reactor setups, the sludge minimization techniques that were evaluated, and the sample analysis methods used.

\subsection{Batch Reactor Experiments}

The first phase of the project was a set of batch reactor tests in $2.0 \mathrm{~L}$ Erlenmeyer flasks. The purpose of the batch reactor experiments was to investigate and compare the ability of three simple and inexpensive pretreatment techniques (enzyme and bacterial additives, microaeration, and grinding) to improve digestion rates and reduce sludge accumulation. Four enzyme and bacterial additive doses, three grinding cycles and microaeration were tested in duplicate, at two solids concentrations: $4.2 \%$ solids (undiluted primary sludge) and $2.1 \%$ solids (diluted primary sludge), for a total of 40 flasks. All flasks were kept at room temperature $\left(22-24^{\circ} \mathrm{C}\right)$, and stirred manually once a day throughout the five week testing period. 


\subsubsection{Batch Reactor Setup}

Batch reactor tests were carried out in $2.0 \mathrm{~L}$ Erlenmeyer flasks, with a total working volume of $1.6 \mathrm{~L}$. A diagram of the setup used for the enzyme, grinding and control batch reactors is shown in Figure 3-1a and a diagram of the setup used for the microaeration batch reactors is shown in Figure 3-1b. The enzyme, grinding and control flasks were sealed with a rubber stopper (\#10) which housed a 1/4 inch gas exit line, and a glass stopper (Pyrex \#16) for the sampling port. The gas exit line was connected to $3.0 \mathrm{~L}$ Tedlar gas sampling bags (CEL Scientific Corp, CA). The microaeration flasks were closed with a rubber stopper (\#10) which housed a $1 / 4$ inch gas inlet line connected to the diffusing stone, and a gas exit line which was vented to the laboratory exhaust system.

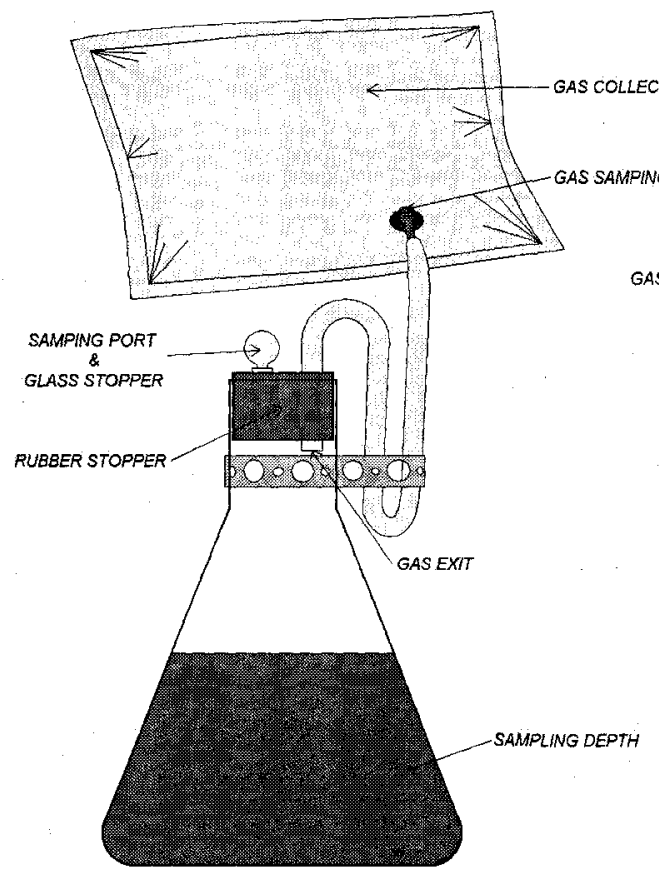

(a)

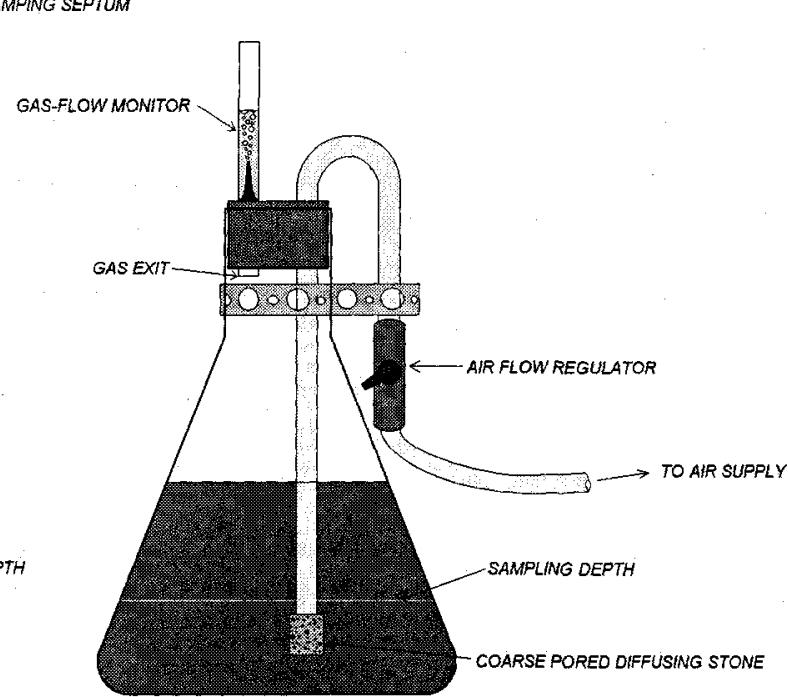

(b)

Figure 3-1: Diagram of the setup used for the (a) enzyme, grinding and control flasks, and the (b) microaeration flasks (courtesy B. Lynch, Carleton University) 


\subsubsection{Batch Reactor Seeding}

Primary (raw) sludge was obtained from the Richard O. Pickard Environmental Center (ROPEC) in Ottawa, Ontario. Two primary sludge batches obtained on July 30th and August 6th 2007 were used for the experiments. The first batch was used for the microaeration, grinding and control A batch reactors, and the second sludge batch was used for the enzyme and control B batch reactors. The initial characteristics of the primary sludge samples are presented in Table 3. All batch tests were performed at room temperature in duplicate, on raw (undiluted) primary sludge and a primary sludge diluted 1:1 with distilled water to observe the effect of solids concentration.

Table 3: Initial characteristics of the raw primary sludges used in the batch reactor experiments

\begin{tabular}{|c|c|c|c|}
\hline Parameter & Unit & $\begin{array}{l}\text { Primary Sludge } \\
\text { Batch \#1: } \\
\text { Microaeration. } \\
\text { Grinding, Control A } \\
\text { AVC ( } 1 \text { stdev) }\end{array}$ & $\begin{array}{l}\text { Primary Sludge } \\
\text { Batch } \# 2 \text { : } \\
\text { Enzymes, } \\
\text { Control B } \\
\text { AVG (tstdev) } \\
\end{array}$ \\
\hline Total Solids (TS) & $\mathrm{g} / \mathrm{L}$ & $41.3 \pm 0.2$ & $41.0 \pm 0.3$ \\
\hline Total Suspended Solids (TSS) & $\mathrm{g} / \mathrm{L}$ & $40.5 \pm 1.2$ & $40.5 \pm 1.2$ \\
\hline Volatile Solids (VS) & $\mathrm{g} / \mathrm{L}$ & $33.2 \pm 0.1$ & $32.3 \pm 0.2$ \\
\hline Volatile Suspended Solids (VSS) & $\mathrm{g} / \mathrm{L}$ & $34.0 \pm 2.3$ & $32.0 \pm 0.2$ \\
\hline Total COD & $\mathrm{mg} / \mathrm{L}$ & $65,000 \pm 100$ & $55,000 \pm 4000$ \\
\hline Soluble COD & $\mathrm{mg} / \mathrm{L}$ & $3810 \pm 100$ & $3930 \pm 100$ \\
\hline Ammonia $\left(\mathrm{NH}_{3}-\mathrm{N}\right)$ & $\mathrm{mg} / \mathrm{L}$ & $230 \pm 2$ & $200 \pm 7.5$ \\
\hline Proteins & $\mathrm{mg} / \mathrm{L}$ & $2550 \pm 100$ & $1890 \pm 2.5$ \\
\hline Carbohydrates & $\mathrm{mg} / \mathrm{L}$ & $15,000 \pm 440$ & $10,500 \pm 55$ \\
\hline
\end{tabular}

\subsubsection{Sludge Minimization Techniques}

The following sections describe the enzyme and bacterial additive, microaeration and grinding techniques used for the batch reactor experiments. 


\subsubsection{Enzyme and Bacterial Additives}

Enzyme and bacterial additions were an "all-in-one" enzyme and bacterial additive using wheat bran as a carrier. The additive contained lipase, amylase, protease, cellulase and a mixture of aerobic and anaerobic bacteria, (Septaid Powder ${ }^{\mathrm{TM}}$ - Bio-Cat Inc, Troy VA). The characteristics of the enzyme additive used in the batch reactor experiments, and the first 3 months of the continuous flow reactor experiments is presented in Table 4. Doses of $0.1,0.5,1.0$ and $5.0 \mathrm{~g} /$ flask were added at the beginning of the experiment. Each enzyme dose was tested in duplicate on diluted and undiluted sludge for a total of 16 enzyme flasks.

Table 4: Characteristics of the Septaid Powder ${ }^{\mathrm{TM}}$ used as an enzyme additive for the batch reactor tests and for the first 3 months of the continuous flow reactor experiments

\begin{tabular}{|l|c|c|}
\hline \multicolumn{1}{|c|}{ Parameter } & Unit & $\begin{array}{c}\text { Septaid Powder } \\
\text { AVG }( \pm \text { stdev })\end{array}$ \\
\hline Total COD & $\mathrm{mg} / \mathrm{g}$ & $900 \pm 400$ \\
\hline Soluble COD & $\mathrm{mg} \mathrm{s} / \mathrm{g}$ & $250 \pm 25$ \\
\hline Total Solids (TS) & $\%$ & $91 \pm 2.5$ \\
\hline Volatile Solids (VS) & $\%$ & $57 \pm 2$ \\
\hline Organic (Volatile) Acids & $\mathrm{mg} / \mathrm{g} \mathrm{as} \mathrm{HOAc}$ & $30 \pm 20$ \\
\hline Ammonia (NH $\left.{ }_{3}-\mathrm{N}\right)$ & $\mathrm{mg} / \mathrm{g}$ & $0.5 \pm 0.1$ \\
\hline Proteins & $\mathrm{mg} / \mathrm{g}$ & $30 \pm 10$ \\
\hline Carbohydrates & $\mathrm{mg} / \mathrm{g}$ & $650 \pm 60$ \\
\hline Aerobic \& Anaerobic Bacteria & $\mathrm{CFU} / \mathrm{g}$ & $2 \times 10^{9}$ \\
\hline Amylase Activity & $\mathrm{BAU} / \mathrm{g}$ & 1000 \\
\hline Protease Activity & $\mathrm{PC} / \mathrm{g}$ & 7900 \\
\hline Cellulase Activity & $\mathrm{CU} / \mathrm{g}$ & 450 \\
\hline Lipase Activity & $\mathrm{FIP} / \mathrm{g}$ & 500 \\
\hline
\end{tabular}




\subsubsection{Microaeration}

Microaeration was tested on both diluted and undiluted primary sludge, in duplicate, for a total of four microaeration flasks. Each flask was fitted with a Pyrex coarse grained diffusing stone mounted on an $8 \mathrm{~mm}$ diameter glass rod, so that the diffusing stone was $2.5 \mathrm{~cm}$ from the bottom of the flask. House air was used to microaerate samples at a rate of 5 to $10 \mathrm{~mL} / \mathrm{min}(0.031-0.062 \mathrm{vvm})$. The air was passed through a pressure regulator, then a disk-shaped HEPA filter, then to an air flow meter (Tube No. 032-41-N, glass float, Cole-Palmer Instrument Co., $\mathrm{IL}$ ). The regulated flow was then split into four lines and sent to each of the four microaeration flasks. At each flask, the flow was regulated with an individual flow valve to get an equal amount of air discharge from each flask, visible in the gas flow monitor.

\subsubsection{Grinding}

Grinding was achieved using a blender, with blending times of 1,2 and 5 minutes. The grinding times were chosen to simulate the typical particle size range obtained from commercially available grinding pumps that are used at homes to pump the septage to the septic tanks. Grinding reduced the average particle size, and increased the particle number concentrations of the samples. 1,2 and 5 minute grinding cycles reduced the average particle size of the solution by $4.5,8.5$ and $12.5 \%$ respectively, relative to the control, un-ground sludge. Detailed procedures used to measure the particle size distributions of the sludge samples are presented in section 3.1.4.10. Histograms of the particle size distributions for the various grinding experiments are attached as Appendix A: Particle Size Distribution (PSD) Analysis. 


\subsubsection{Analytical Methods}

The following sections detail the analytical methods performed on the batch reactor sludge samples. Many of the tests employed the Beer-Lambert law, which equates the linear relationship between the absorbance of a solution at a specific wavelength to the concentration of a certain species in the solution. A HACH DR 2800 spectrophotometer was used to measure the absorbance of the samples at various wavelengths. Established HACH methods were used to measure the COD, nitrate, ammonia and volatile acids concentrations directly, whereas protein and carbohydrate concentrations were measured against calibration curves generated using stock solutions.

\subsubsection{Sample Collection}

Prior to sampling, the flasks were vigorously mixed by hand using a stern orbital motion

for 5 seconds, on a small piece of laboratory mat lubricated with soapy water. Samples were withdrawn using a modified wide-mouth $10 \mathrm{~mL}$ glass pipette inserted through the sampling port on the rubber stopper. Some of the sludge samples were homogenized using a small pestle and mortar, and diluted if necessary depending on the test.

All tests were performed in duplicate, for a total of 80 tests per analysis (tCOD, sCOD, TS, VS, TSS, VSS, $\mathrm{NH}_{3}$, Protein, Carbohydrate). The standard deviation and $95 \%$ confidence interval were calculated for each data point. All in text figures have error bars of plus or minus one standard deviation. A collection of the same figures with error bars of plus or minus 1.96 standard deviations (95\% confidence interval) is attached in Appendix C: Figures with 95\% C.I. - Batch Reactor Tests. 
To make the testing procedure more manageable, tCOD and SCOD tests were conducted on the same day so that the degree of solubilisation could be determined effectively. Likewise, all solids tests were conducted on the same days. And finally ammonia, protein and carbohydrate concentrations were measured together on the same day.

\subsubsection{Total and Soluble COD}

The total and soluble COD of the sludges were measured in duplicate using $\mathrm{HACH}$ method 8000, High Range Plus, 200-15,000 mg/L COD (HACH Company, 2005a). Initial measurements on the primary sludge used for the batch reactor experiments suggested that a 10:1 dilution was suitable for all COD tests to allow enough variance so that the dilution factor did not need to be changed for the remainder of the batch reactor experiments. The soluble component of the sludges was prepared by centrifuging $30 \mathrm{~mL}$ of sample at $3400 \mathrm{rpm}$ for 20 minutes. $10 \mathrm{~mL}$ of the centrate was filtered through a 4.5 $\mathrm{cm}$ diameter, $0.45 \mathrm{~mm}$ pore-size filter paper into $25 \mathrm{~mL}$ glass vacuum bottles.

\subsubsection{Total Solids and Total Volatile Solids}

The total solids (TS) and volatile solids (VS) of the sludge were measured according to standard methods 2540 B and 2540 E respectively (American Public Health Association (APHA), American Water Works Association (AWWA) and Water Environment Federation (WEF), 2005). To prepare, $8050-\mathrm{mL}$ aluminum weigh dishes were labelled, then cleaned in a muffle furnace, in batches of ten, at $550^{\circ} \mathrm{C}$ for 45 minutes. The dishes were allowed to cool in a dessicator for 45 minutes, then weighed on an analytical balance (mass of dish $=$ A). Samples withdrawn from the batch reactors were kept small 
to maintain adequate sludge volumes for the duration of the experiment, while yielding a reasonable amount of residue in each weigh dish following sample ignition. Standard Methods protocols suggest a residue between 2.5 and $200 \mathrm{mg}$. $5 \mathrm{~mL}$ of the undiluted sludge ( $4.2 \%$ initial solids), and $10 \mathrm{~mL}$ of the diluted sludge (2.1\% initial solids) were used for each TS and VS replicate. 5-10 $\mathrm{mL}$ of sludge was withdrawn from the first ten batch reactors and placed in the appropriate dish using a modified wide-mouth glass pipette. The dishes with the sludge samples were weighed (mass of wet sample + dish $=$ B), dried in an oven under a fume hood for $3-4$ hours at $105^{\circ} \mathrm{C}$, and cooled in a dessicator. Once cool, the dishes and dry sample were weighed (mass of dry sample + dish $=\mathrm{C}$ ), ignited in a furnace vented to the laboratory exhaust gas system at $550^{\circ} \mathrm{C}$ for 1 hour, cooled in a dessicator, and weighed (mass of ignited sample + dish $=\mathrm{D}$ ). The percent total and volatile solids were calculated using Equation 3-1 and Equation 3-2 respectively.

$$
\begin{array}{ll}
\% T S=100 \times \frac{C-A}{B-A} & \text { Equation 3-1 } \\
\% V S=100 \times \frac{C-D}{B-A} & \text { Equation 3-2 }
\end{array}
$$

where:
A: mass of dish (mg)
B: mass of wet sample + dish (mg)
C: mass of dried residue + dish (mg)
$\mathrm{D}$ : mass of residue + dish after ignition $(\mathrm{mg})$ 


\subsubsection{Total Suspended and Volatile Suspended Solids}

The total suspended solids (TSS) and volatile suspended solids (VSS) were measured according to standard methods $2540 \mathrm{D}$ and $2540 \mathrm{E}$ respectively (American Public Health Association (APHA), American Water Works Association (AWWA) and Water Environment Federation (WEF), 2005). To prepare, 80 Whatman $^{\mathrm{TM}}$ 934-AH glass fibre filter papers ( $1.5 \mu \mathrm{m}$ retention) were placed into clean and dry labelled crucibles. The crucibles and filters papers were ignited in a muffle furnace for 30 minutes, cooled in a dessicator, and weighed (mass of filter paper $=\mathrm{F}$ ). $2-4 \mathrm{~mL}$ of sludge sample was vacuum filtered using a Buchner funnel apparatus, and rinsed three times with small amounts of distilled water. The filter paper was then carefully removed from the filtration apparatus and replaced into the appropriately labelled crucible. Two replicates of this process were performed for all flasks. Batches of ten crucibles and filter papers were dried in an oven at $105^{\circ} \mathrm{C}$ for 2 hours, cooled in a dessicator, and weighed (mass of filter + dried residue $=\mathrm{G})$. The crucibles and filter papers were subsequently ignited in a muffle furnace at $550{ }^{\circ} \mathrm{C}$ for 1 hour. The crucibles and filter papers were allowed to cool in the furnace until reaching $250^{\circ} \mathrm{C}$, then were moved to an oven $\left(\mathrm{T}=105^{\circ} \mathrm{C}\right)$ for $1-2$ hours. The filter papers were carefully removed from the crucibles, placed in a dessicator to cool to room temperature, and weighed (mass of filter + ignited residue $=\mathrm{H}$ ). The TSS and VSS concentrations were calculated using Equation 3-3 and Equation 3-4 respectively. 


$$
\begin{array}{ll}
T S S(m g / L)=1000 \times \frac{G-F}{E} & \text { Equation 3-3 } \\
V S S(m g / L)=1000 \times \frac{G-H}{E} & \text { Equation 3-4 }
\end{array}
$$

where:

E: sample volume $(\mathrm{mL})$

F: mass of filter paper (mg)

G: mass of dried residue + filter paper (mg)

$\mathrm{H}$ : mass of residue + filter paper after ignition $(\mathrm{mg})$

\subsubsection{Protein}

The protein concentrations of the sludges were determined using a Coomassie Brilliant Blue G-250 reagent with the Bradford method (Bradford, 1976). A Coomassie (Bradford) reagent kit, containing a pre-made protein assay kit with Albumin Standard Ampoules of bovine serum albumin (BSA) solution was purchased from Pierce Biotechnology Inc. The BSA solution was diluted to various known concentrations between 0 and $2000 \mathrm{mg} / \mathrm{L}$ to generate a colour response calibration curve (Figure 3-2). The response curve was linear up to $1000 \mathrm{mg} / \mathrm{L}$, which was set as the working range. Test tubes were filled with $5.0 \mathrm{~mL}$ of the Coomassie reagent, and then $3.0 \mathrm{~mL}$ of each standard or unknown sample was added to the test tubes. Test tubes were inverted to mix, and incubated at room temperature for ten minutes. The spectrophotometer was zeroed with a test tube filled with distilled water, then the absorbance of a blank, consisting of $3.0 \mathrm{~mL}$ of distilled water and $5.0 \mathrm{~mL}$ of the Coomassie reagent was 
measured at a wavelength of $595 \mathrm{~nm}$. The absorbance of the blank was subtracted from the absorbance of all the other absorbance measurements. The corrected absorbance measurements of the samples were then compared the calibration curve to get the protein concentrations of the samples. The appropriate back calculations were made to get the actual concentration in the flasks. Initially the concentration of proteins in the undiluted sludge was around $2500 \mathrm{mg} / \mathrm{L}$, and a dilution of 1:10 was suitable. Subsequently the dilution ratio was increased to 1:50 for the duration of the experiments.

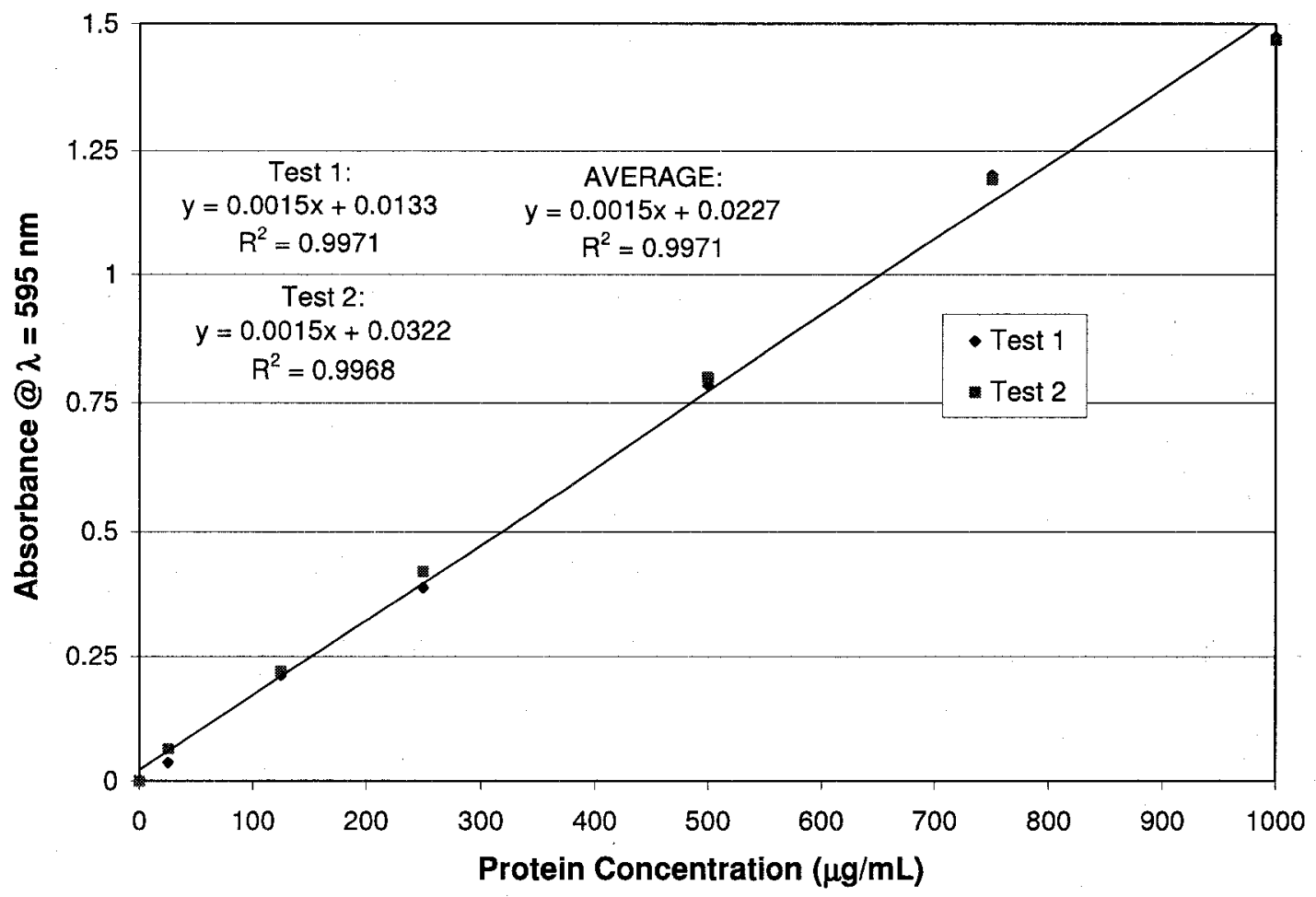

Figure 3-2: Colour response curve for BSA between 0 and $1000 \mathrm{mg} / \mathrm{L}$ 


\subsubsection{Carbohydrate}

The carbohydrate concentrations of the sludges were determined using the Anthrone method (Morris, 1948). A solution of $95 \%$ sulphuric acid with $2.0 \mathrm{~g} / \mathrm{L}$ of anthrone reagent was created. Using a $98 \%$ pure galactose powder (Acros Organics, NJ), galactose stock solutions of $0,25,50,75,100,150,200,300 \mathrm{mg} / \mathrm{mL}$ were made. Test tubes were filled with $6.0 \mathrm{~mL}$ of the anthrone reagent, and then $3.0 \mathrm{~mL}$ of each standard or unknown sample was added to the test tubes. Test tubes were inverted to mix, and incubated at room temperature for ten minutes. Samples were then analysed to produce a colour response calibration curve at a wavelength of $620 \mathrm{~nm}$ (Figure 3-3). The spectrophotometer was zeroed with a test tube filled with distilled water, then the absorbance of a blank, consisting of $3.0 \mathrm{~mL}$ of distilled water and $6.0 \mathrm{~mL}$ of the anthrone reagent was measured at a wavelength of $620 \mathrm{~nm}$. The absorbance of the blank was subtracted from the absorbance of all the other absorbance measurements. The corrected absorbance measurements of the samples were then compared to the calibration curve to get the carbohydrate concentration of the samples. The appropriate back calculations were made to get the actual concentration in the flasks. Initially the concentration of carbohydrates in the undiluted sludge was around $15,000 \mathrm{mg} / \mathrm{L}$, and required a dilution of 1:150. Subsequently the dilution ratio was changed to $1: 50$ for the duration of the experiments. 


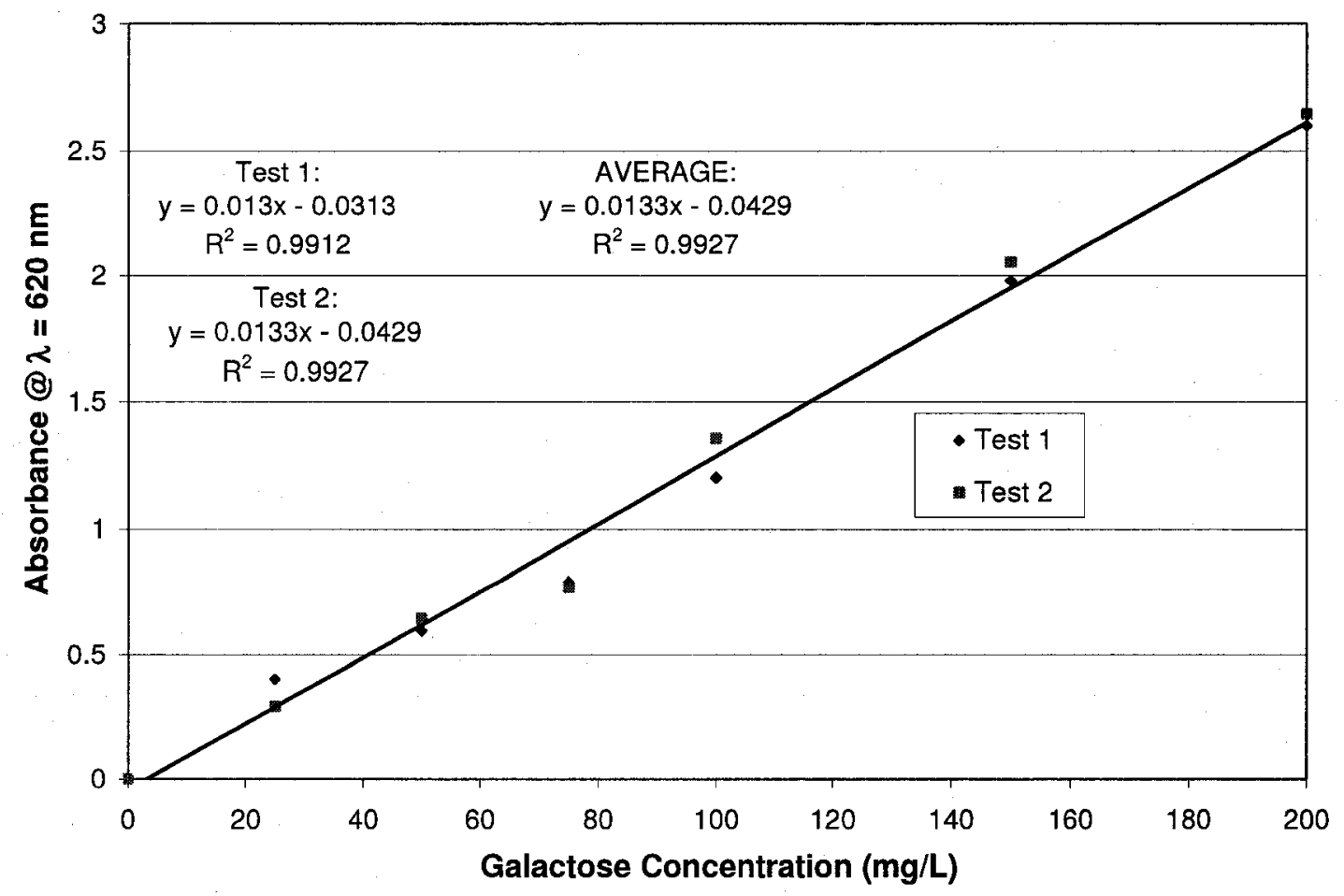

Figure 3-3: Colour response curve for galactose between 0 and $200 \mathrm{mg} / \mathrm{L}$

\subsubsection{Ammonia}

The ammonia concentrations of the sludge samples were measured using $\mathrm{HACH}$ method 10031 (Salisylate Method), High Range, 0.4-50 mg/L NH${ }_{3}-\mathrm{N}$ (HACH Company, 2005b). Initial tests on the raw primary sludge demonstrated that the protein concentration was around 200 to $230 \mathrm{mg} / \mathrm{L}$ as $\mathrm{NH}_{3}$. Samples were diluted 10:1 with distilled water to fall within the measurable range of the test. Profiles of increasing ammonia concentration help to assess the level of digestion since ammonia generation will result from the degradation of nitrogen-containing compounds. 


\subsubsection{Gas Analysis}

The headspace gas was collected using individual $3.0 \mathrm{~L}$ Tedlar gas sampling bags. 1.0 $\mathrm{mL}$ gas samples were extracted using a $1.0 \mathrm{~mL}$ syringe, and analyzed using an SRI Instruments $8610 \mathrm{C}$ gas chromatograph (GC) equipped and flame ionization detector (FID). The GC was operated at a temperature of $90^{\circ} \mathrm{C}$ for 9 minutes, and used helium as the carrier gas. Carbon dioxide and methane was proportionally measured to confirm methanogenic activity. During the tests however, leaks in the GC instrument allowed air to enter the system, which hindered carbon-based mass balance attempts. Furthermore, gas generation volumes by day where very small, which prevented a time profile gas analysis, instead the gas collection bags enabled a visual quantification of the gas generation volumes for each of the batch reactors.

\subsubsection{Dissolved Oxygen}

The dissolved oxygen (DO) of the sludge samples was measured using a VWR Symphony SP700 DO meter equipped with a VWR Symphony DO probe. DO readings required long periods to stabilise. Furthermore, the harsh nature of the sludge quickly degraded the membrane on the DO probe, which reduced the sensitivity of the probe. After early attempts to measure the DO all forty batch reactors, the DO measurements were ceased for the rest of the batch reactor experiments. 


\subsubsection{Particle Size Analysis}

The particle size distributions of the sludge samples were determined using a DPA4100 Particle Analysis System and HEV Sample Platform, by Brightwell Technologies Inc. Sludge samples were diluted 5000:1 in distilled water to reduce the particle number concentration to below the devices concentration limit of 80,000 particles $/ \mathrm{mL}$, then screened through a $400 \mu \mathrm{m}$ Nitex screen to avoid clogging the flow cell. Preliminary tests demonstrated that when the undiluted sample was screened through the $400 \mu \mathrm{m}$ screen, $50 \%$ of the solids were retained, however after dilution (1:5000), the retention on the $400 \mu \mathrm{m}$ screen (percent of particles greater than $400 \mu \mathrm{m}$ ) was only $3.4 \%$. To test the latter, $5 \mathrm{~mL}$ of sludge was diluted into $25 \mathrm{~L}$ of water and screened through the $400 \mu \mathrm{m}$ screen. 


\subsection{Continuous Flow Reactor Experiments}

The second phase of the project evaluated the effect of an enzyme and bacterial additives and microaeration on the performance of bench-scale septic tanks operating under continuous flow conditions. Two tanks were equipped with air diffusers to test two different microaeration rates and diffuser configurations, two tanks were treated with an enzyme and bacterial additive, and a fifth tank was operated as a control. Each tank was inoculated with $8.0 \mathrm{~L}$ of primary sludge and fed a synthetic wastewater feed of $9.0 \mathrm{~L} / \mathrm{d}$ to attain a hydraulic retention time of 3.6 days. All reactors were operated for 5 months. Effluents from the reactors was collected periodically and analysed for TSS, VSS, tCOD, sCOD, $\mathrm{NH}_{3}, \mathrm{NO}_{3}{ }^{-}$, organic acids, proteins carbohydrates, $\mathrm{pH}, \mathrm{ORP}$ and $\mathrm{DO}$.

\subsubsection{Continuous Flow Reactor Setup}

Continuous flow reactor tests were carried out in $40.0 \mathrm{~L}$ bench-scale septic tanks. Five two-compartment tanks were constructed using $1 / 2$ inch thick acrylic (Canus Plastics, Ottawa, ON). Each tank was $47 \mathrm{~cm}$ long x $33 \mathrm{~cm}$ wide $\times 32.4 \mathrm{~cm}$ high, and operated at a liquid depth of $24.6 \mathrm{~cm}$ resulting in a liquid volume of $32.4 \mathrm{~L}$. The dividing wall between the two compartments was $35.6 \mathrm{~cm}$ from the front wall and 7.6 from the back wall. The resulting internal dimensions of the first and second compartments were 35.6 cm long x $30.5 \mathrm{~cm}$ wide $x 30.5 \mathrm{~cm}$ high and $7.6 \mathrm{~cm}$ long $x 30.5 \mathrm{~cm}$ wide $\times 30.5 \mathrm{~cm}$ high respectively. The dimensions of the tanks and the relative size of each compartment-

were chosen based on the drawings for the $4500 \mathrm{~L}$ Clearford Clarifier with $82: 18$ primary-secondary length ratio. The two compartments were hydraulically connected at 
a depth of 8.5 inches, through a 1 inch diameter hole located $1 / 2$ inch off the vertical centre line of the wall. A $3 / 4$ inch PVC threaded elbow was screwed into the hole and pointed at 45 degrees downwards and towards the vertical centre line of the tank. Each tank had a $1 / 4$ inch thick acrylic lid with a $1 / 2$ inch overhand along all sides. The lids were sealed to the tank for the duration of the experiment using a clear silicon sealant. $1 \frac{3 / 4}{4}$ inch holes were drilled in the lids at the middle of compartments one and two, and plugged with rubber stoppers (\#10). The rubber stoppers housed gas exit lines, and a glass stopper (Pyrex \#16) for the sampling port. The microaeration tanks had extra holes and rubber stoppers to accommodate the air inlet lines, diffusing stones, and exhaust lines with bubble monitors. One of the tanks was equipped with two air diffusing stones mounted 4.5 inches from the front of the tank, and spaced off the left and right edges by 4.5 inches. The second microaeration tank was equipped with one air diffusing stone mounted 4.5 inches from the front wall of the tank, and along the front-to-back centre line. The air diffusing stones in all tanks were mounted such that minute amounts of air were delivered at a depth between 0.5 and 1.5 inches from the base of the tank. A diagram and picture of the continuous flow reactors are presented in Figure 3-4 and Figure 3-5. 

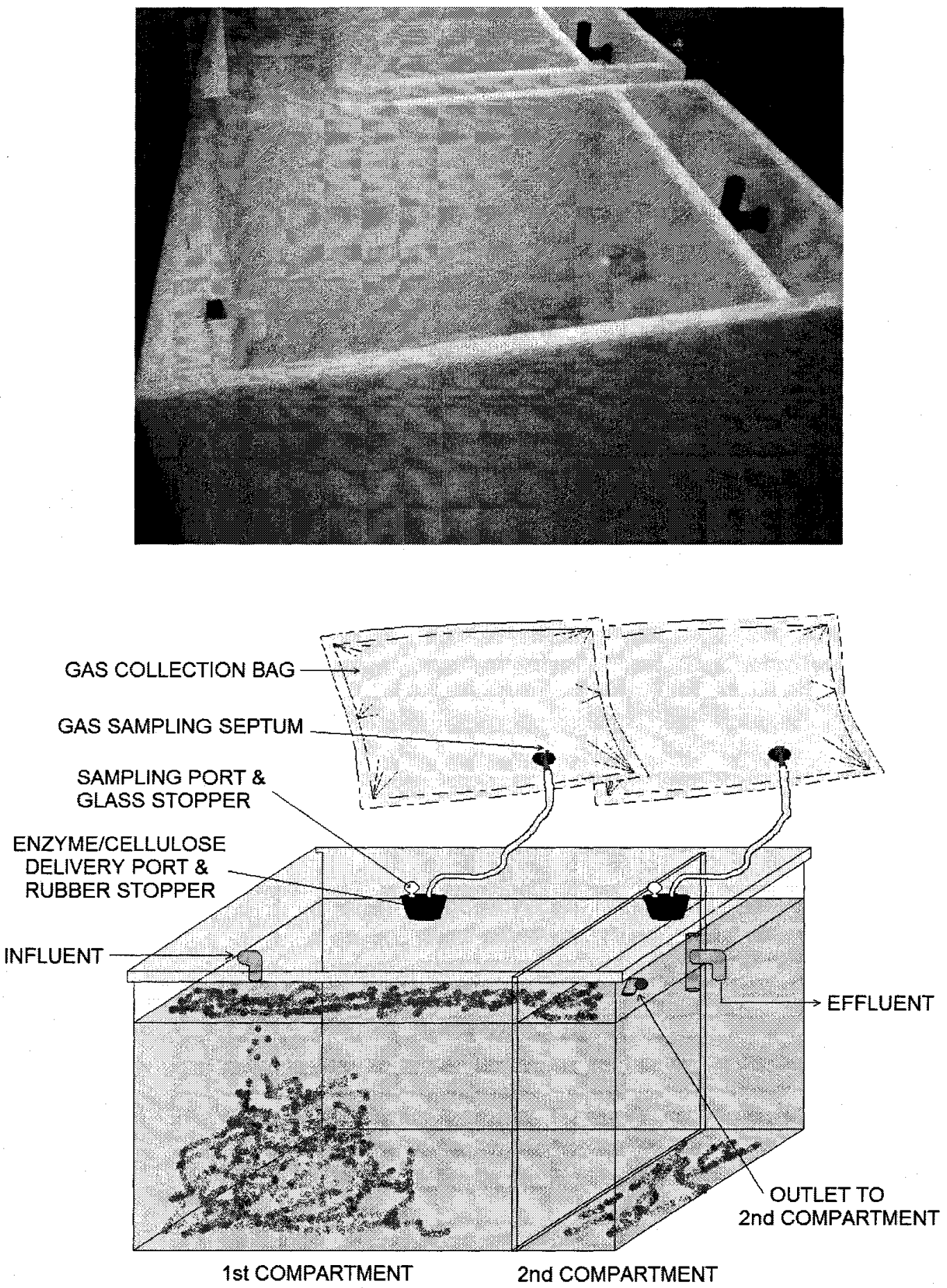

Figure 3-4: Picture and diagram of the setup used for the enzyme and control tanks 

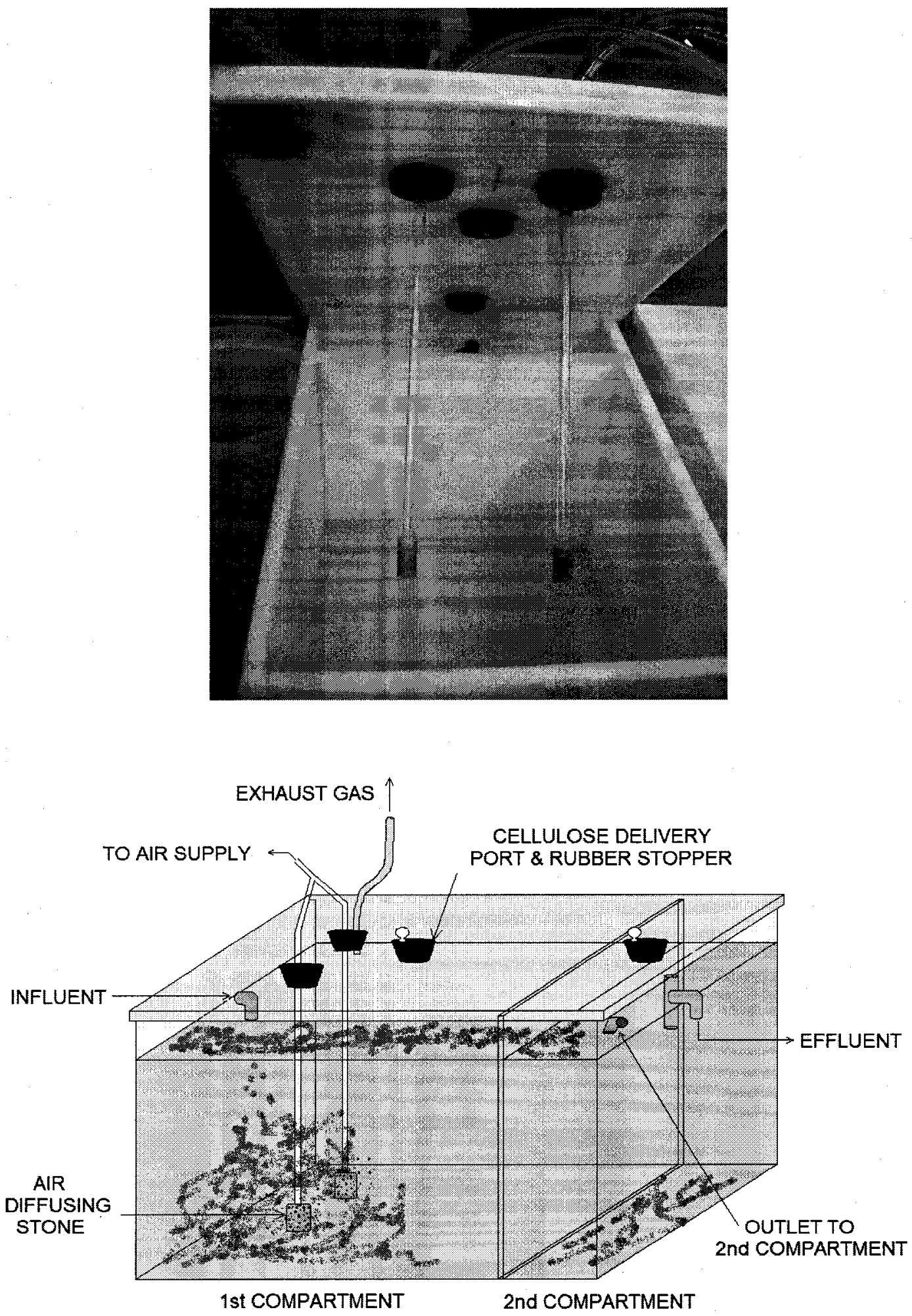

Figure 3-5: Picture and diagram of the setup used for the microaeration tank with two air diffusers 


\subsubsection{Continuous Flow Reactor Seeding}

Each tank was seeded with $8.0 \mathrm{~L}$ of primary sludge obtained from ROPEC, then filled to the hydraulic operating level with synthetic wastewater. The characteristics of the primary sludge used to seed the reactors are presented in Table 5.

Table 5: Initial characteristics of: the raw primary sludge used to seed the continuous flow reactors,

\begin{tabular}{|l|c|c|}
\hline \multicolumn{1}{|c|}{ Parameter } & Unit & $\begin{array}{c}\text { Primary Shudge } \\
\text { AVG ( } 1 \text { stdev) }\end{array}$ \\
\hline Total Solids (TS) & $\mathrm{g} / \mathrm{L}$ & $49.3 \pm 0.6$ \\
\hline Total Suspended Solids (TSS) & $\mathrm{g} / \mathrm{L}$ & $32.6 \pm 4.4$ \\
\hline Volatile Solids (VS) & $\mathrm{g} / \mathrm{L}$ & $38.3 \pm 1.2$ \\
\hline Volatile Suspended Solids (VSS) & $\mathrm{g} / \mathrm{L}$ & $25.9 \pm 1.8$ \\
\hline Total COD & $\mathrm{mg} / \mathrm{L}$ & $95,600 \pm 4300$ \\
\hline Soluble COD & $\mathrm{mg} / \mathrm{L}$ & $14,100 \pm 250$ \\
\hline Organic Acids & $\mathrm{mg} / \mathrm{L} \mathrm{as} \mathrm{HOAc}$ & $2500 \pm 43$ \\
\hline Ammonia (NH $\left.{ }_{3}-\mathrm{N}\right)$ & $\mathrm{mg} / \mathrm{L}$ & $330 \pm 23$ \\
\hline Proteins & $\mathrm{mg} / \mathrm{L}$ & $1850 \pm 225$ \\
\hline Carbohydrates & $\mathrm{mg} / \mathrm{L}$ & $11,250 \pm 1625$ \\
\hline
\end{tabular}

\subsubsection{Synthetic Wastewater Feed}

The synthetic wastewater was prepared using tap water, dechlorinated with sodium thiosulphate. Preliminary tests demonstrated that $10.0 \mathrm{mg}$ sodium thiosulphate per litre of fresh tap water was sufficient to consume all the free and total chlorine. Periodic tests were conducted throughout the experiment to confirm the absence of total and free chlorine. The synthetic wastewater composition was based on the studies by Ortega et al. (2007), Zaveri and Flora (2002), and Vaishnav and McCabe (1996). It contained 350 $\mathrm{mg} / \mathrm{L}$ peptone trypticase, $140 \mathrm{mg} / \mathrm{L}$ beef extract, $50 \mathrm{mg} / \mathrm{L}\left(\mathrm{NH}_{4}\right)_{2} \mathrm{CO}_{3}, 40 \mathrm{mg} / \mathrm{L}$ urea, 35 
$\mathrm{mg} / \mathrm{L} \mathrm{NaCl}, 20 \mathrm{mg} / \mathrm{L} \mathrm{CaCl} 22 \mathrm{H}_{2} \mathrm{O}, 20 \mathrm{mg} / \mathrm{L} \mathrm{K}_{2} \mathrm{HPO}_{4}$, and $10 \mathrm{mg} / \mathrm{L} \mathrm{MgSO} \mathrm{M}_{4} 2 \mathrm{H}_{2} \mathrm{O}$. The characteristics of the synthetic wastewater are presented in Table 6.

Table 6: Characteristics of the synthetic wastewater used to feed the continuous flow reactors

\begin{tabular}{|l|c|c|}
\hline \multicolumn{1}{|c|}{ Parameter } & Unit & Synthetic Wastewater \\
\hline Total Solids (TS) & & 0.80 \\
\hline Total Suspended Solids (TSS) & $\mathrm{g} / \mathrm{L}$ & 0.50 \\
\hline Volatile Solids (VS) & $\mathrm{g} / \mathrm{L}$ & 0.44 \\
\hline Volatile Suspended Solids (VSS) & $\mathrm{g} / \mathrm{L}$ & 0.37 \\
\hline Total COD & $\mathrm{mg} / \mathrm{L}$ & $650-1000$ \\
\hline Soluble COD & $\mathrm{mg} / \mathrm{L}$ & $500-750$ \\
\hline Organic (Volatile) Acids & $\mathrm{mg} / \mathrm{L} \mathrm{as} \mathrm{HOAc}$ & $110-180$ \\
\hline Ammonia (NH $\left.{ }_{3}-\mathrm{N}\right)$ & $\mathrm{mg} / \mathrm{L}$ & $40-80$ \\
\hline Proteins & $\mathrm{mg} / \mathrm{L}$ & $10-20$ \\
\hline Carbohydrates & $\mathrm{mg} / \mathrm{L}$ & $10-20$ \\
\hline
\end{tabular}

A crystalline cellulose powder mixed with $100 \mathrm{~mL}$ of warm $\left(\mathrm{T}=35^{\circ} \mathrm{C}\right)$ distilled water was added to the first compartment of the tanks daily. Preliminary tests on the cellulose powder in distilled water showed the tCOD of the cellulose powder to be $1260 \mathrm{mg}$ $\mathrm{tCOD} / \mathrm{g}$ cellulose powder. $1.8 \mathrm{~g}$ of cellulose powder, with an equivalent COD of 2250 mg tCOD, was added daily for an extra $250 \mathrm{mg} / \mathrm{L}$ of tCOD in the feed. The resulting wastewater feed had a tCOD of around 1000 to $1200 \mathrm{mg} / \mathrm{L}$, with $25 \%$ from the cellulose powder.

A 1-100 rpm peristaltic pump (Model No. 7553-80, Cole-Palmer Instrument Co., IL) fitted with a multi-cartridge pump head system (Pump Head Model No. 07519-15, Cartridge Model No. 07519, Masterflex, IL) was used to provide $2.75 \mathrm{ml} / \mathrm{min}$ of concentrated synthetic wastewater to each reactor from a $60.0 \mathrm{~L}$ feed reservoir. The 
concentrated synthetic wastewater feed reservoir was stirred periodically with an adjustable-speed mixer and a large stainless steel paddle. The mixer was connected to a programmable digital timer set to turn on and off 20 times per day (every 36 minutes). A 6-600 rpm peristaltic pump (Model No. 7553-70, Cole-Palmer Instrument Co., IL) fitted with a multi-cartridge pump head system (Pump Head Model No. 07519-15, Cartridge Model No. 07519 , Masterflex, IL) was used to provide $3.5 \mathrm{~mL} / \mathrm{min}$ of tap water with 10 $\mathrm{mg} / \mathrm{L}$ sodium thiosulphate to each reactor from a $60.0 \mathrm{~L}$ feed reservoir. The combined flow from both pumps was $5.5 \mathrm{~mL} / \mathrm{min}$ to each tank $(9.0 \mathrm{~L} /$ day $)$. The resulting hydraulic retention time of the reactors was 3.6 days

\subsubsection{Sludge Minimization Techniques}

\subsubsection{Enzyme and Bacterial Additives}

For the first three months of reactor operation, two continuous flow reactors were treated biweekly with $4.0 \mathrm{~g}$ and $2.0 \mathrm{~g}$ of Septaid Powder ${ }^{\mathrm{TM}}$ respectively. The characteristics of the Septaid Powder ${ }^{\mathrm{TM}}$ are presented in Table 4. The powder was mixed into $100 \mathrm{~mL}$ of warm water, along with the daily cellulose dose, and added to the first compartment of

the reactors. After three months of reactor operation, the enzyme and bacterial additive mixture was replaced with a specialised pure-powder enzyme mixture containing $30 \%$ amylase, $30 \%$ protease, $25 \%$ cellulase and $15 \%$ lipase. 10 and $20 \mathrm{mg}$ of the enzyme mixture per litre of reactor volume were added biweekly to the reactors (324 and $648 \mathrm{mg}$ enzymes biweekly). The characteristics of the enzyme mixture are presented in Table 7. 
Table 7: Characteristics of the pure-powder enzyme additive mixture used after 3 months of reactor operation to the end of the experiments

\begin{tabular}{|l|c|c|}
\hline \multicolumn{1}{|c|}{ Parameter } & Unit & Enzyme Additive \\
\hline Aerobic \& Anaerobic Bacteria & $\mathrm{CFU} / \mathrm{g}$ & 0 \\
\hline Amylase Activity & $\mathrm{BAU} / \mathrm{g}$ & 15,000 \\
\hline Protease Activity & $\mathrm{PC} / \mathrm{g}$ & 150,000 \\
\hline Cellulase Activity & $\mathrm{CU} / \mathrm{g}$ & 12,500 \\
\hline Lipase Activity & $\mathrm{FIP} / \mathrm{g}$ & 2250 \\
\hline
\end{tabular}

\subsubsection{Microaeration}

Microaeration was tested on two continuous flow reactors. One of the reactors was equipped with two Pyrex coarse grained diffusing stones, while the other reactor only had one. House air delivered to each of the reactors was controlled using two $150 \mathrm{~mm}$ flow meters (Tube No. 032-41-N, glass float, Cole-Palmer Instrument Co., IL).

The initial microaeration rates disturbed the settling conditions in the reactors, resulting in some sludge bed washout. This prompted a series of reductions in the microaeration rates during the first two weeks, until microaeration rates of 20 and $40 \mathrm{~mL} / \mathrm{min}$ were achieved for the reactors with one and two air diffusing stones respectively. After 4 weeks of reactor operation, the microaeration rates were reduced to $10 \mathrm{ml} / \mathrm{min}$ and 20 $\mathrm{mL} / \mathrm{min}$ for the reactors with one and two diffusing stones respectively to evaluate the effectiveness of the treatment with minimised operating costs. Figure 3-6 shows a plot of the various microaeration rates used during the experiment. Slight variations occurred due to pressure variations in the house air supply. 


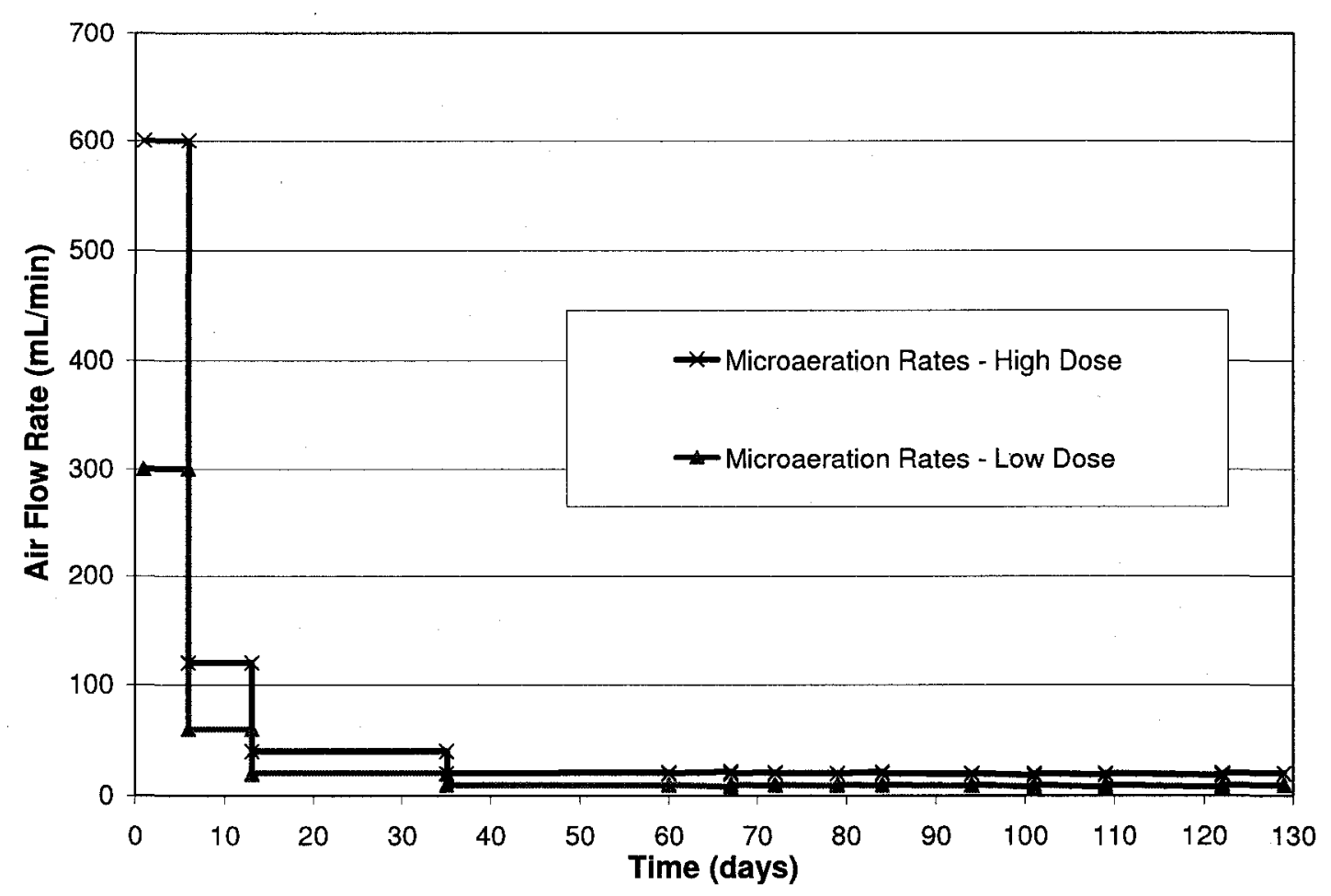

Figure 3-6: Microaeration rates delivered to the two continuous flow reactors equipped with coarse grained diffusing stones

\subsubsection{Analytical Methods}

The following sections detail the analytical methods used during the second phase of the project which tested the effect of enzyme and bacterial additives, and microaeration on the performance of continuous flow reactors. Effluent from the reactors was collected and analysed, in replicates of three, for TS, TVS, TSS, VSS, tCOD, SCOD, $\mathrm{NH}_{3}, \mathrm{NO}_{3}{ }^{-}$, organic acids, proteins and carbohydrates. The effluent tests and the standard deviation and $95 \%$ confidence interval (1.96 standard deviations) was calculated for each data point. All in-text figures have error bars of plus or minus one standard deviation. A collection of the same figures with error bars of plus or minus 1.96 standard deviations is attached in Appendix F: Figures with 95\% C.I. - Continuous Flow Reactor Tests. 


\subsubsection{Sample Collection and Preparation}

For the first 40 days of reactor operation, effluent samples were collected and analysed from each of the continuous flow reactors every 4 days. After 40 days of reactor operation, weekly sampling was performed on the reactor effluents. Reactor effluents were collected in 2.0L Erlenmeyer flasks for about 1 to 2 hours, resulting in between 300 and $700 \mathrm{~mL}$ of reactor effluent. Effluent collection times were recorded, and used to determine the hydraulic retention time for each of the reactors.

Reactor effluents were stirred using magnetic stirrer bars while $50 \mathrm{~mL}$ was withdrawn, and placed in $50 \mathrm{~mL}$ centrifuge tubes, and centrifuged at $3400 \mathrm{rpm}(\mathrm{RCF}=1200 \mathrm{~g})$ for 15 minutes, prior to being filtered through a $0.45 \mu \mathrm{m}$ retention Whatman type WCN cellulose nitrate membrane filter paper.. The filtrate collected was used for the soluble COD measurement and the volatile organic acids measurement. $200 \mathrm{~mL}$ of the remaining reactor effluents was homogenised for 2 minutes in a conventional kitchen blender. 40 $\mathrm{mL}$ of the homogenised effluent was placed in a $50 \mathrm{~mL}$ beaker and used for $\mathrm{tCOD}$, proteins, carbohydrates, and nitrates measurements. $10 \mathrm{~mL}$ of homogenised effluent was placed in another $50 \mathrm{~mL}$ beaker with $30 \mathrm{~mL}$ of distilled water, for a 3:1 dilution of reactor effluent in distilled water. The diluted reactor effluent sample was used for the ammonia measurements.

\subsubsection{Total and Soluble COD}

The total and soluble COD of the reactor effluents were measured in triplicate using HACH method 8000, High Range, 20-1500 mg/L COD (HACH Company, 2005c). 
Samples for the soluble COD measurements were prepared as outlined in section 3.2.5.1. $2.0 \mathrm{~mL}$ of sample was placed in a COD digestion vial and heated at $150{ }^{\circ} \mathrm{C}$ for two hours in a DRB 200 Reactor. Once cool, COD test results, in $\mathrm{mg} / \mathrm{L}$, were measured at $620 \mathrm{~nm}$ using a DR 2800 Spectrophotometer.

\subsubsection{Total Solids and Total Volatile Solids}

Total solids (TS) and total volatile solids (TVS) of the sludge and scum layers within the continuous flow reactors were measured using standard methods $2540 \mathrm{~B}$ and $2540 \mathrm{E}$ respectively (American Public Health Association (APHA), American Water Works Association (AWWA) and Water Environment Federation (WEF), 2005). $10 \mathrm{~mL}$ samples were withdrawn from the bottom the first compartment of the reactors for sludge bed solids analysis, and the top of the first compartment for scum layer solids analysis. Samples were placed into labelled, cleaned, ignited and weighed 50-mL aluminum dishes

\subsubsection{Total Suspended and Volatile Suspended Solids}

Total suspended solids (TSS) and volatile suspended solids (VSS) of the reactor effluents were measured using standard methods $2540 \mathrm{D}$ and $2540 \mathrm{E}$ respectively (American Public Health Association (APHA), American Water Works Association (AWWA) and Water Environment Federation (WEF), 2005). The solids analysis of the reactor effluents required at least $500 \mathrm{~mL}$ of sample to obtain representative amount of dry mass. Where sampling circumstances permitted, $1.0 \mathrm{~L}$ of effluent was filtered through the Whatman ${ }^{\mathrm{TM}}$ 934-AH glass fibre filter papers $(1.5 \mu \mathrm{m}$ retention). Filter papers were dried, then ignited, as described in section 3.1.4.4. 


\subsubsection{Protein}

The protein concentrations of the reactor effluents were measured using the Coomassie Brilliant Blue G-250 reagent with the Bradford method (Bradford, 1976), as described in section 3.1.4.5. Each test was performed three times, then the corrected average absorbance was compared to the calibration curve to get the protein

\subsubsection{Carbohydrate}

The carbohydrate concentrations of the reactor effluents were measured in triplicate using the Anthrone method (Morris 1948); as described in section 3.1.4.6.

\subsubsection{Ammonia and Nitrate}

The ammonia concentrations of the reactor effluents were measured using $\mathrm{HACH}$ method 10031 (Salisylate Method), High Range, 0.4-50 mg/L NH $3-\mathrm{N}$ (HACH Company, 2005b). Feed and effluent samples for ammonia measurements were diluted with 3 parts of distilled water, as described in section 3.2.5.1 to be in the appropriate range for the test. The nitrate content of the sludge was measured using HACH method 10020 (Chromotropic Acid Method), High Range, 0.2-30 mg/L N0${ }_{3}^{-}-\mathrm{N}$ (HACH Company, 2005d). 


\subsubsection{Volatile (Organic) Acids}

The volatile organic acids content of the effluents was measured in triplicate using HACH method 8196 (Esterification Method), 27-2800 mg/L as HOAc (HACH Company, $2005 e)$.

\subsubsection{Gas Analysis}

The two enzyme reactors and the control reactor were equipped with two $3.0 \mathrm{~L}$ Tedlar gas sampling bags. $1.0 \mathrm{~mL}$ gas samples were extracted using a $1.0 \mathrm{~mL}$ syringe, and analyzed using an SRI Instruments $8610 \mathrm{C}$ gas chromatograph (GC) equipped with a column and flame ionization detector (FID) as described in section 3.1.4.8. The instrument was used to measure methane percentage, carbon dioxide percentage, and a combined nitrogen and oxygen percentage in the gas sample.

\subsubsection{Dissolved Oxygen}

Dissolved Oxygen (DO) was measured using a handheld portable VWR Symphony SP700 DO meter equipped with a VWR Symphony DO probe (VWR, Missassauga, ON). Samples were placed in $50 \mathrm{~mL}$ beakers for reactor effluent DO measurements. DO "spot-checks" were performed in the reactors by attaching the DO probe to a longer rod, so that the DO in various locations of both compartments could be periodically measured. The DO probe was calibrated at the start of each day of testing. In between measurements, the probe was rinsed thoroughly with distilled water 


\subsubsection{1. $\quad \mathrm{pH}$ and Oxidation-Reduction Potential}

The $\mathrm{pH}$ and oxidation reduction potential (ORP) $\mathrm{mV}$ of the reactor effluents was measured using a Orion Model 420A bench-top $\mathrm{pH}$ meter with an Orion ORP Triode ${ }^{\mathrm{TM}}$ (Orion Corporation, Espoo, Finland). Samples were placed in $50 \mathrm{~mL}$ beakers. Between readings the electrode was rinsed thoroughly with distilled water. 


\section{Results and Discussion}

The following chapter will present the major results from the experiments, and discuss the significance of the results in an assessment of the ability of the various treatments tested to improve anaerobic sludge digestion, and improve septic tank performance. First, the results from the batch reactor phase of experiments will be presented and discussed, followed by the results and discussion for the continuous flow reactor tests.

\subsection{Batch Reactor Experiments}

During the initial stages of the batch reactor operation, a typical solubilisation period occurred, during which time bacterial populations acclimatised and the system approached anaerobic conditions. Primary sludge is readily degradable, and as a result dramatic changes were observed in the early stages of reactor operation, particularly in the reactors treated with the enzyme and bacterial additive. The following sections present and discuss the trends in the solids concentrations, the chemical oxygen demand (COD), proteins, carbohydrates and ammonia.

\subsubsection{Total and Volatile Solids}

Total solids (TS) and volatile solids (VS) are vital parameters for assessing the degree of solubilisation. As the organic components are degraded, so will the TS and VS. The following sections will present the TS and VS profiles of the of the microaeration, grinding and enzyme and bacterial additive batch reactors tests, and discuss the value of these trends. 


\subsubsection{Enzyme and Bacterial Additives}

Within the first four days of reactor operation, the TS of all of the raw sludge batch reactors decreased by 20 to $33 \%$, similarly the VS component was degraded by around $30 \%$ for all reactors, with the exception of one of the low-dose enzyme and bacterial additive reactors (Figure 4-1). The initial solubilisation trend was observed in all reactors, including the control reactors, which indicates that the enzyme and bacterial additives did not significantly contribute, or enhance the initial solubilisation period. In fact, by the end of the batch reactor experiments, the reactors treated with the additive had up to 23 and $26 \%$ more TS and VS respectively. The increased mass is most likely the result of the wheat carrier in the Septaid Powder ${ }^{\mathrm{TM}}$. The additive had a TS and VS concentration of 91 and 57\% respectively, which means that the TS and VS concentrations of the reactors treated with the $0.1,0.5,1.0$ and $5.0 \mathrm{~g}$ doses of the additive had an additional $0.09,0.46,0.91$ and $4.55 \mathrm{~g} / \mathrm{L}$ and $0.06,0.29,0.57$ and $2.85 \mathrm{~g} / \mathrm{L}$ respectively. In the study by Gömeç, 2006, who tested the effects of scum addition and $\mathrm{pH}$ control on the degradation of primary sludge in completely stirred batch reactors operating under mesophillic conditions $\left(\mathrm{T}=35^{\circ} \mathrm{C}\right)$, a similar four-day initial solubilisation period was observed. However, the destruction of TS and VS continued after this point and to a lesser extent, for the duration of the experiments. In our experiments however, the initial solubilisation period was followed by very little decreases in the TS and VS concentrations to the end of the batch reactor experiments. This suggests that the initial decrease in TS and VS was the result of the solubilisation of the readily degradable constituents in the fresh raw sludge, and that a significant portion of the non-readily degradable constituents remained undegraded. 


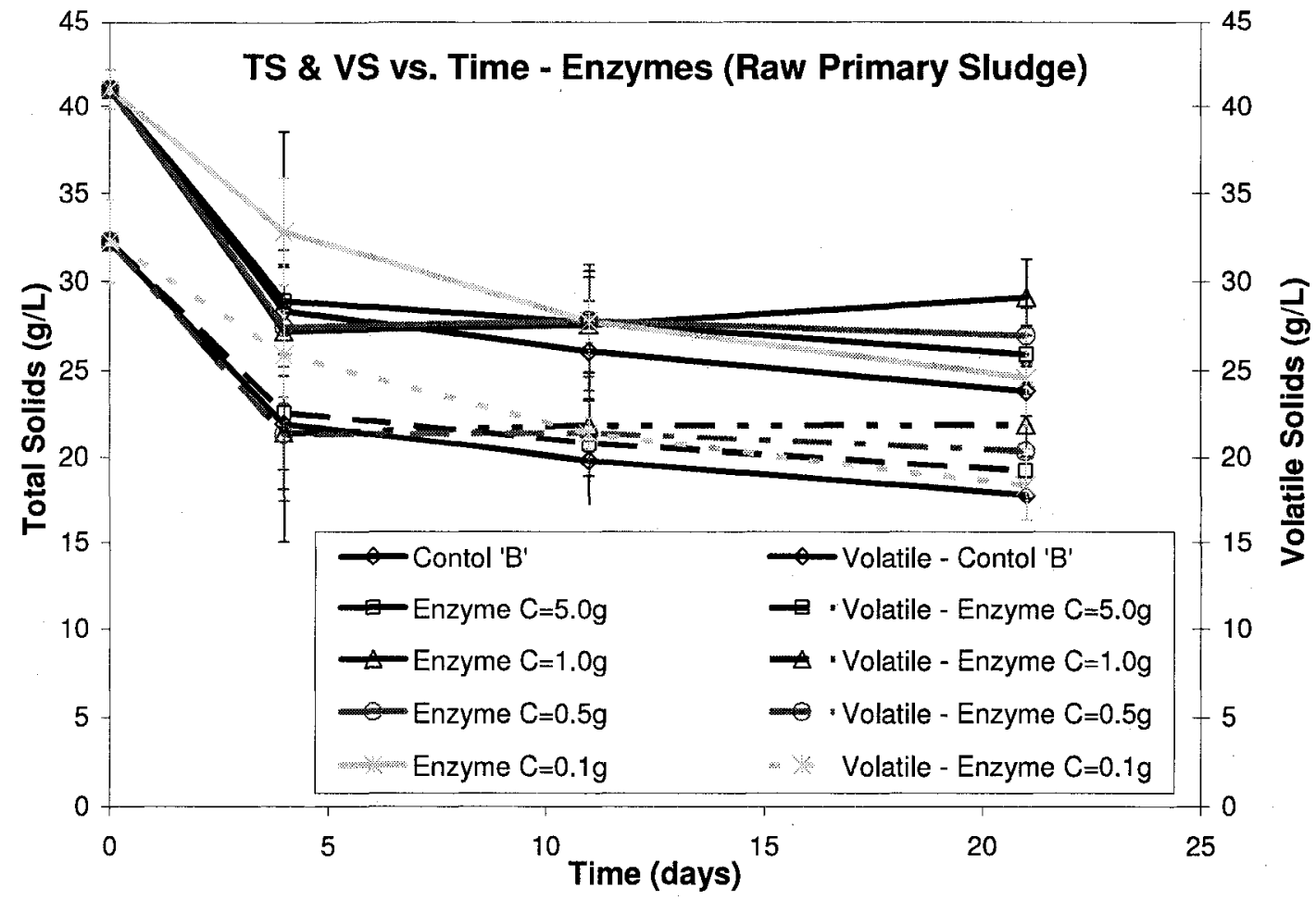

Figure 4-1: Profiles of the total and volatile solids concentrations during the batch reactor tests with raw sludge treated with an enzyme and bacterial additive

The batch reactors using diluted sludge samples had a similar initial solubilisation period, during the first week, as the same tests with the raw sludge samples. The TS and VS of all reactors decreased by 15 to $20 \%$ (Figure 4-2). During the second week however, the solubilisation period did not cease as drastically as with the raw sludge samples. This suggests that perhaps the diluted sludge provided more bioavailability of the readily degradable constituents in the sludge that may have been confined and protected in the raw sludge samples, due to the much higher solids concentration, and denser particle suspensions. 
The last set of test results on day 20 showed an apparent increase in the TS and VS concentrations, however this is most likely the result of experimental error. The increase is attributable to experimental error since the increase in the TS concentrations were greater than the increase in VS, which would suggest that there was an increase in the inorganic particulate mass (fixed solids). This however, should not have occurred to such an extent in a batch system. This error may have occurred when the extracted sample from these reactors had a chance to dry in the air before the TS and VS samples were withdrawn. It is also possible that there was some evaporation and loss of water from the reactors during the last ten days of operation, since the batch reactors were opened numerous times per day throughout this period for the other tests.

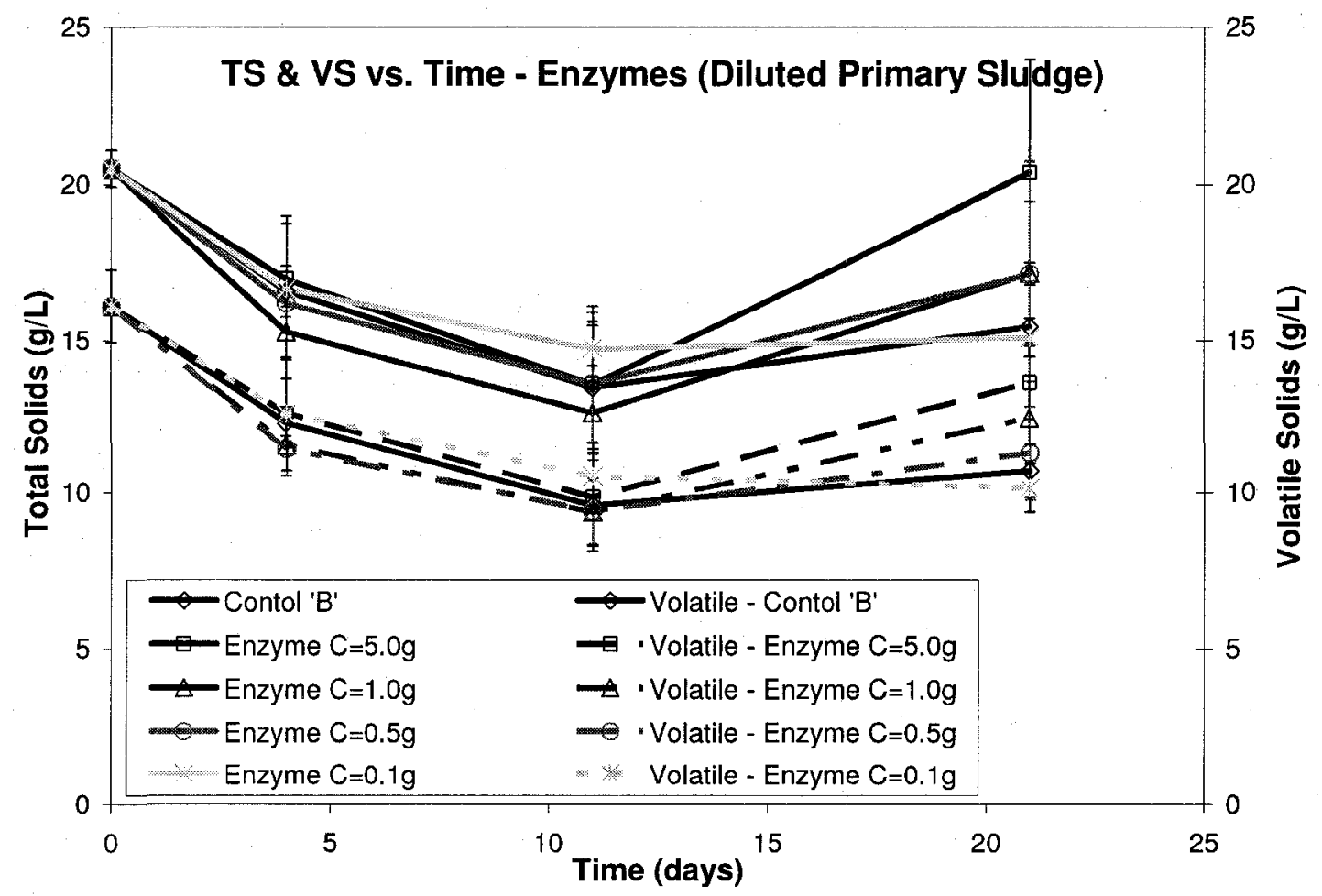

Figure 4-2: Profiles of the total and volatile solids concentrations during the batch reactor tests with diluted sludge treated with an enzyme and bacterial additive 


\subsubsection{Microaeration}

Microaeration treatments on the raw sludge samples did not show any significant impact on the degradation of TS and VS relative to the control reactors. The profiles show almost identical trends throughout the batch reactor testing period (Figure 4-3). Data points suggest that the initial solubilisation period occurred within the first 8 days of whereas an earlier testing day conducted on the enzyme and bacterial additive reactors (Figure 4-1 and Figure 4-1) demonstrated that this solubilisation period actually occurred within the first four days of reactor operation. This means there may have been some unseen variations during the initial solubilisation period.

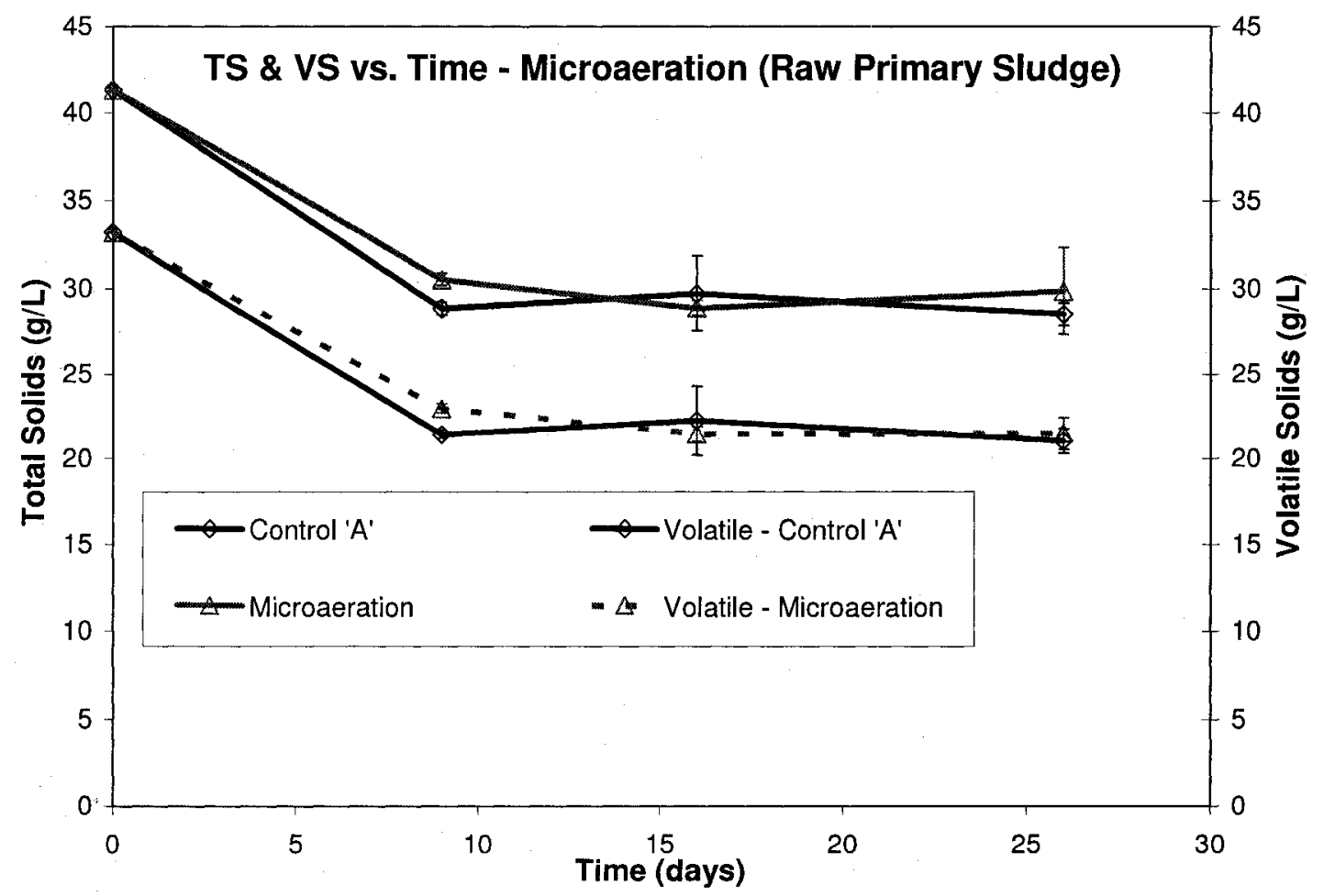

Figure 4-3: Profiles of the total and volatile solids concentrations during the batch reactor tests with raw primary sludge treated with microaeration 
The microaeration treatments on the diluted sludge samples seemed to have altered the solubilisation of organic solids compared to all other raw sludge sample tests, and the control reactors. The control reactors had an initial decrease in TS and VS within the first week and plateaued at approximately 16 and $12 \mathrm{~g} / \mathrm{L}$ respectively, whereas the microaeration treatments on the diluted sludge samples resulted in more gradual and consistent decreases in TS and VS concentrations (Figure 4-4). Comparing the profiles of the soluble COD, which are discussed in more detail in section 4.1.3.2, the trends of the decrease in COD of the raw and diluted sludge samples are almost identical.

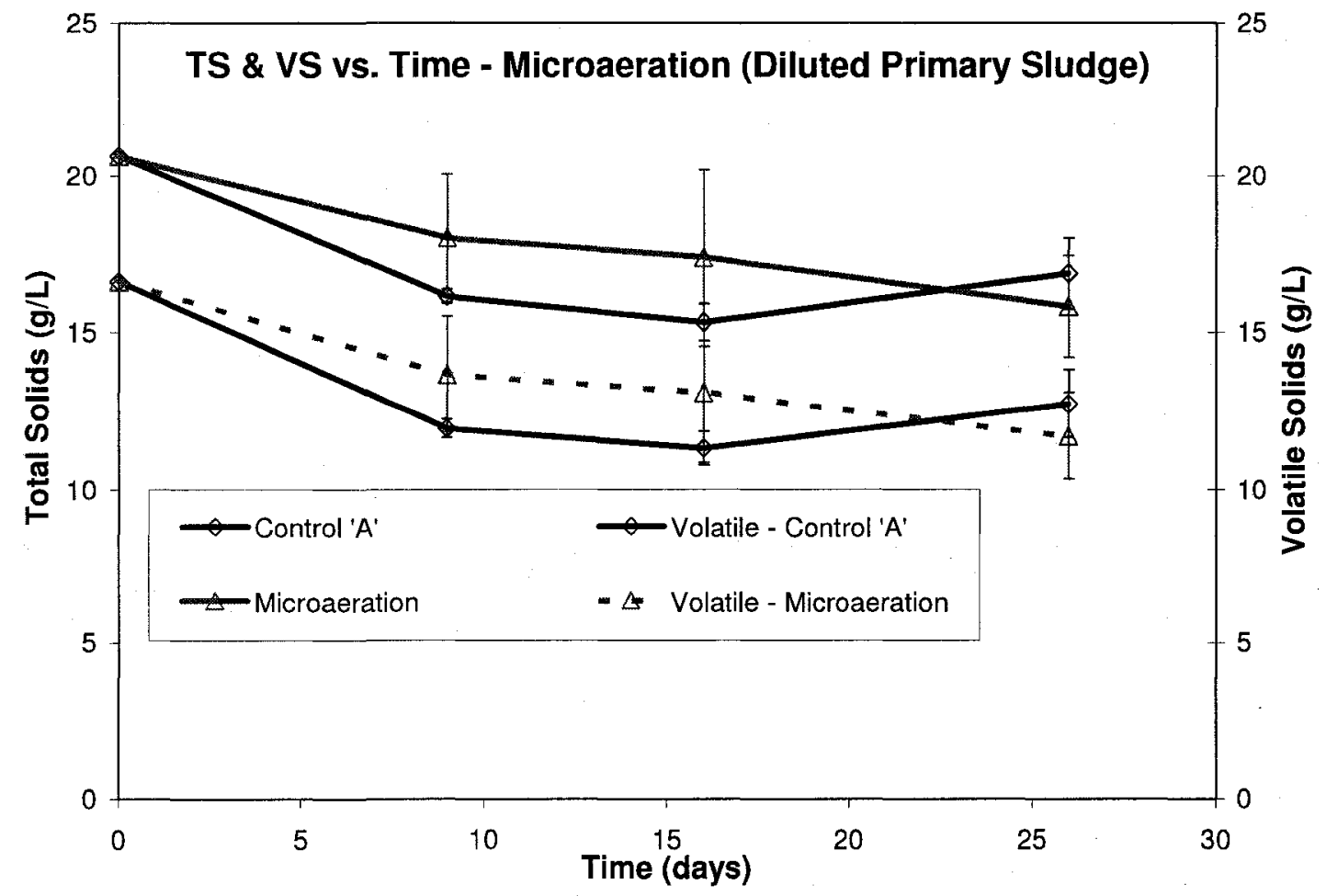

Figure 4-4: Profiles of the total and volatile solids concentrations during the batch reactor tests with diluted primary sludge treated with microaeration 


\subsubsection{Grinding}

In the batch reactor tests with raw sludge, the grinding cycles had no apparent effect on the initial decrease in the TS and VS concentrations relative to the control reactors (Figure 4-5). Although some slight increases are observable in the initial decrease in VS, this was not complemented with a decrease in the TS which suggest sampling error due to the heterogeneity of the sludge. Through to the final week of reactor operation, the grinding cycles showed a moderately improved VS removal relative to the control reactors (5 to 26\%). This suggests that grinding, by decreasing the average particle size and enhancing the bioavailability of the organic constituents in sludge, improved degradation, but for the reasons mentioned above, the results are not clear.

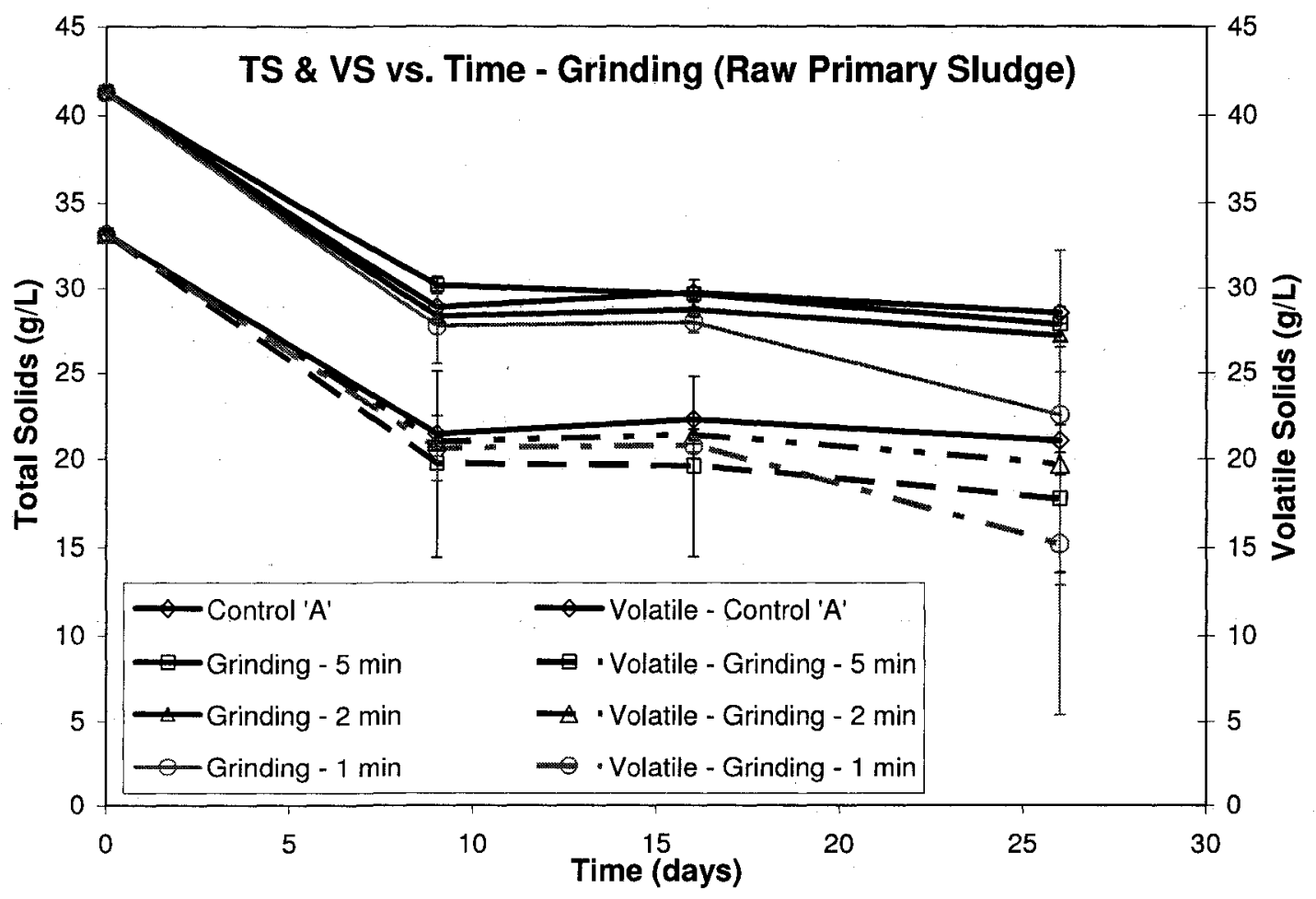

Figure 4-5: Profiles of the total and volatile solids concentrations during the batch reactor tests with raw primary sludge treated with an initial grinding cycle 
Similar to the batch reactor tests with raw sludge, the initial grinding cycles did not have any significant effect on the initial solubilisation period on the diluted sludge samples (Figure 4-6). In fact, for the duration of the experiments, the profiles of the TS and VS concentrations are very similar to the control reactors, up until the last week of testing, during which time the TS and VS concentrations of the control reactors show an apparent increase of around $10 \%$. The $10 \%$ increase is actually the average of the two control reactors which showed a 5 and 15\% increase in TS, and a 6 and 17\% increase in VS during the last week of reactor operation. Due to the large variation in these two reactors, no trend should be drawn from their results. Furthermore, the variations in the grinding cycle intensity did not show any correlations to one another. One can observe however, that there was a consistent amount of readily degradable organic solids in all reactors. The profile lines for the TS and corresponding VS are parallel, which is expected since only the volatile (organic) fraction are expected to degrade in a biological system. Initially, $80 \%$ of the total solids were volatile, and thus considered organic. After the first week of reactor operation, the volatile component of all reactors decreased to around $74 \%$ of the TS. This indicates that all reactors, with both raw and diluted sludge, contained a proportionally equal amount of readily degradable organic solids, which were consumed during the first week of reactor operation. A complete set of figures to illustrate the profiles of the VS/TS ratio throughout the batch reactor experiments are attached as Appendix D: Volatile/Total Solids Analysis - Batch Reactor Tests. 


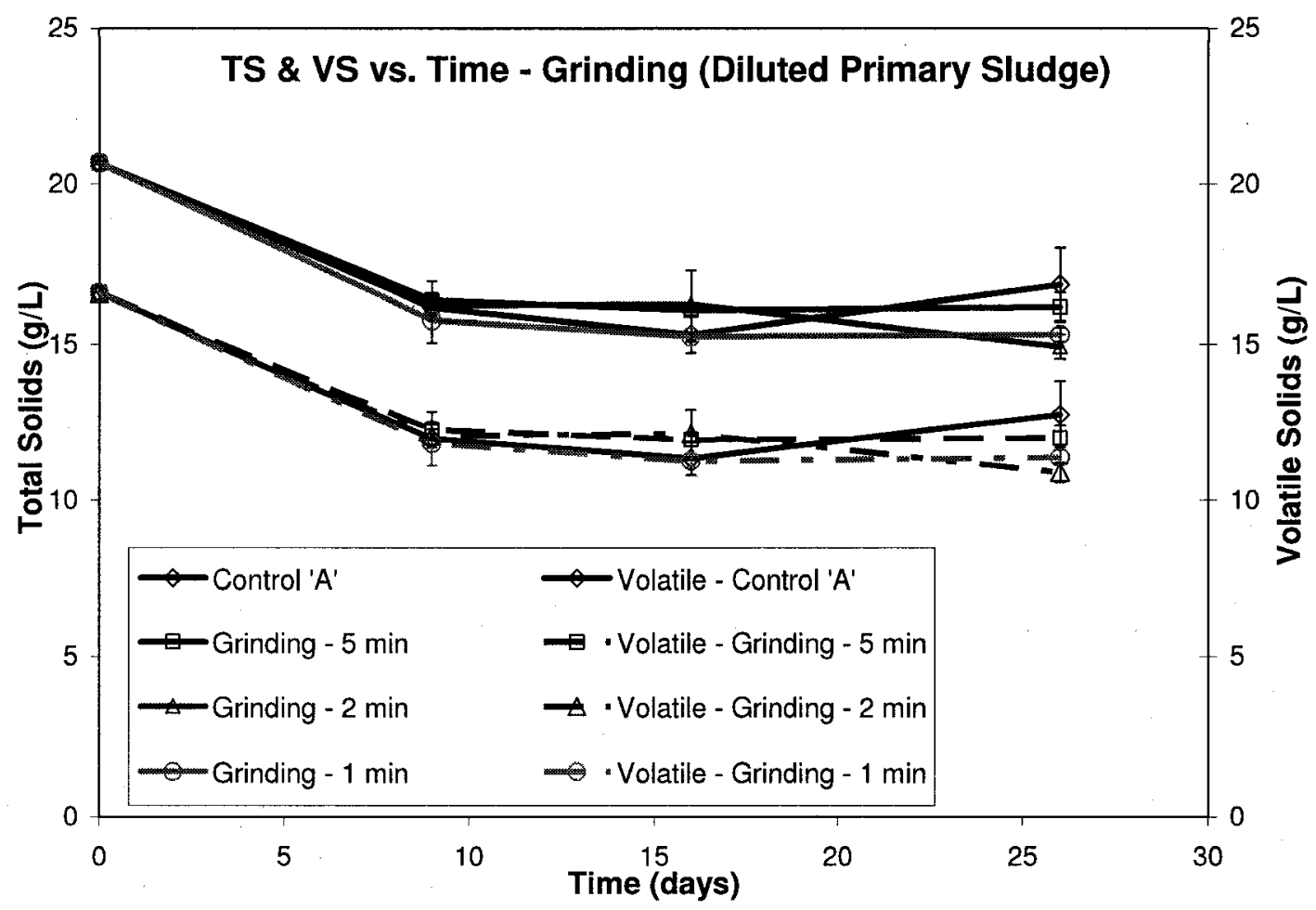

Figure 4-6: Profiles of the total and volatile solids concentrations during the batch reactor tests with diluted primary sludge treated with an initial grinding cycle

\subsubsection{Total Suspended and Volatile Suspended Solids}

The following sections will discuss some of the results obtained from the suspended solids tests performed on the primary sludge samples during the batch reactor experiments. All solids tests require significant sample volumes however, during the batch reactor experiments, sample conservation was the utmost of importance to maintain adequate reactor volumes for the duration of the batch reactor experiments. Therefore, small sample volumes were used for the TSS and VSS tests. Due to the difficulties involved in taking representative subsamples from a heterogeneous suspension of water and solids the TSS and VSS profiles show some unexplainable and likely unrepresentative trends. 


\subsubsection{Enzyme and Bacterial Additives}

Similar to the TS and VS concentrations, the TSS and VSS concentrations decreased drastically within the first four days of reactor operation (Figure 4-7). The TSS and VSS concentrations of some of the reactors treated with the enzyme and bacterial additive decreased slightly more, and some decreased slightly less than the control reactors during the initial four-day solubilisation period. The differences are however very small, and do not show a significant correlation between the additive dose and the observed decrease in TSS and VSS.

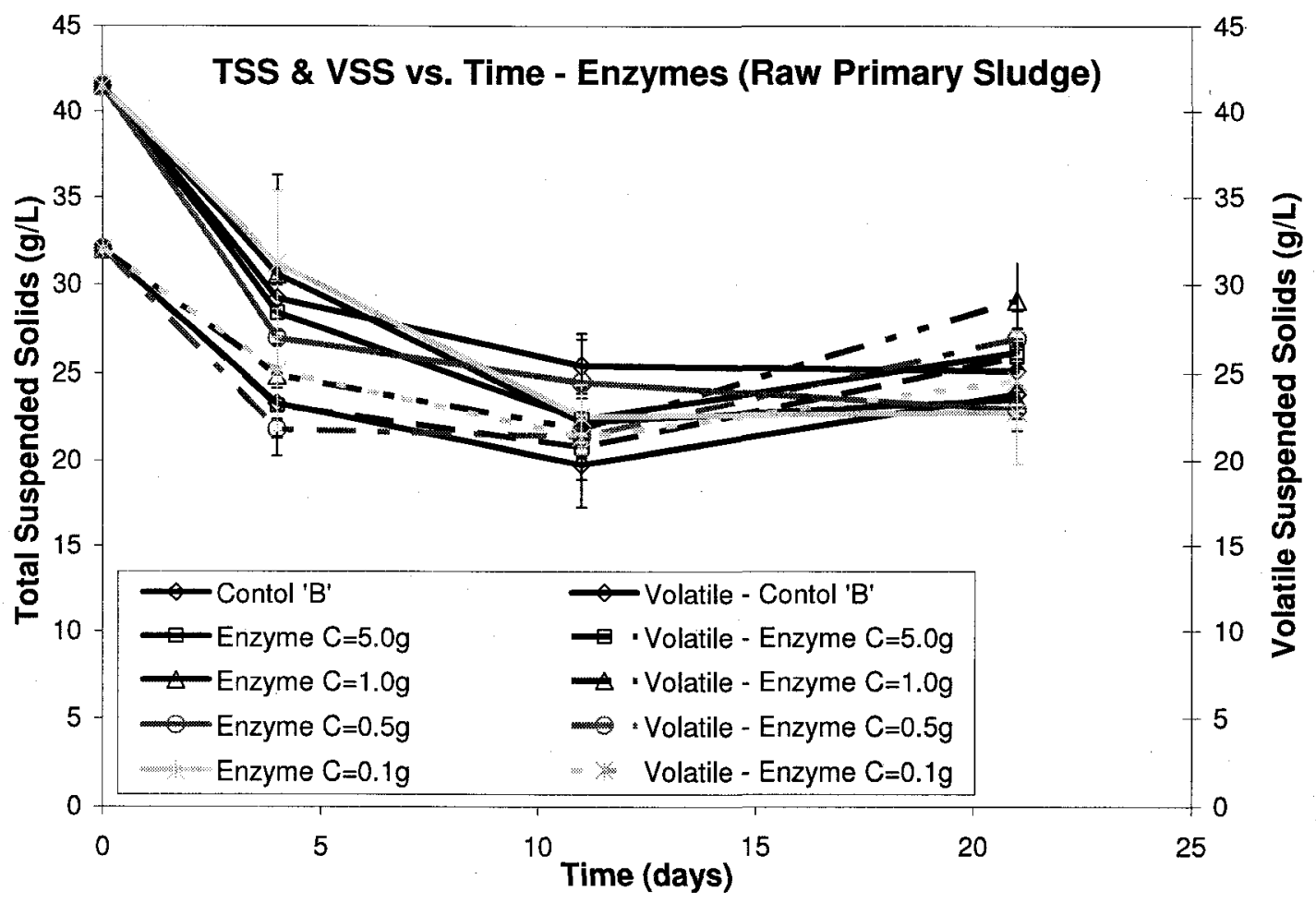

Figure 4-7: Profiles of the total suspended and volatile suspended solids concentrations during the batch reactor tests with raw sludge treated with an enzyme and bacterial additive 
The TSS and VSS profiles of the diluted sludge reactors treated with the enzyme and bacterial additive are very similar to those of the raw sludge tests, in that, the additives did not seem to improve or affect the initial solubilisation (Figure 4-8). There were however some differences observed as a result of the dilution process. In the figure for the raw sludge samples, roughly $70 \%$ of the total solids destruction occurred within the first four days of reactor operation (Figure 4-7), whereas the solubilisation period of the diluted sludge samples was more gradual throughout the first two weeks (Figure 4-8).

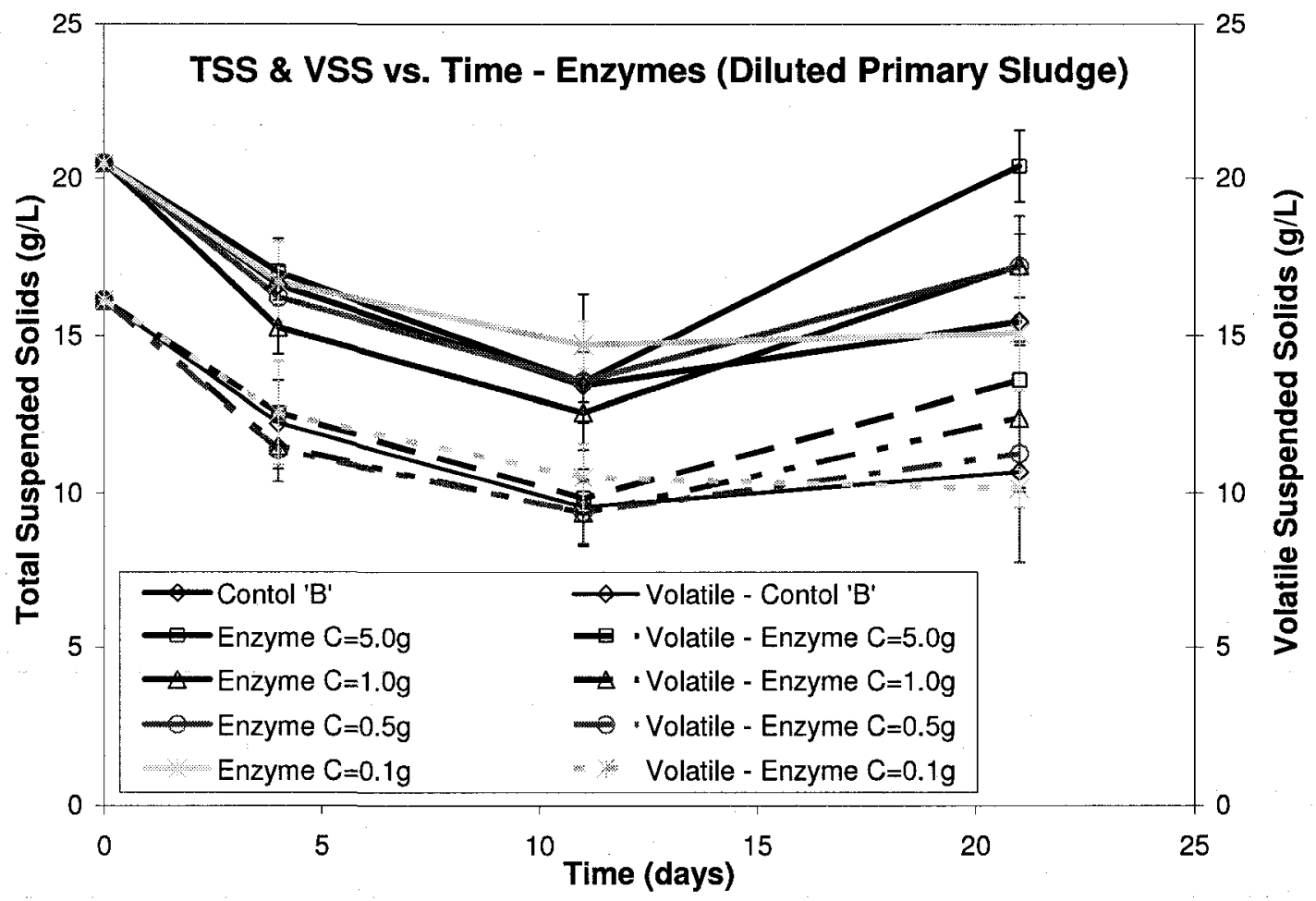

Figure 4-8: Profiles of the total suspended and volatile suspended solids concentrations during the batch reactor tests with diluted sludge treated with an enzyme and bacterial additive 


\subsubsection{Microaeration}

Microaeration did not affect the initial solubilisation, or reduction in TSS and VSS concentrations. In fact, the profiles for the microaerobic reactors are almost identical to the profiles of the control reactors except for the last testing day (Figure 4-9). The measured TSS and VSS concentrations of the microaerobic reactors show an apparent increase of $35 \%$ by the last day of testing, however this high value is the result of one of the microaerobic reactors which had an increase of $60 \%$, while the other microaerobic reactor had an increase of only $10 \%$. The latter in combination with the circumstances surrounding the suspended solids analysis allow us to omit the observed increase in TSS and VSS.

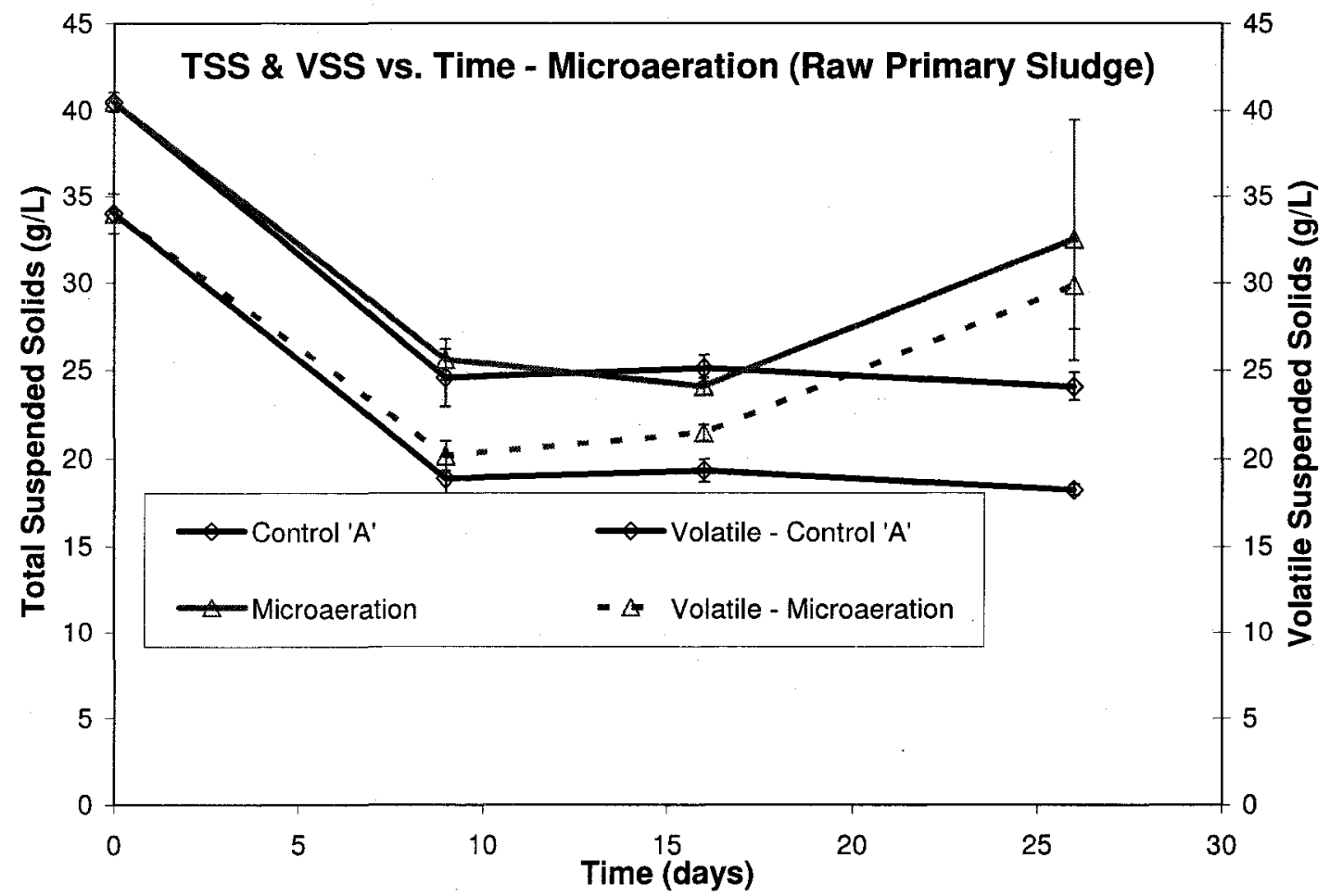

Figure 4-9: Profiles of the total suspended and volatile suspended solids concentrations during the batch reactor tests with raw primary sludge treated with microaeration 
Microaeration treatments on the diluted sludge samples seemed to have prolonged the initial rapid solubilisation period observed in the control reactors, into a much more gradual solubilisation period, extending throughout the batch reactor testing period (Figure 4-10). These same results were observed in the TS and VS analysis of the diluted sludge samples which confirm the reliability of the results. Furthermore, a plot of the VS to TS ratio (attached as Appendix D: Volatile/Total Solids Analysis - Batch Reactor Tests) demonstrates that the microaeration treatments caused the VS/TS ratio to stay slightly higher than the other reactors on day 8 and day 16 of testing, which further suggests that there was some delay in the initial solubilisation period. It is possible also, that the VS concentrations in the microaerobic reactors were slightly higher in the early stages of reactor operation as a result of an increase in biomass content due to cellular activities which may be stimulated by the microaerobic conditions. By the end of the batch reactor experiments however, a similar degree of solubilisation was achieved in both the microaerobic and the control reactors, which indicates that the microaeration treatments did not cause an increase in biomass, which has been linked with typical aerobic treatments. It may also be that the small amount of excess biomass produced as a result of the microaerobic treatments were offset by improved enzymatic hydrolysis, through microaeration, as observed in the experiments by Johansen and Bakke, (2006). 


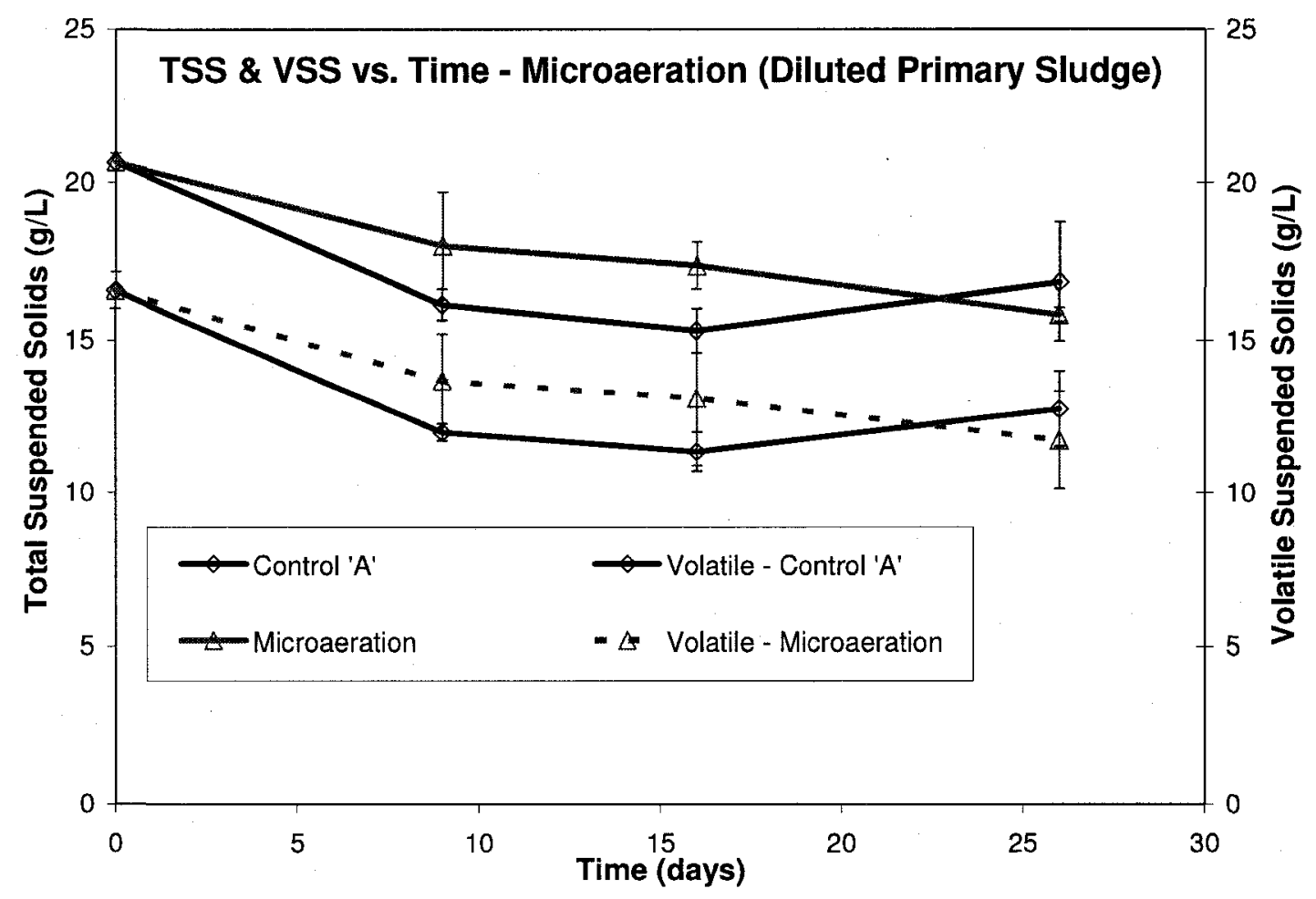

Figure 4-10: Profiles of the total suspended and volatile suspended solids concentrations during the batch reactor tests with diluted primary sludge treated with microaeration

\subsubsection{Grinding}

The various grinding cycles did not show any significant differences in the TSS and VSS concentration profiles throughout the batch reactor experiments, relative to the control reactors (Figure 4-11). These same trends were observed in the TS and VS profiles described in section 4.1.1.3. 


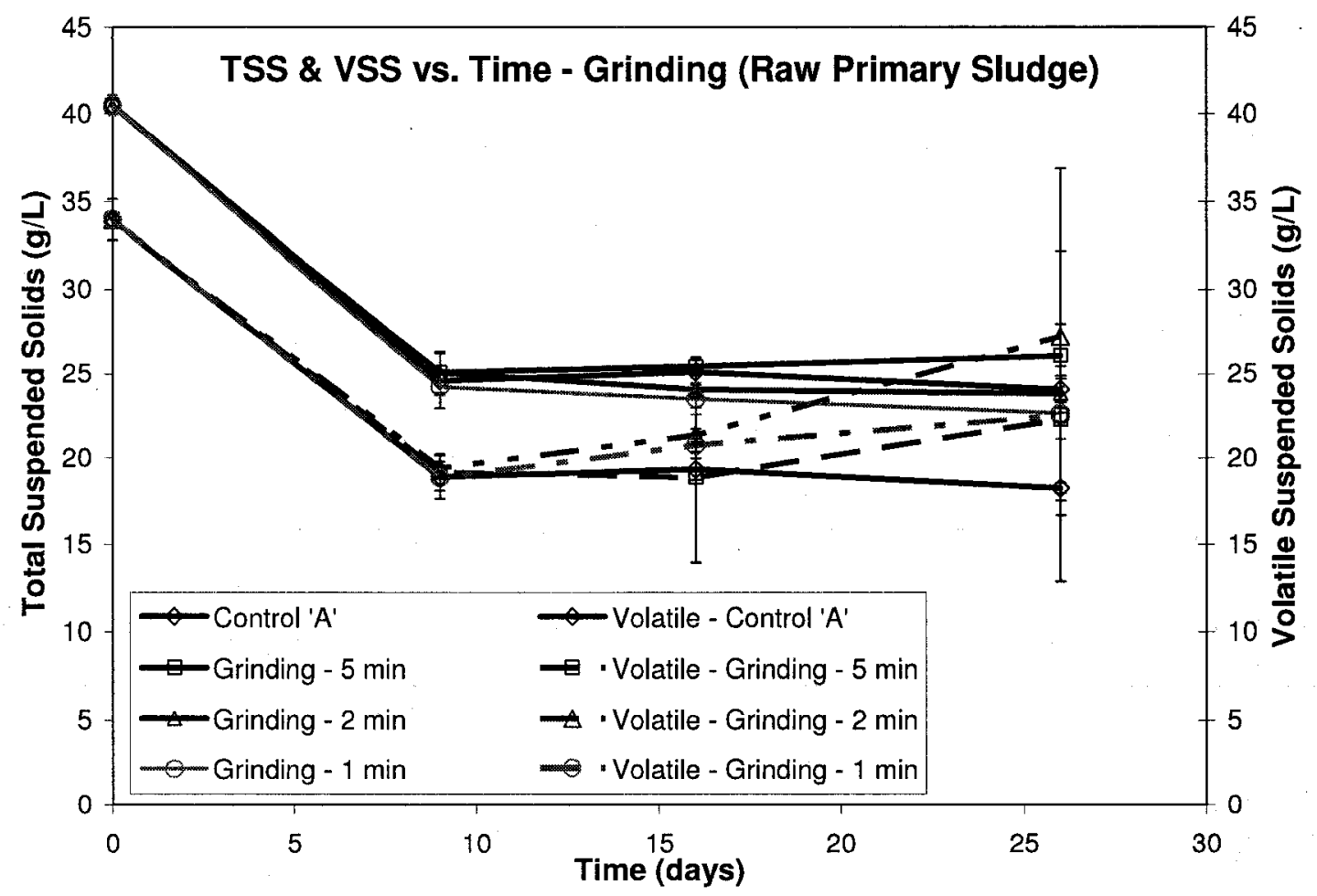

Figure 4-11: Profiles of the total suspended and volatile suspended solids concentrations during the batch reactor tests with raw primary sludge treated with an initial grinding cycle

Similar to the tests with the raw sludge samples, the various grinding cycles did not significantly affect the TSS and VSS profiles throughout the batch reactor experiments, relative to the control reactors (Figure 4-12). After the first week of testing, the TSS and VSS concentrations of some of the reactors increased slightly, but these increases were very moderate, and are inversely related to the trends presented in the TS and VS discussion (section 4.1.1.3), which suggest that the trends may be insignificant due to flaws in the testing procedures. 


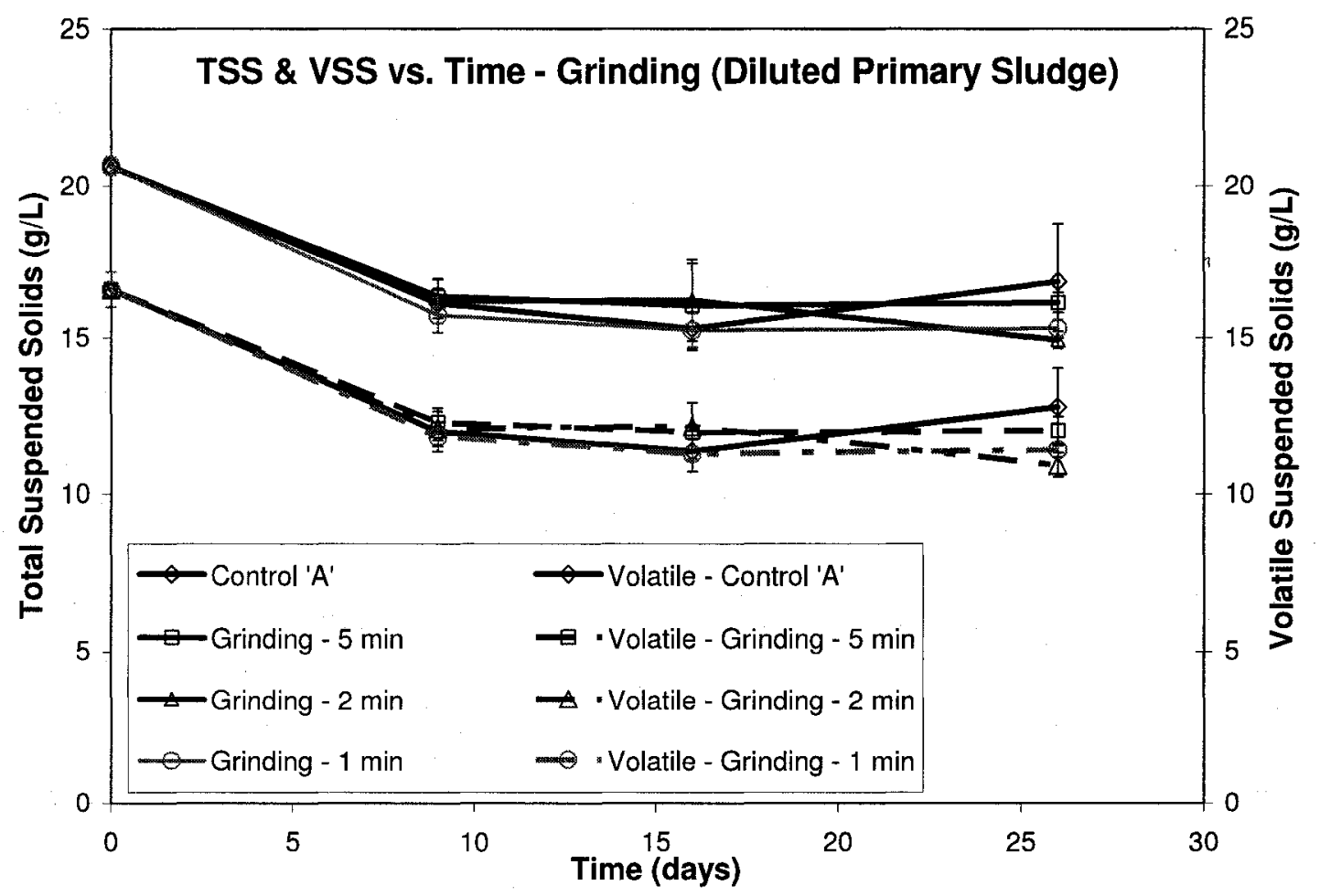

Figure 4-12: Profiles of the total suspended and volatile suspended solids concentrations during the batch reactor tests with diluted primary sludge treated with an initial grinding cycle

\subsubsection{Total and Soluble COD}

The total COD (tCOD) and soluble COD (sCOD) are some of the most common ways of expressing the strength of wastewater and sludge, and the health and stage of digestion. The following sections will present and discuss the tCOD and SCOD trends throughout the batch rector experiments for the enzyme and bacterial additive tests, the microaeration tests and the grinding cycle tests. 


\subsubsection{Enzyme and Bacterial Additives}

In the first week of reactor operation, the young and readily degradable primary sludge showed significant changes in all of the reactors (Figure 4-13). During this time, a significant solubilisation period occurred, where the SCOD of all reactors increased significantly, and as described in the previous sections, the solids concentrations decreased significantly. At the same time, unexplainable changes in the measured tCOD concentrations occurred in the reactors treated with the enzyme and bacterial additive. In the first two days, there was a significant decrease in the measured tCOD accompanied by a large amount of gas production, and by day 9 , the measured tCOD in the reactors treated with the enzyme and bacterial additives was up to $20 \%$ higher than the initial tCOD value, prior to the addition of the enzyme and bacterial additive. Tests on the Septaid Powder ${ }^{\mathrm{TM}}$ dissolved in distilled waster demonstrated the tCOD of the dry powder to be around $1000 \mathrm{mg}$ tCOD/g Septaid Powder ${ }^{\mathrm{TM}}$, which only accounts for an increase of about $5000 \mathrm{mg} / \mathrm{L}$ or $9 \%$ of the initial tCOD for the reactors treated with the highest dose of the enzyme and bacterial additive (5.0 g Septaid Powder $\left.{ }^{\mathrm{TM}}\right)$, and $1000 \mathrm{mg} / \mathrm{L}$ or $2 \%$ of the tCOD for the reactors treated with the second highest dose of the additive $(2.0 \mathrm{~g}$ Septaid Powder ${ }^{\mathrm{TM}}$ ). It is very possible that the tCOD associated with the wheat bran carrier used in the additive was not properly quantified since the wheat flakes were dispersed in the test solution. Nonetheless, the net reduction in TCOD of the reactors treated with the additives was around $8 \%$, same as the control reactors, however the reactors treated with the enzyme and bacterial additive had higher reaction rates, both initially and after the initial solubilisation period, and the reduction in COD observed after day 8 was far greater than the reduction in the control reactors. By day 8 , the 
solubilisation of COD of all of the reactors levelled off around $18,000 \mathrm{mg} / \mathrm{L}$, where it was fairly constant for the rest of the experiments (Figure 4-13). The reactors treated with the highest additive dose $(5.0 \mathrm{~g})$ had a slightly higher SCOD plateau value of around 19,000 $\mathrm{mg} / \mathrm{L}$, however the differences relative to the control reactors are minimal, and likely insignificant. This indicates that the enzyme additions did neither significantly improve nor affect the generation and digestion of soluble COD relative to the control reactors. This also relates to trends in the solubilisation period that were discussed in the solids analysis sections (4.1.1.1 and 4.1.2.1). However, the gradual solubilisation of the wheat bran flakes, which would lead to an increase in the SCOD, was not observed which may suggest that the subsequent acetogenesis and methanogenesis phases were accelerated.

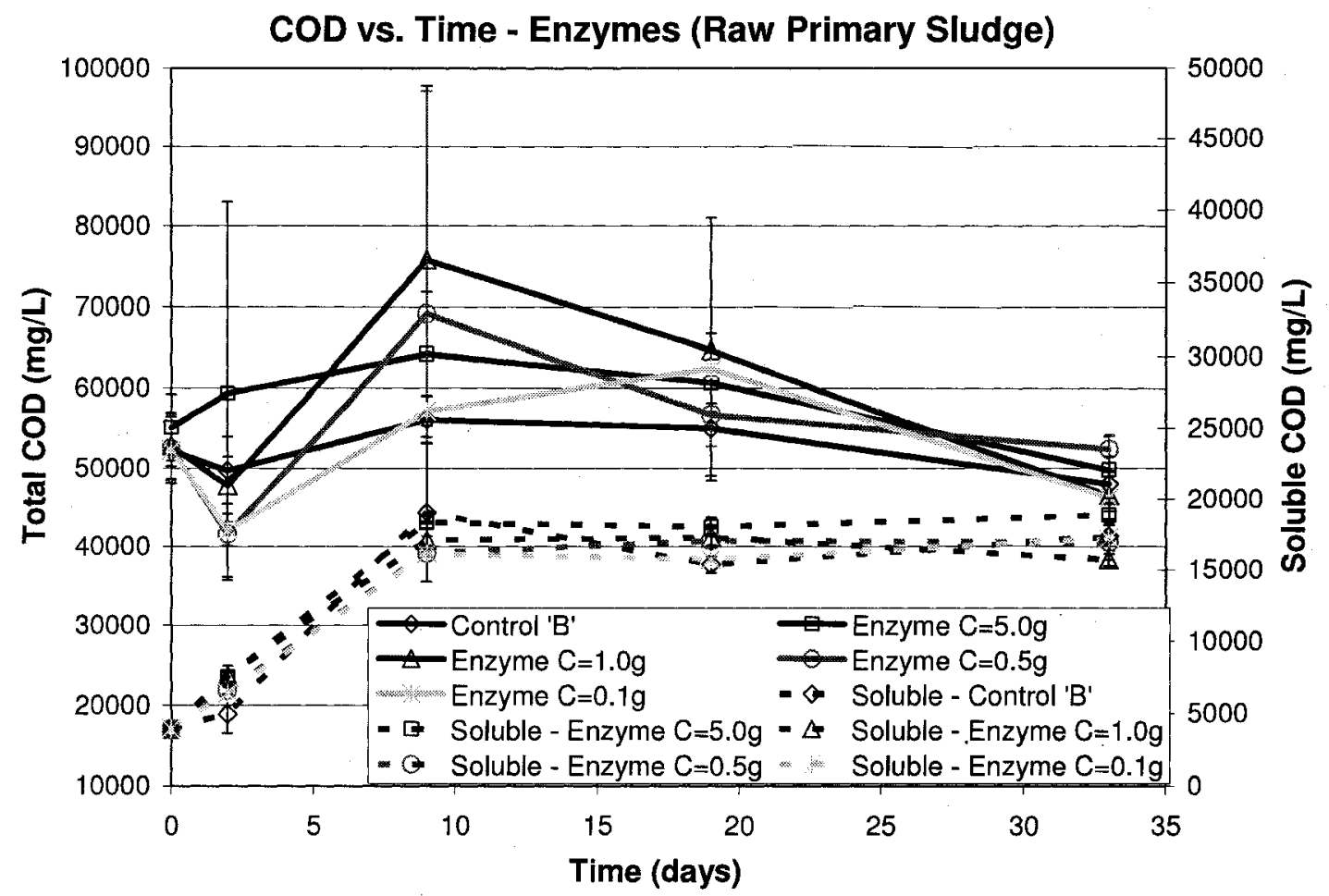

Figure 4-13: Profiles of the total and soluble COD during the batch reactor tests with raw sludge treated with an enzyme and bacterial additive 
The profiles of the tCOD concentrations in the batch reactors with diluted sludge show a similar increase in tCOD in the early stages of reactor operation as with the reactors with raw sludge (Figure 4-14). On the other hand, the initial sharp decrease in tCOD after two days, was not observed. The latter offers a number of potential explanations, the most probable being related to the wheat bran flakes. In any case, the SCOD profiles show similar trends as the raw sludge tests. Furthermore, the highest additive dose $(5.0 \mathrm{~g})$ showed a consistently higher SCOD concentrations than the control reactors throughout the batch reactor experiments. This may be the result of readily soluble constituents in the enzyme and bacterial additive. Perhaps what is more significant is the fact that the enzyme and bacterial additives did not help the destruction of the sCOD. In an anaerobic system, the solubilisation period is often the rate limiting step, however the results from the batch reactor experiments demonstrate that there was an effective solubilisation of organics in the early stages, however the sequential digestion process was hindered somewhere following the initial hydrolysis phase. The same trend was observed in the experiments by Gömeç, 2006, who tested the effects of scum addition and $\mathrm{pH}$ control on the digestion of primary sludge in batch reactors. The results from the experiments demonstrated that the addition of scum, which contains large amounts of lipids (longchain fatty acids), hindered the methanogenic activity of the system, but allowed acidogenesis to continue. Further experimentation revealed that $\mathrm{pH}$ control was able to compensate for the adverse effects of 'scum addition. As a result, it was determined that the high concentration of acids produced by the scum degradation caused the $\mathrm{pH}$ to drop to below the healthy limit for the methanogenic bacteria. In our batch reactor experiments, a significant portion of the sludge floated to the surface, which is typical of 
scum, and may indicate the presence of fats, oils, greases and other tough-to-degrade lipids. On the other hand, the production of gases would increase the buoyancy of the particles and cause a suspension at the surface.

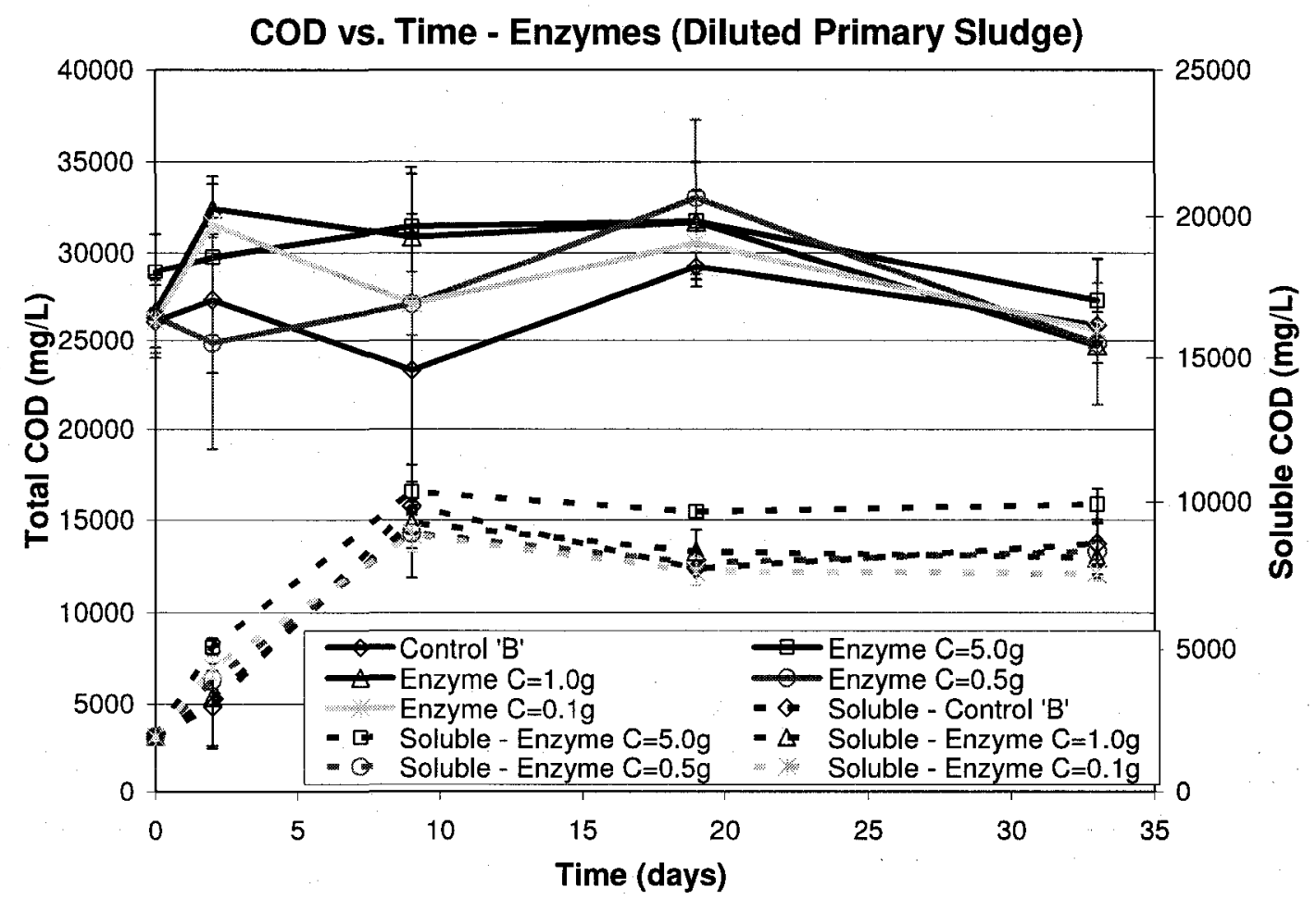

Figure 4-14: Profiles of the total and soluble COD during the batch reactor tests with diluted sludge treated with an enzyme and bacterial additive

\subsubsection{Microaeration}

Microaeration treatments resulted in a $40 \%$ reduction in tCOD by the end of the batch reactor experiments (Figure 4-15). This was the largest net reduction observed of all of the batch reactor tests using raw sludge. During the first week of reactor operation, the tCOD of the control reactors decreased by $12 \%$, whereas the tCOD of the microaerobic reactors decreased by only $3 \%$. This suggests that the initial anaerobic acclimatisation 
period of the microaerobic reactors was prolonged, whereas the anaerobic reactors acclimatised more rapidly, and began to degrade the tCOD faster. On the other hand, the sCOD generation rate was not affected in the early stages of reactor operation, with almost the same level of solubilisation after the first week of reactor operation. The sCOD of the microaerobic reactors reached a maximum sCOD of around $16,000 \mathrm{mg} / \mathrm{L}$ after two weeks, and then proceeded to decline to a low of around $9000 \mathrm{mg} / \mathrm{L}$ by the end of the experiments. This was the lowest final sCOD concentration achieved of all of the batch reactor tests with raw sludge, which suggest that microaeration did not affect the initial solubilisation period, as discussed in the solids analysis sections (4.1.1.2 and 4.1.2.2), and improved the degradation of the SCOD in the later stages of digestion.

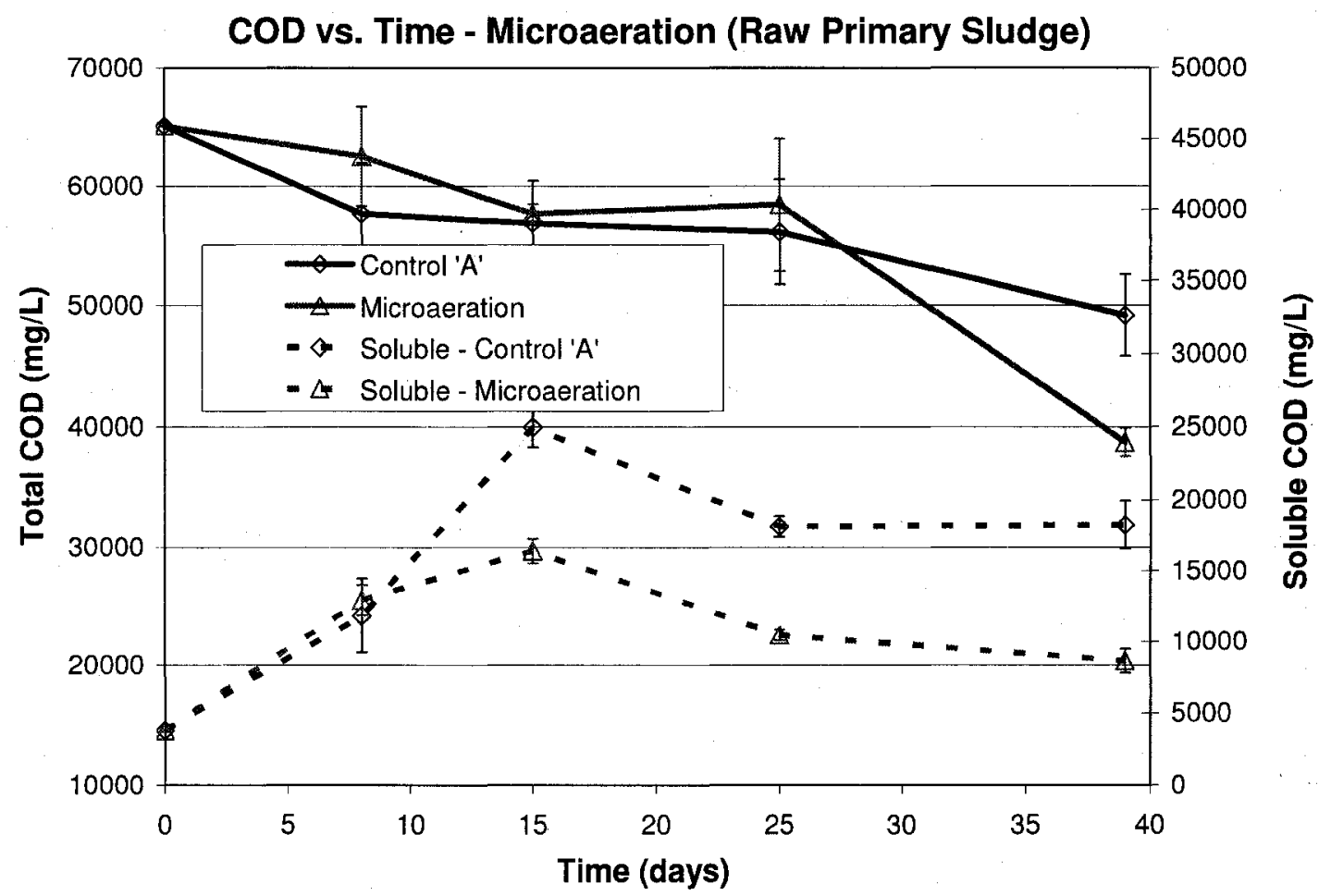

Figure 4-15: Profiles of the total and soluble COD during the batch reactor tests with raw primary sludge treated with microaeration 
The COD profiles of the microaerobic reactors with diluted sludge follow a very similar trend as the microaerobic reactors with the raw sludge samples (Figure 4-16). The microaeration treatments resulted in a tCOD reduction of around $40 \%$ by the end of the experiments. Similar to the microaeration tests with the raw sludge samples however, the anaerobic acclimatisation period of the microaerobic reactors with diluted sludge was prolonged. This trend was also observed in the experiments by Ortega et al., 2007, who used electrolysis to microaerate primary sludge samples in batch reactors. In these experiments, the anaerobic control reactor went completely anaerobic within the first day of operation, whereas the microaerobic reactors required roughly 7 days to reach completely anaerobic conditions. Although the degradation of tCOD was very small during the acclimatisation period, the soluble SCOD generation was apparently unaffected. During the initial two-week solubilisation period, the SCOD concentrations of the microaerobic reactors with diluted sludge, gradually increased to a measured peak around $7500 \mathrm{mg} / \mathrm{L}$ on day 15 . After this point, the sCOD concentrations of the microaerobic reactors began to decrease gradually until reaching a low of around 1000 $\mathrm{mg} / \mathrm{L}$ by the end of the batch reactor experiments. Similar to the raw sludge tests, the control reactors with diluted sludge were unable to degrade to SCOD to even close to the extent of the microaerobic reactors. Pirt and Lee, 1983, suggested that microaeration of algae samples in batch reactors enhanced the growth of facultative anaerobes, which could maintain a low redox potential and provide better growth conditions for the sensitive anaerobes, namely the methanogens. The latter could explain the dramatically improved sCOD destruction observed in the microaerobic batch reactor experiments. 


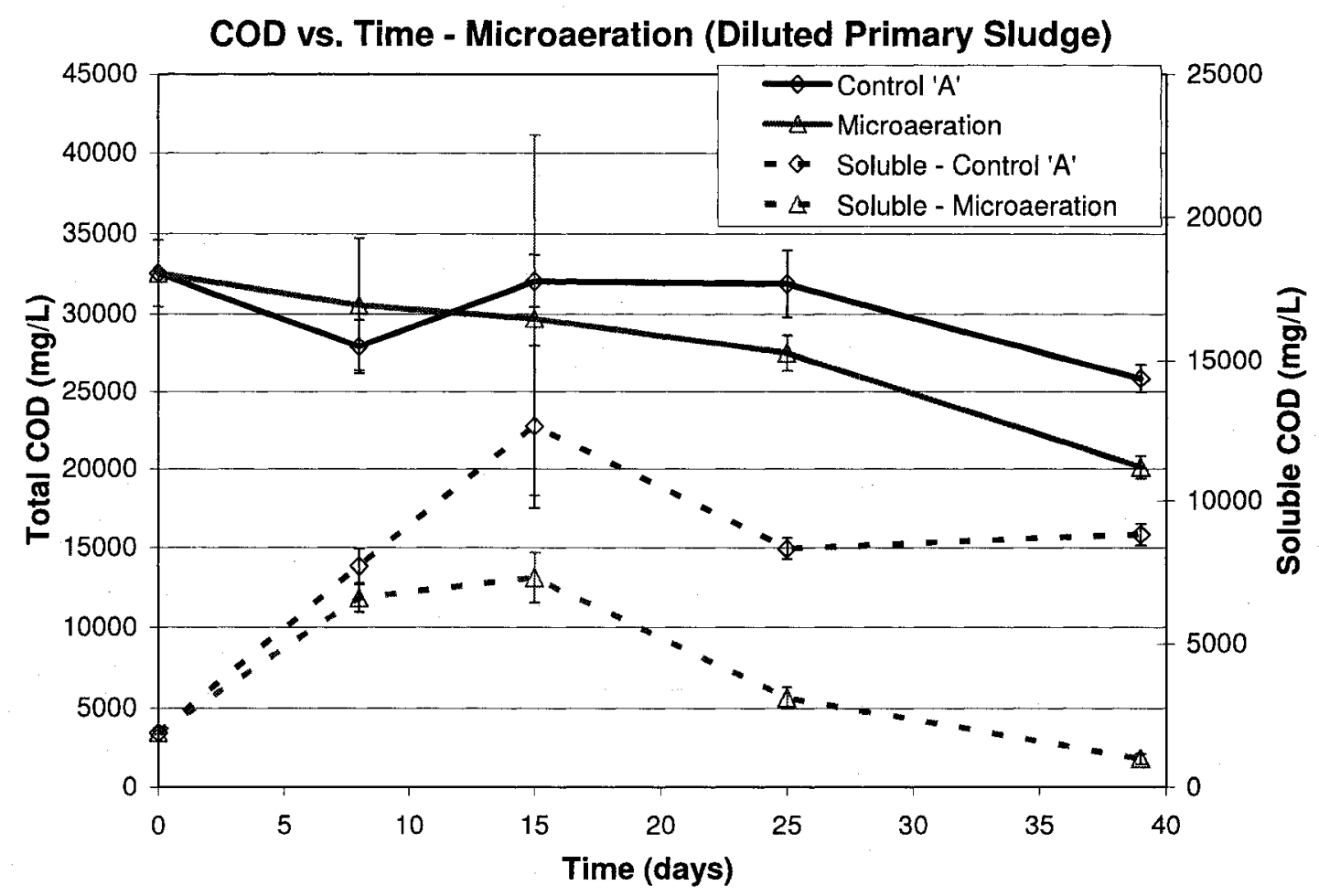

Figure 4-16: Profiles of the total and soluble COD during the batch reactor tests with diluted primary sludge treated with microaeration

\subsubsection{Grinding}

During the first week of reactor operation, the solids content of the raw sludge samples that were treated with the initial grinding cycles decreased significantly, as discussed in sections 4.1.1.3 and 4.1.2.3. This solubilisation period was complemented with an increase in the SCOD, during which time there was little or no reduction in the tCOD (Figure 4-17). In this first week, the sCOD of the raw sludge samples treated with the grinding cycles increased from around $4000 \mathrm{mg} / \mathrm{L}$ to a peak of around $18,000 \mathrm{mg} / \mathrm{L}$, with the exception of the reactors that were treated with the longest grinding cycle ( 5 minutes). These reactors achieved a maximum $\mathrm{sCOD}$ of around $21,000 \mathrm{mg} / \mathrm{L}$ sometime during the third week. This suggests that extended grinding cycles may lead to higher degrees of 
solubilisation, however the higher SCOD could also be due to a slightly larger solids content in the sludge samples used in the reactors that were treated with the five minute grinding cycles. The latter agrees with the total solids analysis presented in section 4.1.1.3, and would also explain the slightly higher tCOD values throughout the experiment. The control reactor was measured to have a peak SCOD concentration of $25,000 \mathrm{mg} / \mathrm{L}$ on day 15 , after which point the SCOD level decreased to around 18,000 $\mathrm{mg} / \mathrm{L}$, where it remained for the rest of the experiments. This high peak suggests that there was an accumulation of VFAs, while the temperamental methanogens acclimatised. The grinding cycles however, seem to have relieved this accumulation of VFAs that occurred in the control reactors.

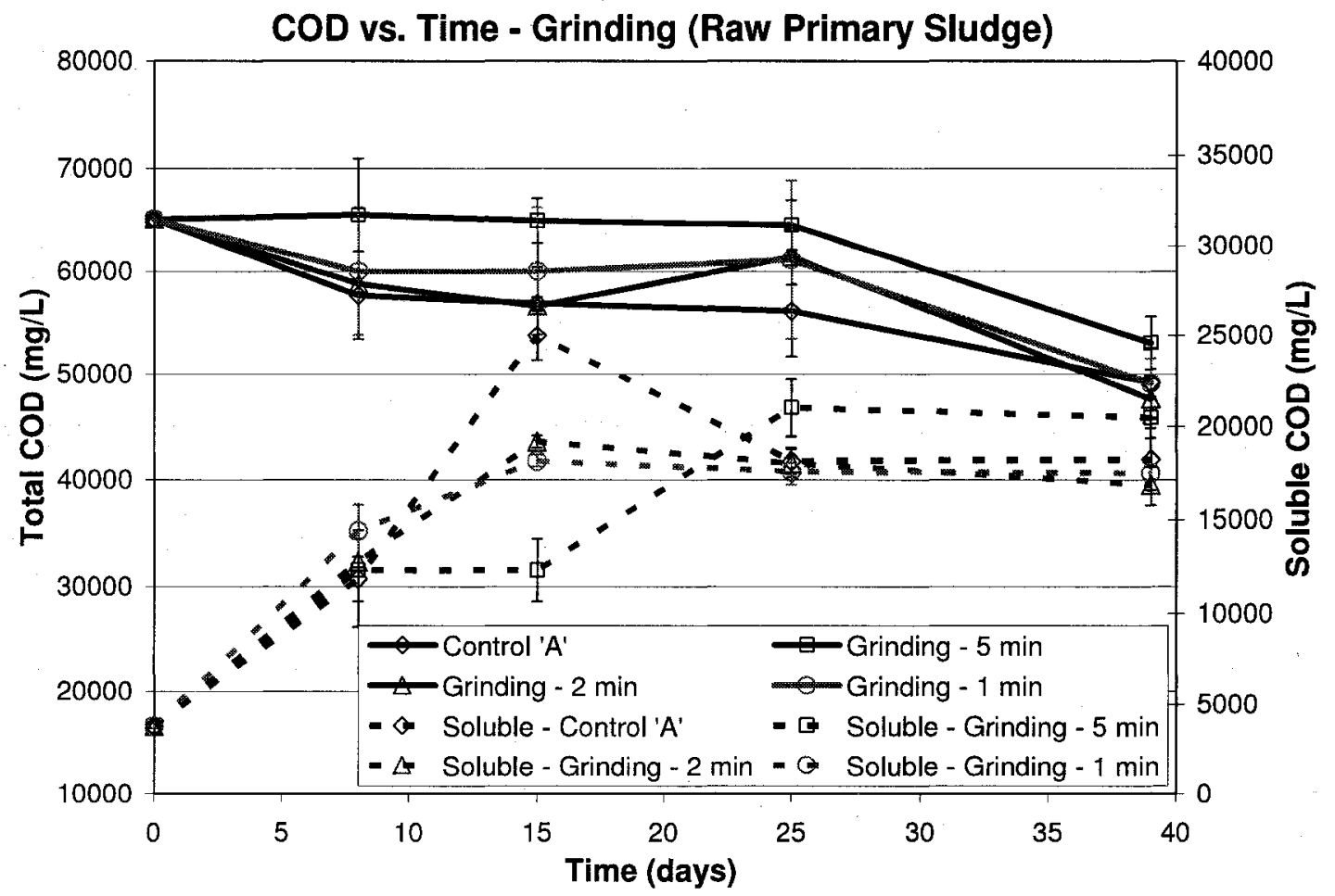

Figure 4-17: Profiles of the total and soluble COD during the batch reactor tests with raw primary sludge treated with an initial grinding cycle 
The various grinding cycles on the diluted sludge samples did not significantly improve the tCOD removal or improve the solubilisation of COD (Figure 4-18). Profiles of the tCOD concentration show some inconsistent results, oscillating around $33,000 \mathrm{mg} / \mathrm{L}$ for the first three weeks of reactor operation. During the last week of reactor operation however, the tCOD concentrations of all of the reactors with diluted sludge decreased by roughly $20 \%$. It should be pointed out that during this period of tCOD destruction, the sCOD concentrations were constant, which indicates that the solubilisation, fermentation and methanogenic phases were working harmoniously. Furthermore, the grinding cycles apparently reduced the peak sCOD concentrations relative to the control reactors, as was seen and discussed in the grinding cycle test with the raw sludge samples.

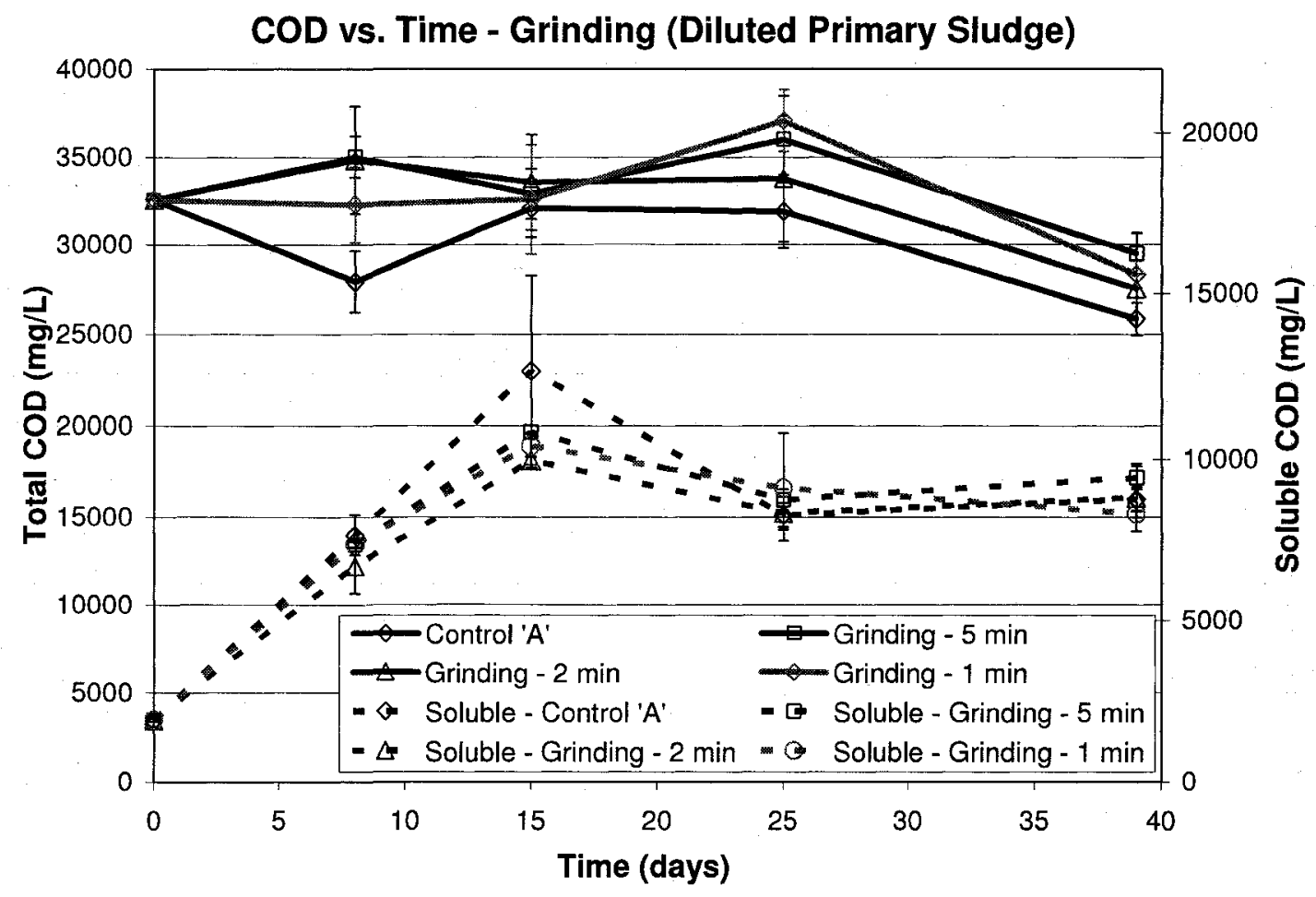

Figure 4-18: Profiles of the total and soluble COD during the batch reactor tests with diluted primary sludge treated with an initial grinding cycle 


\subsubsection{Protein}

Proteins represent roughly $50 \%$ of the dry weight of cells, and are the most structurally complex macromolecules known (Stein Carter, 2004). Protein concentration measurements provide an indication of the microbial activity and level of digestion. During digestion, proteins will be released by bacteria and eventually degraded through microbial and enzymatic activities. Proteins contain large amounts of nitrogen containing compounds, which will contribute to the ammonia levels when degraded anaerobically.

\subsubsection{Enzyme and Bacterial Additives}

During the first week of reactor operation, the protein concentrations of all of the reactors treated with enzyme and bacterial additives increased from an initial $1900 \mathrm{mg} / \mathrm{L}$ to between 25,000 and 30,000 $\mathrm{mg} / \mathrm{L}$, where they essentially reached a plateau (Figure 4-19). The plot for the control reactors however, shows a much higher spike to around 42,500 $\mathrm{mg} / \mathrm{L}$. The latter is actually the result of one of the control reactors which was measured to have a protein concentration of around $52,600 \mathrm{mg} / \mathrm{L}$ at the end of the first week, whereas the other control reactor had a protein concentration of around $32,850 \mathrm{mg} / \mathrm{L}$ at the end of the first week. This suggests that the observed spike may not be representative, meaning that there was no observable significant difference between the reactors treated with the enzyme and bacterial additives and the control reactors, during the first week of reactor operation. By the end of the batch reactor experiments, some of the raw sludge reactors treated with the enzyme and bacterial additives maintained a fairly consistent protein concentration of around $28,000 \mathrm{mg} / \mathrm{L}$, while one of the low-dose reactors and the control reactors started to decline to below $25,000 \mathrm{mg} / \mathrm{L}$. Although the 
latter seems insignificant, it may be that the enzyme and bacterial additives sustained certain cellular activities, while the control (and low additive dose) began to cease, allowing the hydrolysis of proteins to dominate.

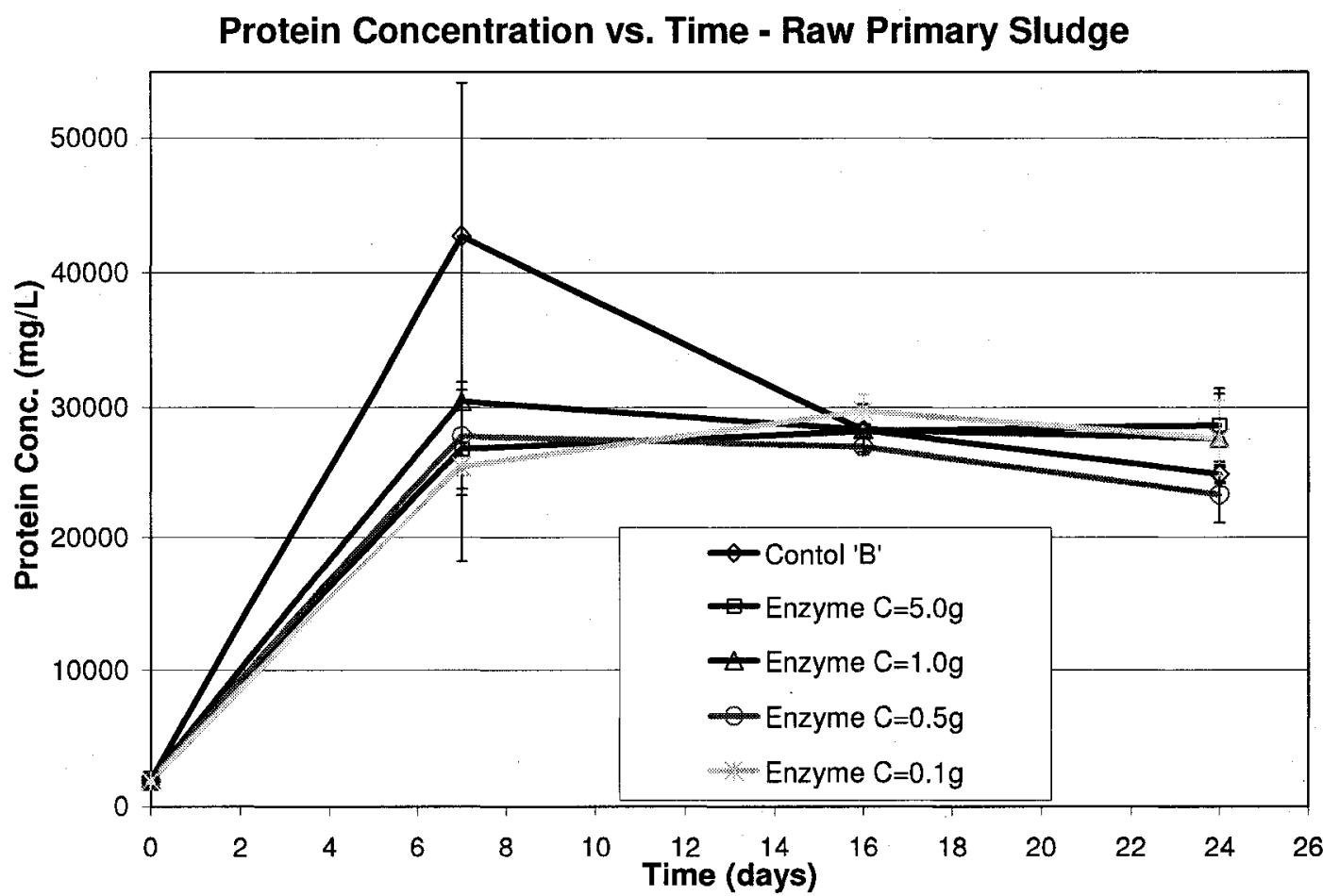

Figure 4-19: Profiles of the protein concentrations during the batch reactor tests with raw primary sludge samples treated with an enzyme and bacterial additive

The enzyme and bacterial additive reactors with diluted sludge showed similar trends as the tests with raw sludge samples. By the end of the first week, the protein concentrations of all reactors, even the control reactors, were between 11,500 and 12,000 $\mathrm{mg} / \mathrm{L}$, with the exception of one of the mid-dose enzyme and bacterial additive reactors, which spiked to nearly $22,000 \mathrm{mg} / \mathrm{L}$ (Figure 4-20). Similar to the scenario discussed in the previous paragraph, this spike was also the result of one of the reactors which was 
measured to have a much higher protein concentration of $29,000 \mathrm{mg} / \mathrm{L}$ by the end of the first week, while its matching reactor had a protein concentration of $14,800 \mathrm{mg} / \mathrm{L}$. Thus suggesting that the spike is not representative, and that there is no significant difference between the reactors by the end of the first week. In the days following the first week, up until the end of the batch reactor experiments, the protein concentrations of the control reactors began to level off, increasing by only $14 \%$ from day 7 to day 16 , whereas the enzyme and bacterial additive reactors continued to increase, from around $12,000 \mathrm{mg} / \mathrm{L}$ up to between 16,000 and $18,000 \mathrm{mg} / \mathrm{L}$ (29-43\% increase). This further reinforces what was discussed in the previous paragraph, with the raw sludge samples, in that the additives helped to sustain more microbial activity.

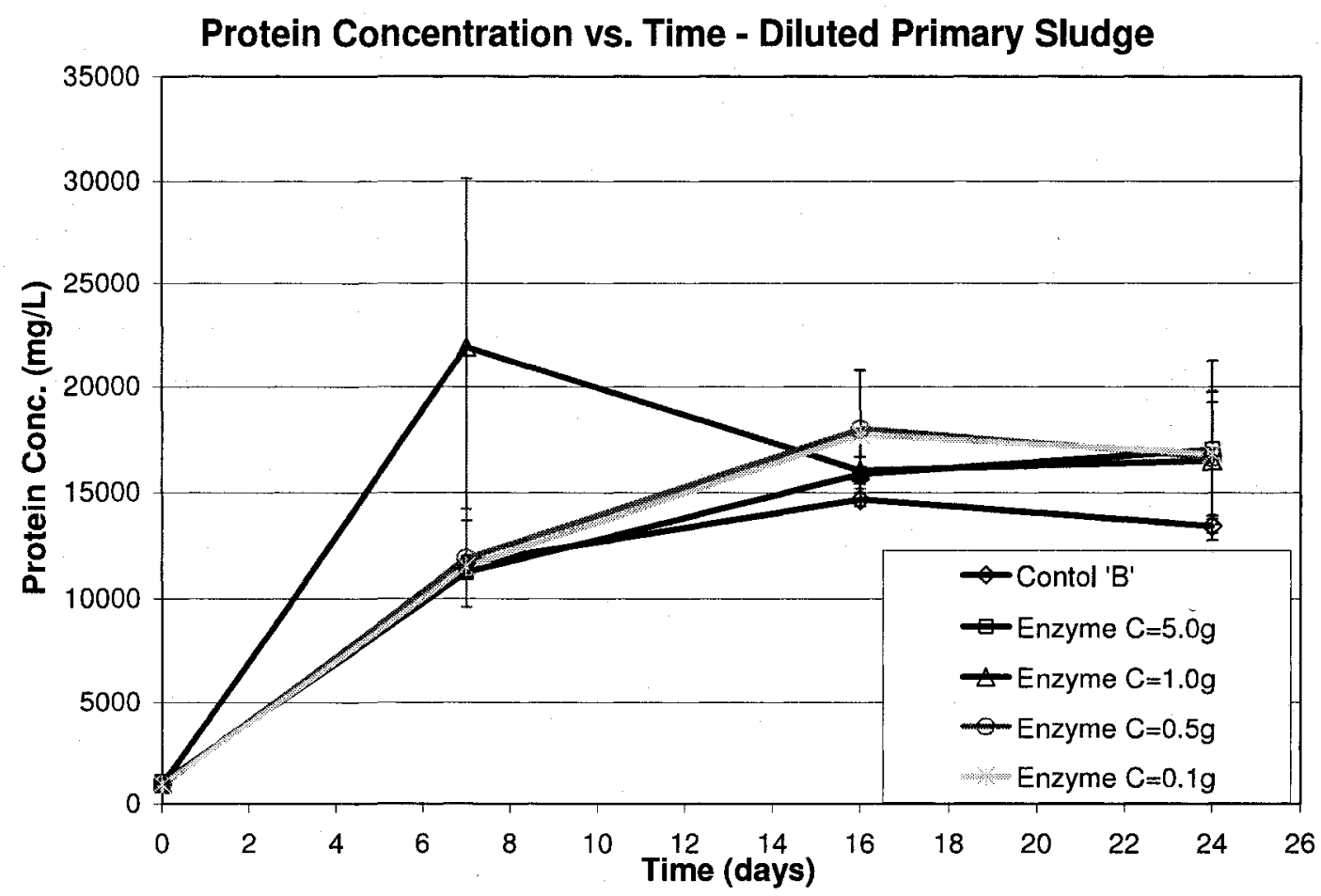

Figure 4-20: Profiles of the protein concentrations during the batch reactor tests with diluted primary sludge samples treated with an enzyme and bacterial additive 


\subsubsection{Microaeration and Grinding}

During the first two weeks of reactor operation, the protein concentrations of all reactors increased significantly from around $2500 \mathrm{mg} / \mathrm{L}$ to well above $25,000 \mathrm{mg} / \mathrm{L}$ (Figure 4-21), although the microaeration and the high grinding cycle treatments resulted in roughly $15 \%$ more protein generation than the control reactors during this period. After two weeks of reactor operation, the protein concentrations of the control reactors levelled off, whereas the reactors treated with microaeration and the grinding cycles continued to increase, although very slightly. By the end of the batch reactor tests, the protein concentrations of the reactors treated with the grinding cycle had decreased from the previous weeks' peaking values, however the protein concentrations were still between 6 and $24 \%$ higher than the control reactors. Microaeration on the raw sludge samples did not show a decrease in protein concentrations during the final week of testing, which suggests that microbial growth was still predominant over protein degradation, although drastically reduced compared to the initial growth phase. 


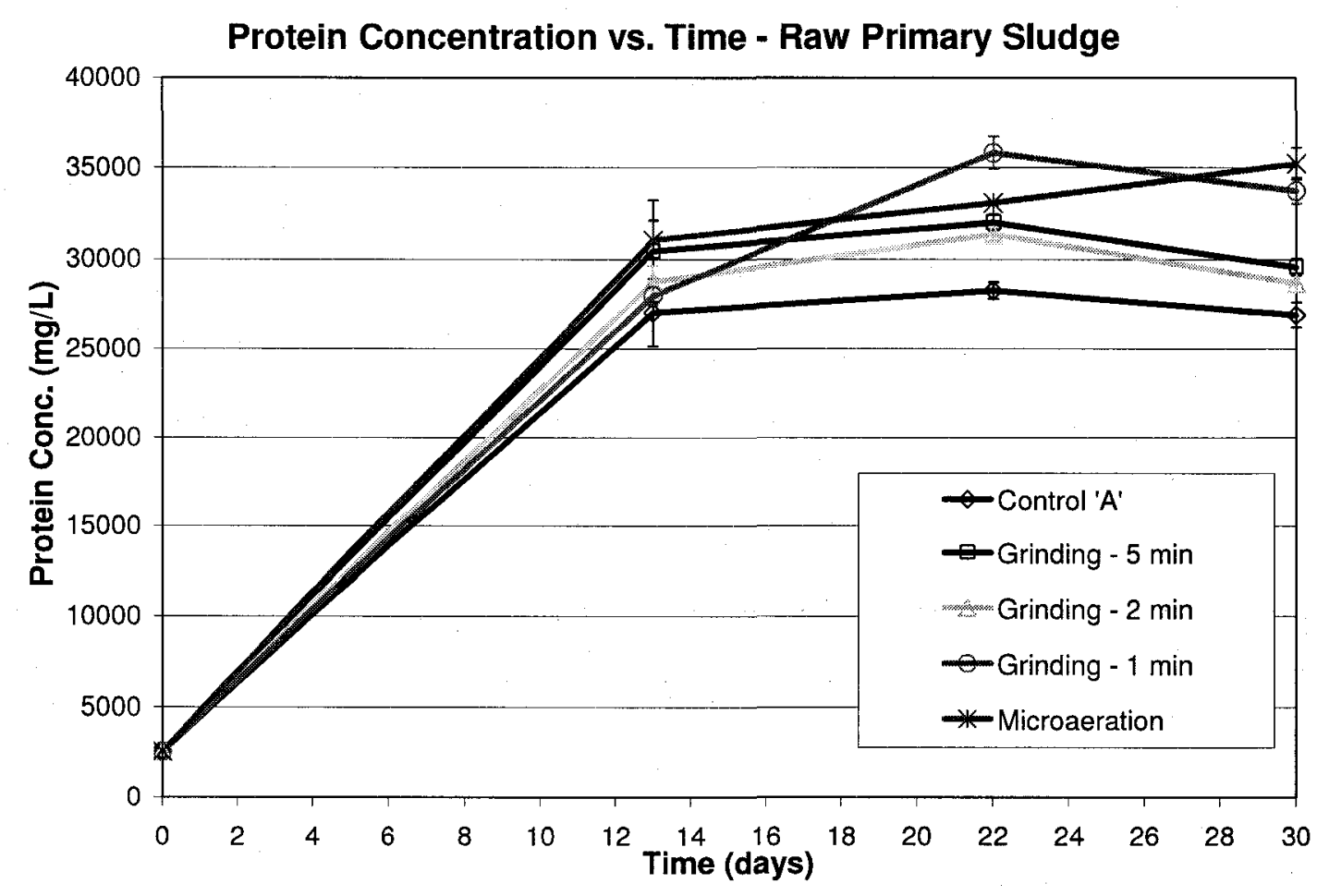

Figure 4-21: Profiles of the protein concentrations during the batch reactor tests with raw primary sludge treated with microaeration and an initial grinding cycle

The batch reactor tests with the diluted sludge samples showed similar trends as the tests with raw sludge, with more exaggeration and clearer results (Figure 4-22). Both microaeration and the grinding treatments caused a greater increase in the protein concentrations during the first two weeks of reactor operation, and maintained between 17. and $43 \%$ higher protein concentrations through to the end of the batch reactor experiments. During the last week of reactor operation, the protein concentration of the reactors treated with the high and low grinding cycles began to decrease slightly, along with the control reactors. Whereas the protein concentrations of the microaerobic reactors continued to increase, although very slightly. 


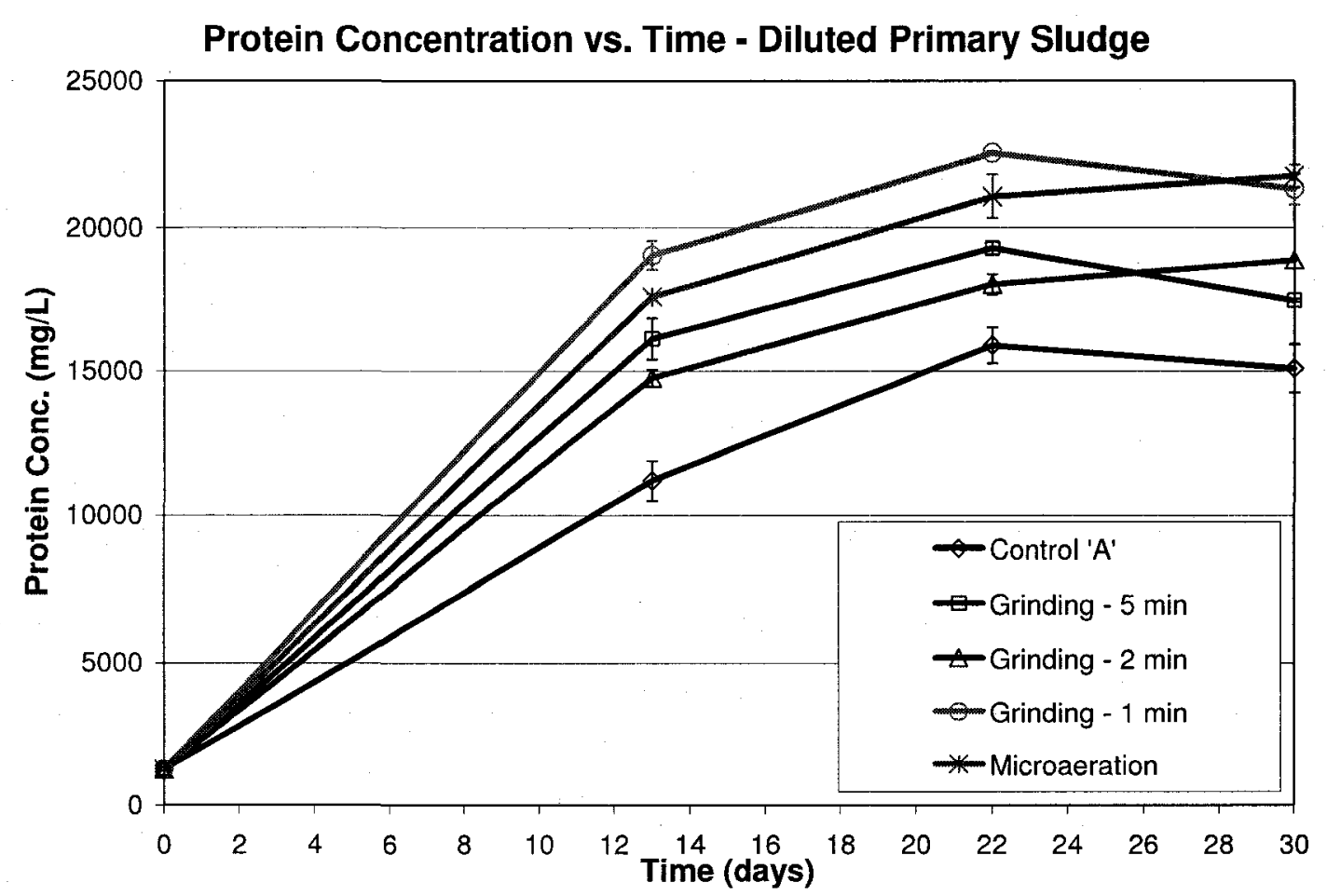

Figure 4-22: Profiles of the protein concentrations during the batch reactor tests with diluted primary sludge treated with microaeration and an initial grinding cycle

\subsubsection{Carbohydrate}

Carbohydrates are food for the microorganisms present in the sludge. They exist in simple form as sugars, and in complex forms such as starch and cellulose. A measurement of the carbohydrates concentration helps to assess the microbial conditions and the stage of digestion.

\subsubsection{Enzyme and Bacterial Additives}

The enzyme and bacterial additives contained roughly $650 \mathrm{mg}$ of carbohydrates per gram of Septaid Powder ${ }^{\mathrm{TM}}$, and therefore increased the initial carbohydrates concentrations of 
the enzyme and bacterial additive reactors by $65,325,650$ and $3250 \mathrm{mg} / \mathrm{L}$ for the 0.1 , 0.5, 1.0 and $5.0 \mathrm{~g}$ doses of Septaid Powder ${ }^{\mathrm{TM}}$ respectively. The additive used wheat bran as a carrier for the enzymes and bacteria, which was likely a predominant contributor to the increased carbohydrate concentrations. Throughout the testing period, the carbohydrate concentrations of the additive reactors remained between 25,000 and 40,000 $\mathrm{mg} / \mathrm{L}$, whereas the carbohydrate concentrations of the control reactors dropped off consistently from an initial $10,000 \mathrm{mg} / \mathrm{L}$ to a final $3000 \mathrm{mg} / \mathrm{L}$ (Figure 4-23). The sharp increase in carbohydrate concentrations during the first week could be the result of the hydrolysis of the wheat bran carrier, thus releasing carbohydrates to the system.

The sampling and dilution process make the wheat bran flakes very dispersed in solution, which makes the measure of the total carbohydrates of the system very difficult. As a result, the measure of the carbohydrate concentration is more a measurement of the amount of carbohydrates in solution. 


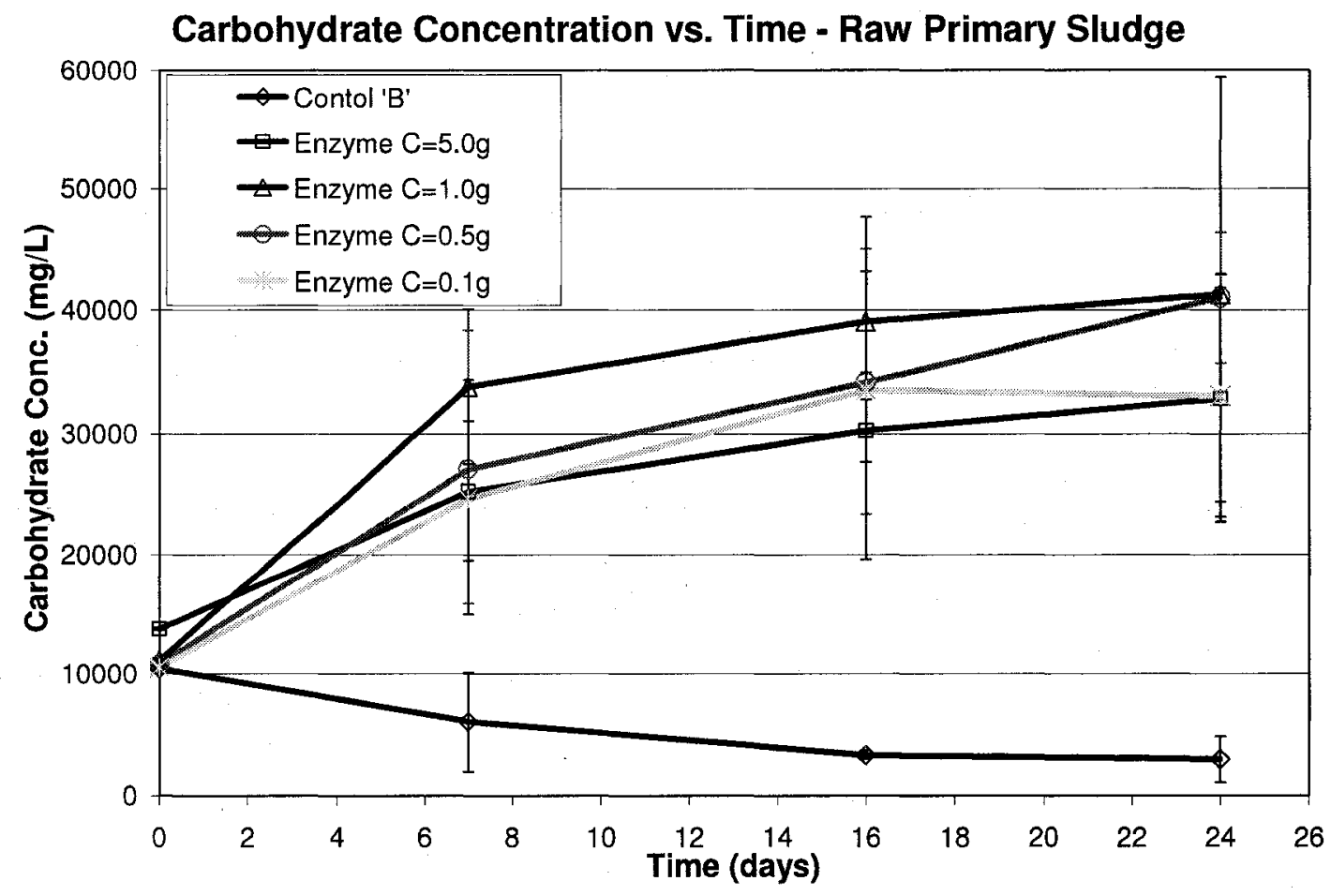

Figure 4-23: Profiles of the carbohydrates concentrations during the batch reactor tests with raw primary sludge samples treated with an enzyme and bacterial additive

The batch reactor diluted sludge sample tests followed very similar trends as the raw sludge sample tests. The enzyme and bacterial additive provided consistently higher carbohydrates concentrations than the control reactors, which dropped off significantly to an apparent baseline level of around $1000 \mathrm{mg} / \mathrm{L}$ by the end of the first week (Figure 4-24). As mentioned in the previous paragraph, high carbohydrate concentrations suggest that there is an abundance of food for the microorganisms, which should improve biodegradation in the long term. 


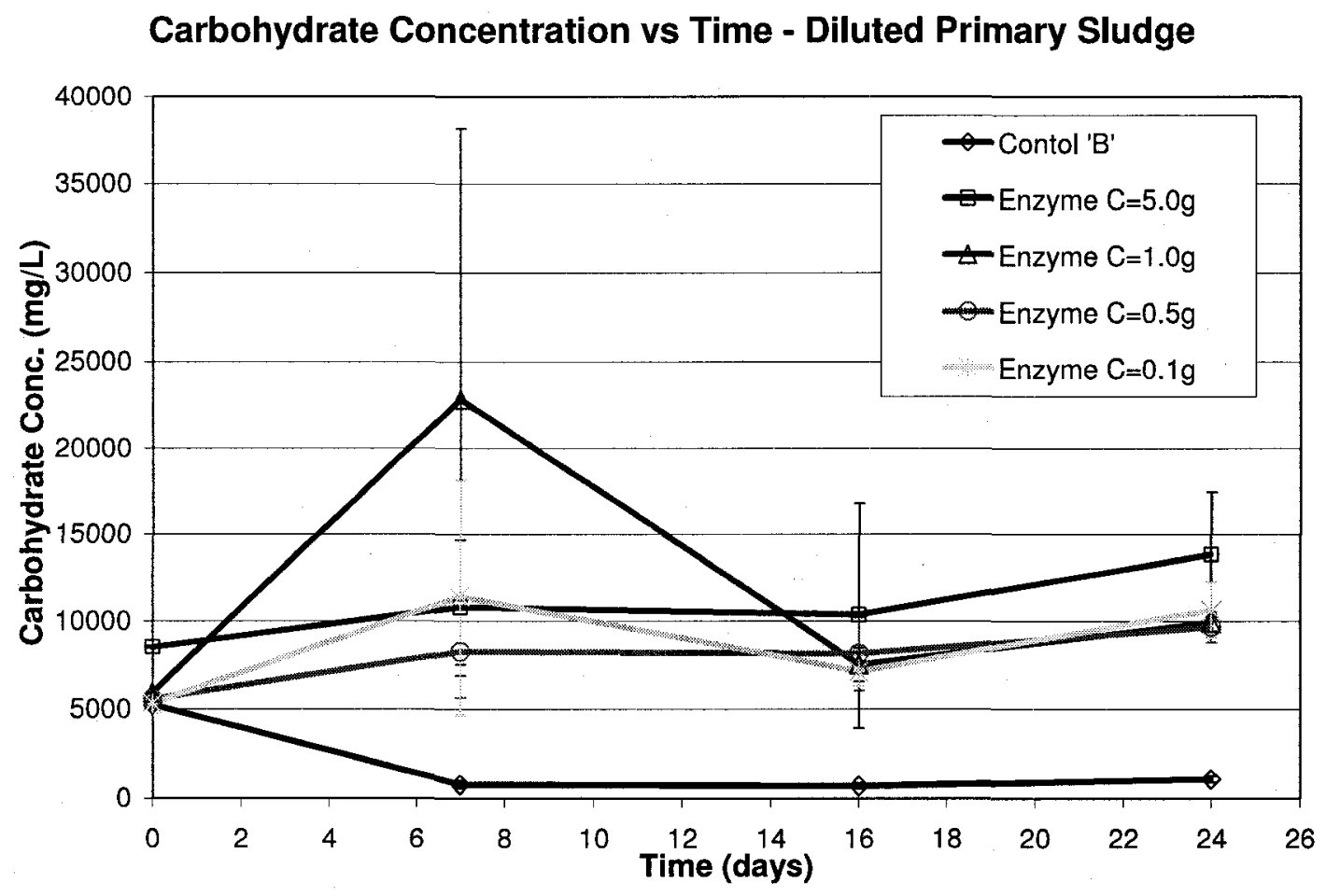

Figure 4-24: Profiles of the carbohydrates concentrations during the batch reactor tests with diluted primary sludge samples treated with an enzyme and bacterial additive

\subsubsection{Microaeration and Grinding}

Microaeration and grinding did not show any significant differences in the consumption of carbohydrates relative to the control reactors. Within the first two weeks of reactor operation, the carbohydrate concentrations of all of the microaeration, grinding and control reactors dropped off to an apparent baseline level between 2000 and $2500 \mathrm{mg} / \mathrm{L}$ (Figure 4-25). The microaeration reactors maintained slightly higher carbohydrate concentrations than the control reactors, although the difference was quite minimal. It is very possible that during the first two weeks, there were some differences in the initial rate of carbohydrates consumption between the various tests, but these differences were not measured and cannot be addressed. 


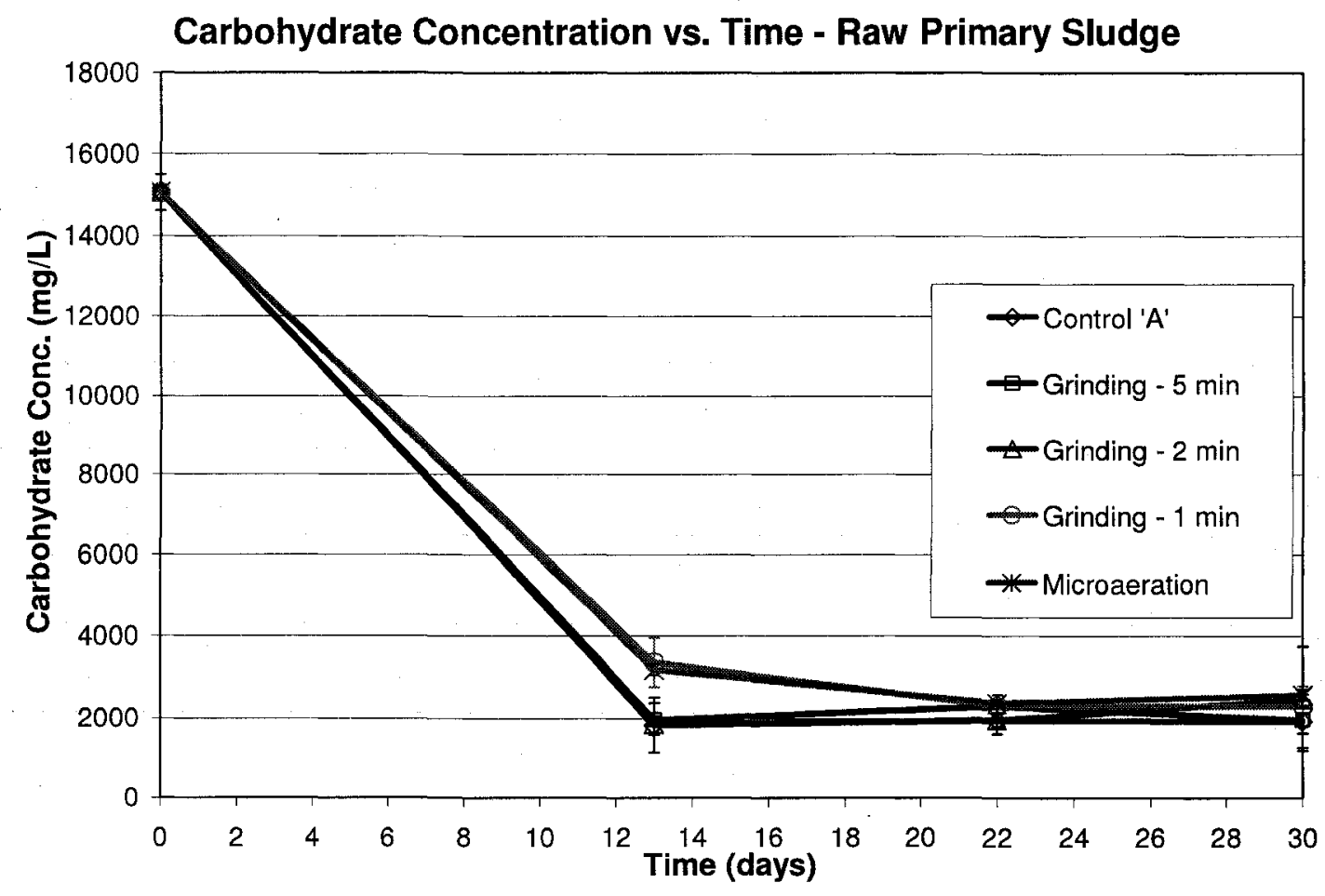

Figure 4-25: Profiles of the carbohydrate concentrations during the batch reactor tests with raw primary sludge treated with microaeration and an initial grinding cycle

The batch reactor tests with diluted sludge samples showed very similar trends as with the raw sludge samples, in that the carbohydrate concentrations of all of the microaeration, grinding and control flasks dropped off to an apparent baseline of around $1000 \mathrm{mg} / \mathrm{L}$ within the first two weeks (Figure 4-26). The microaeration reactors and one of the grinding reactors were slower to reach this baseline, however similar to the raw sludge tests, the difference was very minimal. 


\section{Carbohydrate Concentration vs Time - Diluted Primary Sludge}

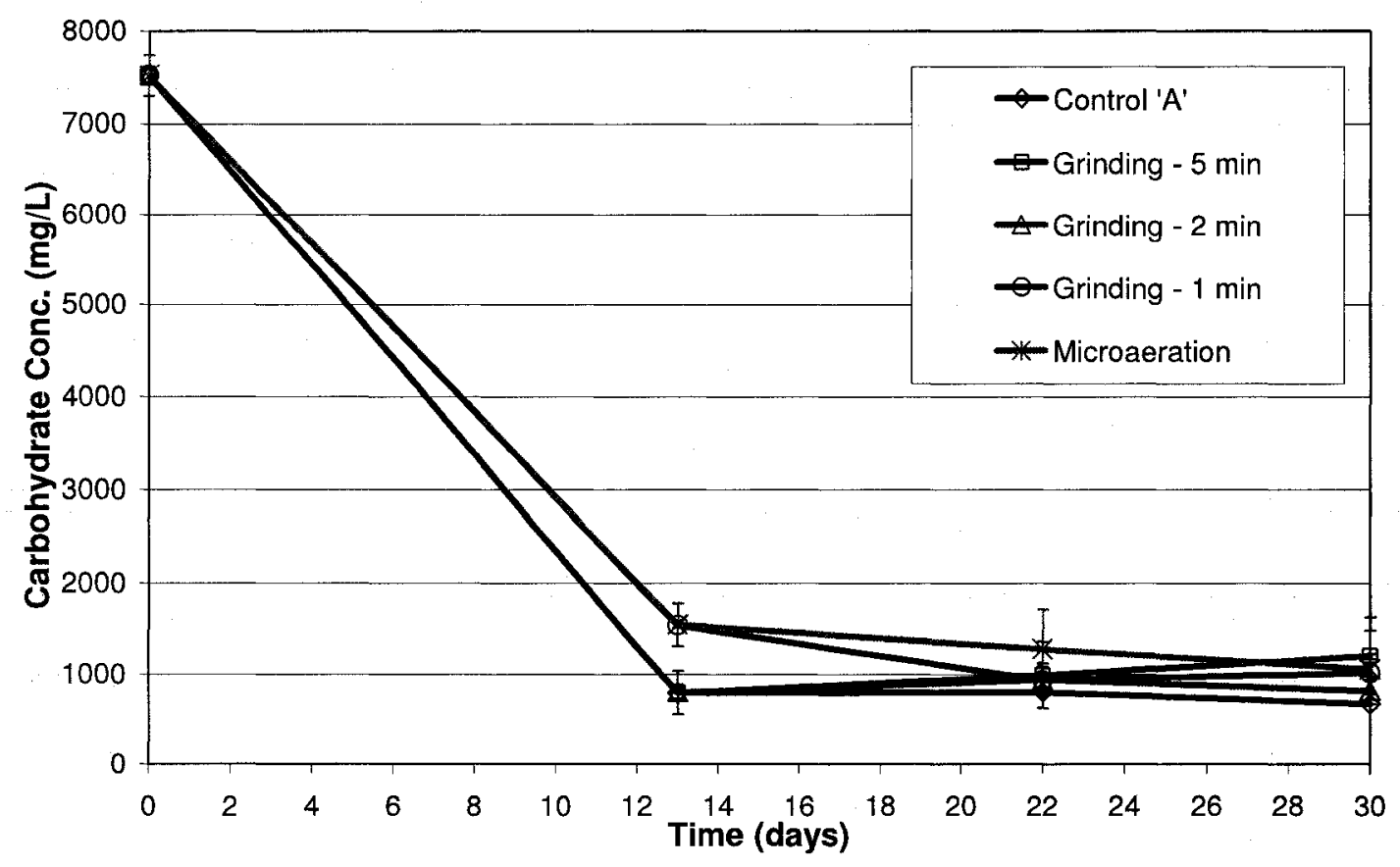

Figure 4-26: Profiles of the carbohydrate concentrations during the batch reactor tests with diluted primary sludge treated with microaeration and an initial grinding cycle

\subsubsection{Ammonia}

Ammonia measurements of the sludge samples were used to evaluate the degradation of nitrogen containing compounds, such as proteins and urea, in the sludge samples, and also to monitor the anaerobic acclimatisation period. The following sections discuss the trends in the measured ammonia concentrations for the enzyme and bacterial additive, microaeration and grinding reactors. 


\subsubsection{Enzyme and Bacterial Additives}

Enzyme and bacterial additives improved the degradation of nitrogen containing compounds in the sludge samples and seemed to reduced the time taken for the system to acclimatise anaerobically. Ammonia profiles for raw primary sludge samples show a clear trend relating ammonia generation to the enzyme and bacterial additive dose (Figure 4-27). The highest two doses (1.0 and $5.0 \mathrm{~g}$ of Septaid Powder ${ }^{\mathrm{TM}}$ ), caused a rapid initial degradation of nitrogen containing compounds, causing a release of ammonia. The two low doses of additives did not result in the initial rapid ammonia generation, instead following a similar profile as the control reactors. However, by the end of the batch reactor experiments, the raw sludge samples dosed with $0.1,0.5,1.0$ and $5.0 \mathrm{~g}$ of Septaid Powder ${ }^{\mathrm{TM}}$ resulted in $1.5,11,6.5$ and $25 \%$ more ammonia generation respectively than the control reactors. The enzyme additive contained very small amounts of ammonia $(0.6$ $\mathrm{mg} / \mathrm{g}$ ), however easily degradable nitrogen containing compounds in the additive likely contributed to some of the ammonia generation recorded. 


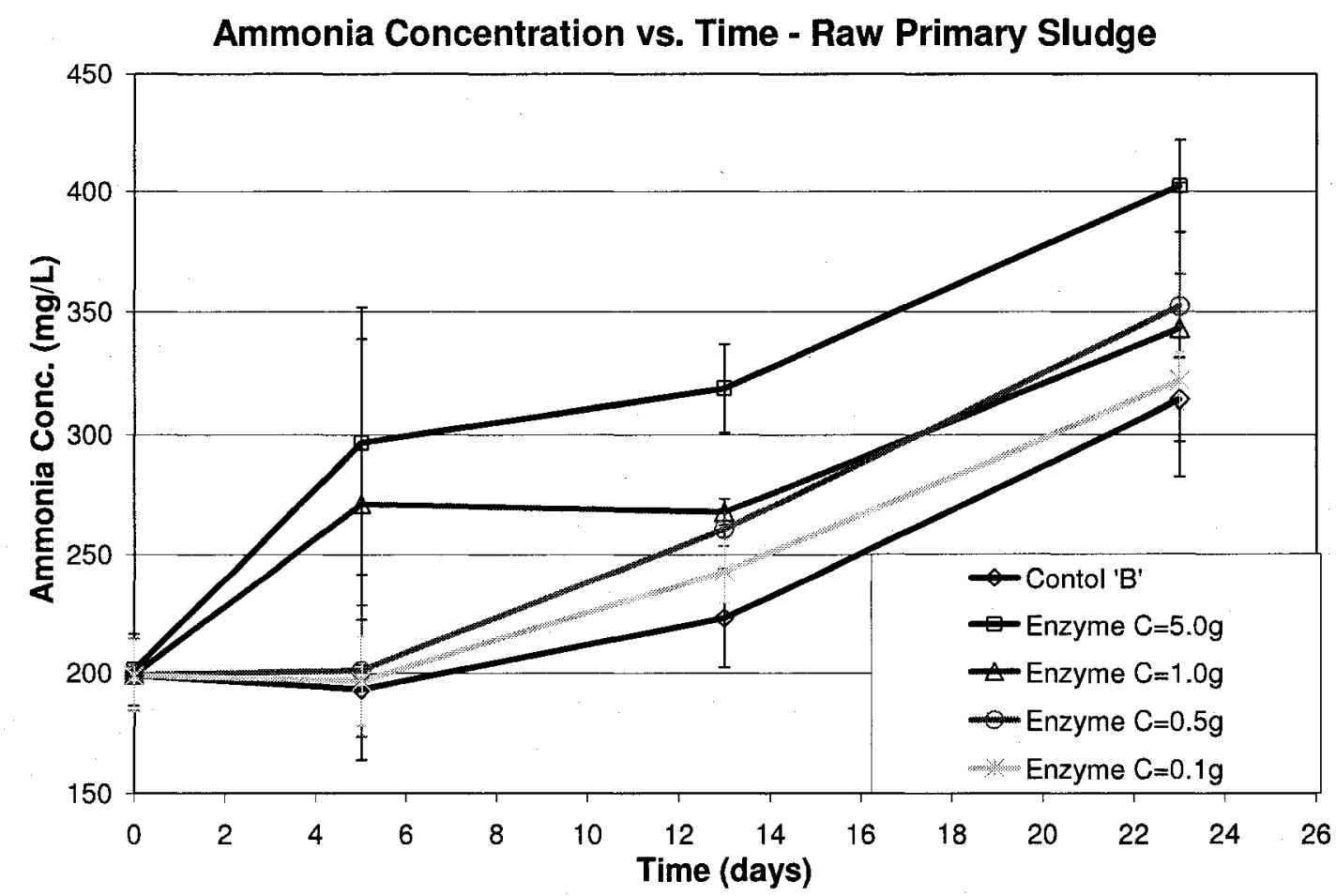

Figure 4-27: Profiles of the ammonia concentrations during the batch reactor tests with raw primary sludge samples treated with an enzyme and bacterial additive

As seen in Figure 4-28, the diluted sludge samples show an apparent decrease in the ammonia concentrations in the first week following dilution, with the exception of the reactors with the highest enzyme and bacterial additive (5.0 $\mathrm{g}$ of Septaid Powder $\left.{ }^{\mathrm{TM}}\right)$. The initial decrease may be the result of the dilution process during the initial reactor seeding process, which may have provided some oxygen to the system, and oxidised some of the ammonia. In the study by Ortega et al., 2007, when primary sludge was diluted by a factor of four, the ammonia concentrations of the batch reactors actually decreased by a factor of ten (raw sludge: $125 \mathrm{mg} / \mathrm{L} \mathrm{NH}_{4}{ }^{+}, 3: 1$ diluted sludge: $12.5 \mathrm{mg} / \mathrm{L} \mathrm{NH}_{4}{ }^{+}$). In this study however, an initial reading for the diluted sludge samples was not taken directly, instead it was assumed that the diluted sludge samples would have initial values equal to 
half of the raw sludge values for all of the parameters tested, due to the $1: 1$ dilution of raw sludge with distilled water.

Only the reactors with the additive dose $\left(5.0 \mathrm{~g}\right.$ of Septaid Powder $\left.{ }^{\mathrm{TM}}\right)$ resulted in a significantly higher amount of ammonia generation in the diluted sludge sample reactors (Figure 4-28). All of the other batch reactors followed very similar trends compared to the control reactors with diluted sludge samples. By the end of the batch reactor experiments, the diluted sludge samples dosed with $0.1,0.5,1.0$ and $5.0 \mathrm{~g}$ of additives (Septaid Powder ${ }^{\mathrm{TM}}$ ) resulted in 2, 13, 20 and 90\% more ammonia generation (respectively) than the control reactors.

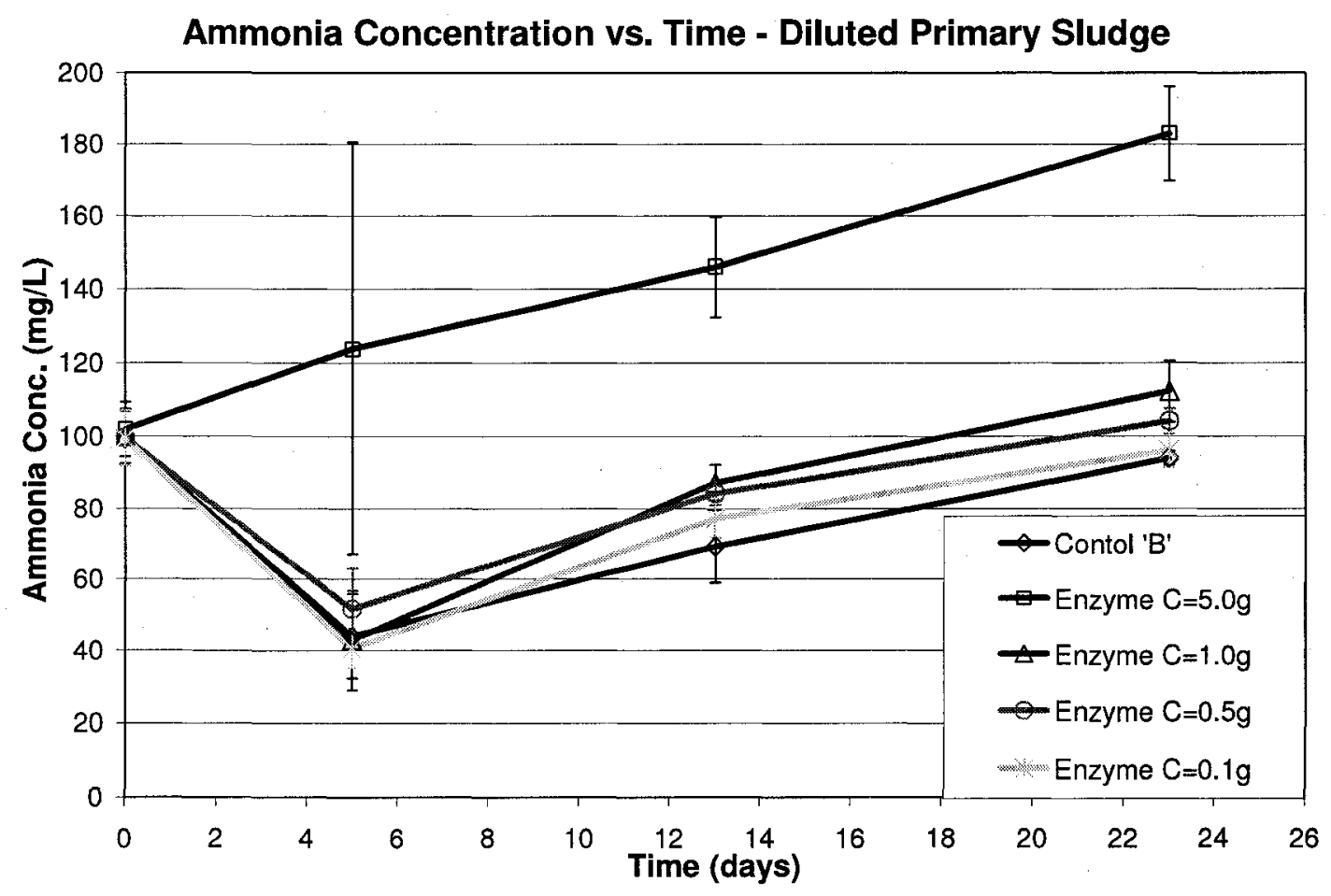

Figure 4-28: Profiles of the ammonia concentrations during the batch reactor tests with diluted primary sludge samples treated with an enzyme and bacterial additive 


\subsubsection{Microaeration and Grinding}

Microaeration and the initial grinding cycles ultimately helped to improve the degradation of nitrogen containing compounds, and the formation of ammonia, in the raw and diluted primary sludge samples. Grinding also seemed to have reduced the acclimatisation period, causing a greater degradation of nitrogen containing compounds and release of ammonia within the first two weeks of reactor operation. By the end of the batch reactor experiments, raw sludge samples treated with an initial grinding cycle of 1,2 , and 5 minutes had 17,11 and $18 \%$ higher ammonia concentrations respectively compared to the control reactors (Figure 4-29).

Microaeration did not increase the initial generation of ammonia in the first two weeks, as was seen with the high enzyme and bacterial additive dose and the high grinding dose. This could be attributable to the air supply, which likely prolonged the anaerobic stabilisation period. A similar trend was observed in the study by Ortega et al, 2007, who provided microaeration to primary sludge in batch reactors, through electrolysis. In this study, the microaerobic reactors required 7 days of operation to reach anaerobic conditions, whereas the anaerobic control tank was completely anaerobic after the first day of reactor operation. Although microaeration did not improve the initial ammonia generation, as was seen in the other tests, by the start of the third week of reactor operation, the microaerobic reactors showed $25 \%$ higher ammonia concentrations than the anaerobic control reactors in the raw sludge tests. 


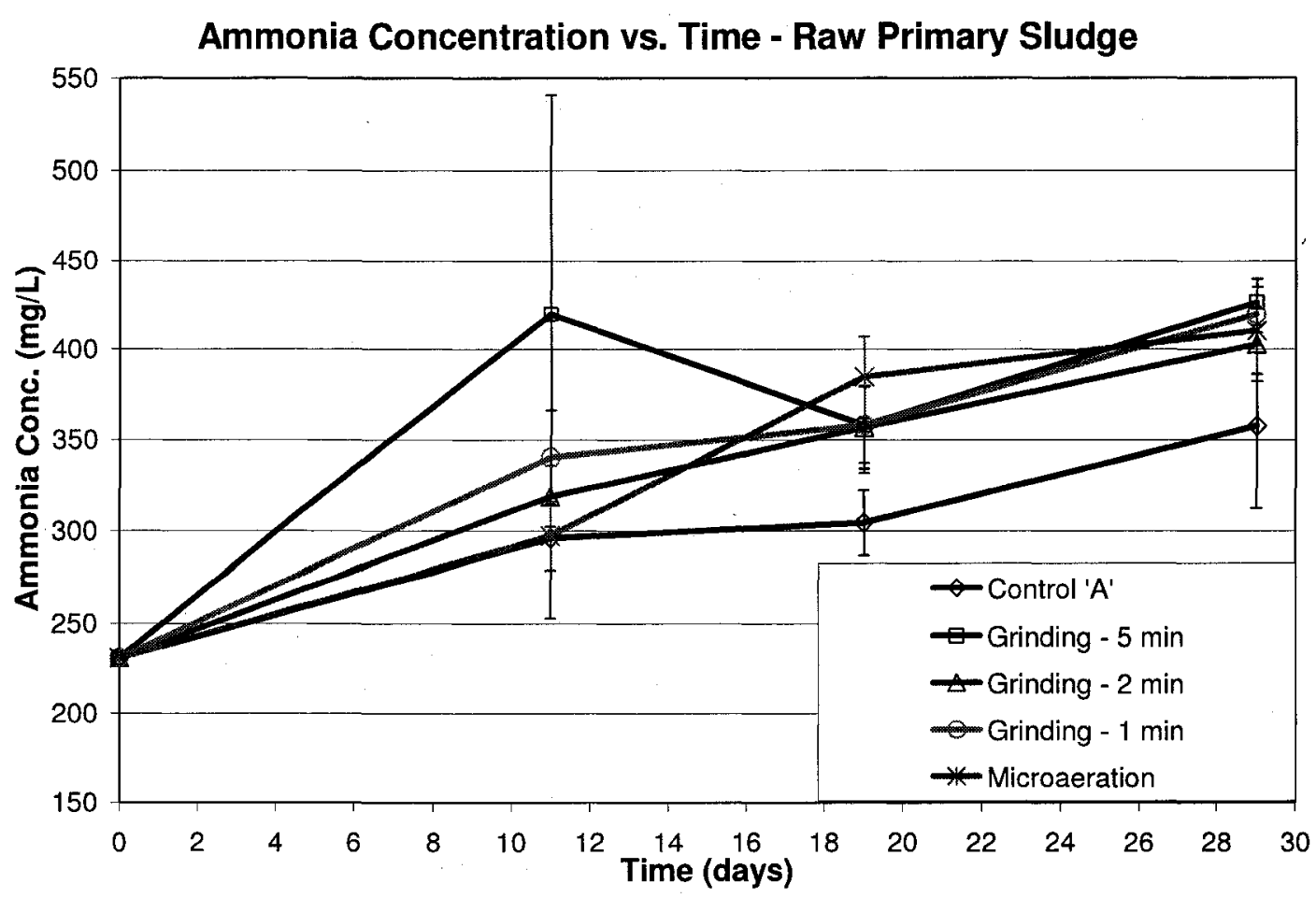

Figure 4-29: Profiles of the ammonia concentrations during the batch reactor tests with raw primary sludge treated with microaeration and an initial grinding cycle

The grinding cycles on the diluted sludge samples increased the amount of ammonia generated in the first two weeks, and also resulted in higher ammonia concentrations by the end of the experiments. As seen in Figure 4-30, grinding cycles on the diluted sludge resulted in a steady increase in ammonia concentrations, caused by the degradation of nitrogen containing compounds. By the end the of the experiments, the final ammonia concentrations were $23,3,27 \%$ higher than the control reactors, for the 1,2 and 5 minute grinding cycles respectively. The relatively small increase $(2 \%)$ by the reactors treated with the 2 minute grinding cycle is actually the result of one of the reactors, which decreased from around 155 to $150 \mathrm{mg} / \mathrm{L}_{\text {of }} \mathrm{NH}_{4}{ }^{+}$in the final week of operation, whereas its matching reactor continued to increase from 150 to $155 \mathrm{mg} / \mathrm{L} \mathrm{of}^{N_{4}}{ }_{4}^{+}$. 
The microaeration treatments on the diluted sludge reactors resulted in similar trends as the raw sludge microaeration reactors, in that both followed very similar paths as the controls reactors for the first two weeks of reactor operation. The diluted sludge samples were almost identical to the controls up to the third week, but by the end of the batch reactor experiments, microaeration on the diluted sludge samples ultimately improved, degradation of nitrogen containing compounds, causing ammonia generation (Figure 4-30). Similarly with the raw sludge reactors, microaeration likely delayed the anaerobic stabilisation process, during which time ammonia generation would be hindered.

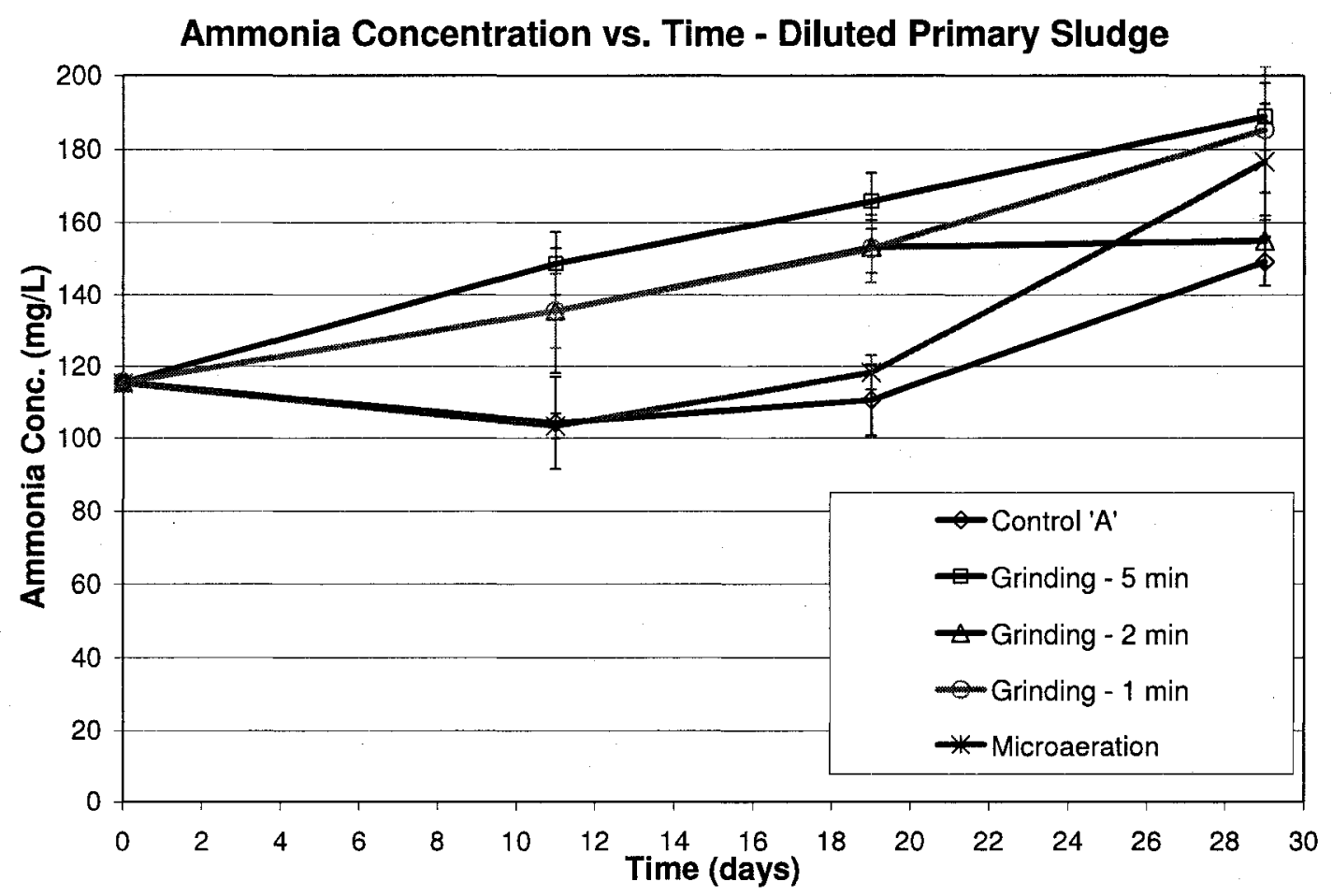

Figure 4-30: Profiles of the ammonia concentrations during the batch reactor tests with diluted primary sludge treated with microaeration and an initial grinding cycle 


\subsection{Continuous Flow Reactor Experiments}

The following sections present and discuss the results obtained for the five continuous reactor tests. Two of the reactors were treated with microaeration, two of the reactors were treated with an enzyme and bacterial additive, and the fifth tank was an untreated, control reactor. The equipment and materials of this phase of experiments are presented in more detail in section 3.2. Effluent samples were collected and analysed for suspended solids, COD, organic acids, protein, carbohydrates and ammonia concentrations.

\subsubsection{Total Suspended Solids}

During reactor seeding and fill up, the primary sludge bed was disturbed resulting in high amounts of suspended solids in the reactor effluents (Figure 4-31). During the first week of reactor operation, the effluents from all reactors contained between 80 and $160 \mathrm{mg} / \mathrm{L}$ of total suspended solids. The microaeration tanks had the highest suspended solids contents in the effluent due to the disturbances caused by high microaeration rates. The latter prompted a series of reductions in the microaeration rates, as presented in Figure $3-6$, until rates of 10 and $20 \mathrm{~mL} / \mathrm{min}$ were achieved. The reactor with the higher microaeration dose was equipped with two air diffusers, while the reactor treated with the low dose had only one air diffuser. As a result, the microaeration rate supplied to each of the air diffusers was the same $(10 \mathrm{~mL} / \mathrm{min})$. This rate was finally chosen since the rising air bubbles created almost no disturbances at the scum and liquid surface. 
After two weeks of reactor operation, inspections on each of the reactors revealed that a portion of the solids had re-settled forming a sludge bed, while a large portion of the sludge remained on the surface, forming a scum layer, almost 1 inch thick. By this time, the effluents from all reactors were generally free of large particles, except when the tanks were disturbed. The effluent from the reactors treated with the enzyme and bacterial additives, and effluent from the control reactor was a very thin milky colour similar to the feed, while the effluents from the microaeration tanks had a greyish colour. In the following weeks, the scum layer on the surface of the microaeration tanks slowly deteriorated and eventually became patchy across the surface, while the scum layer on the surface of the other reactors did not deteriorate. After three weeks, the effluent from the microaeration tanks had the lowest solids content $(30-40 \mathrm{mg} / \mathrm{L})$, while all of the reactors were below $50 \mathrm{mg} / \mathrm{L}$. This trend continued, and after 2 months, the effluent from both microaeration tanks had the lowest solids content $(20-30 \mathrm{mg} / \mathrm{L})$, where they remained for all subsequent tests. The effluent from the control tank and the enzyme tanks had solids between 30 and $50 \mathrm{mg} / \mathrm{L}$.

Results from the continuous flow reactor experiments showed that excessive microaeration rates hindered the settling conditions within the reactor, which led to high TSS concentrations in the effluent. Results also suggest that low microaeration rates may lead to a reduction in the TSS concentrations of the effluents relative to the control reactor, and the reactors treated with the enzyme and bacterial additive. The reduction in TSS may be attributable to an increased level of solubilisation and subsequent degradation of organic matter. 
The enzyme and bacterial additives did not have a significant effect on the effluent TSS concentrations, relative to the control reactor. In fact, the effluent from the reactors that were treated with the additive often had a slightly higher TSS concentration than the control reactor. It is possible that the increased rate of gas generation in the reactors that were treated with the additive resulted in the suspension and floatation of particles. This was clearly seen in the batch reactor experiments with the enzyme and bacterial additive, although the suspension of particles was assisted by the bottle neck and wall effects of the Erlenmeyer flasks used in the batch reactor experiments.

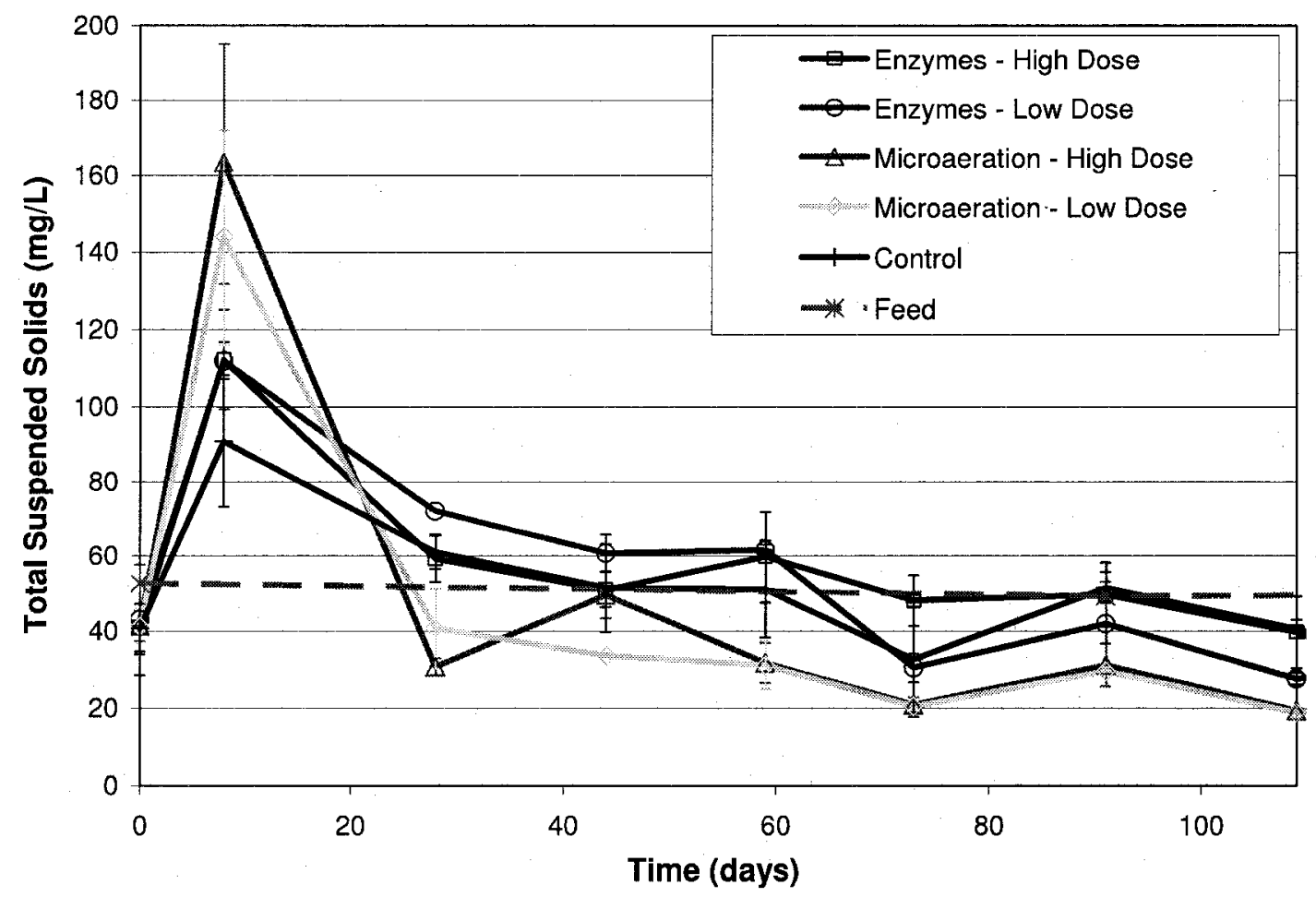

Figure 4-31: Profiles of the total suspended solids of the influent and the effluents from the continuous flow reactors 


\subsubsection{Total and Soluble COD}

The tCOD and sCOD profiles of the reactor effluents help to assess the degrees of solubilisation and the level of degradation that are occurring in each of the reactors. The following two sections first describe and explain the COD results for the two microaeration reactors relative to the control reactor, followed by the $\mathrm{COD}$ analysis for the reactors treated with the enzyme and bacterial additive.

\subsubsection{Microaeration}

During the first two weeks, the tCOD and sCOD of the effluents from all of the reactors were higher than the influent due to the initial seeding phase, which re-suspended some of the primary sludge (Figure 4-32). Furthermore, in the first week the microaeration rates were too high, which hindered the settling conditions in these tanks, and caused some sludge bed and scum layer wash-out. The solids washout is apparent by comparing the degrees of solubilisation, or the difference between the tCOD and SCOD. The profiles of the SCOD (dashed lines) are far below their corresponding tCOD profiles (solid lines), which indicates a low percent soluble, and higher percent particulate COD. The latter complements the TSS analysis described in the previous section.

After two weeks of adjustments and acclimatisation, the tCOD of the effluent from both of the microaeration tanks was down to around 1000 to $1200 \mathrm{mg} / \mathrm{L}$, similar to the effluent from the control tank, and the influent to all tanks. From day 14 to day 44, oscillating effluent COD concentrations between 400 and $1200 \mathrm{mg} / \mathrm{L}$ were recorded, with general trends of lower effluent COD concentrations from the microaeration reactors. For the 
first 44 days of reactor operation, COD tests were conducted every four days. After this point, the testing period was extended to one week between COD measurements, which reduced the oscillations in the measured COD values from one testing day to another. From day 50 to day 80 , Figure 4-32 shows consistent and clear trends that while the control reactor and both of the microaeration reactors had effective degrees of solubilisation, the microaeration reactors had effluent COD concentrations (350-400 $\mathrm{mg} / \mathrm{L})$ around half of those of the control reactor $(700-800 \mathrm{mg} / \mathrm{L})$, which had effluent concentrations similar to the COD concentration of the feed. This trend is consistent with the trends observed in the batch reactor experiments, where an accumulation of SCOD was measured in the control reactors, whereas the microaeration reactors led to the degradation of the soluble COD. Measurements of the organic acid concentrations in the reactor effluents help to confirm a greater accumulation of acids in the control reactor, which suggests that the methanogenesis phase was hindered in the control reactor. Profiles of the effluent organic acid concentrations are discussed later in section 4.2.3. After 90 days of reactor operation, the tCOD concentrations of the effluent from the control reactor began to drop consistently from around $750 \mathrm{mg} / \mathrm{L}$ to $500 \mathrm{mg} / \mathrm{L}$ by day 110 , which represented a COD reduction of about $50 \%$ relative to the concentration of the feed. At this point the effluent COD concentrations from the microaeration reactors was around 300 to $350 \mathrm{mg} / \mathrm{L}, 35 \%$ less than the effluent from the control reactor, and almost $70 \%$ lower than the COD concentration of the feed. This suggests that although microaeration improved the earlier stages of digestion, the control reactors may eventually be capable of providing a similar level of treatment following a longer acclimatisation period. 


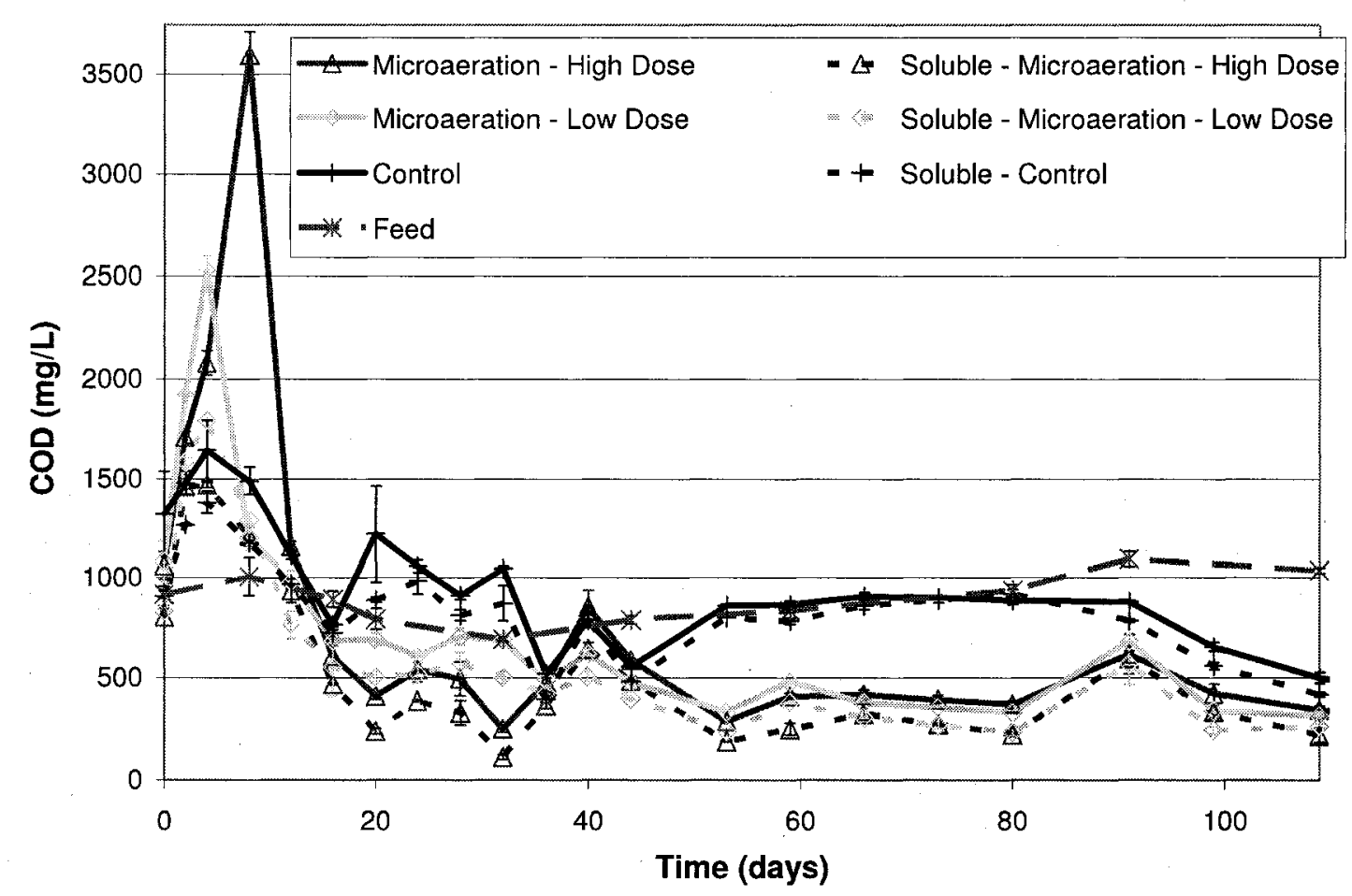

Figure 4-32: Profiles of the total and soluble COD of the influent and the effluents from the microaeration and control continuous flow reactors

\subsubsection{Enzyme and Bacterial Additives}

The time profile of the effluent total and soluble COD from the enzyme and bacterial additive reactors and control reactor is presented in Figure 4-33. In the first two weeks, the COD of the effluent from all the tanks was higher than the influent due to the initial seeding and fill-up process. After two weeks of adjustments and acclimatisation, the tCOD of the effluent from both enzyme and bacterial additive reactors was down to around $1200 \mathrm{mg} / \mathrm{L}$, slightly higher than the effluent from the control reactor, and the influent to all reactors. 
From day 20 until day 60 , the tCOD concentrations of the effluent from both of the enzyme and bacterial additive reactors, and the control reactor oscillated around 800 $\mathrm{mg} / \mathrm{L}$, with no significant difference between the additive and the control reactors. While some mild spikes in the effluent COD concentration profiles would be expected for the reactors that were treated with the enzyme and bacterial enzyme additive, due to the biweekly additions of the Septaid Powder ${ }^{\mathrm{TM}}$, most of the spikes follow uniformly with spikes on the COD concentration profile for the control reactor. This suggests that these variations were more likely due to variations in the feed COD concentration. The COD concentration profile for the feed is based on biweekly COD measurements of the feed reservoir, plus an averaged COD increase due to the daily cellulose powder addition. As a result, the averaged COD profile of the feed, presented in Figure 4-32 and Figure 4-33, should contain a series of spikes surrounding the hour when the cellulose dose was added, however such a plot was not attempted since the minor variations are not significant for the purposes of this research.

From day 60 to day 90 , the tCOD of effluent from reactor treated with the low dose of the enzyme and bacterial additive reactor was around $100 \mathrm{mg} / \mathrm{L}$ lower than the control tank, whereas the reactor treated with the high dose of additives had an effluent COD concentration approximately equal to the $\mathrm{COD}$ concentration of the effluent from the control reactor, and equal to the COD concentration of the feed. By day 100 , the differences in the tCOD concentrations in the effluents from the control reactor and the reactor treated with the enzyme and bacterial additive were insignificant, which ultimately suggests that the enzyme and bacterial additives did not improve degradation. 


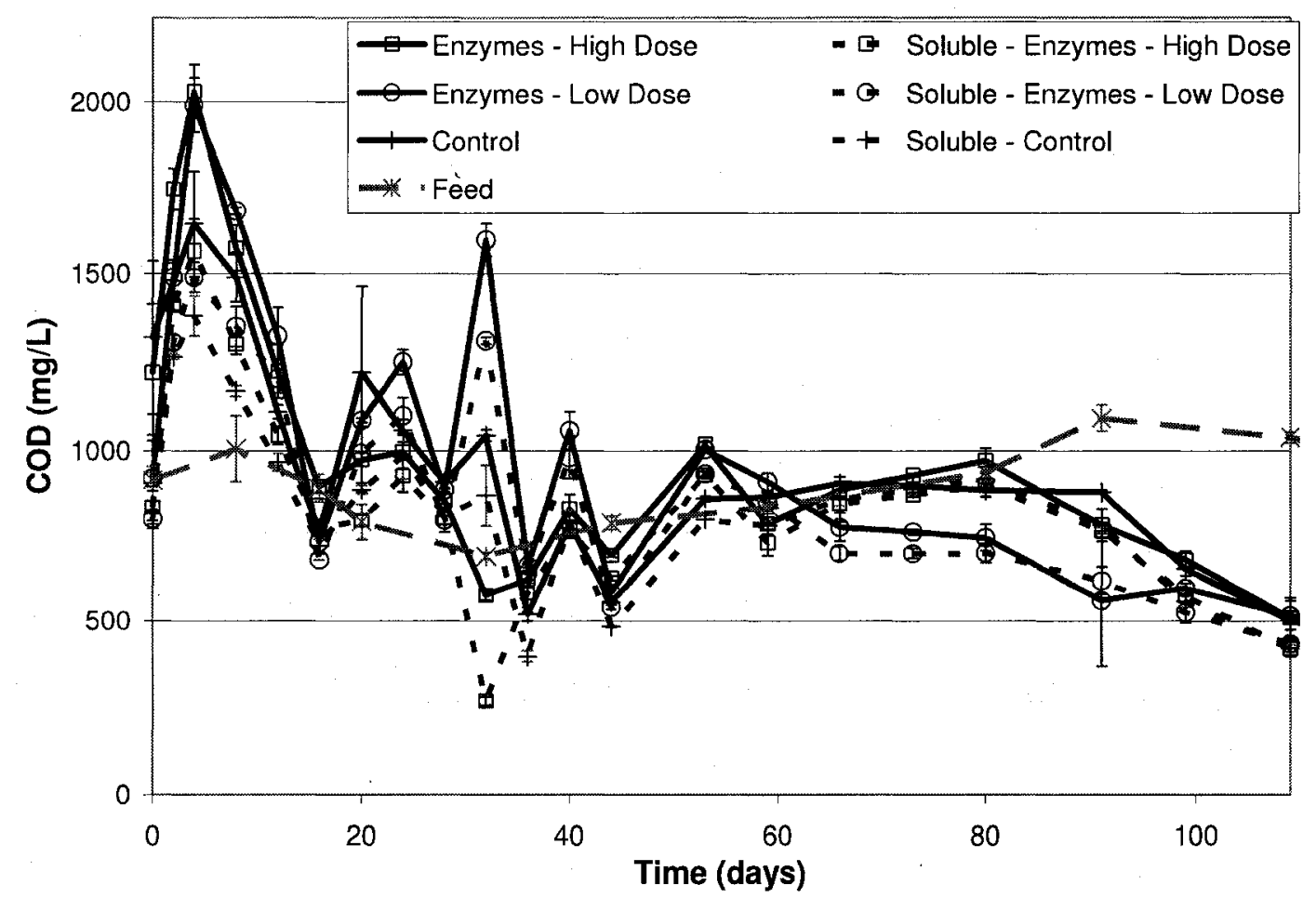

Figure 4-33: Profiles of the total and soluble COD of the influent and effluents from the enzyme and control continuous flow reactors

\subsubsection{Volatile (Organic) Acids}

High concentrations of organic acids were measured in the effluent from all of the reactors in the first two-weeks, after the primary sludge and the synthetic wastewater were initially added to the reactors (Figure 4-34). During this stage a significant amount of sludge solubilisation, and an increase in organic acids concentration in the reactor effluents was expected. However, peak values in the organic acids concentrations of the effluents from both of the microaeration reactors, and both of the enzyme and bacterial additive reactors were around $900 \mathrm{mg} / \mathrm{L}$ after one week, whereas the control reactor had an effluent organic acids concentration of around $700 \mathrm{mg} / \mathrm{L}$ after one week. The $30 \%$ higher concentrations of organic acids in the effluent from the treated reactors $(2 \mathrm{x}$ 
microaeration, $2 \mathrm{x}$ enzyme and bacterial additive), relative to the control reactor, may be an indication that the microaeration and the enzyme and bacterial additives increased the initial hydrolysis and acidogenesis rates.

By day 16, the concentration of organic acids in the effluents from all reactors was between 250 and $350 \mathrm{mg} / \mathrm{L}$, roughly $50 \%$ higher than the organic acids concentration of the feed. This suggests that there was still a large degree of sludge solubilisation occurring in all reactors. On day 20 , the microaeration tanks had organic acids concentrations in the effluent of approximately 120 and $170 \mathrm{mg} / \mathrm{L}$ as HOAc for the reactor treated with the high and low microaeration rate, respectively. In the weeks to follow, the organic acids concentrations in the effluents from both of the microaeration reactors continued to decline. The declining trend can be explained by the degradation of the soluble constituents, as was seen in the tCOD and sCOD profiles (Figure 4-32) presented in section 4.2.2.1.

The enzyme and control tanks had similar organic acids concentrations in their effluents after two weeks, and followed somewhat similar trends throughout the experiment. After two months, organic acids concentrations of the enzyme and control tanks began to decline consistently from around $250-300 \mathrm{mg} / \mathrm{L}$ to $150-180 \mathrm{mg} / \mathrm{L}$, as HOAc, after 90 days. By the end of the experiments, the organic acids concentrations in the effluents from all of the tanks was less than $140 \mathrm{mg} / \mathrm{L}$ as HOAc, however the effluent from the microaeration tanks had roughly half the concentration of organic acids in the effluent from the enzyme and control tanks. 


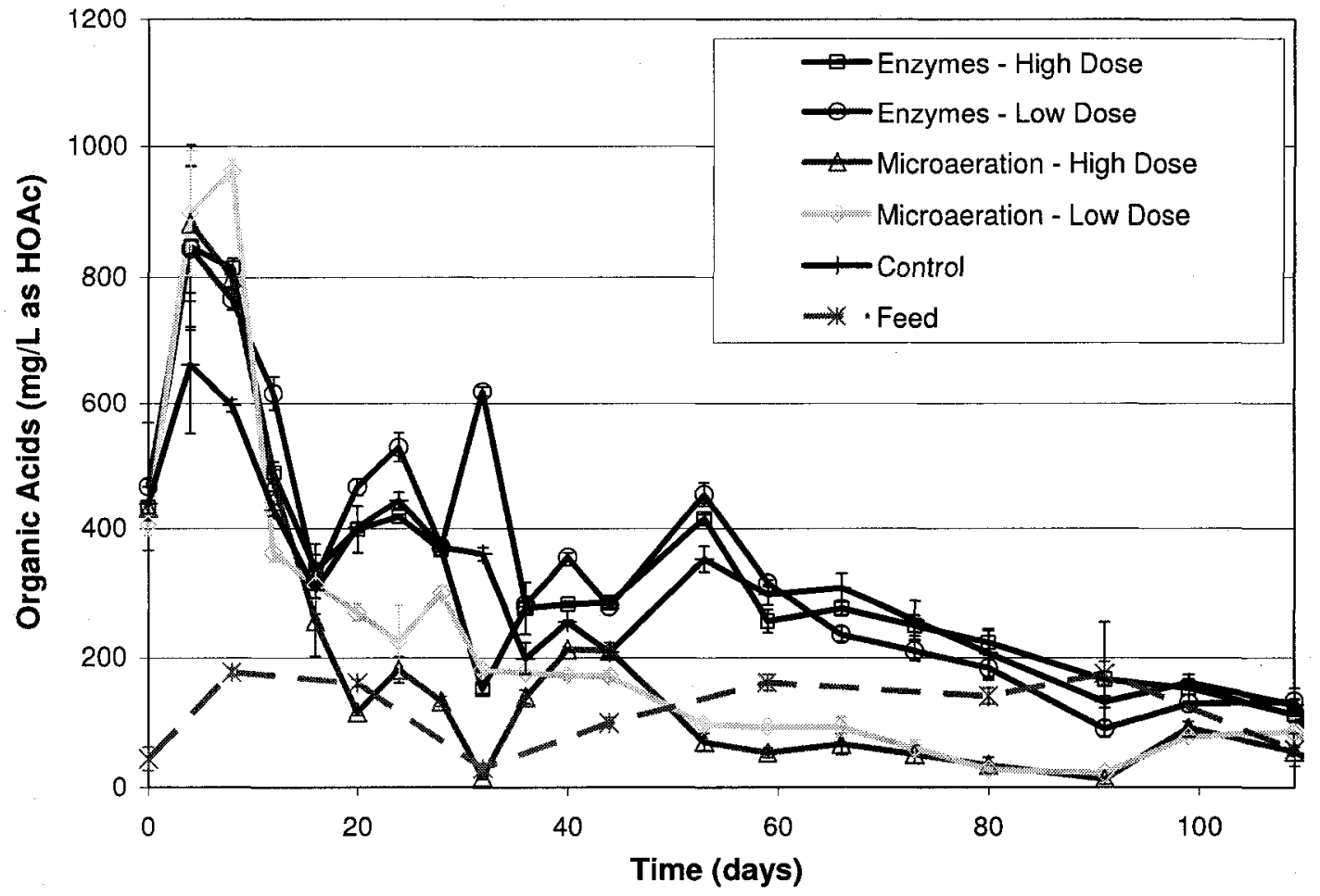

Figure 4-34: Profiles of the volatile (organic) acids concentrations in the influent and effluents from the continuous flow reactors

\subsubsection{Protein and Carbohydrate}

The protein concentrations of all of the effluents were consistently quite low for the test method used. In the first phase of experiments, raw (undiluted) primary sludge samples had an initial protein concentrations of approximately 1900 and $2500 \mathrm{mg} / \mathrm{L}$ for the first and second sludge batches respectively. Similarly, the initial protein concentration of the raw primary sludge used to seed each of the continuous flow reactor had an initial protein concentration of $1850 \mathrm{mg} / \mathrm{L}$. The synthetic wastewater used to feed the reactor had a protein concentration of only $10-20 \mathrm{mg} / \mathrm{L}$. This value was obtained by measuring samples of concentrated wastewater to achieve measurable protein concentrations between 400 and $1000 \mathrm{mg} / \mathrm{L}$. 
Profiles of the effluent protein concentrations are presented in Figure 4-35. The profiles generally follow the same trends as the influent profile line, with the exception of the high protein concentration measured in the effluent from the high dose microaeration reactor on day 8 , and the low protein concentration measured in the effluent from the control reactor on day 44. The former is the result of the washout of suspended solids in the early stages of operation, the latter can be explained by experimental error due to the low protein concentrations measured. For the reasons described in the previous paragraph, the protein assay was intended for protein levels greater than $100 \mathrm{mg} / \mathrm{L}$, and was unsuitable for the determination of minor variances in the effluent protein concentrations that may have been occurred throughout the continuous flow reactor tests.

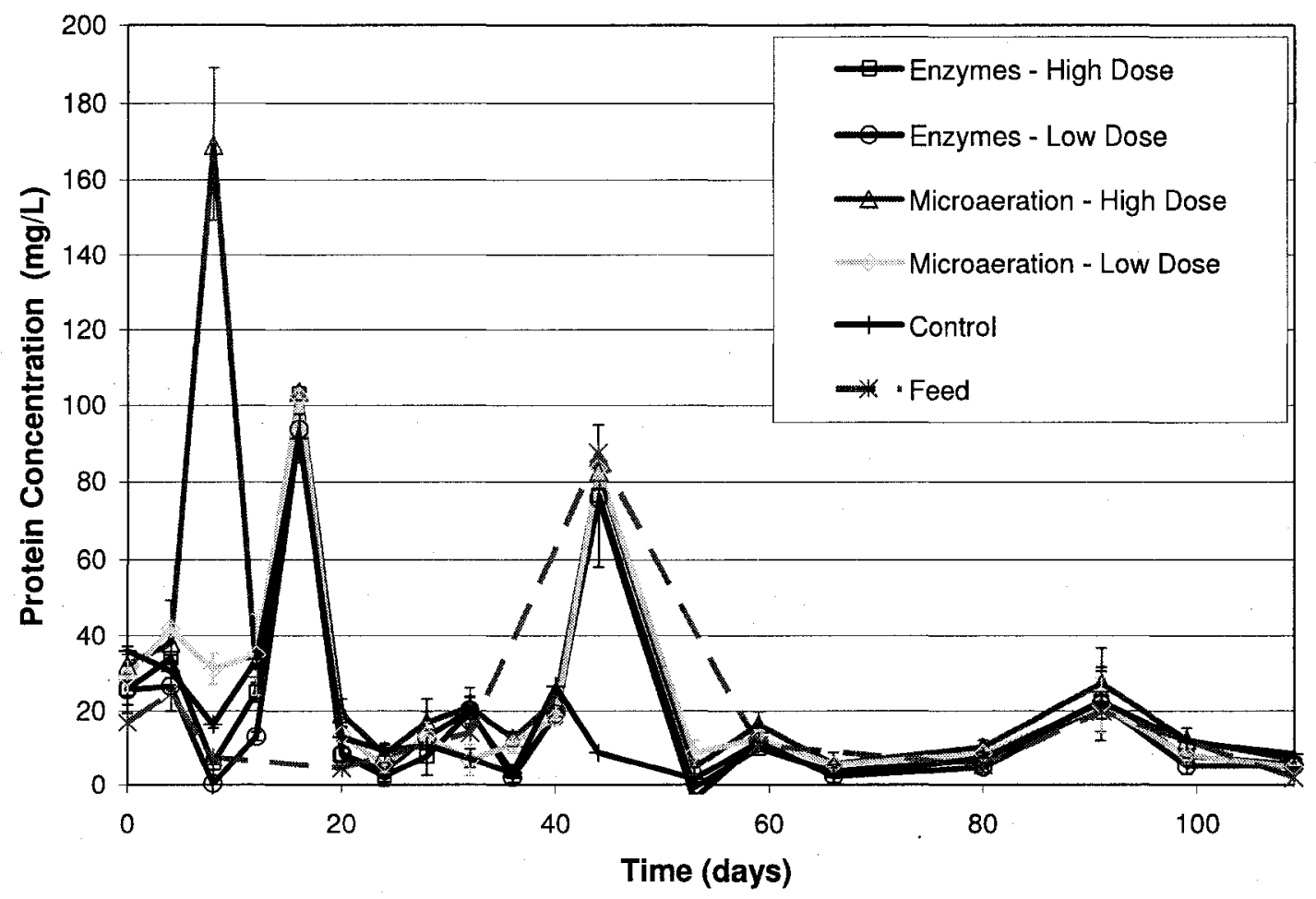

Figure 4-35: Profiles of the protein concentrations in the influent and effluents from the continuous flow reactors 
The profiles of the carbohydrate concentrations in the effluents from the continuous flow reactors are presented in Figure 4-36. Similar to the effluent protein concentration profiles, the carbohydrate concentrations in the effluent from all reactors were generally quite low, with the exception of the high peak concentrations measured in the effluent from the microaeration reactors on day 8 . These high carbohydrate concentrations were the result of the suspended solids in the effluent samples, which were washed out of the reactors in the first week.

By day 16 , the carbohydrate concentrations of the effluents from all of the reactors were between 15 and $20 \mathrm{mg} / \mathrm{L}$. After this point, the effluent carbohydrate concentrations from all reactors remained fairly consistent for the duration of the experiment. From day 60 to day 90, weekly measurements showed a very consistent effluent carbohydrate concentration of between 12 to $15 \mathrm{mg} / \mathrm{L}$, while the feed was around $8 \mathrm{mg} / \mathrm{L}$. This suggests that sludge solubilisation in the form of carbohydrate release was occurring. After 90 days, the influent and effluent carbohydrate concentrations from all reactors were $10 \mathrm{mg} / \mathrm{L}$, which may be the result of a decrease in the sludge solubilisation.

Some occasional peaks in the effluent carbohydrate concentration profiles for the enzyme an bacterial reactors were expected as a result of the bi-weekly Septaid Powder ${ }^{\mathrm{TM}}$ additions, since wheat bran, which is a significant source of carbohydrates, is the carrier for the bacteria and enzymes. The additive contained approximately $650 \mathrm{mg}$ of carbohydrates per gram of Septaid Powder ${ }^{\mathrm{TM}}$, which is equivalent to $65 \%$ of the mass. This represents an instantaneous increase of $2600 \mathrm{mg}$ and $1300 \mathrm{mg}$ of carbohydrates into 
the $33.4 \mathrm{~L}$ system, for the reactors treated with the high and low doses of the additive respectively. Effluent samples from the enzyme and bacterial additive reactors were collected one hydraulic time (3.6 days) after the addition of the additives, to attempt to measure a direct increase in the effluent carbohydrate concentrations as a result of the enzyme and bacterial additive, however no definitive and synchronised increases were ever measured. This could be due to the retention of the wheat bran flakes in the reactors, resulting in a slow release of carbohydrates to the soluble phase as the flakes degrade.

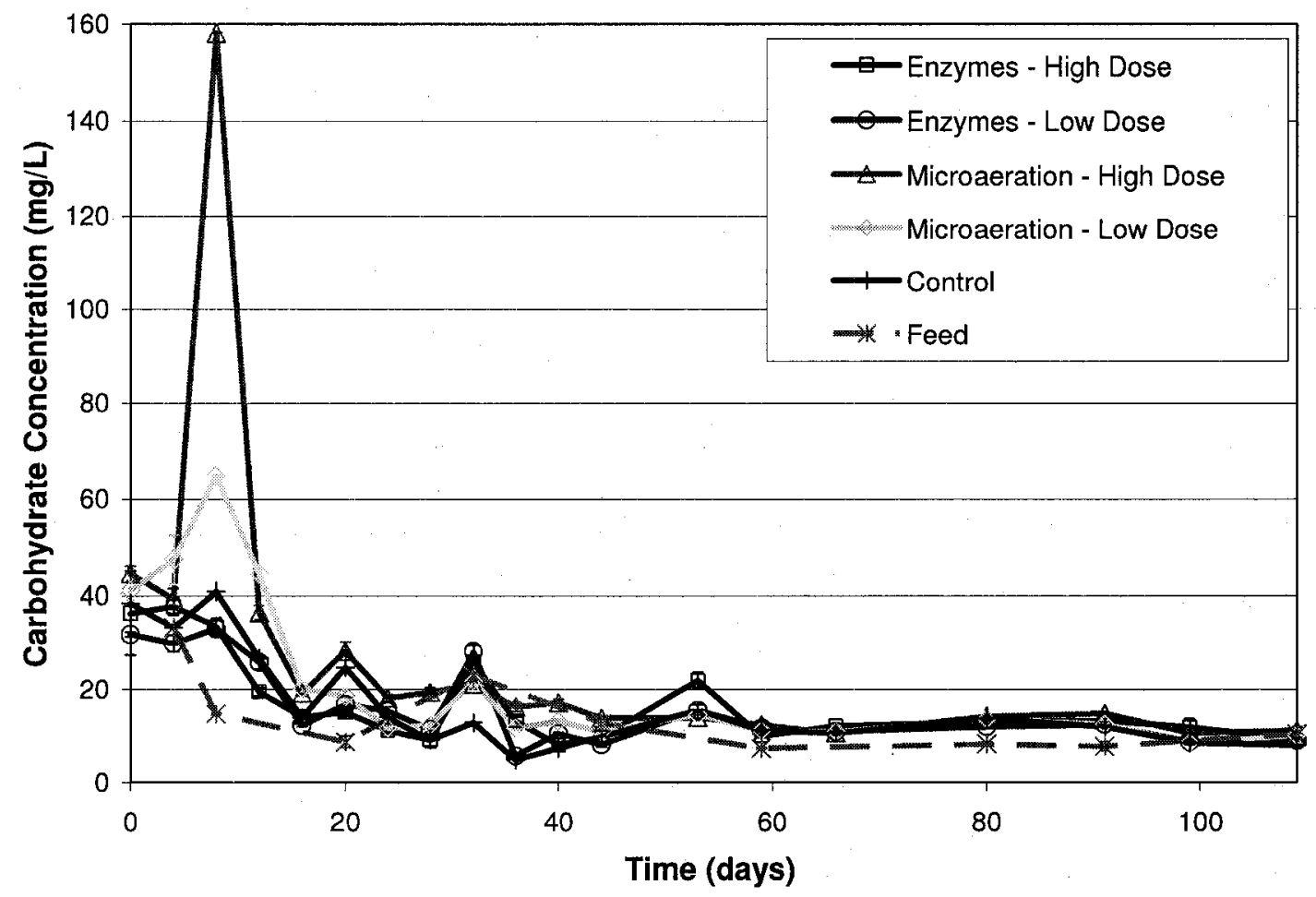

Figure 4-36: Profiles of the carbohydrates concentration in the influent and effluents from the continuous flow reactors 


\subsubsection{Ammonia and Nitrate}

The profiles of the ammonia concentrations are presented in Figure 4-37. Throughout the experiment, inconsistent ammonia concentrations were measured in the effluents from all of the reactors, and the influent. One discernable trend for all reactors is the increased ammonia concentrations in the effluent from all reactors, relative to the influent concentrations. The generation of ammonia within the reactors implies that there was some degradation of nitrogen containing compounds within the reactors. Also, the presence of ammonia confirms that the conditions in the reactors are reduced, and that the degradation of these nitrogen containing compounds occurred under anaerobic conditions.

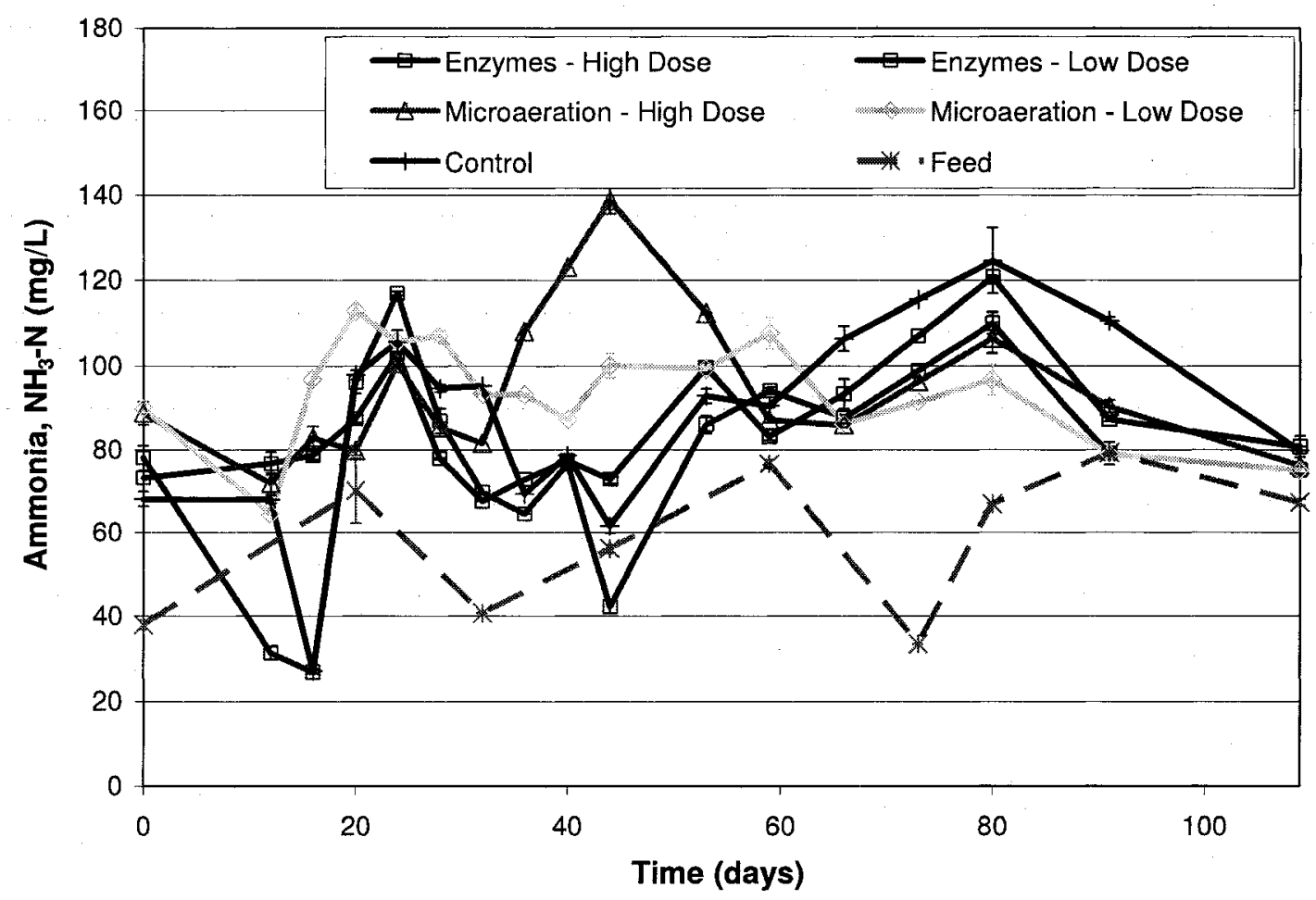

Figure 4-37: Profiles of the ammonia concentrations in the influent and effluents from the continuous flow reactors 
Biweekly tests on the reactor effluents confirmed the absence of nitrates. In all tests, the measured nitrate concentrations were less than $1.0 \mathrm{mg} / \mathrm{L}$, and often the measured nitrate concentration was below zero, sometimes up to $-1.0 \mathrm{mg} / \mathrm{L}$. This implies that the nitrate concentrations were below detectable levels, or within the range of the sampling error and sensitivity to interfering substances. The tests were useful for confirming anaerobic conditions, particularly in the microaeration reactors which could not be included in the gas phase analysis.

\subsubsection{Gas Phase Analysis}

During the continuous flow reactor experiments, the gas generated from the control reactor, and both of the reactors that were treated with the enzyme and bacterial additive was collected in $3.0 \mathrm{~L}$ Tedlar gas sampling bags. The two microaeration reactors were vented to the laboratory exhaust system due to the excessive amounts of off gas as a result of the microaeration treatments. The gas volumes collected were recorded in the early stages of reactor operation to attempt a carbon mass balance, however this was later determined to be unachievable for a number of reasons. First, leaks in the seams connecting the lids to the reactors were susceptible to failure. In the early stages of the continuous flow reactor experiments, there was a consistent smell of biogas around both of the enzyme and bacterial additive reactors and the control reactors. Second, when analysing the gas sample using the GC instrument, there was a consistent infiltration of air into the sample. Various attempts were made to reduce the introduction of air into the sample, but finally an adjustment in the programs integration function was made to quantify the amount of air in the sample, as a combined percent nitrogen and oxygen. 
Gas samples were withdrawn periodically from the gas sampling bags using a $1.0 \mathrm{~mL}$ syringe, and tested for methane, carbon dioxide, and a combined nitrogen and oxygen, as air, by GC. A plot of the gas compositions measured is presented in Figure 4-38. All gas samples had detectable amounts of methane by the first testing period on day 14 , which indicates that methanogenesis was able to occur in the early stages of operation, in all reactors. As expected, the methane concentration increased towards the end of the experiment, however this is more of a reflection on the increasing methane concentration in the headspace, which was initially entirely air.

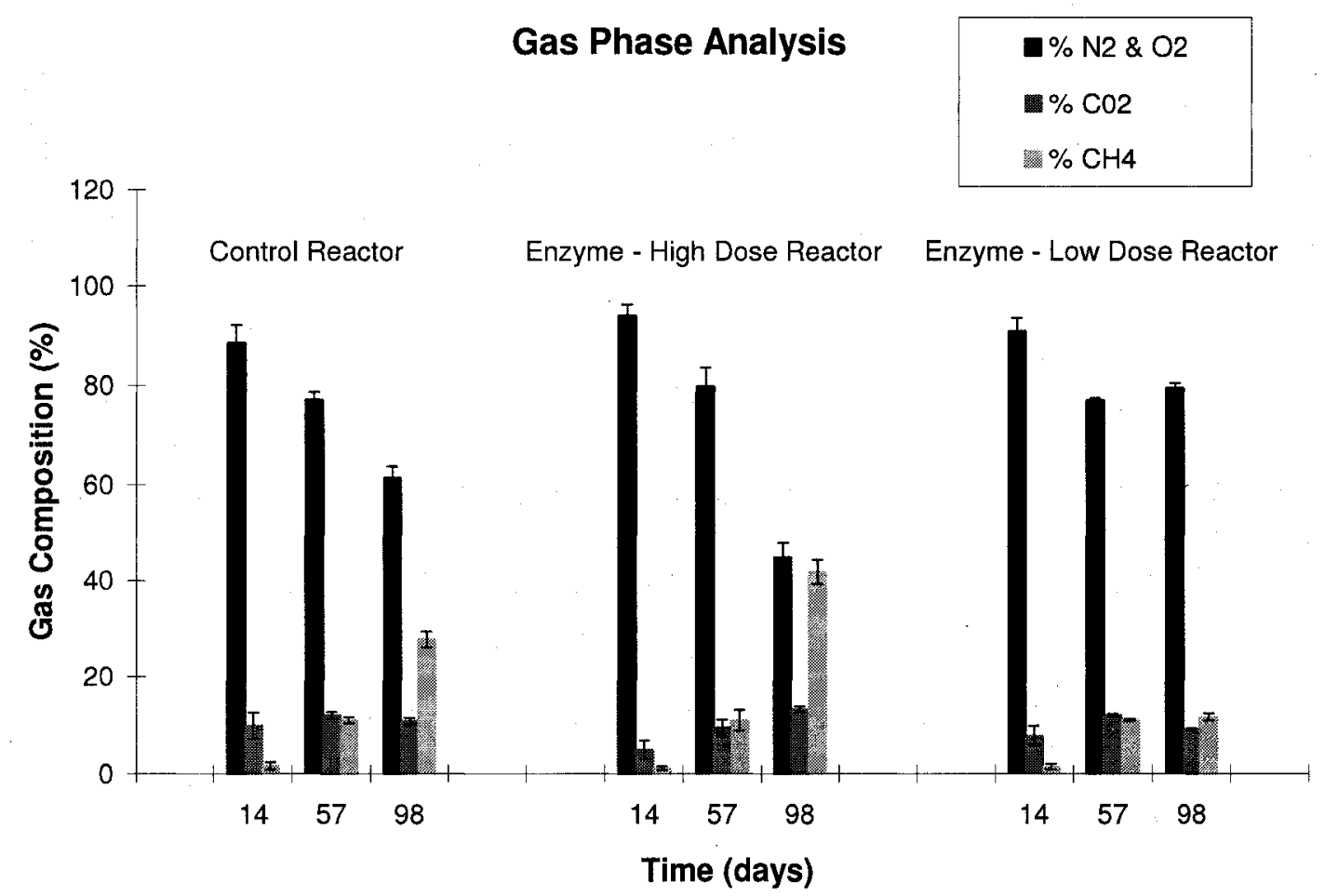

Figure 4-38: Gas phase analysis of the headspace gas collected from the two enzyme and bacterial additive reactors, and the control reactor 


\subsubsection{Oxygen Reduction Potential, $\mathrm{pH}$ and Dissolved Oxygen}

The oxidation reduction potential (ORP), $\mathrm{pH}$ and dissolved oxygen (DO) of the reactor effluents were measured, however the harsh nature of the wastewater and sludge caused a rapid deterioration of the electrode membranes which reduced their sensitivity and reliability of the measurements. To confirm the following, a succession of tests was performed with alternating measurements between the test sample and the calibration standard. Between each measurement the electrodes was carefully rinsed off with distilled water.

The ORP and $\mathrm{pH}$ of the reactor effluents were both measured using a Orion Model 420A bench-top pH meter with an Orion ORP Triode ${ }^{\mathrm{TM}}$ (Orion Corporation, Espoo, Finland). Throughout the experiments, the ORP and $\mathrm{pH}$ measurements were very inconsistent. The ORP readings on the same sample varied by $10 \mathrm{mV}$ for almost every successive measurement. ORP values ranged from +20 to $-20 \mathrm{mV}$ for the three completely anaerobic reactors, and +2 to $-45 \mathrm{mV}$ for the microaerobic reactors. The $\mathrm{pH}$ measurements were slightly more consistent, varying by roughly 0.5 between measurements on the same sample, and were sufficiently reliable to determine that the $\mathrm{pH}$ of the effluents was consistently near neutral, with an error margin of plus or minus 0.5 . DO tests on a continuously aerated sample of distilled water were performed to monitor the DO sensor. Initial DO measurements on the aerated sample confirmed near saturated conditions of $8.9 \mathrm{mg} / \mathrm{L}$, however successive readings on the wastewater samples reduced the sensitivity of the probe, and the subsequent DO readings of air-saturated water sample, as shown in Figure 4-39. 


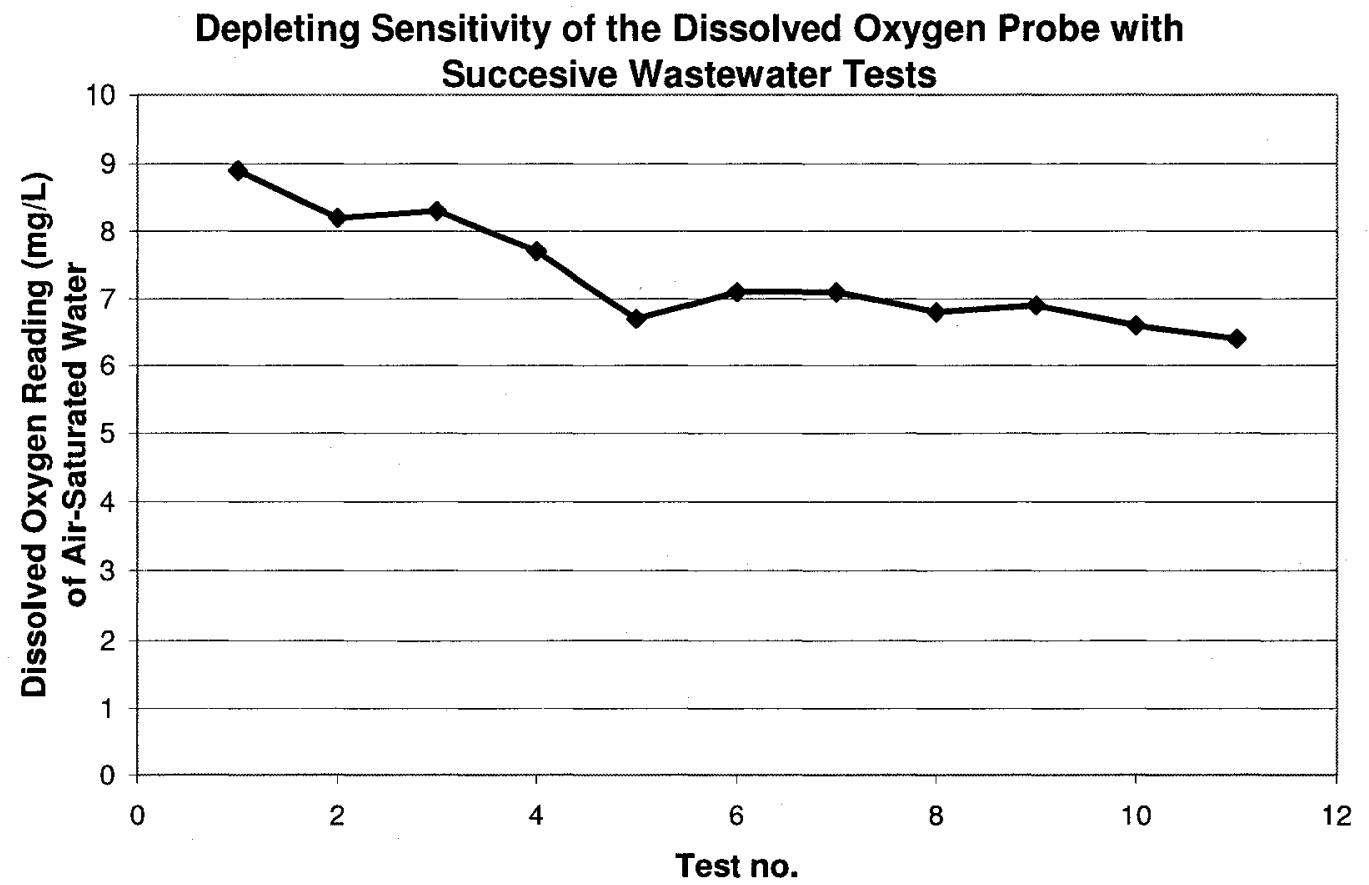

Figure 4-39: Dissolved oxygen measurements on the sample of air-saturated water to show how wastewater reduces the sensitivity of the DO probe

The DO in various locations of the first and second compartments of the continuous flow reactors was occasionally measured. Although the DO measurements were inexact due to the deterioration of the membrane, attempts were made with fresh membranes to confirm with the presence of aerobic zones within the microaerobic reactors. DO measurements in the first compartments of the microaerobic reactors, in proximity to the air diffusers, confirmed aerobic zones with DO readings up $0.8 \mathrm{mg} / \mathrm{L}$, while the other three completely anaerobic reactors had maximum DO concentrations of $0.3 \mathrm{mg} / \mathrm{L}$, which was considered to be near the low limit of the sensor. 


\section{Conclusions}

The purpose of this study was to investigate and compare the effects of three treatment techniques (enzyme and bacterial additives, microaeration, and grinding) on septic tank performance and sludge accumulation rates. The research intended to see if the treatments enhance the digestion rate and eventually maximize the pump-out intervals, and improve the effluent quality using simple means that do not require expensive or complex modifications to septic tanks.

Grinding treatments help improve the degradation of primary sludge during the batch reactor experiments. The latter was marked by a slight increase in the volatile solids destruction, ammonia generation and protein release. The benefits of the grinding cycles are far outweighed by the added cost and complexity of the system when considered as a household application. The effects of the grinding cycles on the primary sludge samples were not as beneficial as the results reported for other disintegration techniques that were used to improve the anaerobic degradation of waste activated sludge (WAS). Primary sludge is young sludge and does not have the same type of microbial floc formations that are typically found in waste activated sludge. As a result, the beneficial results from the disintegration of the WAS were not seen when applied to primary sludge digestion in batch reactors, operating at room temperature. 
In the batch reactor experiments with primary sludge, the enzyme and bacterial additive increased the rate of COD reduction, however the additive also increased the COD and carbohydrate concentrations of the system, which meant that the overall net COD reduction was minimal. The accumulation of soluble COD in the additive reactors, as with the control reactors, suggests also that the additive did not improve the methanogenesis phase of digestion. During the continuous flow experiments, the enzyme and bacterial additive had no significant improvement on the effluent quality relative to the control reactor. Enzyme and bacterial additives have been used in previous studies with mixed results (Jeganathan et al., 2007, Noyola and Tinajero, 2005, Barjenbruch and Kopplow, 2003, Higgins and Swartzbaugh, 1985). In these experiments, under the conditions tested, namely room temperature $\left(21-23^{\circ} \mathrm{C}\right)$, the enzyme and bacterial additive did not improve biodegradation rates.

Microaeration rates as low as $10 \mathrm{~mL} / \mathrm{min}$ effectively solubilised the COD of the system, and subsequently improved the degradation of organic acids, and the soluble COD. This suggests that microaeration improved the hydrolysis and the methanogenesis phases of digestion. Excessive microaeration rates hindered the settling conditions within the reactor, which lead to the high amounts of suspended solids in the effluent. In full-scale applications the microaeration rate should be carefully controlled. Using a filter at the outlet, as commonly used these days, would also protect the drainage tiles, leaching bed and subsequent effluent distribution network. 


\section{References}

American Public Health Association (APHA), American Water Works Association (AWWA) and Water Environment Federation (WEF) (2005). Standard methods for the examination of water and wastewater, 21 st ed., APHA/AWWA/WEF, Washington DC

Ayol, A. (2005a). Enzymatic treatment effects on dewaterability of anaerobically digested biosolids-I: performance evaluations. Process Biochemistry 40, 2427-2434

Barjenbruch, M., Kopplow, O. (2003). Enzymatic, mechanical and thermal pretreatments of surplus sludge. Advances in Environmental Research 7, 715-720

Bohm N., Kulicke, W.M. (1997). Optimization of the use of polyelectrolytes for dewatering industrial sludge of various origins. Colloid Polym. Sci. 275, 73-81

Bougrier, C., Carrère, H., Delgenès, J.P.(2006a). Solubilisation of waste activated sludge by ultrasonic treatment. Chem. Eng. J. 106, 163-169

Bougrier, C., Albasi, C., Delgenès, J.P., Carrère, H. (2006b). Effect of Ultrasonic, Thermal and Ozone Pre-treatments on Waste Activated Sludge Stabilization and Anaerobic Biodegradability. Chemical Engineering \& Processing 45, 711-718

Bradford, M.M. (1976). A rapid and sensitive method for the quantification of microgram quantities of protein utilizing the principle of protein-dye binding. Analytical Biochemistry 72, 248-254

Bruus, J.H., Nielson, P.H. (1992). On the stability of activated sludge flocs with implications to dewatering. Wat. Res. 26, 1597-1604

Canada Mortgage and Housing Corporation (CMHC) (2008). About Your House General Series: Your Septic System. website:

http://www.cmhc-schl.gc.ca/en/co/maho/gemare/gemare_009.cfm, accessed: 62008

Canadian Water and Wastewater Association. (CWWA)(2003). Water legislation and Substance/Quality Database. website: http://www.cwwa.ca/legislation/faqs/biosolid.htm, accessed 72008

City of Ottawa (2001). Drinking Water - Managing Your Septic System. website: http://www.ottawa.ca/city_services/water/wells/3_3_en.shtml, accessed: 62008

Clearford Industries Inc., (2008). Wastewater Systems Division. website: http://www.clearford.com/index 1.shtml, accessed: 72008

Dewil, R., Baeyens, J., Goutvrind, R. (2006). Ultrasonic Treatment of Waste Activated Sludge. American Institute of Chemical Engineers Environ. Prog. 25, 121-128 
Dohányos, M., Zábranská, J. Jenicek, P. (1997). Enhancement of sludge digestion by using of a special thickening centrifuge. Wat. Sci. Technol. 36(11), 145-153

Eskicioglu, C., Kennedy, K.J., Droste, R.L. (2006). Characterization of soluble organic matter waste activated sludge before and after thermal pretreatment. Water Research $\mathbf{4 0}$ $3725-3736$

Fang, M., Wong, J.W.C. (1999). Effects of lime amendment on availability of heavy metals and maturation in sewage sludge composting. Environ. Pollut. 106, 83-89

Gea, T., Barrena, R., Artola, A., Sanchez, A. (2007). Optimal bulking agent particle size and usage for heat retention and disinfection in domestic wastewater sludge composting. J. Waste Man. 27, 1108-1116

Gömeç, C.Y. (2006). Behavior of the Anaerobic CSTR in the Presence of Scum During Primary Sludge Digestion and the Role of pH, J. Env. Sci.. \& Health, Part A 41(6), 11171127

Goto, M., Shiramizu, D., Kodama, A., Hirose, T. (1999). Kinetic Analysis for Ammonia Decomposition in Supercritical Oxidation of Sewage Sludge. Ind. Eng. Chem. Res. 38, $4500-4503$

HACH Company (2005a). Chemical Oxygen Demand: Reactor Digestion Method, High Range Plus, 200-15,000 mg/L COD. Method 8000:1-8, DR2800 Spectrophotometer Procedures manual. Loveland $\mathrm{CO}$

HACH Company (2005b). Ammonia nitrogen: Salisylate Method, High Range, 0.4-50 $\mathrm{mg} / \mathrm{L} \mathrm{NH}_{3}$-N. Method 10031:1-4, DR2800 Spectrophotometer - Procedures manual. Loveland $\mathrm{CO}$

HACH Company (2005c). Chemical Oxygen Demand: Reactor Digestion Method, High Range Plus, 200-15,000 mg/L COD. Method 8000:1-8, DR2800 Spectrophotometer Procedures manual. Loveland $\mathrm{CO}$

HACH Company (2005d). Nitrate: Chromotropic Acid Method, High Range, 0.2-30 $\mathrm{mg} / \mathrm{L} \mathrm{N0} \mathrm{N}_{3}$-N. Method 10020:1-4, DR2800 Spectrophotometer - Procedures manual. Loveland $\mathrm{CO}$

HACH Company (2005e). Volatile Acids: Esterification Method, 27-2800 mg/L as HOAc, Method 8196:1-6, DR2800 Spectrophotometer - Procedures manual. Loveland $\mathrm{CO}$

Hammond, C., Tyson T.(1991). Septic Tank Design and Construction. University of Georgia, Cooperative Extension Service. Report. Athens GA 
Higgins, G., Swartzbaugh, J.T. (1985). Improved municipal wastewater sludge treatment through enzymatic hydrolysis. Symposium Papers - Energy from Biomass and Wastes 2 , $791-810$

Jeganathan, J., Nakhla, G., Bassi, A., (2007). Oily wastewater treatment using a novel hybrid PBR-UASB system. J. Chemosphere 67, 1492-1501

Johansen J.-E., Bakke, R. (2006). Enhancing hydrolysis with microaeration. Water Sci. Technol. 58(8), 43-50

Kropp, J., Dichtl, N. (2001). Sludge Production and Characterization. Published in: Sludge into Biosolids, Spinosa, L., Vesilind, P. A. (editors). IWA Publishing, London UK pp.19-39

Lewis, A. (2006). Regulatory framework for biosolids management in Canada. Greater Vancouver Regional District, Presented in 2006 British Columbia Water and Waste Association (BCWWA) conference

Luostarinen, S., Sanders, W., Kujawa-Roeleveld, K., Zeeman, G. (2006). Effect of temperature on anaerobic treatment of black water in UASB-septic tank systems. $J$. Bioresource Technol. 98, 980-986

Metcalf \& Eddy, Inc. (2003) Wastewater Engineering: Treatment and Reuse, $4^{\text {th }}$ ed., Tata McGraw-Hill Publishing Company, New York, NY pp. 1447-1628

Morris, D.L. (1948). Quantitative determination of carbohydrates with Dreywood's anthrone reagent. Science 107, 254-255

Mukherjee, R.S., Levine, A.D. (1992). Chemical solubilization of particulate organics as a pretreatment approach. Water. Sci. Technol. 27, 2289-2292

Müller, J. (2003). Comminution of organic material. J. Chem. Eng. Technol. 26, 207-217

Neyens, E., J. Baeyens, (2003a). A review of classic Fenton's peroxidation as an advanced oxidation technique. J. Hazardous Materials B98, 33-50

Noyola, A., Tinajero, A. (2005). Effect of biological additives and micronutrients on the anaerobic digestion of physiochemical sludge. Water Sci. Technol. 52(1-2), 275-281

Nybroe, O., Jørgensen, P.E., Henze, M. (1992). Enzyme activities in waste water and activated sludge. Wat. Res. 26(5), 579-584

Oleszkiewicz, J.A., Mavinic, D.S. (2002). Wastewater biosolids: an overview of processing, treatment, and management. J. Environ. Eng. Sci. 1, 75-88

Ontario Building Code (OBC) (1997). Part 8: Sewage Systems. OBC 8:1-10 
Ortega, L., Guiot S.R., Tartakovsky, B. (2007). Laboratory study on the effects of electrolysis on the accumulation rates of wastewater sludges. BRC-NRI final report prepared for Clearford Industries Inc

Pérez-Elvira, S.I., Nieto Diez P., Fdz-Polanco, F. (2006). Sludge minimisation technologies. Rev. Environ. Sci. Biotechnol. 5, 375-398

Pirt S.J., Lee, Y.K. (1983). Enhancement of methanogenesis by traces of oxygen in bacterial digestion of biomass. FEMS Microbial. Lett. 18, 61-63

Puchajda B., Oleszkiewicz, J. (2006). Themophillic anaerobic acid digestion of biosolids: hydrolysis, acidification, and optimization of retention time in acid digestion. J. Environ. Eng. Sci. 5, 187-195

Saktaywin, W., Tsuno, H., Nagare, H., Soyama, T., Weerapakkaroon, J. (2005). Advanced sewage treatment process with excess sludge reduction and phosphorus recovery. Wat. Res. 39, 902-910

Sheldon Farm Septic Tank Service, Inc. (2008). How Septic Systems Work. website: http://www.sheldonfarmseptic.com/How_Septic_Systems_Work.html, accessed: 72008

Schmitz, U., Berger, C.R., Orth, H. (2000). Protein analysis as a simple method for the quantitative assessment of sewage sludge disintegration. Wat. Res. 34(14), 3682-3685

Song, J.J., Takeda, N., Hiraoka, M. (1992). Anaerobic treatment of sewage sludge treated by catalytic wet oxidation process in upflow anaerobic sludge blanket reactors. Wat. Sci. Tech. 26, 867-875

Stein Carter, J.L. (2004). Amino Acids and Proteins. U. Cincinnati - Clermont College website: http://biology.clc.uc.edu/courses/bio104/protein.htm, accessed: 72008

Thurston County Public Health and Social Services Department (2007). Washington DC, website: http://www.co.thurston.wa.us/health/ehoss/index.html, accessed: 72008

United States Environmental Protection Agency (US EPA) (2000a). Decentralized Systems Technology Fact Sheet - Small Diameter Gravity Sewers. EPA-832-F-00-038; US EPA, Washington DC

United States Environmental Protection Agency (US EPA) (2000b). Decentralized Systems Technology Fact Sheet - Aerobic Treatment. EPA-832-F-00-031; US EPA, Washington DC

United States Environmental Protection Agency (US EPA) (1999). Environmental Regulations and Technology - Control of Pathogens and Vector Attraction in Sewage Sludge. EPA-625/R-92-013; US EPA, Washington DC 
Valo, A., Carrère, H., Delgenès, J.P. (2004). Thermal, chemical and thermo-chemical pre-treatment of waste activated sludge for anaerobic digestion. J. Chem. Technol.

Biotechnol. 79, 1197-1203

Vesilind, P.A., Spinosa, L. (2001). Production and Regulations. Published in: Sludge into Biosolids, Spinosa, L., Vesilind, P. A. (editors). IWA Publishing, London UK pp.364-383

Vlyssides, A.G., Karlis, P.K. (2004). Thermal-alkaline solubilisation of waste activated sludge as a pre-treatment stage for anaerobic digestion. J. Bioresource Technol. 91, 201206

Weemaes, M., Grootaerd, H. , Simoens, F., Verstraete, W. (2000). Anaerobic digestion of ozonized biosolids. Wat. Res. 8, 2330-2336

Weemaes, M., Verstraete, W. (1998). Evaluation of Current Wet Sludge Disintegration Techniques. J. Chem. Technol. Biotechnol. 73, 83-92

Wong, J.W.C., Fang, M. (2000). Effects of lime addition on sewage sludge composting process. Wat. Res. 34, 3691-3698

Wong, J.W.C., Selvam, A. (2006). Speciation of heavy metals during co-composting of sewage sludge with lime. J. Chemosphere 63, 980-986

Wong, L., Henry, J.G., (1988). Bacterial leaching of heavy metals from anaerobically digested sludge. Published in: Biotreatment systems vol. II, Wise, D.L. (editor). CRC Press. Florida USA, pp.125-169

Wong, W.T., Chan, W.I., Liao, P.H. Lo, K.V. (2006). A hydrogen Peroxide/Microwave Advanced Oxidation Process for Sewage Sludge Treatment. J. Env. Sci. \& Health - Pt. A 41, 2623-2633

Yin, X., Han, P., Lu, X., Wang, Y. (2004). A Review on the Dewaterability of BioSludge and Ultrasound Pretreatment. J. Ultrasonics Sonochemistry 11, 337-348

Zaveri, R.M., Flora, J.R.V. (2002). Laboratory septic tank performance response to electrolytic stimulation. Wat. Res. 36, 4513-4524 


\section{Appendix A: Particle Size Distribution (PSD) Analysis}

Appendix A1: Control (no grinding) PSD Histogram

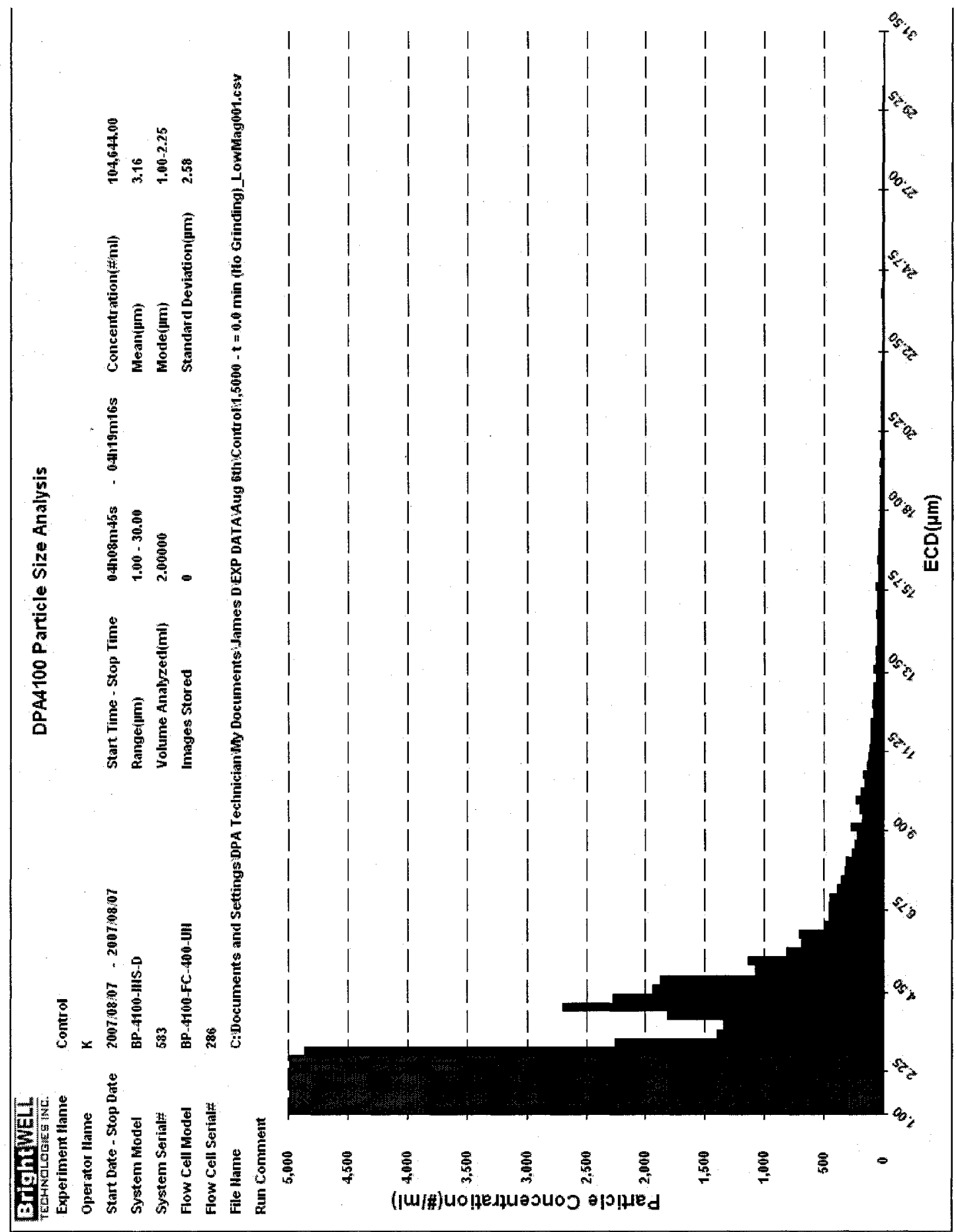


Appendix A2: Low Grinding $\left(t_{d}=1.0 \mathrm{~min}\right)$ PSD Histogram

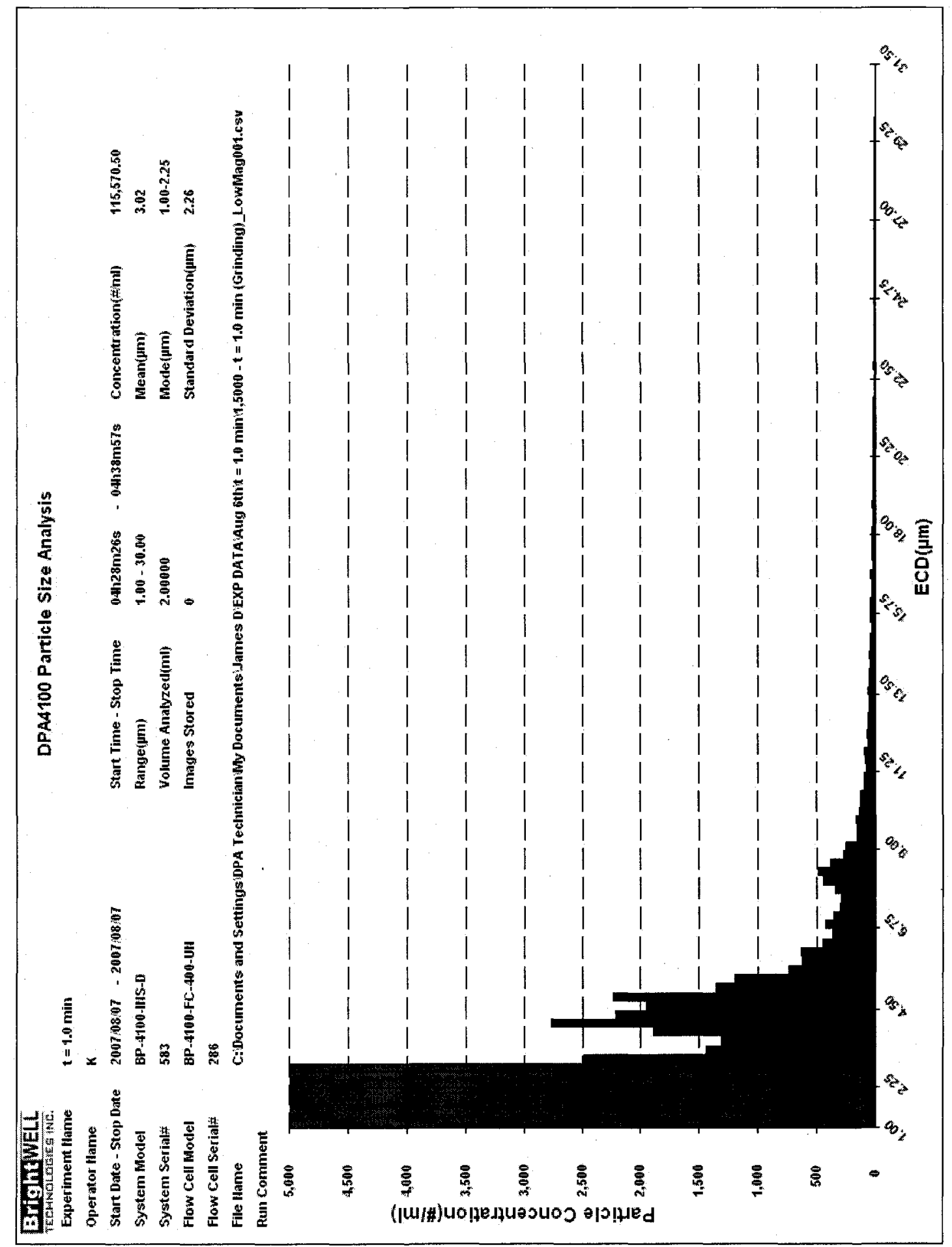


Appendix A3: Moderate Grinding $\left(t_{d}=2.0\right.$ min $)$ PSD Histogram

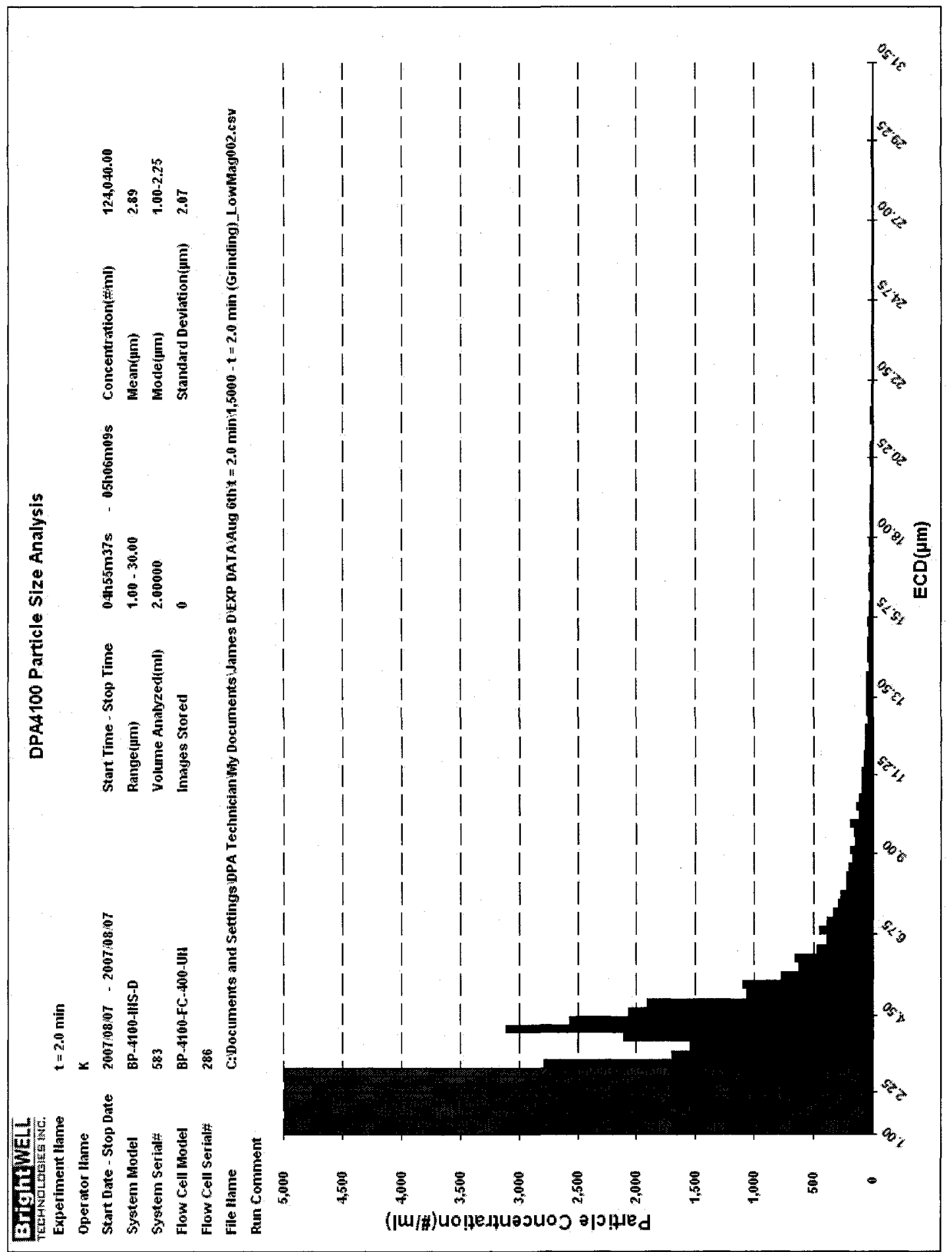




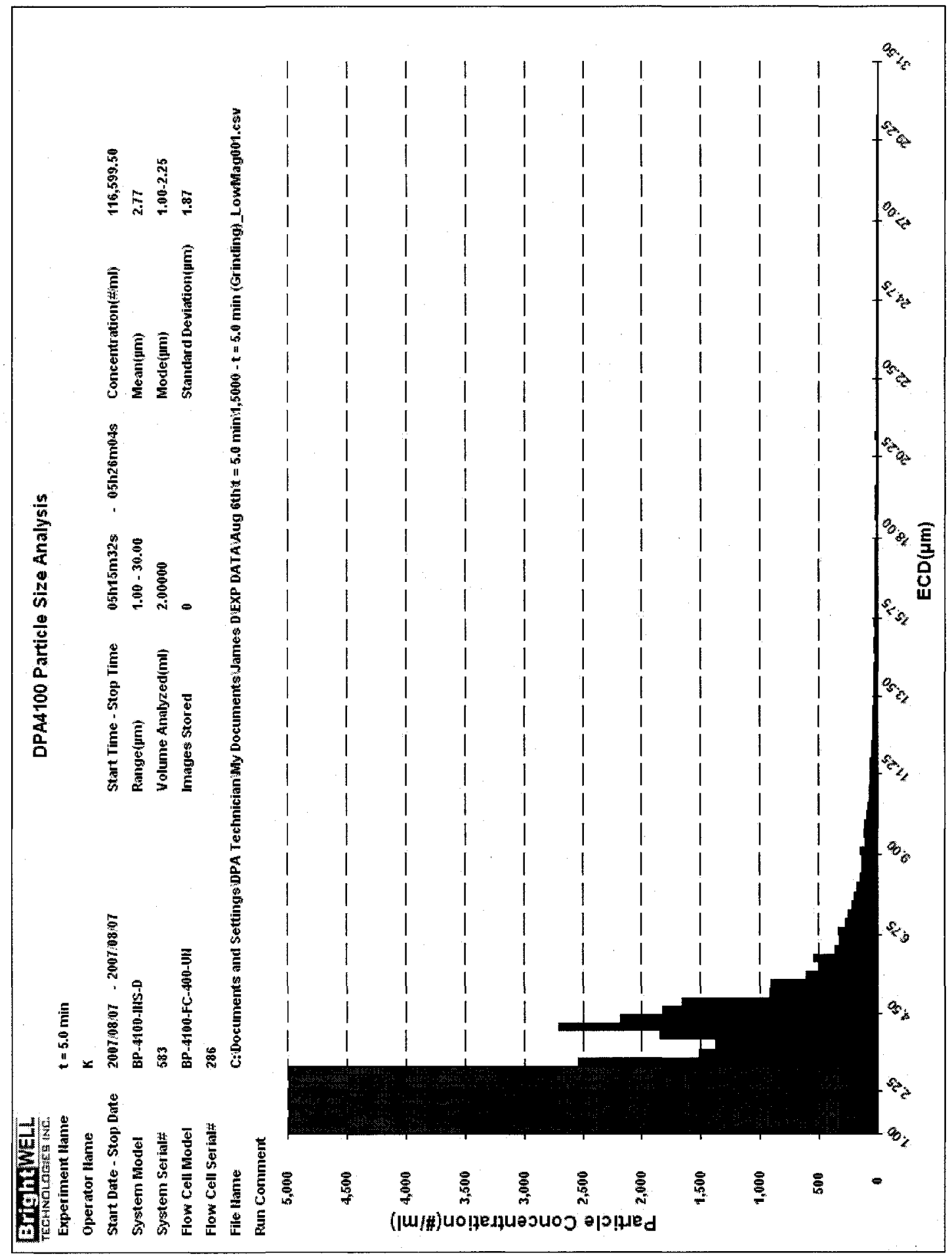




\section{Appendix B: Raw Data - Batch Reactor Tests}

\section{Appendix B1: Total and Volatile Solids}

\begin{tabular}{|c|c|c|c|c|c|c|c|c|}
\hline \multicolumn{5}{|c|}{ Sludge Batch 71 - Grinding \& Migroaeration : } & \multicolumn{4}{|c|}{ 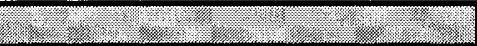 } \\
\hline $\begin{array}{r}\text { Test Date: } \\
\text { Zeroed Time: }\end{array}$ & $\begin{array}{c}\text { 2-Aug } \\
0\end{array}$ & $\begin{array}{c}\text { 11-Aug } \\
9\end{array}$ & $\begin{array}{c}\text { 18-Aug } \\
16\end{array}$ & $\begin{array}{c}28-A u g \\
26\end{array}$ & $\begin{array}{c}\text { 2-Aug } \\
0\end{array}$ & $\begin{array}{c}\text { 11-Aug } \\
9\end{array}$ & $\begin{array}{c}18-A u s \\
16\end{array}$ & $\begin{array}{c}28-\text { Aug } \\
26\end{array}$ \\
\hline Elasuri. & Total S & lids 19 & I. & . & Volatile & Sol10s & 9IL) & 17.m.n. \\
\hline $\begin{array}{l}3 \text { Control 'A' } 4 \% \\
4\end{array}$ & $\begin{array}{l}41.3 \\
41.3\end{array}$ & $\begin{array}{l}28.7 \\
29.0\end{array}$ & $\begin{array}{l}28.2 \\
31.3\end{array}$ & $\begin{array}{l}28.8 \\
28.3\end{array}$ & $\begin{array}{l}33.2 \\
33.2\end{array}$ & $\begin{array}{l}21.5 \\
21.4\end{array}$ & $\begin{array}{l}20.8 \\
23.8\end{array}$ & $\begin{array}{l}21.2 \\
20.8\end{array}$ \\
\hline $2 \%$ & $\begin{array}{l}20.7 \\
20.7\end{array}$ & $\begin{array}{l}16.0 \\
16.3\end{array}$ & $\begin{array}{l}15.5 \\
15.1\end{array}$ & $\begin{array}{l}17.8 \\
15.9\end{array}$ & $\begin{array}{l}16.6 \\
16.6\end{array}$ & $\begin{array}{l}11.9 \\
12.1\end{array}$ & $\begin{array}{l}11.6 \\
11.2\end{array}$ & $\begin{array}{l}13.6 \\
11.9\end{array}$ \\
\hline 2. & 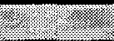 & : & 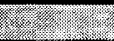 & 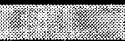 & 207 & (1) & - & (2) \\
\hline $\begin{array}{l}9 \text { Grinding } 4 \% t=5 \mathrm{~min} \\
10\end{array}$ & $\begin{array}{l}41.3 \\
41.3\end{array}$ & $\begin{array}{l}30.0 \\
30.4\end{array}$ & $\begin{array}{l}29.2 \\
30.1\end{array}$ & $\begin{array}{l}28.7 \\
27.0\end{array}$ & $\begin{array}{l}33.2 \\
33.2\end{array}$ & $\begin{array}{l}22.1 \\
17.4\end{array}$ & $\begin{array}{l}21.8 \\
17.4\end{array}$ & $\begin{array}{l}20.1 \\
15.4\end{array}$ \\
\hline $\mathrm{t}=2 \mathrm{~min}$ & 41.3 & 28.2 & 28.4 & 27.5 & 33.2 & 20.9 & 21.1 & 20.0 \\
\hline 22 & 41.3 & 28.5 & 29.0 & 26.9 & 33.2 & 21.1 & 21.6 & 19.4 \\
\hline $\mathrm{t}=1 \mathrm{~min}$ & 41.3 & 26.2 & 27.5 & 27.1 & 33.2 & 19.3 & 20.5 & 19.9 \\
\hline 34 & 41.3 & 29.3 & 28.4 & 18.0 & 33.2 & 21.9 & 21.0 & 10.5 \\
\hline $2 \% t=5 \min$ & 20.7 & 16.3 & 16.0 & 15.8 & 16.6 & 12.1 & 11.9 & 11.7 \\
\hline 12 & 20.7 & 16.5 & 16.2 & 16.5 & 16.6 & 12.4 & 12.1 & 12.3 \\
\hline $\mathrm{t}=2 \mathrm{~min}$ & 20.7 & 16.5 & 15.7 & 14.8 & 16.6 & 12.3 & 11.7 & 10.8 \\
\hline 24 & 20.7 & 15.9 & 16.8 & 15.0 & 16.6 & 11.8 & 12.6 & 11.0 \\
\hline $\mathrm{t}=1 \mathrm{~min}$ & 20.7 & 15.9 & 15.2 & 15.2 & 16.6 & 12.0 & 11.3 & 11.3 \\
\hline 36 & 20.7 & 15.6 & 15.3 & 15.4 & 16.6 & 11.7 & 11.3 & 11.5 \\
\hline (2) & 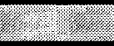 & 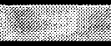 & :- & 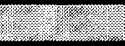 & 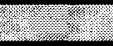 & & 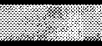 & 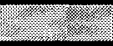 \\
\hline $\begin{array}{l}39 \text { Aeration } \\
40\end{array}$ & $\begin{array}{l}41.3 \\
41.3\end{array}$ & $\begin{array}{l}30.8 \\
30.3\end{array}$ & $\begin{array}{l}28.8 \\
29.0\end{array}$ & $\begin{array}{l}28.2 \\
31.6\end{array}$ & $\begin{array}{l}33.2 \\
33.2\end{array}$ & $\begin{array}{l}23.1 \\
22.8\end{array}$ & $\begin{array}{l}21.3 \\
21.6\end{array}$ & $\begin{array}{l}20.7 \\
22.2\end{array}$ \\
\hline $2 \%$ & 20.7 & 16.4 & 15.5 & 17.1 & 16.6 & 12.4 & 11.6 & 12.8 \\
\hline 38 & 20.7 & 19.6 & 19.2 & 14.5 & 16.6 & 15.0 & 14.7 & 10.7 \\
\hline$=0$ & Six: & W & 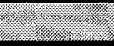 & $\sqrt{2}=$ & 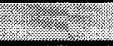 & 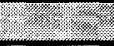 & 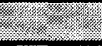 & 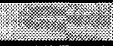 \\
\hline
\end{tabular}


Sludge Batch \#2 - Enzymer Bacterial Addives . I .

\begin{tabular}{|c|c|c|c|c|c|c|c|c|}
\hline $\begin{array}{l}\text { Test Date: } \\
\text { Zeroed Time: }\end{array}$ & $\begin{array}{c}\text { 7-Aug } \\
0\end{array}$ & $\begin{array}{c}11-\text { Aug } \\
4\end{array}$ & $\begin{array}{c}\text { 18-Aug } \\
11\end{array}$ & $\begin{array}{c}28-A u g \\
21\end{array}$ & $\begin{array}{c}\text { 7-Aug } \\
0\end{array}$ & $\begin{array}{c}\text { 11-Aug } \\
4\end{array}$ & $\begin{array}{c}18-A u g \\
11\end{array}$ & $\begin{array}{l}28-A u g \\
21\end{array}$ \\
\hline mask 7 & \multicolumn{3}{|c|}{ Total Solids (GL) } & 25:-2: & \multicolumn{4}{|c|}{ Volatie Soldos (gL) } \\
\hline $\begin{array}{l}5 \text { Control 'B' } 4 \% \\
6\end{array}$ & $\begin{array}{l}41.0 \\
41.0\end{array}$ & $\begin{array}{l}30.3 \\
26.4\end{array}$ & $\begin{array}{l}26.4 \\
25.8\end{array}$ & $\begin{array}{l}23.1 \\
24.6\end{array}$ & $\begin{array}{l}32.3 \\
32.3\end{array}$ & $\begin{array}{l}23.9 \\
20.0\end{array}$ & $\begin{array}{l}20.5 \\
19.1\end{array}$ & $\begin{array}{l}17.4 \\
18.3\end{array}$ \\
\hline $2 \%$ & $\begin{array}{l}20.5 \\
20.5\end{array}$ & $\begin{array}{l}16.1 \\
17.1\end{array}$ & $\begin{array}{l}13.8 \\
13.1\end{array}$ & $\begin{array}{l}13.7 \\
17.2\end{array}$ & $\begin{array}{l}16.1 \\
16.1\end{array}$ & $\begin{array}{l}12.3 \\
12.3\end{array}$ & $\begin{array}{l}10.1 \\
9.1\end{array}$ & $\begin{array}{l}10.1 \\
11.3\end{array}$ \\
\hline 12 & স & 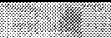 & 2. & $\sqrt{2}$ & $=$ & 2 & P. & (2: \\
\hline $\begin{array}{l}25 \text { Enzymes } 5 \% \mathrm{C}=5.0 \mathrm{~g} \\
13\end{array}$ & $\begin{array}{l}41.0 \\
41.0\end{array}$ & $\begin{array}{l}22.3 \\
35.6\end{array}$ & $\begin{array}{l}26.0 \\
29.4\end{array}$ & $\begin{array}{l}24.9 \\
27.0\end{array}$ & $\begin{array}{l}32.3 \\
32.3\end{array}$ & $\begin{array}{l}17.4 \\
27.8\end{array}$ & $\begin{array}{l}19.7 \\
21.9\end{array}$ & $\begin{array}{l}18.0 \\
20.5\end{array}$ \\
\hline $\mathrm{C}=1.0 \mathrm{~g}$ & 41.0 & 27.8 & 27.9 & 28.9 & 32.3 & 21.9 & 21.6 & 21.7 \\
\hline 14 & 41.0 & 26.6 & 27.2 & 29.3 & 32.3 & 20.9 & 22.1 & 22.0 \\
\hline $\mathrm{C}=0.5 \mathrm{~g}$ & 41.0 & 28.3 & 27.0 & 26.0 & 32.3 & 22.2 & 21.0 & 19.5 \\
\hline 15 & 41.0 & 26.6 & 28.5 & 27.9 & 32.3 & 20.6 & 21.8 & 21.2 \\
\hline $\mathrm{C}=0.1 \mathrm{~g}$ & 41.0 & 34.9 & 27.5 & 25.3 & 32.3 & 27.6 & 21.2 & 19.0 \\
\hline 16 & 41.0 & 30.7 & 28.0 & 23.9 & 32.3 & 24.2 & 21.5 & 17.7 \\
\hline $2 \% C=5.0 \mathrm{~g}$ & 20.5 & 15.8 & 13.9 & 17.5 & 16.1 & 12.0 & 10.4 & 12.8 \\
\hline 17 & 20.5 & 18.3 & 13.2 & 23.3 & 16.1 & 13.1 & 9.3 & 14.4 \\
\hline $\mathrm{C}=1.0 \mathrm{~g}$ & 20.5 & 15.1 & 13.2 & 18.8 & 16.1 & 11.3 & 9.8 & 13.3 \\
\hline 18 & 20.5 & 15.4 & 12.0 & 15.7 & 16.1 & 11.8 & 9.0 & 11.6 \\
\hline $\mathrm{C}=0.5 \mathrm{~g}$ & 20.5 & 16.4 & 15.0 & 17.2 & 16.1 & 11.8 & 10.1 & 12.0 \\
\hline 19 & 20.5 & 16.1 & 12.2 & 17.1 & 16.1 & 11.0 & 8.7 & 10.6 \\
\hline$=0.1 \mathrm{~g}$ & 20.5 & 16.3 & 14.6 & 15.6 & 16.1 & 12.7 & 10.6 & 10.2 \\
\hline 20 & 20.5 & 17.1 & 14.9 & 14.6 & 16.1 & 12.5 & 10.5 & 10.1 \\
\hline
\end{tabular}




\section{Appendix B2: Total Suspended \& Volatile Suspended Solids}

\begin{tabular}{|c|c|c|c|c|c|c|c|c|}
\hline ludge Batch \#1 : : G & & Ion $>+2$ & & & & & & \\
\hline Test Date & 2-Aug & 11-Aug & 18-Aug & 28-Aug & 2-Aug & 11-Aug & 18-Aun & 28-Aug \\
\hline Zeroed Time: & 0 & 9 & 16 & 26 & 0 & 9 & 16 & 26 \\
\hline Flask \# & Totals & Uspende & desolid: & (gL) & Volatif & Suspe & ded So & Is $(g / L)$ \\
\hline 3 Control 'A' $4 \%$ & 40.5 & 23.7 & 25.6 & 24.0 & 34.0 & 18.3 & 19.9 & 18.1 \\
\hline 4 & 40.5 & 25.5 & 24.6 & 24.2 & 34.0 & 19.5 & 18.9 & 18.4 \\
\hline $2 \%$ & 20.3 & 12.0 & 13.8 & 13.8 & 17.0 & 9.3 & 10.6 & 10.7 \\
\hline 2 & 20.3 & 12.0 & 13.9 & 12.4 & 17.0 & 9.4 & 11.0 & 9.5 \\
\hline 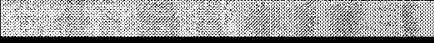 & 20 & 0 & $2=$ & & & & -3 & 20 \\
\hline $4 \% t=5 \min$ & 40.5 & 24.4 & 25.4 & 25.9 & 34.0 & 18.6 & 20.4 & 23.2 \\
\hline 10 & 40.5 & 25.8 & 25.5 & 26.3 & 34.0 & 19.7 & 17.4 & 21.4 \\
\hline$t=2 \min$ & 40.5 & 24.4 & 24.0 & 24.2 & 34.0 & 18.8 & 21.1 & 27.5 \\
\hline 22 & 40.5 & 25.8 & 24.1 & 23.5 & 34.0 & 20.0 & 21.6 & 26.9 \\
\hline$t=1 \mathrm{~min}$ & 40.5 & 23.9 & 22.8 & 21.7 & 34.0 & 18.7 & 20.5 & 27.1 \\
\hline 34 & 40.5 & 24.6 & 24.3 & 23.7 & 34.0 & 19.1 & 21.0 & 18.0 \\
\hline $2 \% t=5 \mathrm{~min}$ & 20.3 & 13.1 & 13.4 & 13.3 & 17.0 & 10.2 & 11.9 & 15.8 \\
\hline 12 & 20.3 & 13.8 & 14.2 & 13.2 & 17.0 & 10.8 & 12.1 & 16.5 \\
\hline$t=2 \min$ & 20.3 & 12.9 & 13.2 & 12.4 & 17.0 & 10.1 & 11.7 & 14.8 \\
\hline 24 & 20.3 & 11.8 & 13.7 & 12.5 & 17.0 & 9.2 & 12.6 & 15.0 \\
\hline$t=1 \mathrm{~min}$ & 20.3 & 12.9 & 12.7 & 11.6 & 17.0 & 10.2 & 11.3 & 15.2 \\
\hline 36 & 20.3 & 12.2 & 12.3 & 11.8 & 17.0 & 9.4 & 11.3 & 15.4 \\
\hline & & & & & & & & \\
\hline 39 Aeration & 40.5 & 25.6 & 24.1 & 38.5 & 34.0 & 20.2 & 21.3 & 28.2 \\
\hline 40 & 40.5 & 25.6 & 24.1 & 26.5 & 34.0 & 20.2 & 21.6 & 31.6 \\
\hline $2 \%$ & 20.3 & 14.7 & 13.6 & 12.6 & 17.0 & 11.7 & 11.6 & 17.1 \\
\hline 38 & 20.3 & 12.5 & 12.9 & 12.3 & 17.0 & 9.8 & 14.7 & 14.5 \\
\hline 109. & & & & & & & & \\
\hline
\end{tabular}


Sludge Batch \#2 - Enzyme/Bacterial Additves

\begin{tabular}{|c|c|c|c|c|c|c|c|c|}
\hline Test Date: & 7-Aug & 11-Aug & 18-Aug & 28-Aug & 7-Aug & 11-Aug & 18-Aug & 28-Aug \\
\hline Zeroed Time: & 0 & 4 & 11 & 21 & 0 & 4 & 11 & 21 \\
\hline 201 & Total Si & uspende & d Solid: & (g/2) & Volatile & Suspen & ded Sol & ds (git) \\
\hline 5 Control 'B' $4 \%$ & 41.5 & 29.8 & 25.6 & 24.3 & 32.0 & 24.1 & 20.5 & 23.1 \\
\hline 6 & 41.5 & 28.6 & 25.3 & 26.0 & 32.0 & 22.5 & 19.1 & 24.6 \\
\hline $2 \%$ & 20.8 & 11.5 & 11.3 & 10.8 & 16.0 & 9.5 & 10.1 & 13.7 \\
\hline 8 & 20.8 & 12.0 & 13.2 & 12.1 & 16.0 & 9.4 & 9.1 & 17.2 \\
\hline 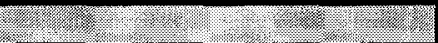 & $x$ & 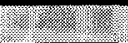 & 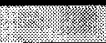 & 2x) & . & 32: & 2 & $2=2$ \\
\hline 25 Enzymes & 41.5 & 27.7 & 22.3 & 25.8 & 32.0 & 22.5 & 19.7 & 24.9 \\
\hline 13 & 41.5 & 29.1 & 22.5 & 26.6 & 32.0 & 23.9 & 21.9 & 27.0 \\
\hline $\mathrm{C}=1.0 \mathrm{~g}$ & 41.5 & 29.0 & 23.2 & 23.3 & 32.0 & 23.8 & 21.6 & 28.9 \\
\hline 14 & 41.5 & 32.2 & 21.3 & 23.8 & 32.0 & 26.0 & 22.1 & 29.3 \\
\hline $\mathrm{C}=0.5 \mathrm{~g}$ & 41.5 & 26.9 & 25.2 & 21.9 & 32.0 & 21.8 & 21.0 & 26.0 \\
\hline 15 & 41.5 & 27.0 & 23.9 & 24.0 & 32.0 & 21.8 & 21.8 & 27.9 \\
\hline $\mathrm{C}=0.1 \mathrm{~g}$ & 41.5 & 30.5 & 22.4 & 20.5 & 32.0 & 24.6 & 21.2 & 25.3 \\
\hline 16 & 41.5 & 31.9 & 22.7 & 25.0 & 32.0 & 25.6 & 21.5 & 23.9 \\
\hline $2 \% \mathrm{C}=5.0 \mathrm{~g}$ & 20.8 & 12.6 & 11.1 & 10.3 & 16.0 & 10.6 & 10.4 & 17.5 \\
\hline 17 & 20.8 & 12.3 & 15.4 & 11.6 & 16.0 & 9.8 & 9.3 & 23.3 \\
\hline $\mathrm{C}=1.0 \mathrm{~g}$ & 20.8 & 11.3 & 10.8 & 11.2 & 16.0 & 9.5 & 9.8 & 18.8 \\
\hline 18 & 20.8 & 12.4 & 11.0 & 10.5 & 16.0 & 10.5 & 9.0 & 15.7 \\
\hline $\mathrm{C}=0.5 \mathrm{~g}$ & 20.8 & 12.4 & 12.7 & 10.2 & 16.0 & 10.5 & 10.1 & 17.2 \\
\hline 19 & 20.8 & 11.5 & 11.7 & 12.8 & 16.0 & 9.2 & 8.7 & 17.1 \\
\hline$=0.1 \mathrm{~g}$ & 20.8 & 11.5 & 12.2 & 11.0 & 16.0 & 8.8 & 10.6 & 15.6 \\
\hline 20 & 20.8 & 11.5 & 13.1 & 11.9 & 16.0 & 9.4 & 10.5 & 14.6 \\
\hline
\end{tabular}




\section{Appendix B3: Total COD}

\begin{tabular}{|c|c|c|c|c|c|c|c|c|}
\hline \multicolumn{6}{|c|}{ STludge Batch \#1 - Grinding \& Microaeration| } & \multirow[b]{2}{*}{ 17-Aug-07 } & \multicolumn{2}{|c|}{ 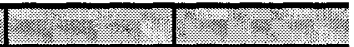 } \\
\hline & & & Test Date & 2-Aug-07 & 10-Aug-07 & & 27-Aug-07 & 10-Sep-07 \\
\hline & & $\overline{Z e r}$ & roed time: & $\overline{0}$ & $\overline{8}$ & 15 & 25 & 39 \\
\hline Flask & \# & 2 & & Total CO & $(\operatorname{mg} / 4)$ & 2 & 101020 & 3. \\
\hline 3 & Control 'A' & $4 \%$ & & 65070 & 60900 & 57390 & 53970 & 48570 \\
\hline 4 & & & & 65070 & 54390 & 56310 & 58260 & 49770 \\
\hline 1 & & $2 \%$ & & 32535 & 26790 & 33420 & 31560 & 25860 \\
\hline 2 & & & & 32535 & 29040 & 30720 & 32220 & 25860 \\
\hline tex: & $=$ & ene & $=2$ & 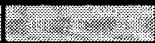 & I=: $=8$ & 2:2:2: & 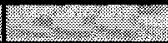 & 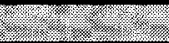 \\
\hline 9 & Grinding & $4 \%$ & $t=5 \mathrm{~min}$ & 65070 & 62460 & 66030 & 64110 & 51390 \\
\hline 10 & & & & 65070 & 68520 & 63870 & 64920 & 54630 \\
\hline 21 & & & $t=2 \min$ & 65070 & 58590 & 56970 & 63690 & 47640 \\
\hline 22 & & & & 65070 & 58920 & 56250 & 59130 & 47550 \\
\hline 33 & & & $t=1 \mathrm{~min}$ & 65070 & 55200 & 63150 & 56670 & 47340 \\
\hline 34 & & & & 65070 & 64800 & 56910 & 65580 & 50910 \\
\hline 11 & & $2 \%$ & $t=5 \mathrm{~min}$ & 32535 & 35910 & 32160 & 35730 & 30360 \\
\hline 12 & & & & 32535 & 34080 & 33600 & 36270 & 28650 \\
\hline 23 & & & $t=2 \min$ & 32535 & 37140 & 34410 & 33030 & 27450 \\
\hline 24 & & & & 32535 & 32460 & 32700 & 34470 & 27660 \\
\hline 35 & & & $t=1 \mathrm{~min}$ & 32535 & 33990 & 29910 & 37140 & 27990 \\
\hline 36 & & & & 32535 & 30540 & 35250 & 37020 & 28680 \\
\hline (2) & $\ln ^{2}=2$ & 2 & $=$ & $2=2$ & 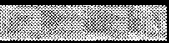 & $2=$ & $2=$ & 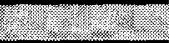 \\
\hline 39 & Aeration & $4 \%$ & & 65070 & 59850 & 56940 & 53880 & 38910 \\
\hline 40 & & & & 65070 & 65160 & 58320 & 62910 & 38610 \\
\hline 37 & & $2 \%$ & & 32535 & 31860 & 27570 & 56730 & 20880 \\
\hline 38 & & & & 32535 & 29250 & 31890 & 26640 & 38700 \\
\hline 2 & & 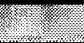 & & 2 & 20 & $2=$ & 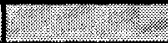 & 2 \\
\hline
\end{tabular}




\begin{tabular}{|c|c|c|c|c|c|c|c|c|}
\hline \multicolumn{6}{|c|}{ Sludge Batch \#2-Enzyma/Bacterial Addirives } & & $=$ & \\
\hline & & \multicolumn{2}{|r|}{ Test Date: } & 8-Aug-07 & 10-Aug-07 & 17-Aug-07 & 27-Aug-07 & 10-Sep-07 \\
\hline & & \multicolumn{2}{|c|}{ Zeroed time: } & 0 & 2 & 9 & 19 & $\overline{33}$ \\
\hline Flask & 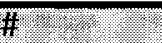 & 8 & 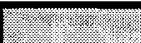 & Total COL & (mgll) & n-1. & $=$ & - \\
\hline & Control 'B' & $4 \%$ & & 52200 & 51960 & 57060 & 50340 & 47130 \\
\hline 6 & & & & 52200 & 47430 & 55140 & 59580 & 48720 \\
\hline 7 & & $2 \%$ & & 26100 & 24210 & 23100 & 29940 & 26460 \\
\hline 8 & & & & 26100 & 30420 & 23520 & 28530 & 25320 \\
\hline (2) & $2=$ & 2 & & 7 & en & 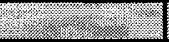 & 2. - = & 20 \\
\hline 25 & Enzymes & $4 \%$ & $\mathrm{C}=5.0 \mathrm{~g}$ & 52200 & 78660 & 58890 & 58650 & 53040 \\
\hline 13 & & & & 52200 & 40050 & 69630 & 62730 & 46440 \\
\hline 26 & & & $\mathrm{C}=1.0 \mathrm{~g}$ & 52200 & 44640 & 89550 & 53520 & 47100 \\
\hline 14 & & & & 52200 & 50910 & 62100 & 75900 & 45780 \\
\hline 27 & & & $\mathrm{C}=0.5 \mathrm{~g}$ & 52200 & 42780 & 51510 & 59220 & $\overline{51390}$ \\
\hline 15 & & & & 52200 & 40380 & 86820 & 54120 & 53340 \\
\hline 28 & & & $\mathrm{C}=0.1 \mathrm{~g}$ & 52200 & 45900 & 50520 & 55290 & 47280 \\
\hline 16 & & & & 52200 & 38160 & 63750 & 69600 & 45150 \\
\hline 29 & & $2 \%$ & $\mathrm{C}=5.0 \mathrm{~g}$ & 26100 & 27330 & 31710 & 32040 & 28500 \\
\hline 17 & & & & 26100 & 32190 & 31170 & 31440 & 26070 \\
\hline 30 & & & $\mathrm{C}=1.0 \mathrm{~g}$ & 26100 & 31740 & 27990 & 32790 & 25470 \\
\hline 18 & & & & 26100 & 33120 & 33720 & 30630 & 23910 \\
\hline 31 & & & $\mathrm{C}=0.5 \mathrm{~g}$ & 26100 & 26550 & 30150 & 34680 & 24600 \\
\hline 19 & & & & 26100 & 23190 & 24030 & 31410 & 25080 \\
\hline 32 & & & $\mathrm{C}=0.1 \mathrm{~g}$ & 26100 & 34050 & 28050 & 31920 & 23700 \\
\hline 20 & & & & 26100 & 29100 & 26160 & 29220 & 27510 \\
\hline 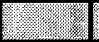 & & & & & & 20. & $=$ & (2) \\
\hline
\end{tabular}




\section{Appendix B4: Soluble COD}

\begin{tabular}{|c|c|c|c|c|c|c|c|c|}
\hline \multicolumn{5}{|c|}{ Sludge Batch \#1 - Grinding \& Microaeration } & & & & rag \\
\hline & & \multicolumn{2}{|c|}{ Test Date: } & 2-Aug-07 & 10-Aug-07 & 17-Aug-07 & 27-Aug-07 & 10-Sep-07 \\
\hline & & \multicolumn{2}{|c|}{ Zeroed time: } & 0 & 8 & 15 & 25 & 39 \\
\hline \multicolumn{2}{|c|}{ Flask \# \# } & $2=$ & 2: & Soluble CO & $D(m g l)$ & 5 & en: & $x^{2}=2$ \\
\hline \multirow{2}{*}{\multicolumn{2}{|c|}{\begin{tabular}{l|l|}
3 & Control 'A' \\
4 &
\end{tabular}}} & $4 \%$ & & 3810 & 14100 & 24510 & 18720 & 18630 \\
\hline & & & & 3810 & 9600 & 25470 & 17580 & 17850 \\
\hline \multirow{3}{*}{\begin{tabular}{l|}
1 \\
2
\end{tabular}} & & $2 \%$ & & 1905 & 8190 & 10710 & 8070 & 8790 \\
\hline & & & & 1905 & 7170 & 14580 & 8520 & 8790 \\
\hline & & (2) & & $=$ & 1.: & . & renese & 20.6. \\
\hline \multirow{2}{*}{$\frac{9}{10}$} & Grinding & $4 \%$ & $t=5$ min & 3810 & 10890 & 10890 & 20820 & 20010 \\
\hline & & & & 3810 & 13740 & 13740 & 21180 & 20940 \\
\hline \multirow{2}{*}{$\frac{2}{22}$} & & & $t=2 \min$ & 3810 & 12990 & 19110 & 17850 & 16020 \\
\hline & & & & 3810 & 12540 & 19260 & 18210 & 17730 \\
\hline \multirow{2}{*}{$\frac{33}{34}$} & & & $t=1 \min$ & 3810 & 13260 & 18030 & 17070 & 17280 \\
\hline & & & & 3810 & 15540 & 18300 & 18120 & 17730 \\
\hline \multirow{2}{*}{$\frac{1}{1}$} & & $2 \%$ & $t=5 \mathrm{~min}$ & 1905 & 7410 & 10950 & 9000 & 9270 \\
\hline & & & & 1905 & 7350 & 10680 & 8550 & 9630 \\
\hline \multirow{2}{*}{$\frac{2}{2}$} & & & $t=2 \min$ & 1905 & 5970 & 9990 & 8190 & 9270 \\
\hline & & & & 1905 & 7440 & 9930 & 8520 & 8400 \\
\hline \multirow{2}{*}{$\frac{3}{3}$} & & & $t=1 \min$ & 1905 & 7380 & 10170 & 8490 & 8250 \\
\hline & & & & 1905 & 7380 & 10650 & 9780 & 8430 \\
\hline 30 & 25: & 3 & 8 & 28 & $x+2$ & 8 & $=2$ & 0 \\
\hline \multirow{2}{*}{$\frac{39}{40}$} & Aeration & $4 \%$ & & 3810 & 12120 & 15840 & 10740 & 9360 \\
\hline & & & & 3810 & 13770 & 16980 & 10230 & 7920 \\
\hline \multirow{2}{*}{37} & & $2 \%$ & & 1905 & 7020 & 7980 & 3390 & 1140 \\
\hline & & & & 1905 & 6150 & 6570 & 2880 & 840 \\
\hline 38 & & & & 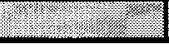 & I. & & 2 & $x^{2}-x_{2}$ \\
\hline
\end{tabular}




\begin{tabular}{|c|c|c|c|c|c|c|c|c|}
\hline \multicolumn{6}{|c|}{ Sludge Batch \#2 - Enzyme/Bacterial Addirives } & & & \\
\hline & & \multicolumn{2}{|r|}{ Test Date: } & 8-Aug-07 & 10-Aug-07 & 17-Aug-07 & 27-Aug-07 & 10-Sep-07 \\
\hline & & \multicolumn{2}{|c|}{ Zeroed time: } & 0 & 2 & 9 & 19 & 33 \\
\hline \multicolumn{2}{|c|}{ Flask \# } & $=$ & & \multicolumn{2}{|c|}{ Soluble COD (mg/L) } & 20 & & 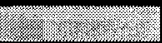 \\
\hline \multicolumn{2}{|c|}{5 Control 'B' } & $4 \%$ & & 3930 & 6120 & 21390 & 15570 & 17730 \\
\hline \multicolumn{2}{|l|}{6} & & & 3930 & 3810 & 16740 & 15150 & 17010 \\
\hline 7 & & $2 \%$ & & 1965 & 1740 & 8850 & 7770 & 8310 \\
\hline \multirow{2}{*}{8} & & & & 1965 & 4320 & 10830 & 7710 & 8880 \\
\hline & 6. & $=$ & & 1027 & s: & 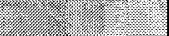 & 1.2. & 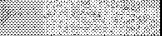 \\
\hline 25 & Enzymes & $4 \%$ & $\mathrm{C}=5.0 \mathrm{~g}$ & 3930 & 7620 & 18300 & 18300 & 17970 \\
\hline \multirow{2}{*}{$\frac{13}{26}$} & & & & 3930 & 7410 & 18390 & 17790 & 19740 \\
\hline & & & $\mathrm{C}=1.0 \mathrm{~g}$ & 3930 & 8100 & 17640 & 17430 & 15360 \\
\hline 14 & & & & 3930 & 7080 & 16560 & 17130 & 16020 \\
\hline \multirow{2}{*}{$\frac{27}{15}$} & & & $\mathrm{C}=0.5 \mathrm{~g}$ & 3930 & 6540 & 15810 & 16410 & 16020 \\
\hline & & & & 3930 & 6600 & 16560 & 17730 & 17850 \\
\hline \multirow{2}{*}{$\frac{28}{11}$} & & & $\mathrm{C}=0.1 \mathrm{~g}$ & 3930 & 6540 & 16020 & 15960 & 16170 \\
\hline & & & & 3930 & 6270 & 16290 & 15480 & 18300 \\
\hline 2. & & $2 \%$ & $C=5.0 \mathrm{~g}$ & 1965 & 5340 & 10050 & 9840 & 9570 \\
\hline \multirow{2}{*}{$\begin{array}{l}17 \\
30 \\
\end{array}$} & & & & 1965 & 4830 & 10620 & 9480 & 10260 \\
\hline & & & $\mathrm{C}=1.0 \mathrm{~g}$ & 1965 & 4350 & 9570 & 7770 & 7980 \\
\hline \multirow{2}{*}{$\frac{18}{31}$} & & & & 1965 & 2370 & 8970 & 8880 & 8250 \\
\hline & & & $\mathrm{C}=0.5 \mathrm{~g}$ & 1965 & 4080 & 8490 & 7800 & 7740 \\
\hline 1 & & & & 1965 & 3810 & 9390 & 8070 & 8940 \\
\hline \multirow{2}{*}{$\frac{32}{20}$} & & & $\mathrm{C}=0.1 \mathrm{~g}$ & 1965 & 4590 & 8700 & 7740 & 7710 \\
\hline & & & & 1965 & 4140 & 9090 & 7560 & 7440 \\
\hline 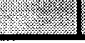 & & & & 3 & 8 & . & 2 & \\
\hline
\end{tabular}




\section{Appendix B5: Protein}

\begin{tabular}{|c|c|c|c|c|c|c|c|}
\hline \multicolumn{4}{|c|}{ Sludge Batch \#1 - Grinding \& Microaeration } & & $e^{2}$ & 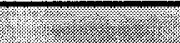 & I. \\
\hline & & \multicolumn{2}{|c|}{ Test Date } & 2-Aug-07 & 15-Aug-07 & 24-Aug-07 & 1-Sep-07 \\
\hline & & \multicolumn{2}{|c|}{ Zeroed Time } & 0 & 13 & 22 & 30 \\
\hline Flask \# & & & (8) & \multicolumn{3}{|c|}{ Protein Concentration (mg/L) } & 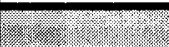 \\
\hline 3 & Control 'A' & $4 \%$ & & 2547 & 28621.2 & 27873.2 & 27465.2 \\
\hline 4 & & & & 2547 & 25442.2 & 28621.2 & 26360.2 \\
\hline 1 & & $2 \%$ & & 1273 & 10839.2 & 15378.2 & 14732.2 \\
\hline 2 & & & & 1273 & 11536.2 & 16432.2 & 15446.2 \\
\hline & & & & $2=$ & (1) & $=$ & 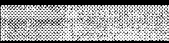 \\
\hline$\overline{9}$ & Grinding & $4 \%$ & $\mathrm{t}=5 \mathrm{~min}$ & 2547 & 32718.2 & 31766.2 & 29862.2 \\
\hline 10 & & & & 2547 & 28162.2 & 32276.2 & 29267.2 \\
\hline 21 & & & $t=2 \min$ & 2547 & 28009.2 & 31545.2 & 28808.2 \\
\hline 22 & & & & 2547 & 29454.2 & 31188.2 & 28502.2 \\
\hline 33 & & & $\mathrm{t}=1 \mathrm{~min}$ & 2547 & 27533.2 & 35064.2 & 33245.2 \\
\hline 34 & & & & 2547 & 28400.2 & 36594.2 & 34231.2 \\
\hline 11 & & $2 \%$ & $t=5 \min$ & 1273 & 16670.2 & 19203.2 & 17486.2 \\
\hline 12 & & & & 1273 & 15582.2 & 19424.2 & 17452.2 \\
\hline 23 & & & $\mathrm{t}=2 \mathrm{~min}$ & 1273 & 14596.2 & 17860.2 & 16347.2 \\
\hline 24 & & & & 1273 & 14919.2 & 18217.2 & 21430.2 \\
\hline 35 & & & $\mathrm{t}=1$ min & 1273 & 19067.2 & 22501.2 & 21243.2 \\
\hline 36 & & & & 1273 & 19033.2 & 22603.2 & 21413.2 \\
\hline 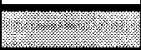 & & & & 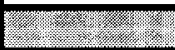 & (2) & 2 & 3) \\
\hline 39 & Aeration & $4 \%$ & & 2547 & 31970.2 & 33007.2 & 34520.2 \\
\hline 40 & & & & 2547 & 30134.2 & 33160.2 & 35931.2 \\
\hline 37 & & $2 \%$ & & 1273 & 17673.2 & 21634.2 & 21447.2 \\
\hline 38 & & & & 1273 & 17537.2 & 20546.2 & 22093.2 \\
\hline & & & & 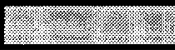 & 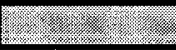 & $\sqrt{2}$ & - \\
\hline
\end{tabular}


Sludge Batch \#2 - Enzyme/Bacterial Additives

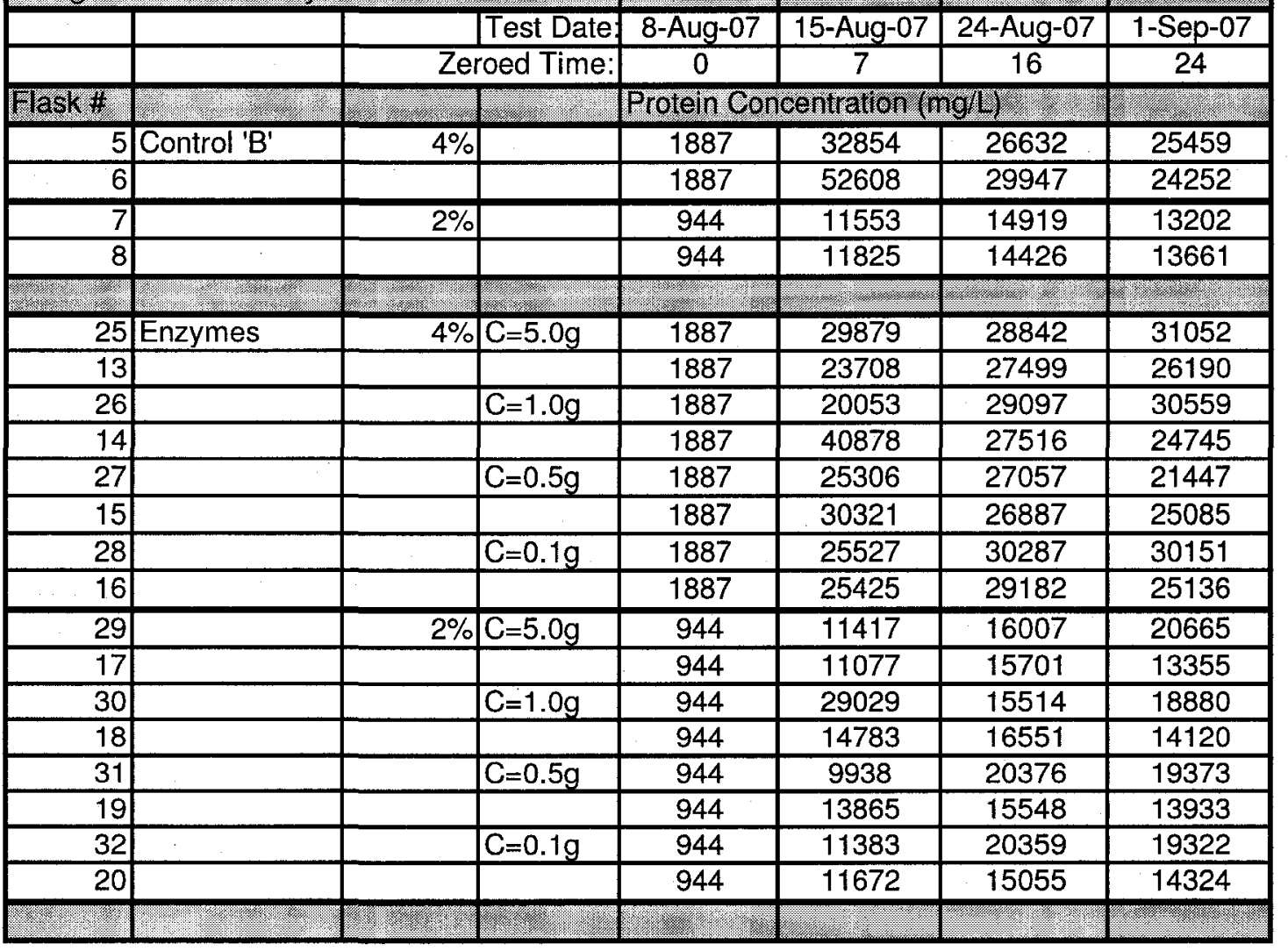




\section{Appendix B6: Carbohydrate}

\begin{tabular}{|c|c|c|c|c|c|c|c|}
\hline \multicolumn{4}{|c|}{ Sludge Batch H1 - Grinding \& Microaeralion } & & & & \\
\hline & & \multirow{2}{*}{\multicolumn{2}{|c|}{ Test Date: }} & 2-Aug-07 & 15-Aug-07 & 24-Aug-07 & 1-Sep-07 \\
\hline & & & & 0 & 13 & 22 & 30 \\
\hline Flask \# & 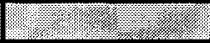 & $=0$ & & \multicolumn{4}{|c|}{ Carbohydrate Concentration (mg/L } \\
\hline 3 & Control 'A' & $4 \%$ & & 15050.0 & 1969.4 & 2235.9 & 2282.0 \\
\hline 4 & & & & 15050.0 & 1662.7 & 1664.6 & 1570.6 \\
\hline 1 & & $2 \%$ & & 7525.0 & 903.4 & 799.9 & 1338.7 \\
\hline 2 & & & & 7525.0 & 682.9 & 805.6 & 0.0 \\
\hline 3. & 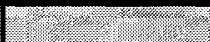 & 2. & 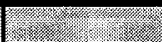 & 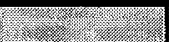 & $x=2$ & 20.12:0 & 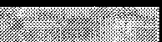 \\
\hline 9 & Grinding & $4 \%$ & $t=5 \min$ & 15050.0 & 2207.2 & 2124.7 & 2228.3 \\
\hline 10 & & & & 15050.0 & 1727.9 & 2466.0 & 1702.9 \\
\hline 21 & & & $t=2 \min$ & 15050.0 & 1917.7 & 2094.1 & 1607.1 \\
\hline 22 & & & & 15050.0 & 1775.8 & 1829.5 & 3323.1 \\
\hline 33 & & & $t=1$ min & 15050.0 & 2839.9 & 2170.8 & 1898.5 \\
\hline 34 & & & & 15050.0 & 3867.6 & 2400.8 & 2692.3 \\
\hline 11 & & $2 \%$ & $t=5 \min$ & 7525.0 & 730.9 & 757.7 & 884.3 \\
\hline 12 & & & & 7525.0 & 853.6 & 1225.5 & 1522.7 \\
\hline 23 & & & $t=2 \min$ & 7525.0 & 819.1 & 903.4 & 832.5 \\
\hline 24 & & & & 7525.0 & 776.9 & 974.4 & 803.7 \\
\hline 35 & & & $t=1 \min$ & 7525.0 & 1620.5 & 1079.8 & 1024.2 \\
\hline 36 & & & & 7525.0 & 1465.2 & 796.1 & 1008.9 \\
\hline 2 & & 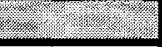 & 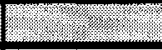 & 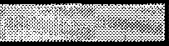 & $1=$ & $x=$ & $=10$ \\
\hline 39 & Aeration & $4 \%$ & & 15050.0 & 3165.8 & 2343.3 & 2596.4 \\
\hline 40 & & & & 15050.0 & 3186.9 & 2379.7 & 2540.8 \\
\hline 37 & & $2 \%$ & & 7525.0 & 1515.0 & 1409.6 & 1112.4 \\
\hline 38 & & & & 7525.0 & 1586.0 & 1150.8 & 997.4 \\
\hline $2=$ & 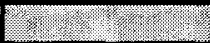 & 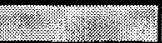 & & $=0$ & 5 & 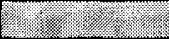 & 38 \\
\hline
\end{tabular}




\begin{tabular}{|c|c|c|c|c|c|c|c|}
\hline udge B & 2-Enzyr & $\mathrm{sacl}$ & & & & & \\
\hline & & & Test Date: & 8-Aug-07 & 15-Aug-07 & 24-Aug-07 & 1-Sep-07 \\
\hline & & & roed Time: & 0 & 7 & 16 & 24 \\
\hline Flask \# & 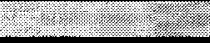 & $y^{2}$ & 2 & Carbohydr & te Concent & ralion (mgl & 15 \\
\hline 5 & Control 'B' & $4 \%$ & & 10497.3 & 2527.4 & 3181.2 & 3472.6 \\
\hline 6 & & & & 10497.3 & 9567.7 & 3436.2 & 2437.3 \\
\hline 7 & & $2 \%$ & & 5248.7 & 763.5 & 799.9 & 1031.9 \\
\hline 8 & & & & 5248.7 & 788.4 & 619.7 & 1146.9 \\
\hline $2=0$ & c & 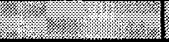 & - & 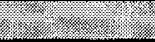 & 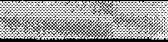 & II. & -2 \\
\hline 25 & Enzymes & $4 \%$ & $\mathrm{C}=5.0 \mathrm{~g}$ & 10497.3 & 30270.2 & 31001.2 & 24439.2 \\
\hline 13 & & & & 10497.3 & 20308.2 & 29522.2 & 41269.2 \\
\hline 26 & & & $\mathrm{C}=1.0 \mathrm{~g}$ & 10497.3 & 30270.2 & 37002.2 & 26564.2 \\
\hline 14 & & & & 10497.3 & 37376.2 & 41167.2 & 55991.2 \\
\hline 27 & & & $\mathrm{C}=0.5 \mathrm{~g}$ & 10497.3 & 35693.2 & 43020.2 & 36917.2 \\
\hline 15 & & & & 10497.3 & 18574.2 & 25391.2 & 45145.2 \\
\hline 28 & & & $C=0.1 \mathrm{~g}$ & 10497.3 & 33007.2 & 44006.2 & 29267.2 \\
\hline 16 & & & & 10497.3 & 16364.2 & 23215.2 & 36985.2 \\
\hline 29 & & $2 \%$ & $\mathrm{C}=5.0 \mathrm{~g}$ & 5248.7 & 14001.2 & 15412.2 & 16398.2 \\
\hline 17 & & & & 5248.7 & 7541.2 & 5280.2 & 11281.2 \\
\hline 30 & & & $\mathrm{C}=1.0 \mathrm{~g}$ & 5248.7 & 35370.2 & 8170.2 & 9547.2 \\
\hline 18 & & & & 5248.7 & 10295.2 & 6827.2 & 10295.2 \\
\hline 31 & & & $\mathrm{C}=0.5 \mathrm{~g}$ & 5248.7 & 10397.2 & 9479.2 & 9003.2 \\
\hline 19 & & & & 5248.7 & 6113.2 & 6759.2 & 10312.2 \\
\hline 32 & & & $\mathrm{C}=0.1 \mathrm{~g}$ & 5248.7 & 17129.2 & 7711.2 & 9683.2 \\
\hline 20 & & & & 5248.7 & 5637.2 & 6572.2 & 11570.2 \\
\hline 20 & & 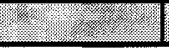 & 1 & 2 & 20 & 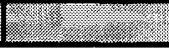 & 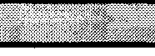 \\
\hline
\end{tabular}




\section{Appendix B7: Ammonia}

\begin{tabular}{|c|c|c|c|c|c|c|c|}
\hline Sludge Ba & ch \#1. Gindi & g \& Microat & aration & 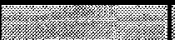 & Wenty & senter & 20 \\
\hline & & & Test Date: & 2-Aug-07 & 13-Aug-07 & 21-Aug-07 & 31-Aug-07 \\
\hline & & $\mathrm{Ze}$ & roed Time: & 0 & 11 & 19 & 29 \\
\hline Flask 1 . & III) & 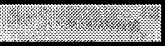 & $\sqrt{2}$ & Amimonia & Oneontratio & n $($ mglu & 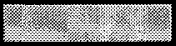 \\
\hline 3 & Control 'A' & $4 \%$ & & 231 & 285.45 & 311.85 & 343.75 \\
\hline 4 & & & & 231 & 306.9 & 297 & 371.25 \\
\hline 1 & & $2 \%$ & & 115.5 & 109.45 & 116.05 & 149.6 \\
\hline 2 & & & & 115.5 & 99 & 105.05 & 149.05 \\
\hline & Ply & . & 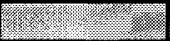 & 2 & - & 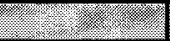 & . \\
\hline 9 & Grinding & $4 \%$ & $t=5 \mathrm{~min}$ & 231 & 460.35 & 349.8 & 418 \\
\hline 10 & & & & 231 & 379.5 & 365.75 & 435.05 \\
\hline 21 & & & $t=2 \min$ & 231 & 315.15 & 347.05 & 390.5 \\
\hline 22 & & & & 231 & 322.85 & 366.3 & 415.25 \\
\hline 33 & & & $t=1 \mathrm{~min}$ & 231 & 354.2 & 342.1 & 411.4 \\
\hline 34 & & & & 231 & 326.7 & 374 & 428.45 \\
\hline 11 & & $2 \%$ & $\mathrm{t}=5 \mathrm{~min}$ & 115.5 & 153.45 & 169.4 & 195.25 \\
\hline 12 & & & & 115.5 & 144.1 & 162.25 & 182.6 \\
\hline 23 & & & $\mathrm{t}=2 \mathrm{~min}$ & 115.5 & 131.45 & 159.5 & 151.8 \\
\hline 24 & & & & 115.5 & 139.7 & 147.4 & 158.4 \\
\hline 35 & & & $t=1 \min$ & 115.5 & 135.85 & 146.85 & 193.05 \\
\hline 36 & & & & 115.5 & 135.3 & 158.95 & 177.65 \\
\hline 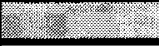 & X & & & 201 & $\sqrt{2} \cdot 3$ & (2) & 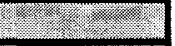 \\
\hline 39 & Aeration & $4 \%$ & & 231 & 312.95 & 365.75 & 402.6 \\
\hline 40 & & & & 231 & 282.15 & 403.7 & 418.55 \\
\hline 37 & & $2 \%$ & & 115.5 & 103.4 & 121 & 171.6 \\
\hline 38 & & & & 114.95 & 103.4 & 115.5 & 181.5 \\
\hline P. & 47 & 1.2 & & ]ा? & 20. & 20 & 12 \\
\hline
\end{tabular}


Sludge Batch \#2 - Enzyme/Bacterial Additives

\begin{tabular}{|c|c|c|c|c|c|c|c|}
\hline & & & Test Date: & 8-Aug-07 & 13-Aug-07 & 21-Aug-07 & 31-Aug-07 \\
\hline & & \multicolumn{2}{|c|}{ Zeroed Time: } & 0 & 5 & 13 & 23 \\
\hline Jask f & $2=$ & 2 & 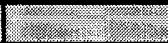 & Ammonia & Soncentratio & $\ln (\mathrm{mg} / \mathrm{L})$ & \\
\hline 5 & Control 'B' & $4 \%$ & & 198.9 & 188.1 & 234.3 & 311.3 \\
\hline 6 & & & & 198.9 & 198 & 212.3 & 317.35 \\
\hline 7 & & $2 \%$ & & 99.45 & 51.7 & 64.35 & 94.6 \\
\hline 8 & & & & 99.45 & 36.3 & 74.25 & 93.5 \\
\hline & & & ㄹ. & 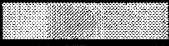 & 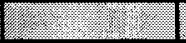 & & 0 \\
\hline 25 & Enzymes & $4 \%$ & $\mathrm{C}=5.0 \mathrm{~g}$ & 198.9 & 334.4 & 328.35 & 385.55 \\
\hline 13 & & & & 198.9 & 259.05 & 309.1 & 419.1 \\
\hline 26 & & & $\mathrm{C}=1.0 \mathrm{~g}$ & 198.9 & 307.45 & 266.2 & 391.05 \\
\hline 14 & & & & 198.9 & 234.85 & 269.5 & 295.35 \\
\hline 27 & & & $C=0.5 \mathrm{~g}$ & 198.9 & 204.6 & 266.2 & 358.05 \\
\hline 15 & & & & 198.9 & 197.45 & 255.2 & 346.5 \\
\hline 28 & & & $\mathrm{C}=0.1 \mathrm{~g}$ & 198.9 & 202.4 & 253.55 & 316.25 \\
\hline 16 & & & & 198.9 & 190.85 & 232.65 & 327.8 \\
\hline 29 & & $2 \%$ & $\mathrm{C}=5.0 \mathrm{~g}$ & 99.45 & 166.1 & 149.05 & 173.8 \\
\hline 17 & & & & 99.45 & 81.4 & 143 & 192.1333 \\
\hline 30 & & & $\mathrm{C}=1.0 \mathrm{~g}$ & 99.45 & 53.9 & 90.75 & 112.2 \\
\hline 18 & & & & 99.45 & 31.9 & 83.6 & 112.2 \\
\hline 31 & & & $\mathrm{C}=0.5 \mathrm{~g}$ & 99.45 & 51.15 & 84.15 & 106.7 \\
\hline 19 & & & & 99.45 & 52.25 & 84.15 & 101.75 \\
\hline 32 & & & $\mathrm{C}=0.1 \mathrm{~g}$ & 99.45 & 42.35 & 80.3 & 94.6 \\
\hline 20 & & & & 99.45 & 39.05 & 74.25 & 97.9 \\
\hline- & 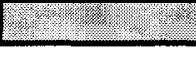 & - & L2 & 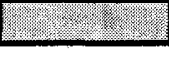 & 20 & $=$ & 2. \\
\hline
\end{tabular}




\section{Appendix C: Figures with 95\% C.I. - Batch Reactor Tests}

Figure 4-1(b): Profiles of the TS and VS concentrations during the batch reactor experiments with raw sludge treated with an enzyme and bacterial additive

Figure 4-2 (b): Profiles of the TS and VS concentrations during the batch reactor experiments with diluted sludge treated with an enzyme and bacterial additive ... 159

Figure 4-3(b): Profiles of the TS and VS concentrations during the batch reactor experiments with raw primary sludge treated with microaeration

Figure 4-4(b): Profiles of the TS and VS concentrations during the batch reactor experiments with diluted primary sludge treated with microaeration

Figure 4-5(b): Profiles of the TS and VS concentrations during the batch reactor experiments with raw primary sludge treated with an initial grinding cycle

Figure 4-6(b): Profiles of the TS and VS concentrations during the batch reactor experiments with diluted primary sludge treated with an initial grinding cycle... .161

Figure 4-7(b): Profiles of the TSS and VSS concentrations during the batch reactor experiments with raw sludge treated with an enzyme and bacterial additive

Figure 4-8(b): Profiles of the TSS and VSS concentrations during the batch reactor experiments with diluted sludge treated with an enzyme and bacterial additive .... 162

Figure 4-9(b): Profiles of the TSS and VSS concentrations during the batch reactor experiments with raw primary sludge treated with microaeration

Figure 4-10(b): Profiles of the TSS and VSS concentrations during the batch reactor experiments with diluted primary sludge treated with microaeration

Figure 4-11(b): Profiles of the TSS and VSS concentrations during the batch reactor experiments with raw primary sludge treated with an initial grinding cycle

Figure 4-12(b): Profiles of the TSS and VSS concentrations during the batch reactor experiments with diluted primary sludge treated with an initial grinding cycle ..... 164

Figure 4-13(b): Profiles of the total and soluble COD during the batch reactor experiments with raw sludge treated with an enzyme and bacterial additive

Figure 4-14(b): Profiles of the total and soluble COD during the batch reactor experiments with diluted sludge treated with an enzyme and bacterial additive .... 165 
Figure 4-15(b): Profiles of the total and soluble COD during the batch reactor experiments with raw primary sludge treated with microaeration

Figure 4-16(b): Profiles of the total and soluble COD during the batch reactor experiments with diluted primary sludge treated with microaeration

Figure 4-17(b): Profiles of the total and soluble COD during the batch reactor experiments with raw primary sludge treated with an initial grinding cycle......

Figure 4-18(b): Profiles of the total and soluble COD during the batch reactor experiments with diluted primary sludge treated with an initial grinding cycle ..... 167

Figure 4-19(b): Profiles of the protein concentrations during the batch reactor tests with raw primary sludge treated with an enzyme and bacterial additive

Figure 4-20(b): Profiles of the protein concentrations during the batch reactor tests with diluted primary sludge treated with an enzyme and bacterial additive 168

Figure 4-21(b): Profiles of the protein concentrations during the batch reactor tests with raw primary sludge treated with microaeration and an initial grinding cycle. 169

Figure 4-22(b): Profiles of the protein concentrations during the batch reactor tests with diluted primary sludge treated with microaeration and an initial grinding cycle.... 169

Figure 4-23(b): Profiles of the carbohydrates concentrations during the batch reactor tests with raw primary sludge treated with an enzyme and bacterial additive 170

Figure 4-24(b): Profiles of the carbohydrate concentrations during the batch reactor tests with diluted primary sludge treated with an enzyme and bacterial additive...... 170

Figure 4-25(b): Profiles of the carbohydrate concentrations during the batch reactor tests with raw primary sludge treated with microaeration and an initial grinding cycle. 171

Figure 4-26(b): Profiles of the carbohydrate concentrations during the batch reactor tests with diluted primary sludge treated with microaeration and a grinding cycle......... 171

Figure 4-27(b): Profiles of the ammonia concentrations during the batch reactor tests with raw primary sludge samples treated with an enzyme and bacterial additive

Figure 4-28(b): Profiles of the ammonia concentrations during the batch reactor tests with diluted primary sludge samples treated with an enzyme and bacterial additive ......172

Figure 4-29(b): Profiles of the ammonia concentrations during the batch reactor tests with raw primary sludge treated with microaeration and an initial grinding cycle

Figure 4-30(b): Profiles of the ammonia concentrations during the batch reactor tests with diluted primary sludge treated with microaeration and an initial grinding cycle 


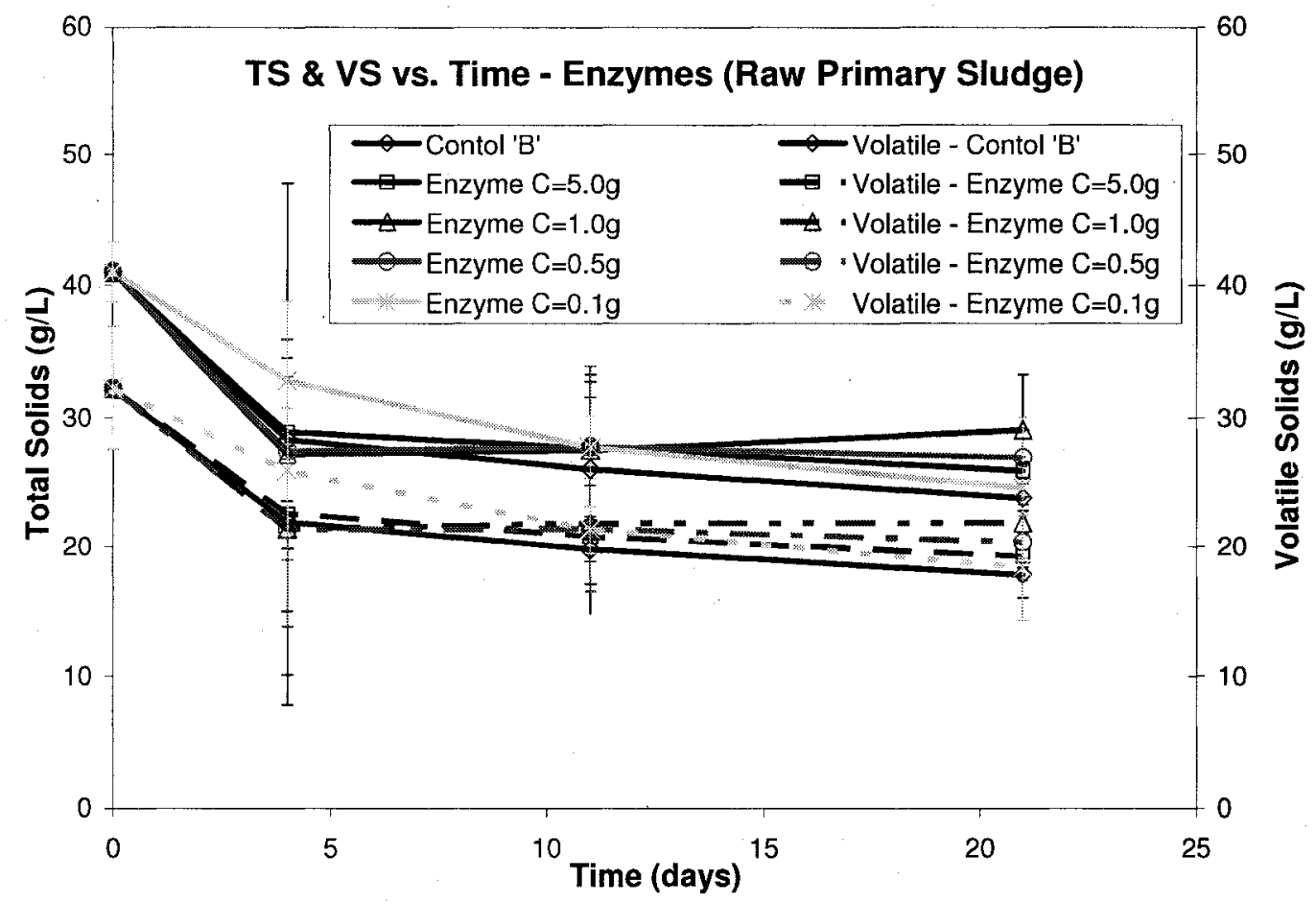

Figure 4-1(b): Profiles of the total and volatile solids concentrations during the batch reactor experiments with raw sludge treated with an enzyme and bacterial additive

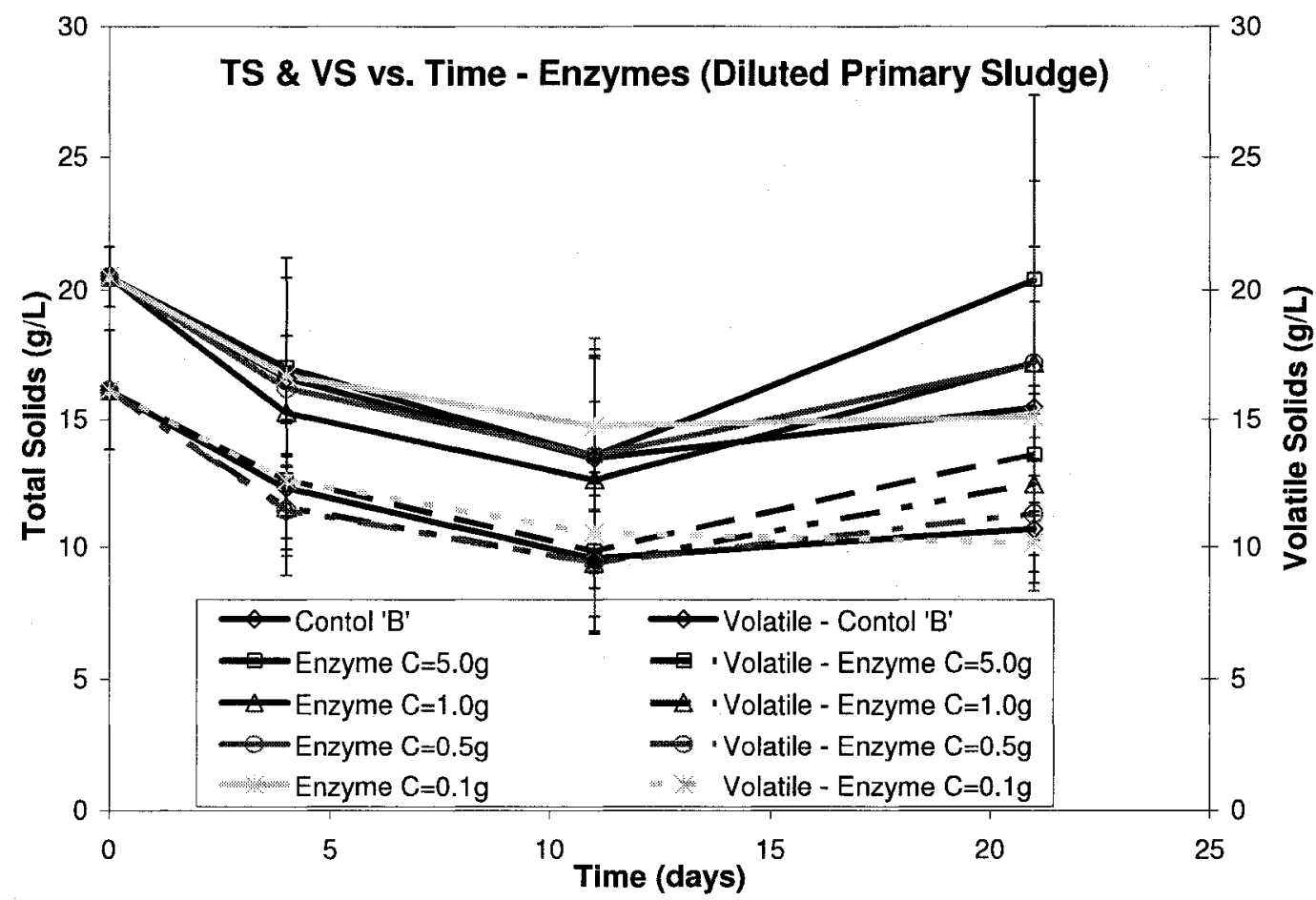

Figure 4-2 (b): Profiles of the total and volatile solids concentrations during the batch reactor experiments with diluted sludge treated with an enzyme and bacterial additive 


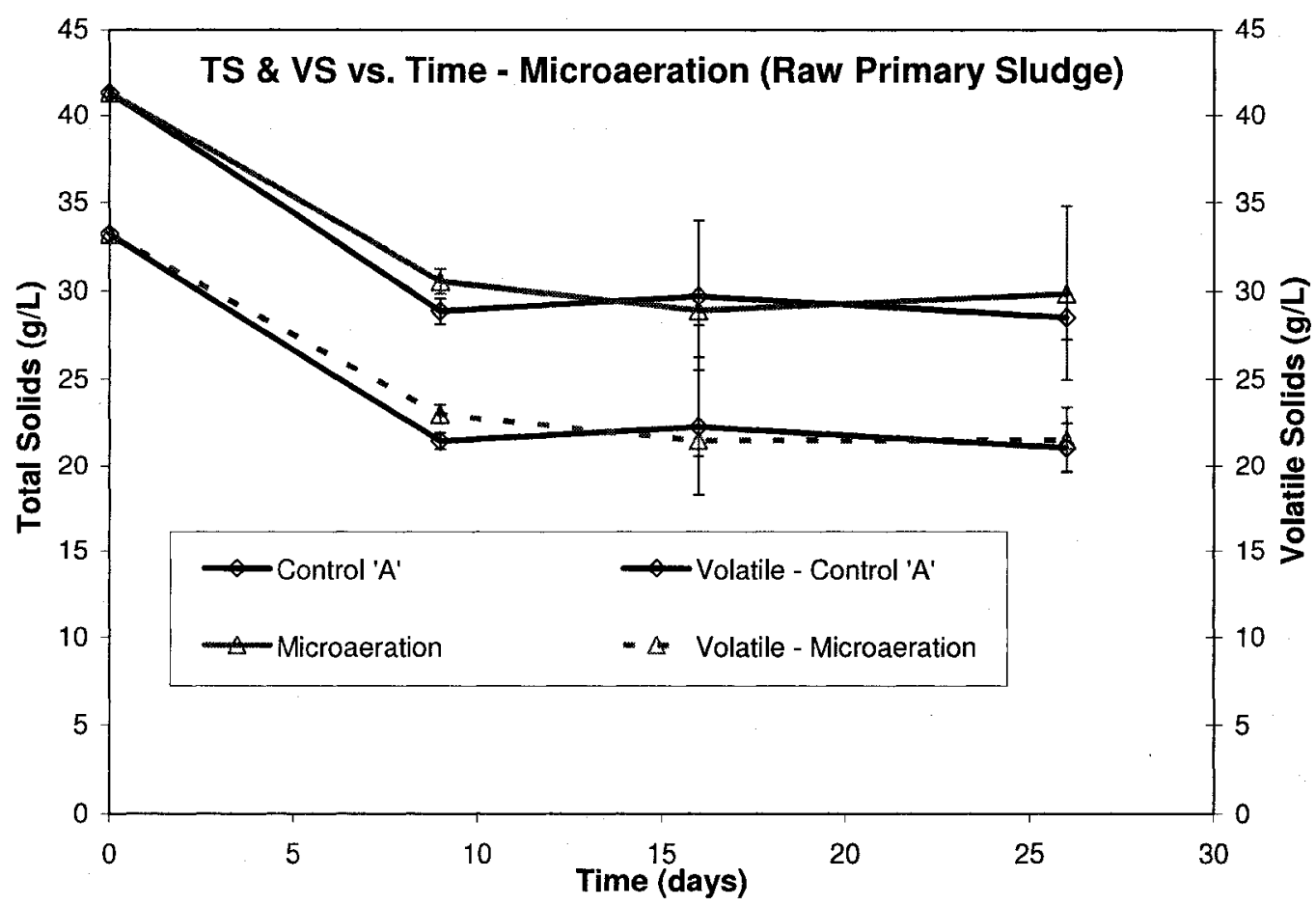

Figure 4-3(b): Profiles of the total and volatile solids concentrations during the batch reactor experiments with raw primary sludge treated with microaeration

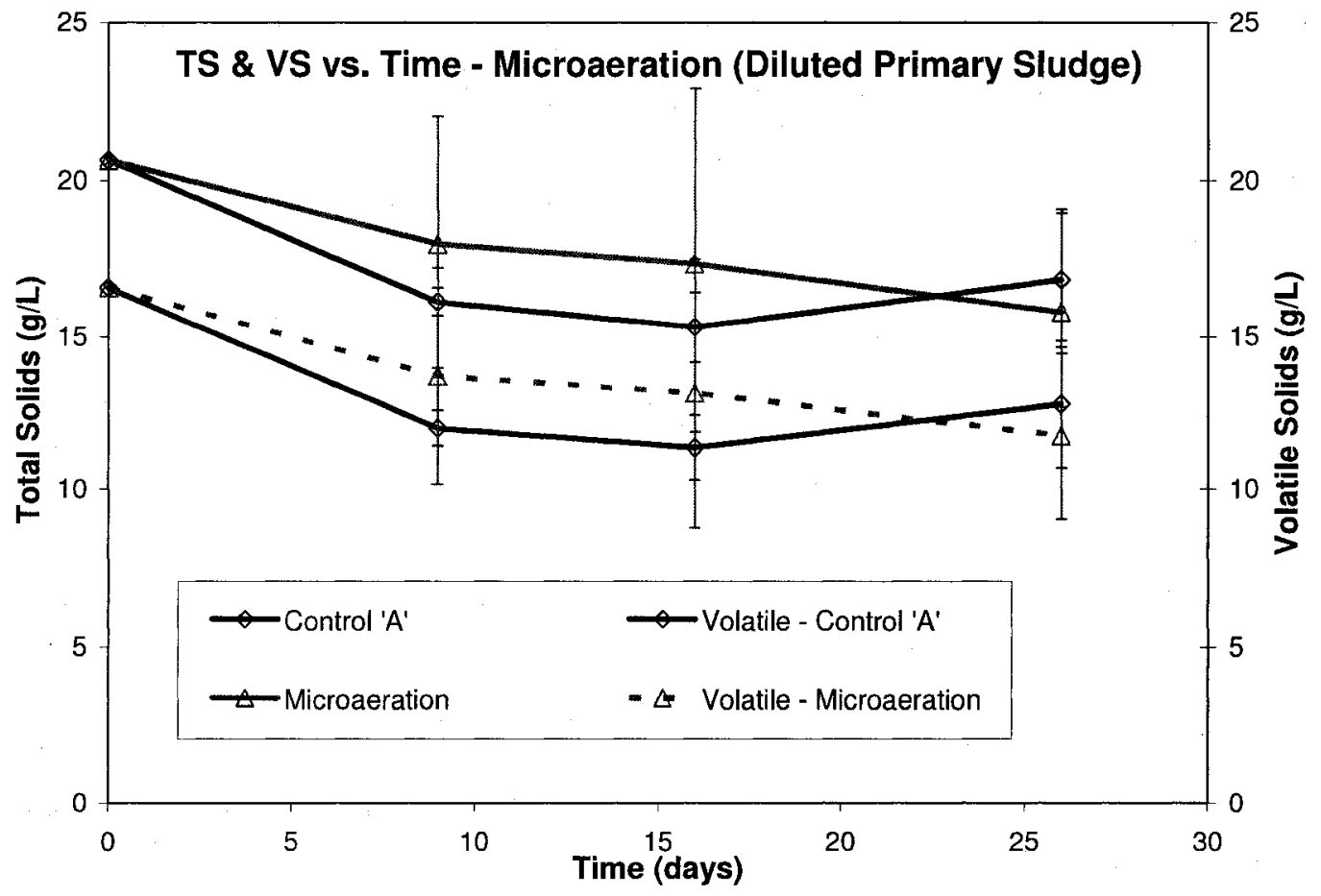

Figure 4-4(b): Profiles of the total and volatile solids concentrations during the batch reactor experiments with diluted primary sludge treated with microaeration 


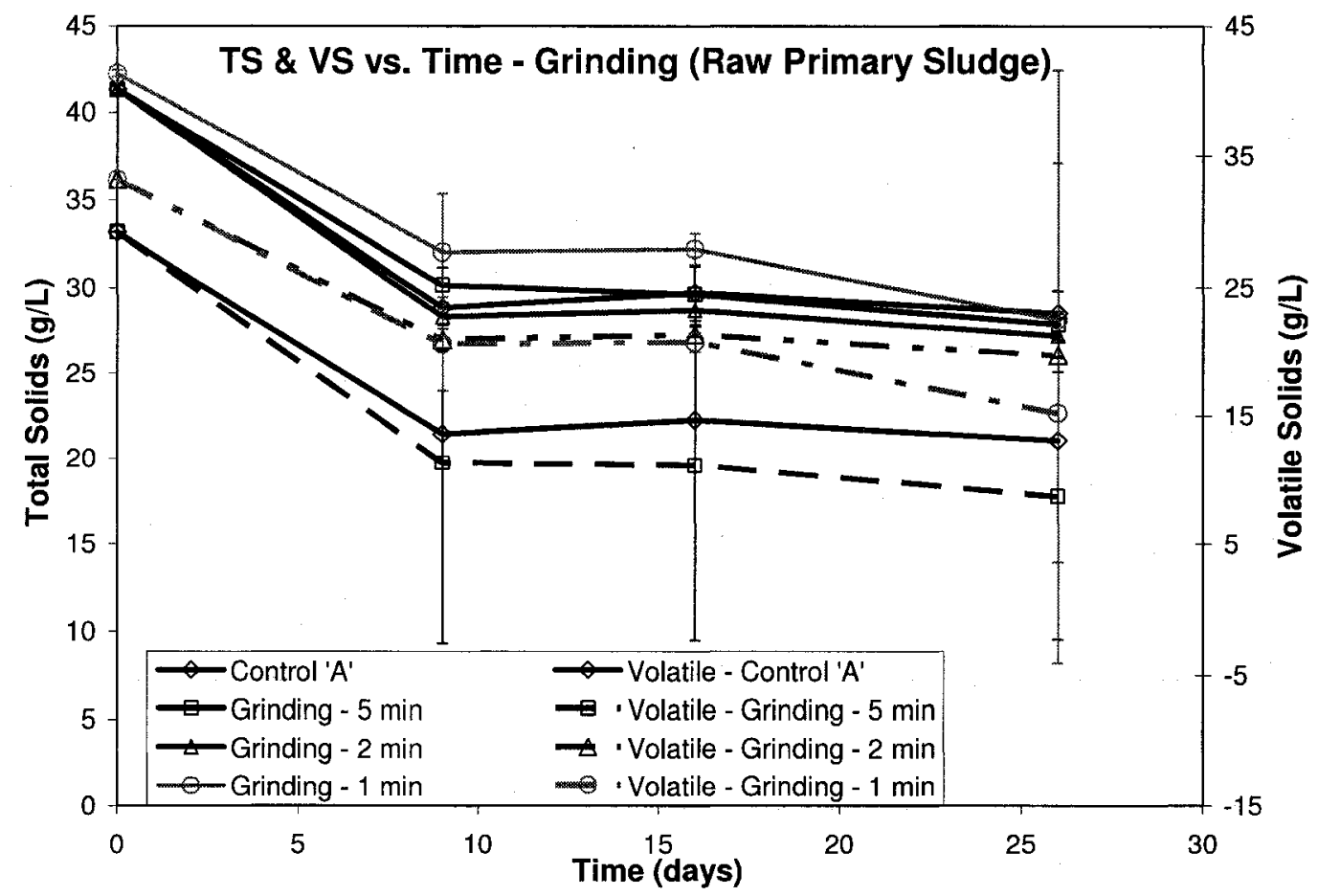

Figure 4-5(b): Profiles of the total and volatile solids concentrations during the batch reactor experiments with raw primary sludge treated with an initial grinding cycle

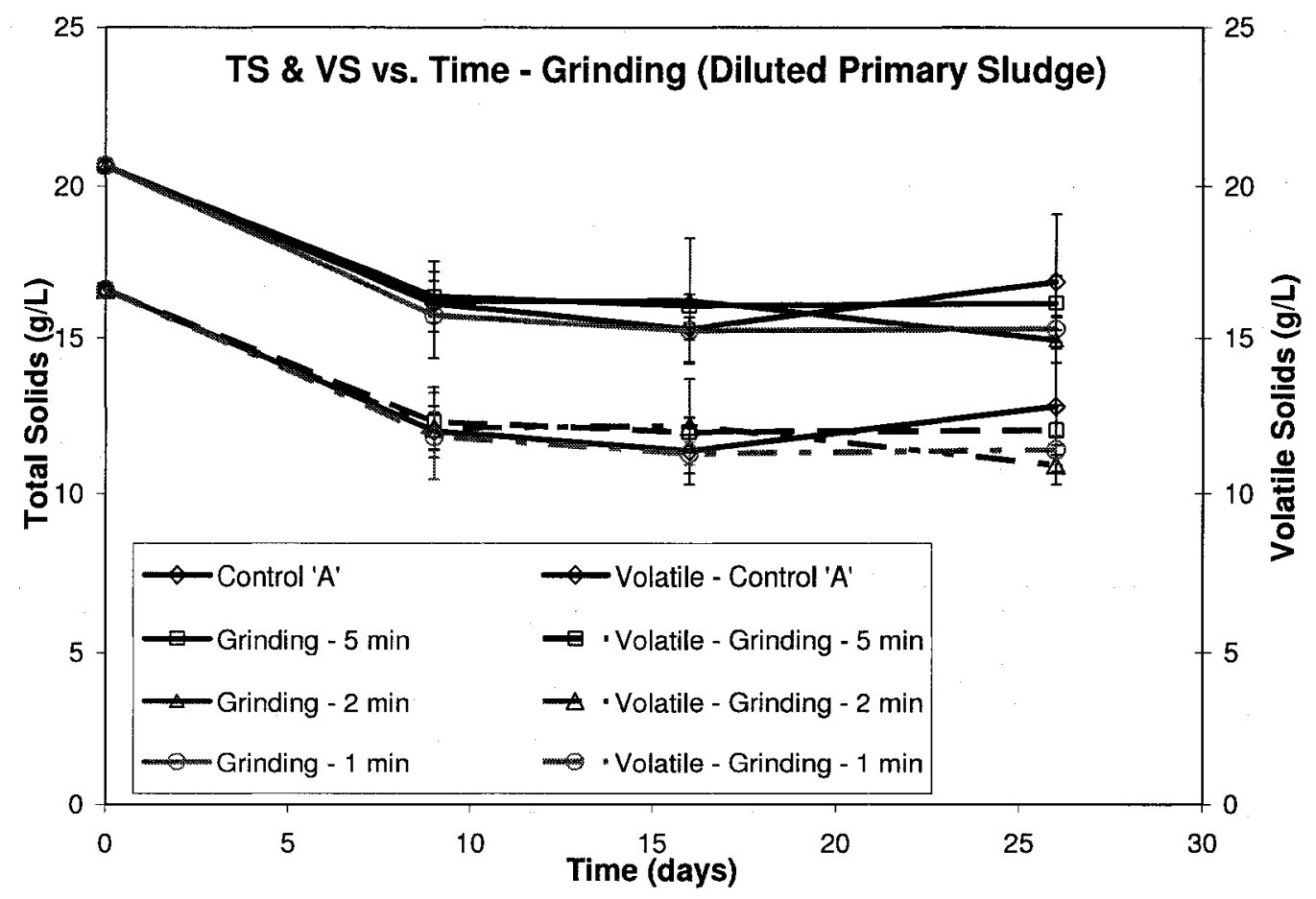

Figure 4-6(b): Profiles of the total and volatile solids concentrations during the batch reactor experiments with diluted primary sludge treated with an initial grinding cycle 


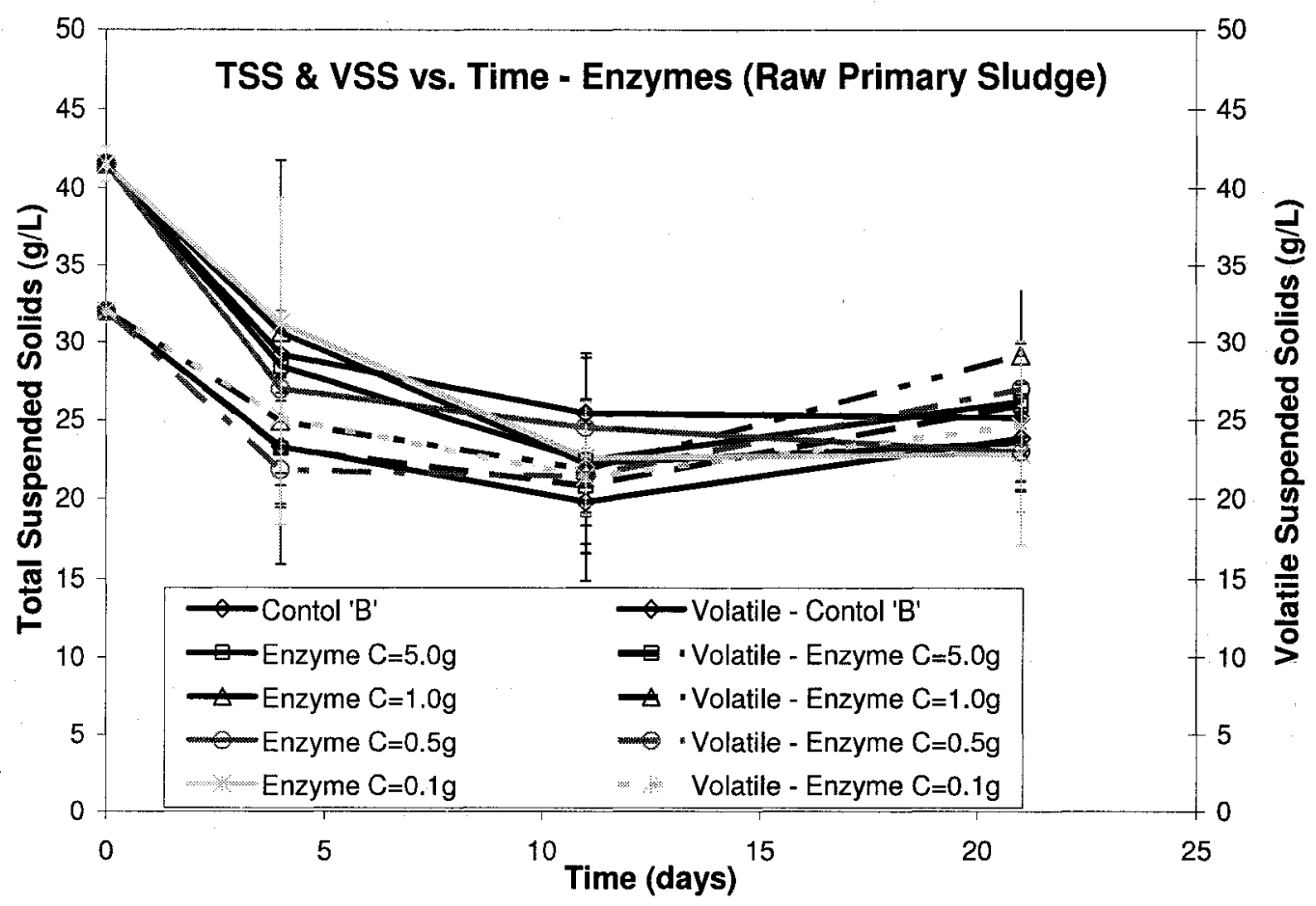

Figure 4-7(b): Profiles of the TSS and VSS concentrations during the batch reactor experiments with raw sludge treated with an enzyme and bacterial additive

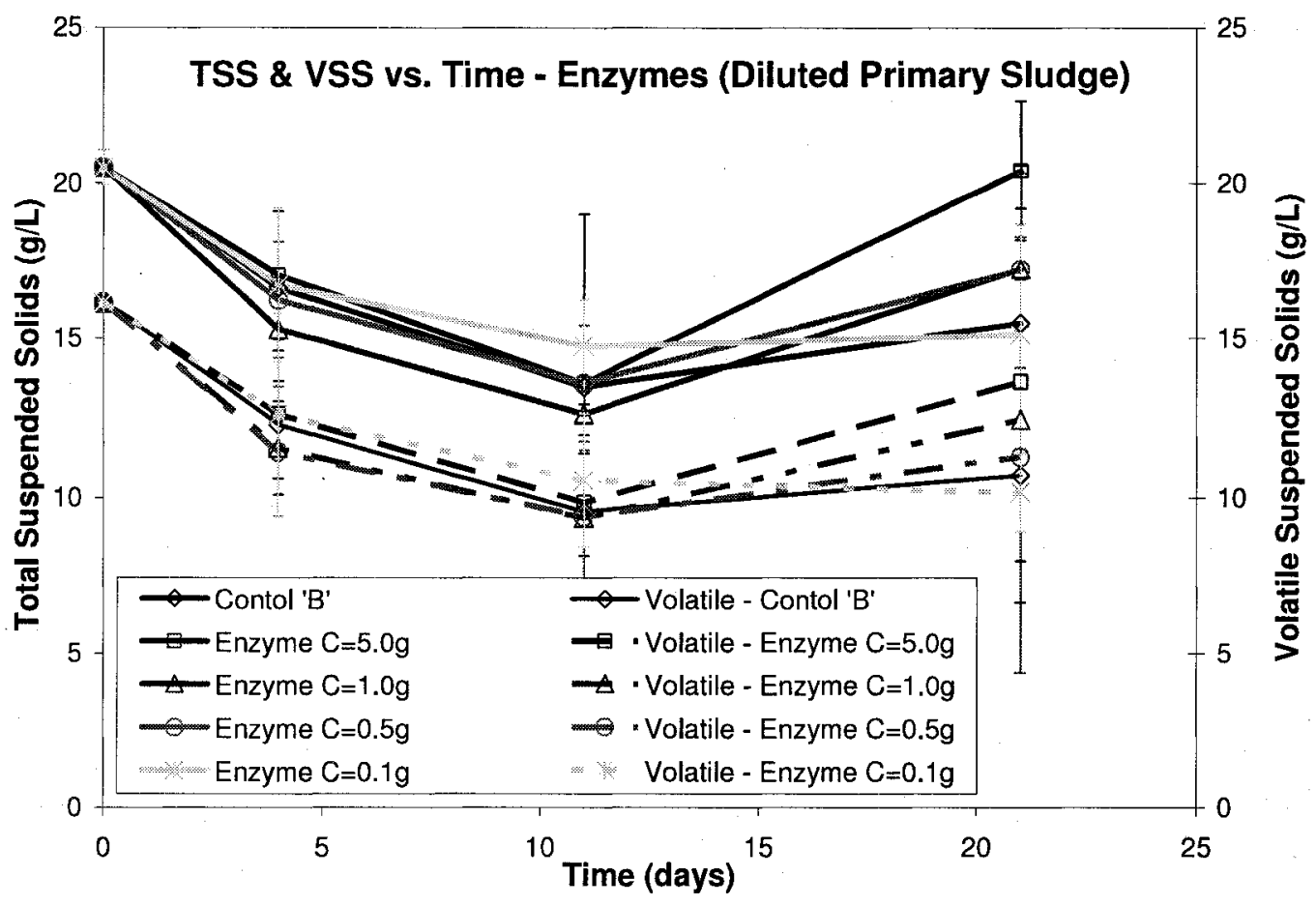

Figure 4-8(b): Profiles of the TSS and VSS concentrations during the batch reactor experiments with diluted sludge treated with an enzyme and bacterial additive 


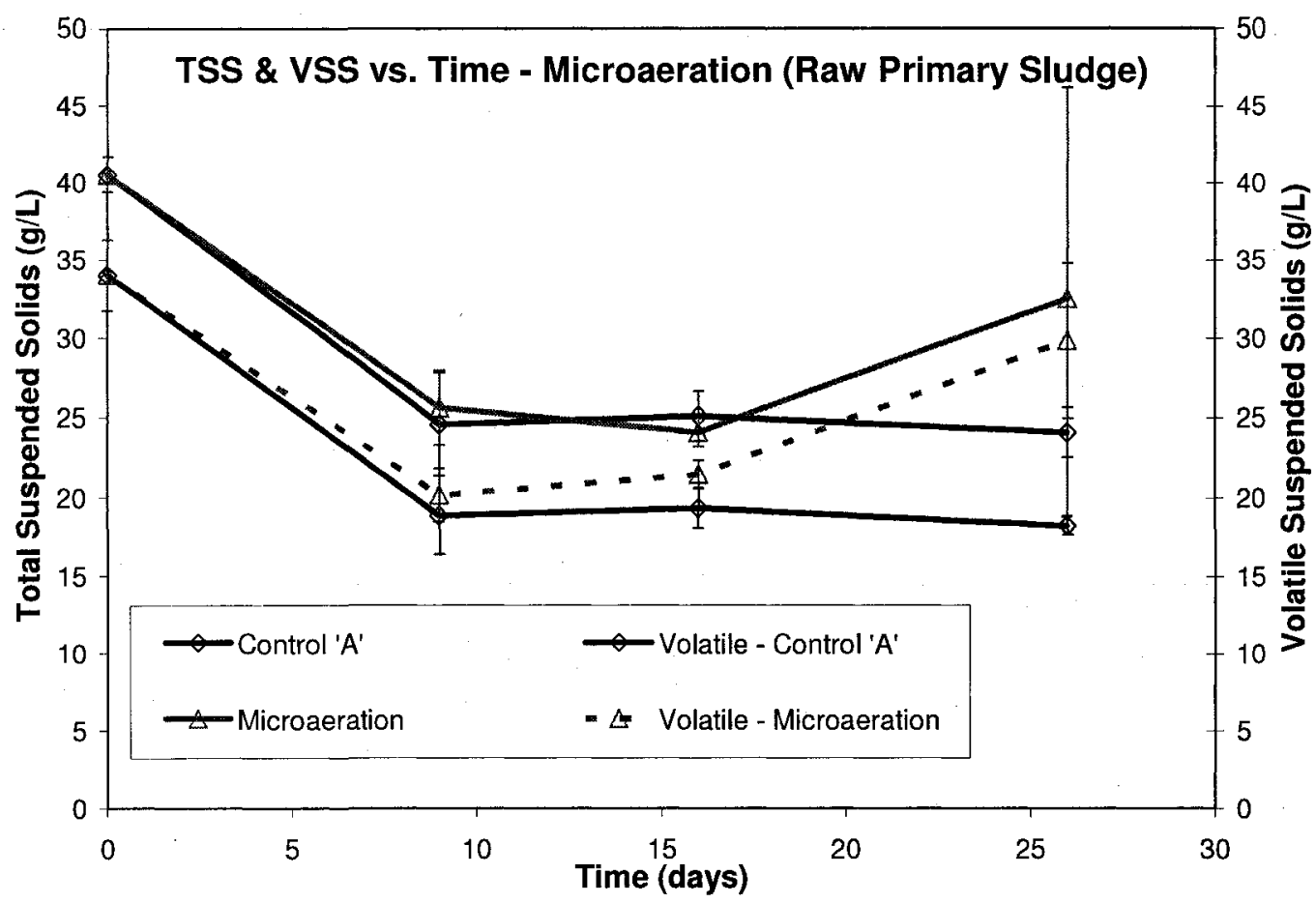

Figure 4-9(b): Profiles of the TSS and VSS concentrations during the batch reactor experiments with raw primary sludge treated with microaeration

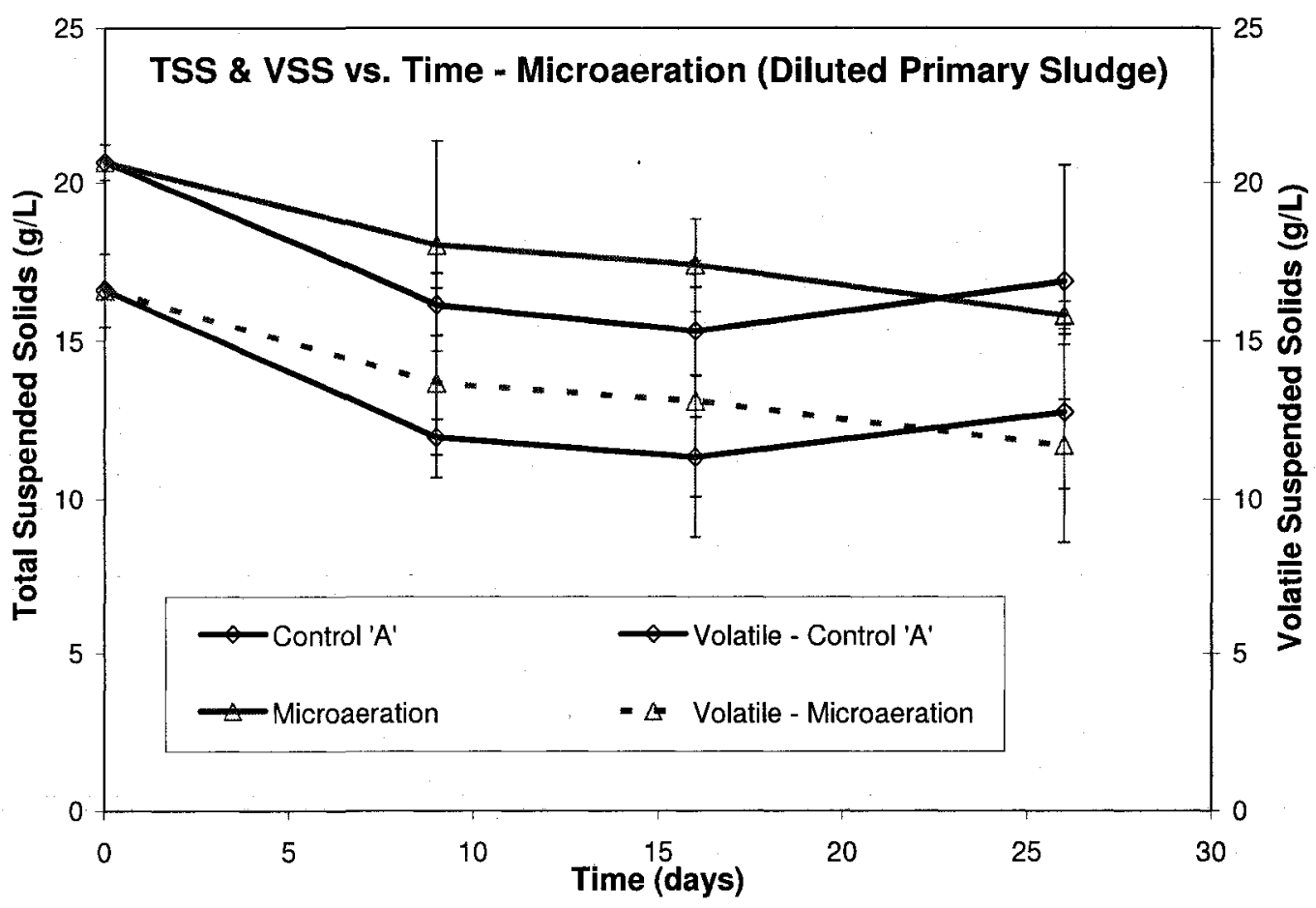

Figure 4-10(b): Profiles of the TSS and VSS concentrations during the batch reactor experiments with diluted primary sludge treated with microaeration 


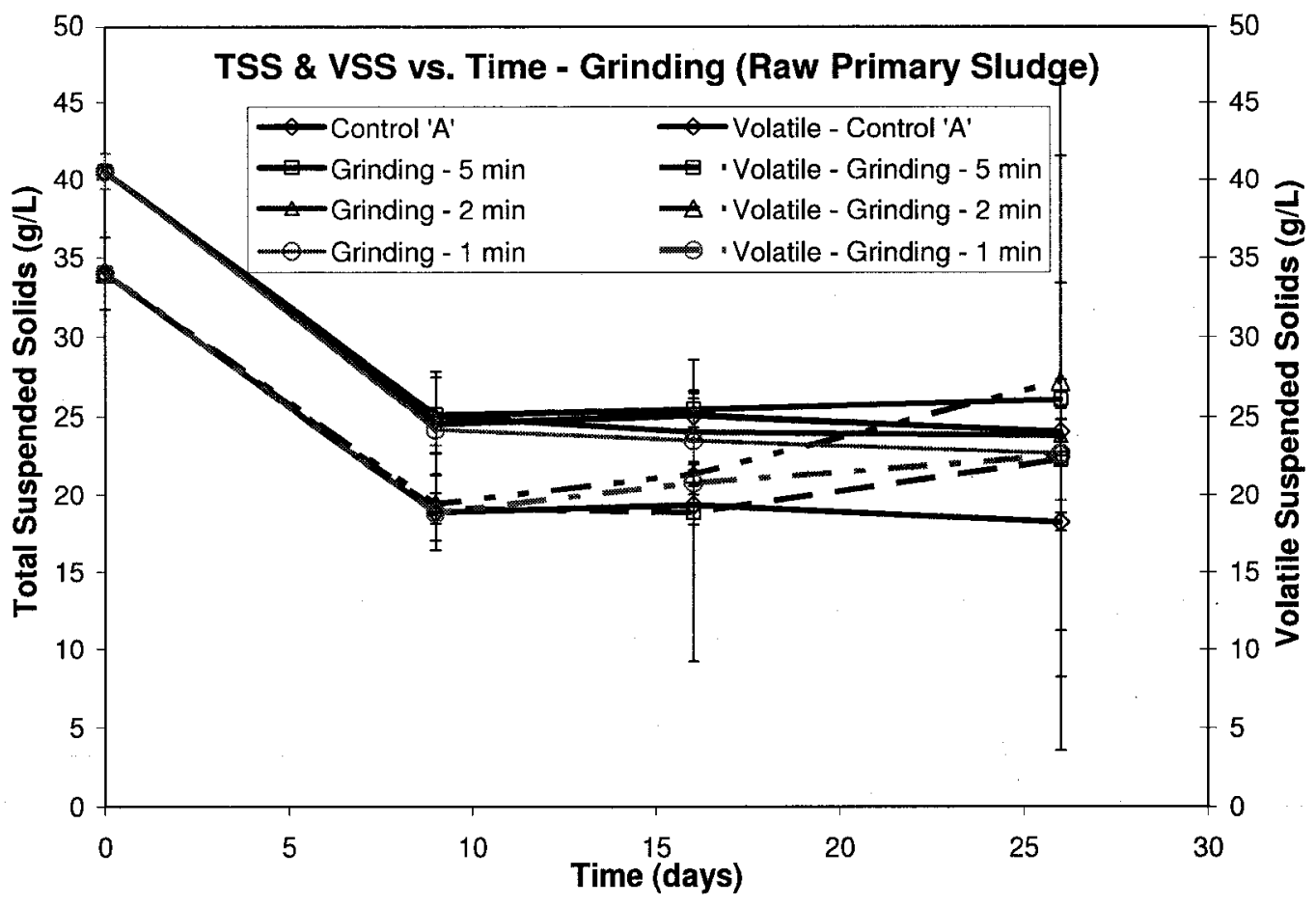

Figure 4-11(b): Profiles of the TSS and VSS concentrations during the batch reactor experiments with raw primary sludge treated with an initial grinding cycle

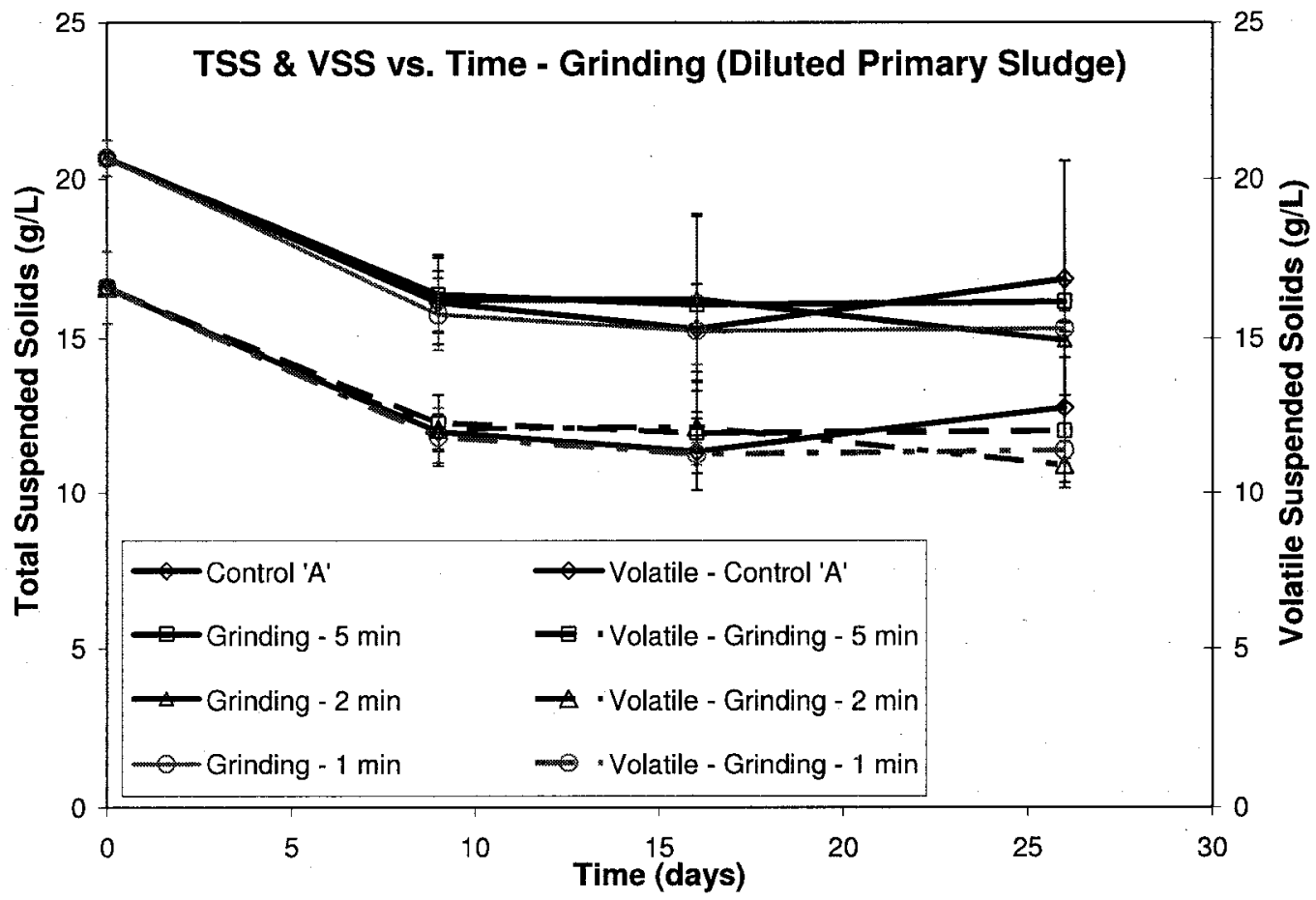

Figure 4-12(b): Profiles of the TSS and VSS concentrations during the batch reactor experiments with diluted primary sludge treated with an initial grinding cycle 


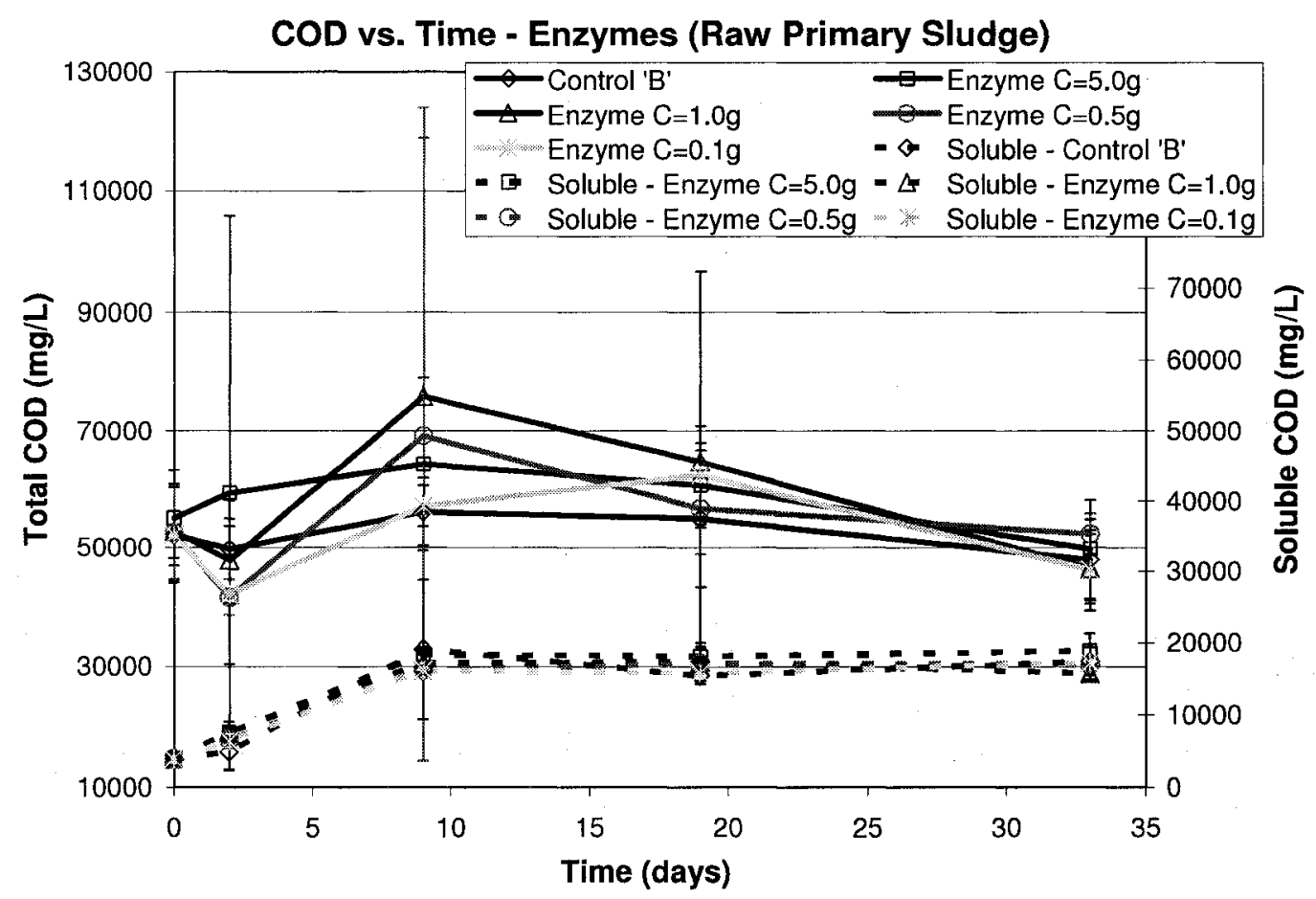

Figure 4-13(b): Profiles of the total and soluble COD during the batch reactor experiments with raw sludge treated with an enzyme and bacterial additive

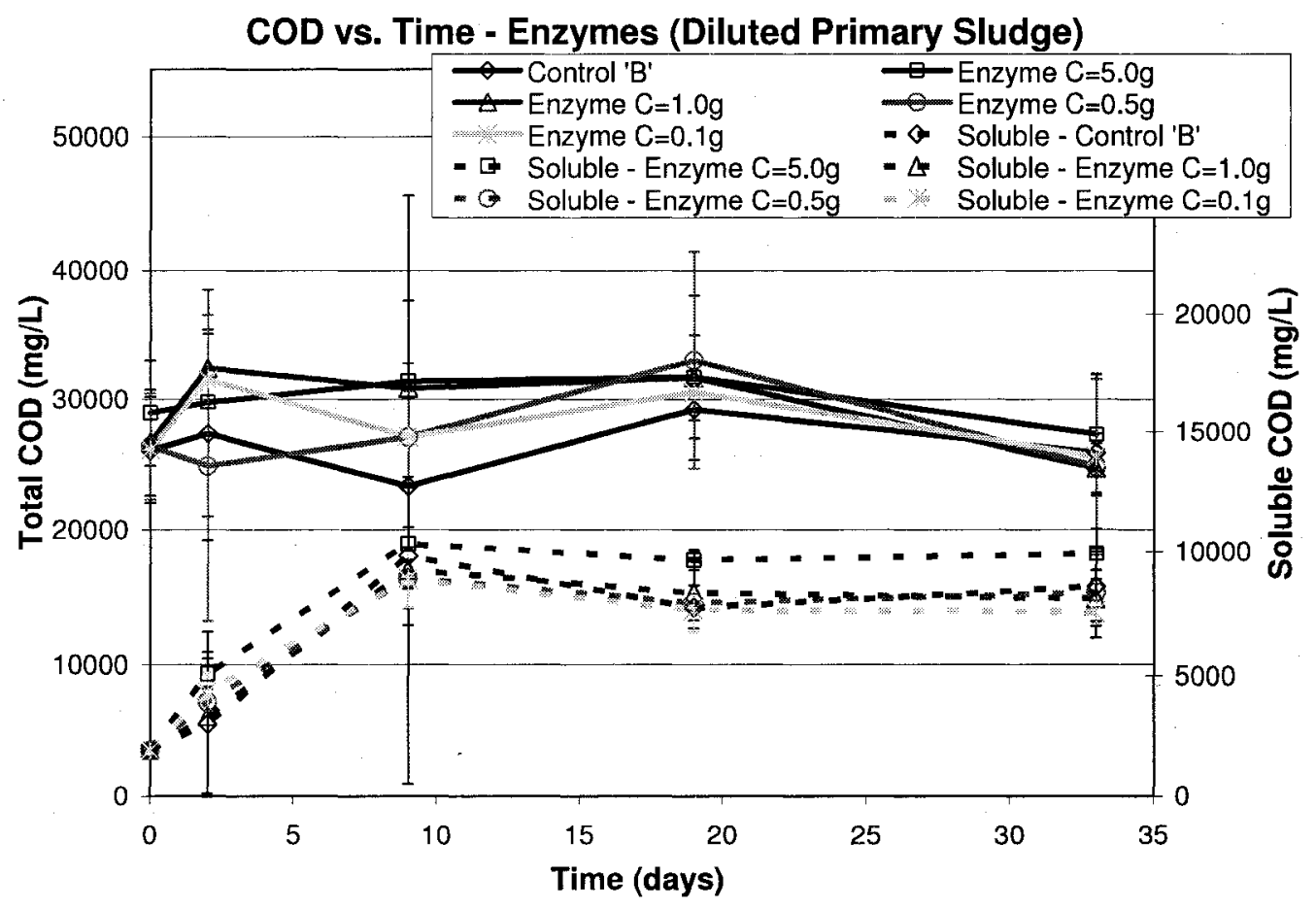

Figure 4-14(b): Profiles of the total and soluble COD during the batch reactor experiments with diluted sludge treated with an enzyme and bacterial additive 


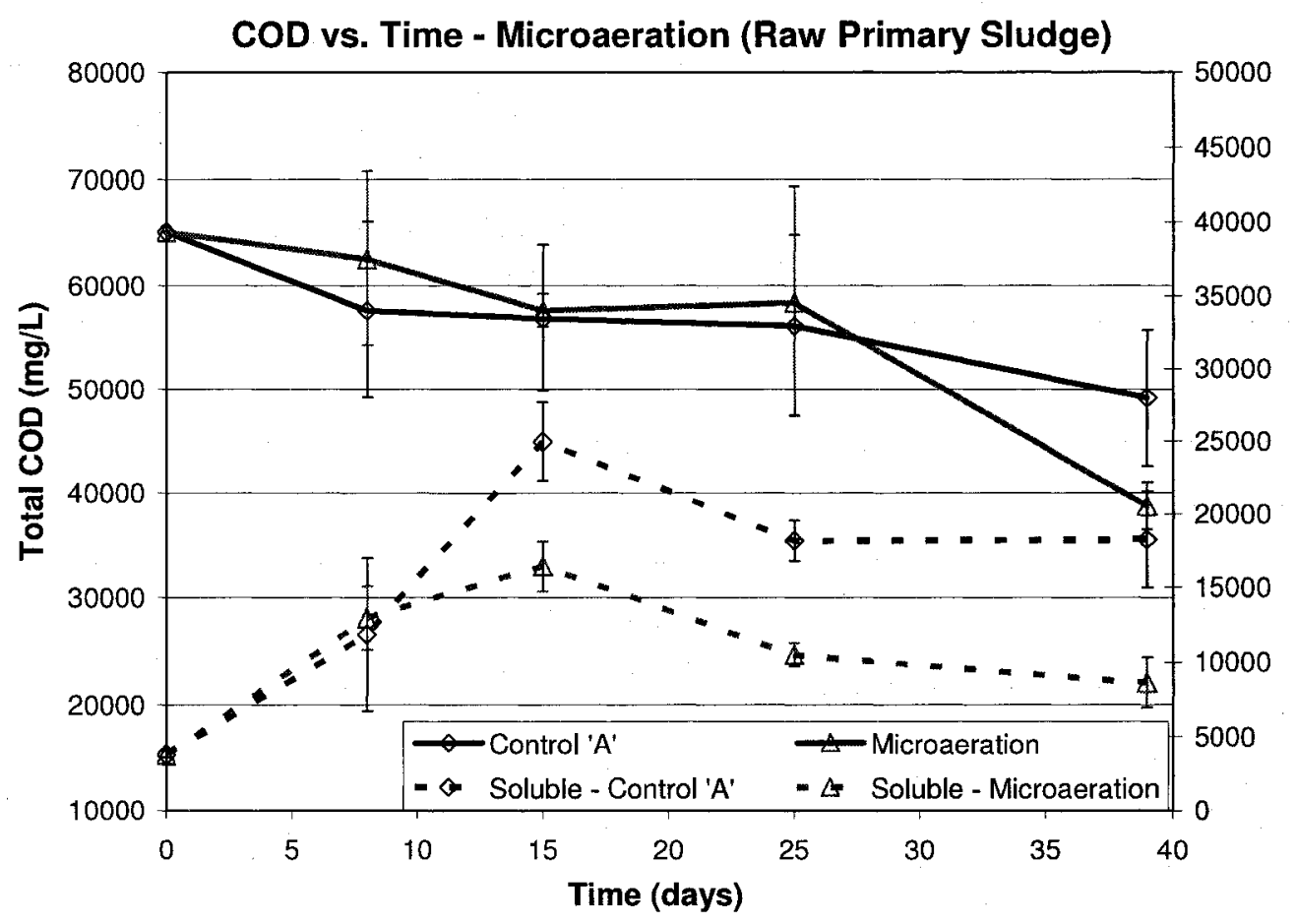

Figure 4-15(b): Profiles of the total and soluble COD during the batch reactor experiments with raw primary sludge treated with microaeration

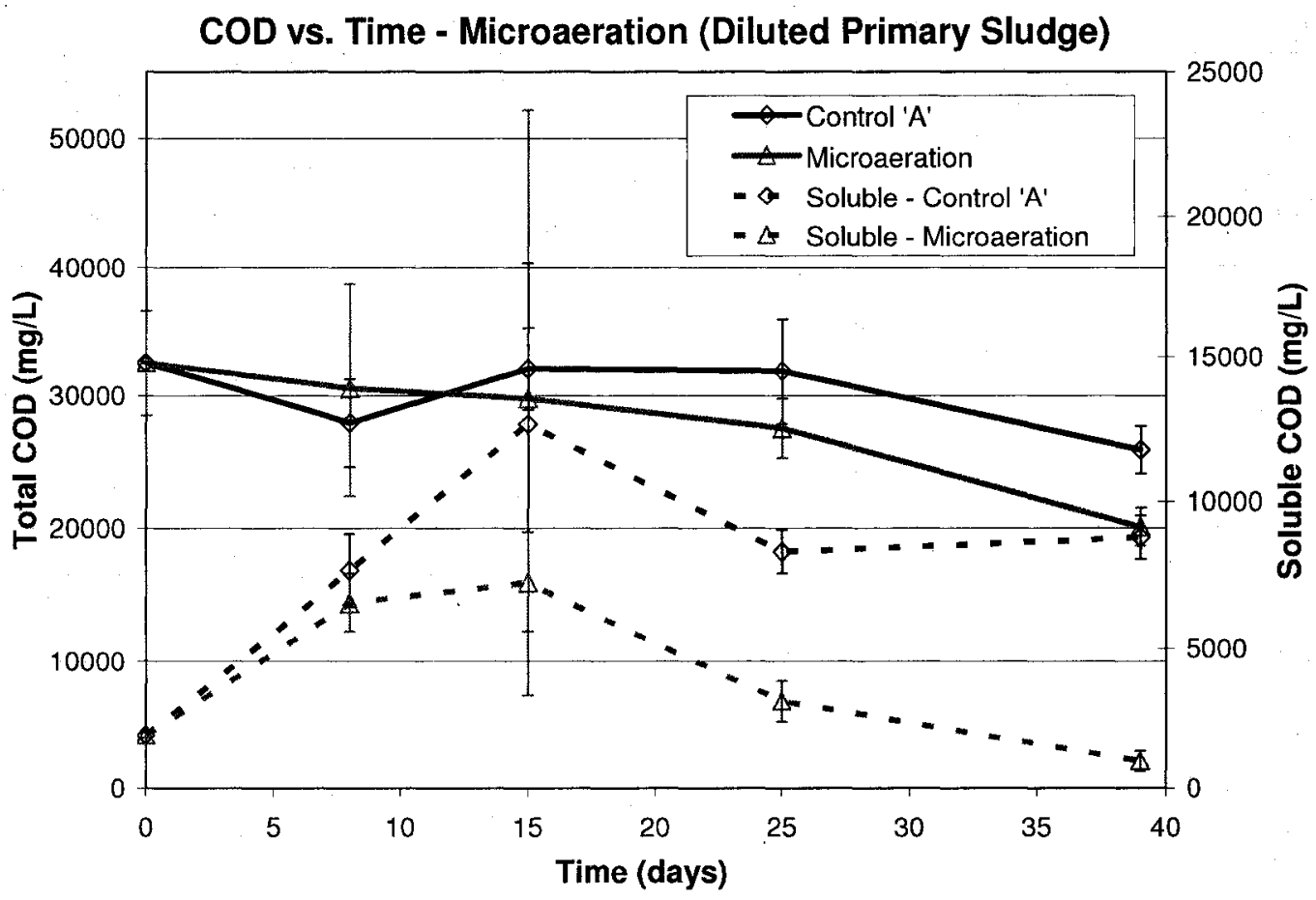

Figure 4-16(b): Profiles of the total and soluble COD during the batch reactor experiments with diluted primary sludge treated with microaeration 


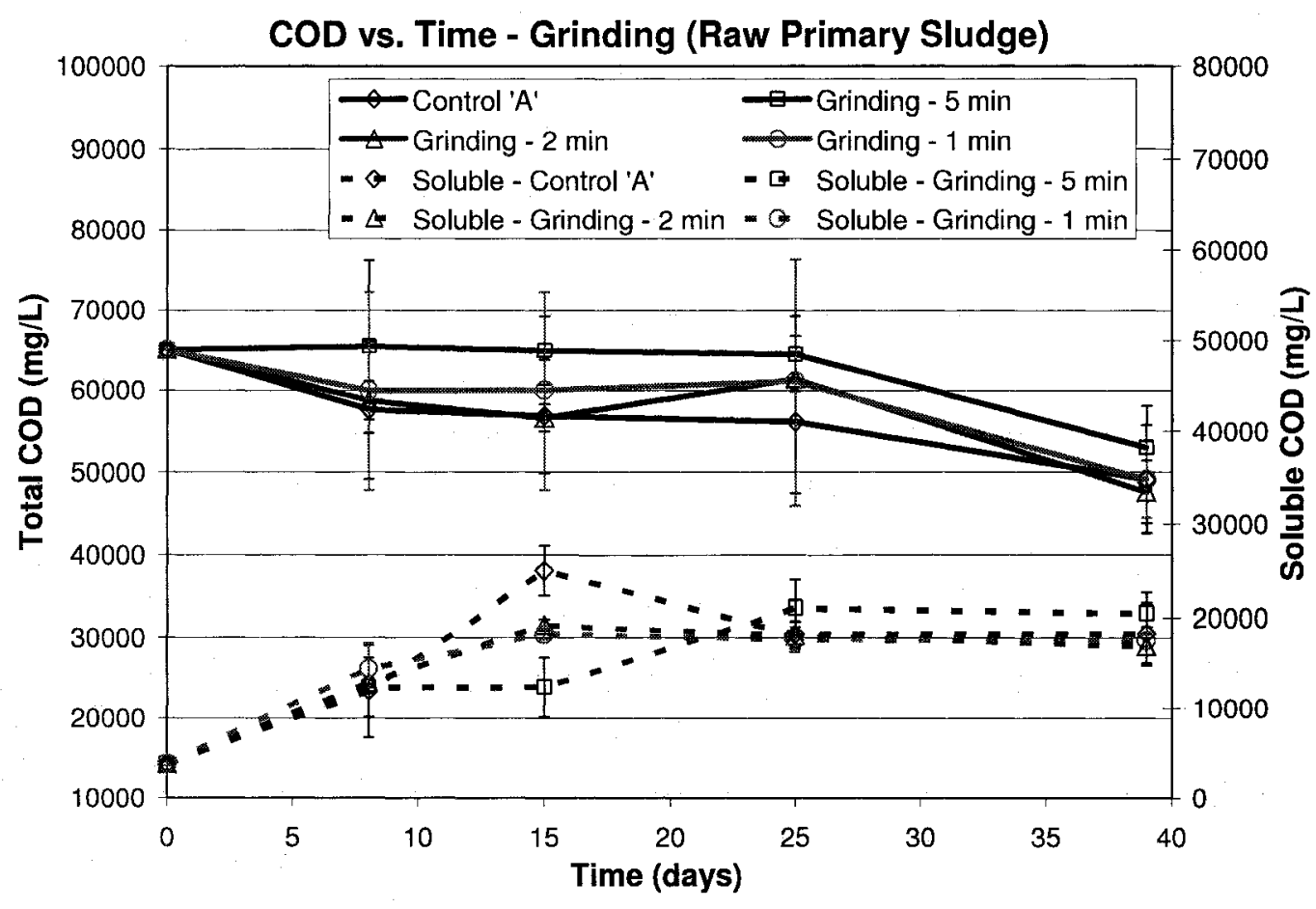

Figure 4-17(b): Profiles of the total and soluble COD during the batch reactor experiments with raw primary sludge treated with an initial grinding cycle

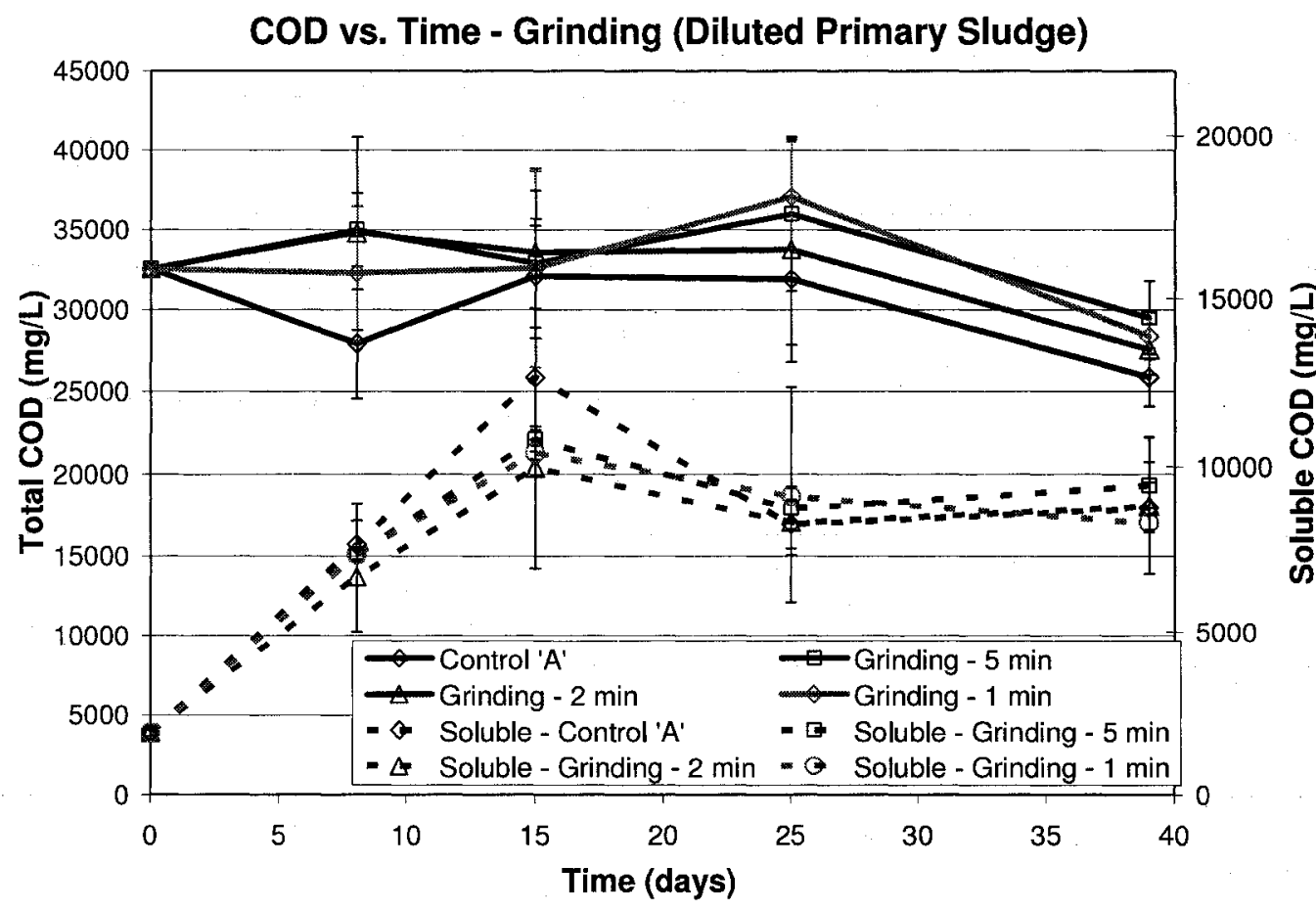

Figure 4-18(b): Profiles of the total and soluble COD during the batch reactor experiments with diluted primary sludge treated with an initial grinding cycle 


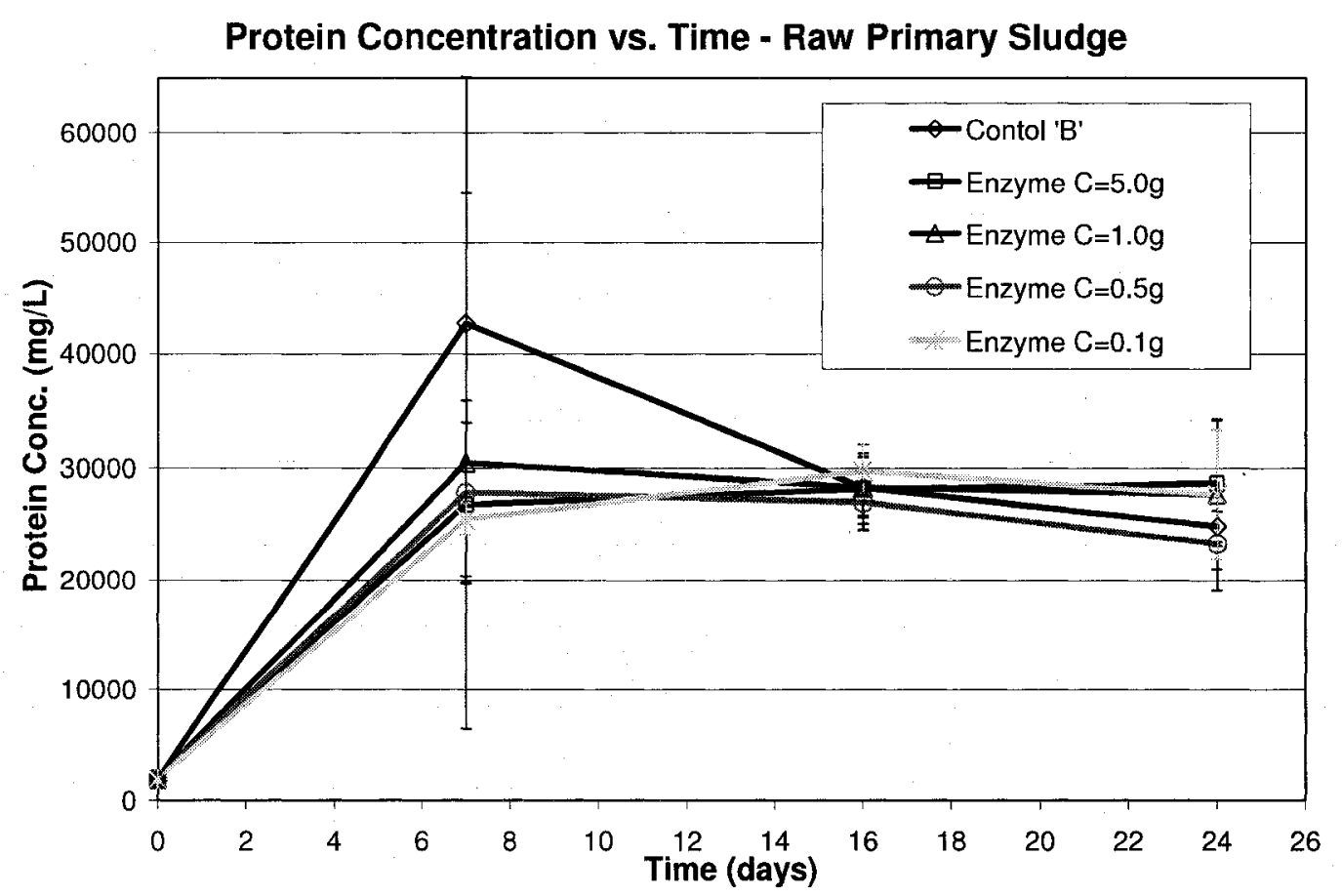

Figure 4-19(b): Profiles of the protein concentrations during the batch reactor tests with raw primary sludge samples treated with an enzyme and bacterial additive

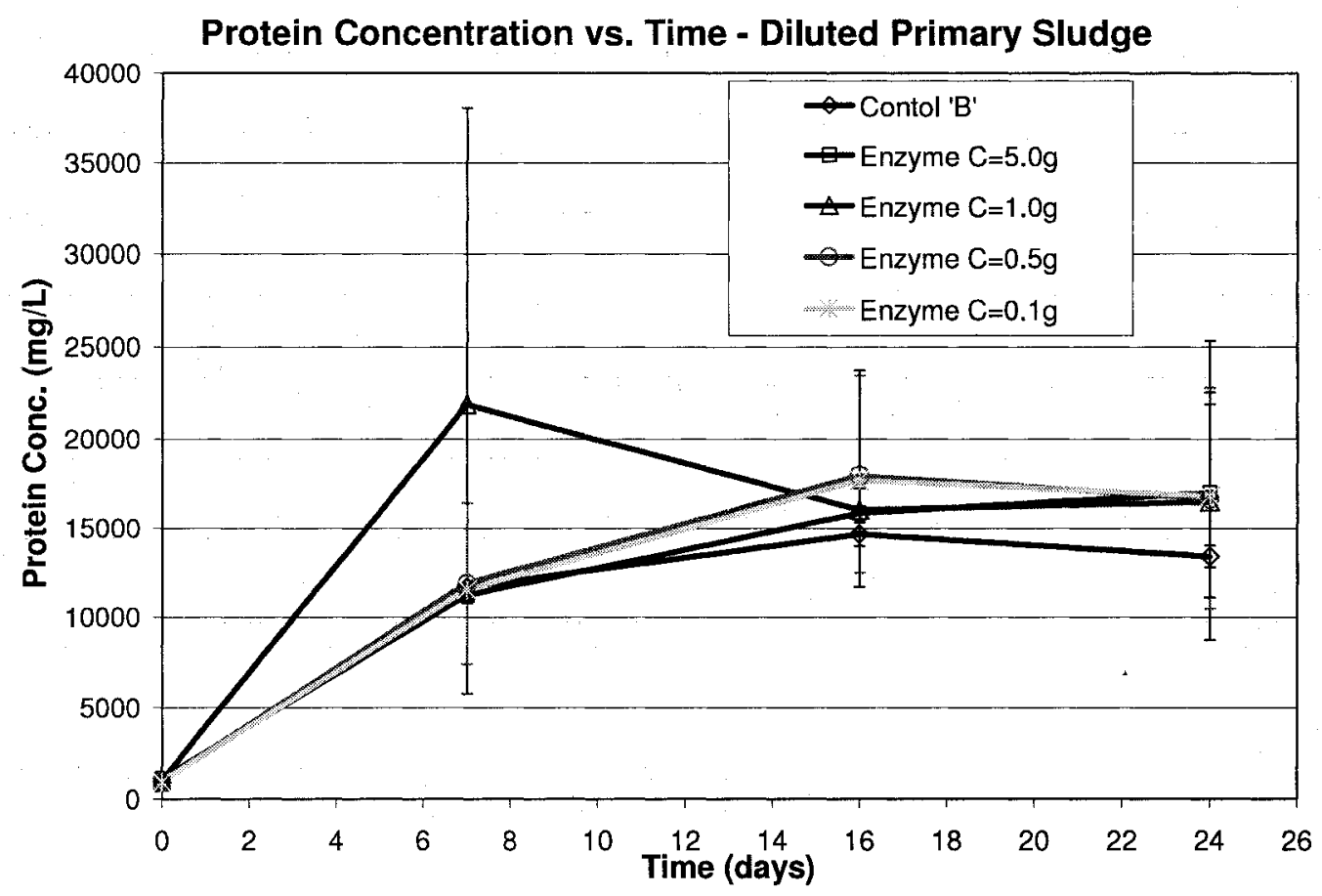

Figure 4-20(b): Profiles of the protein concentrations during the batch reactor tests with diluted primary sludge samples treated with an enzyme and bacterial additive 


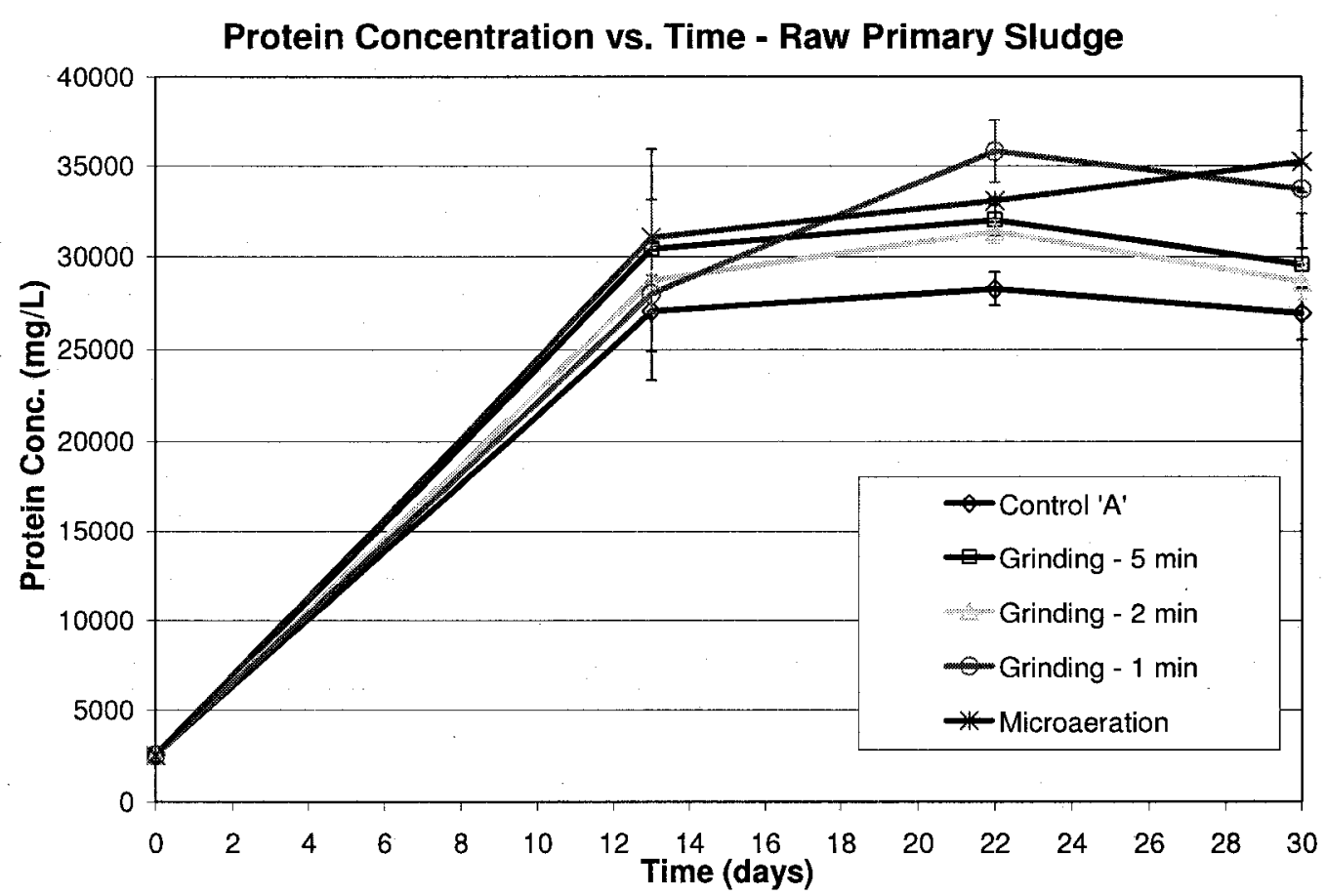

Figure 4-21(b): Profiles of the protein concentrations during the batch reactor tests with raw primary sludge treated with microaeration and an initial grinding cycle

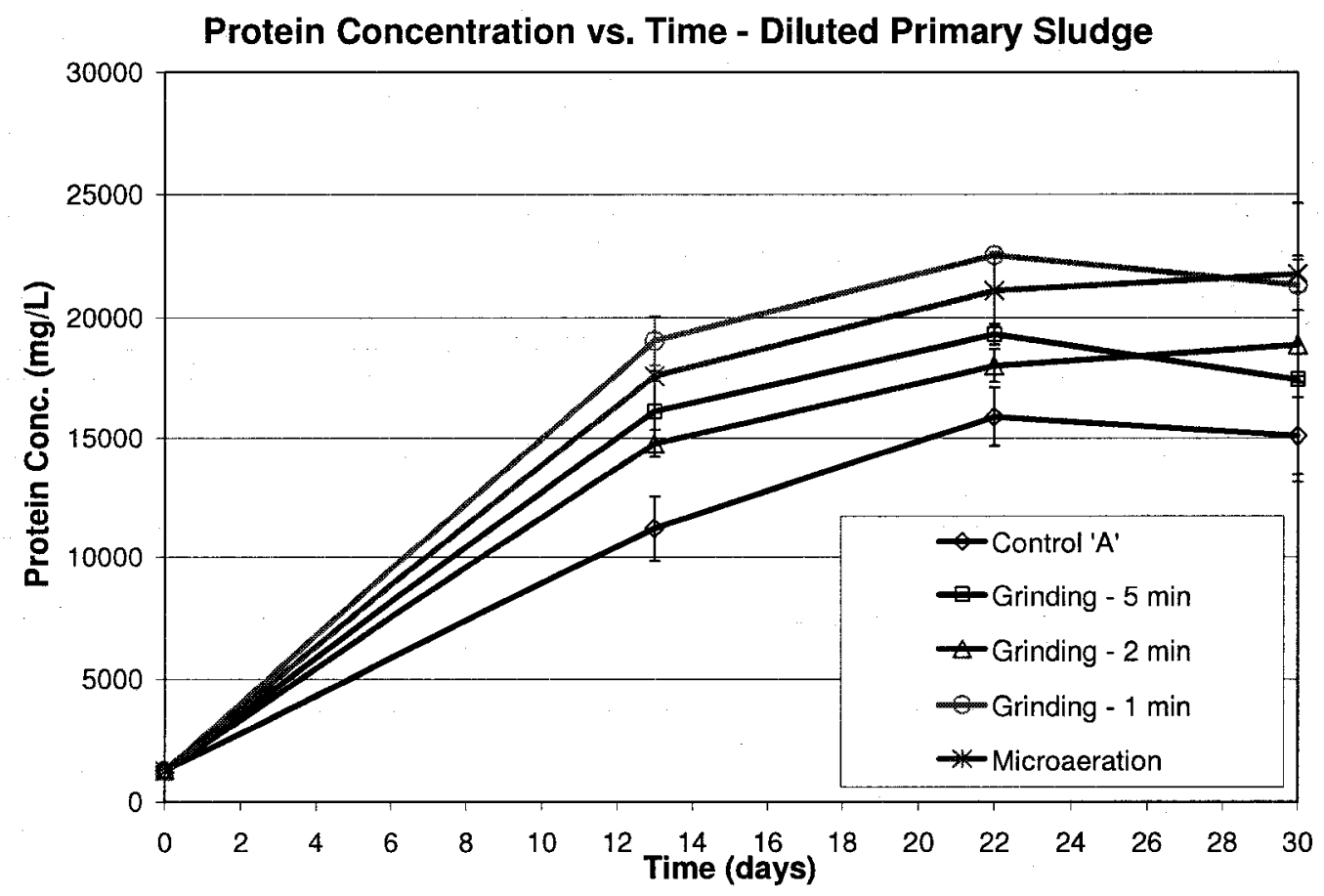

Figure 4-22(b): Profiles of the protein concentrations during the batch reactor tests with diluted primary sludge treated with microaeration and an initial grinding cycle 


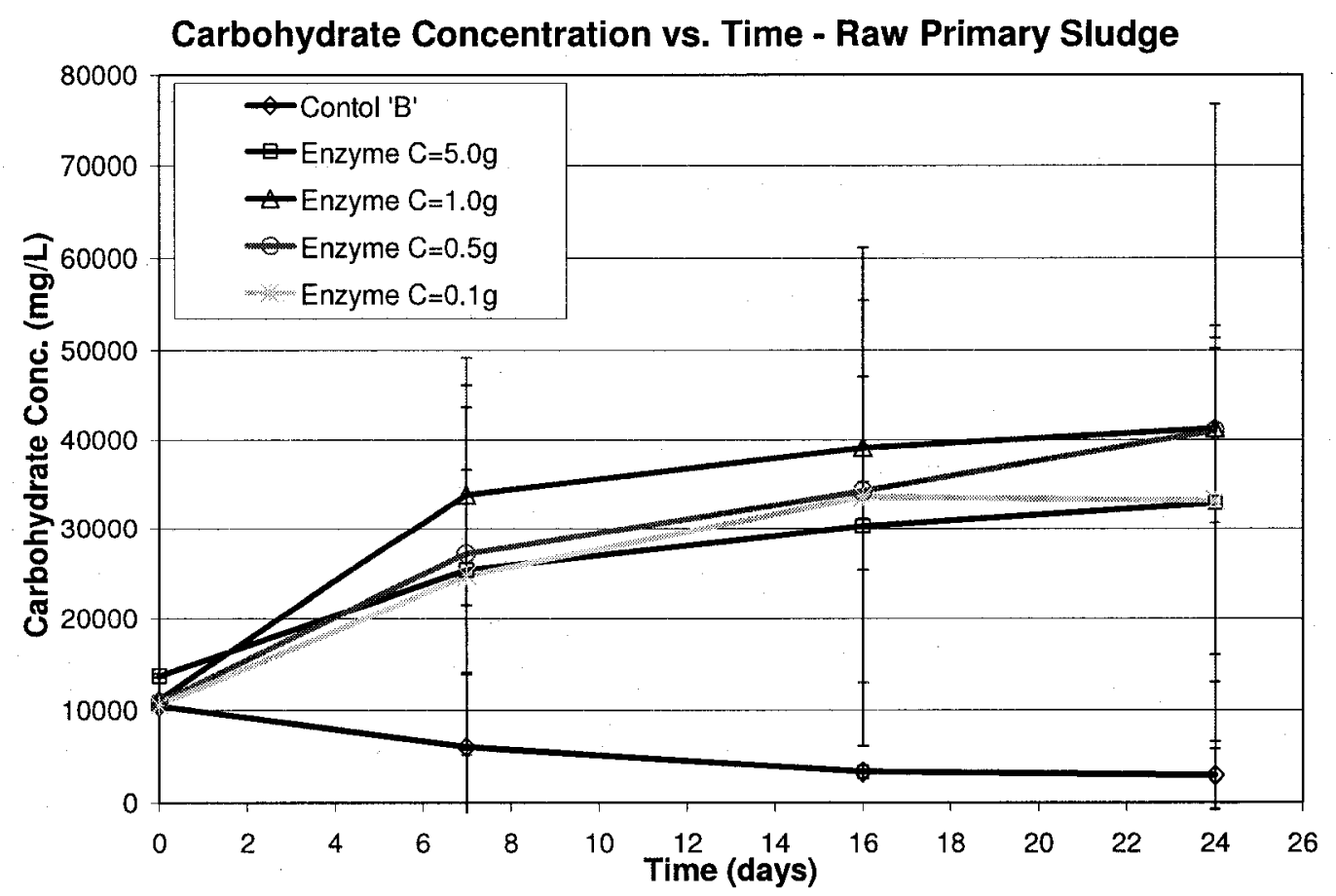

Figure 4-23(b): Profiles of the carbohydrates concentrations during the batch reactor tests with raw primary sludge samples treated with an enzyme and bacterial additive

\section{Carbohydrate Concentration vs Time - Diluted Primary Sludge}

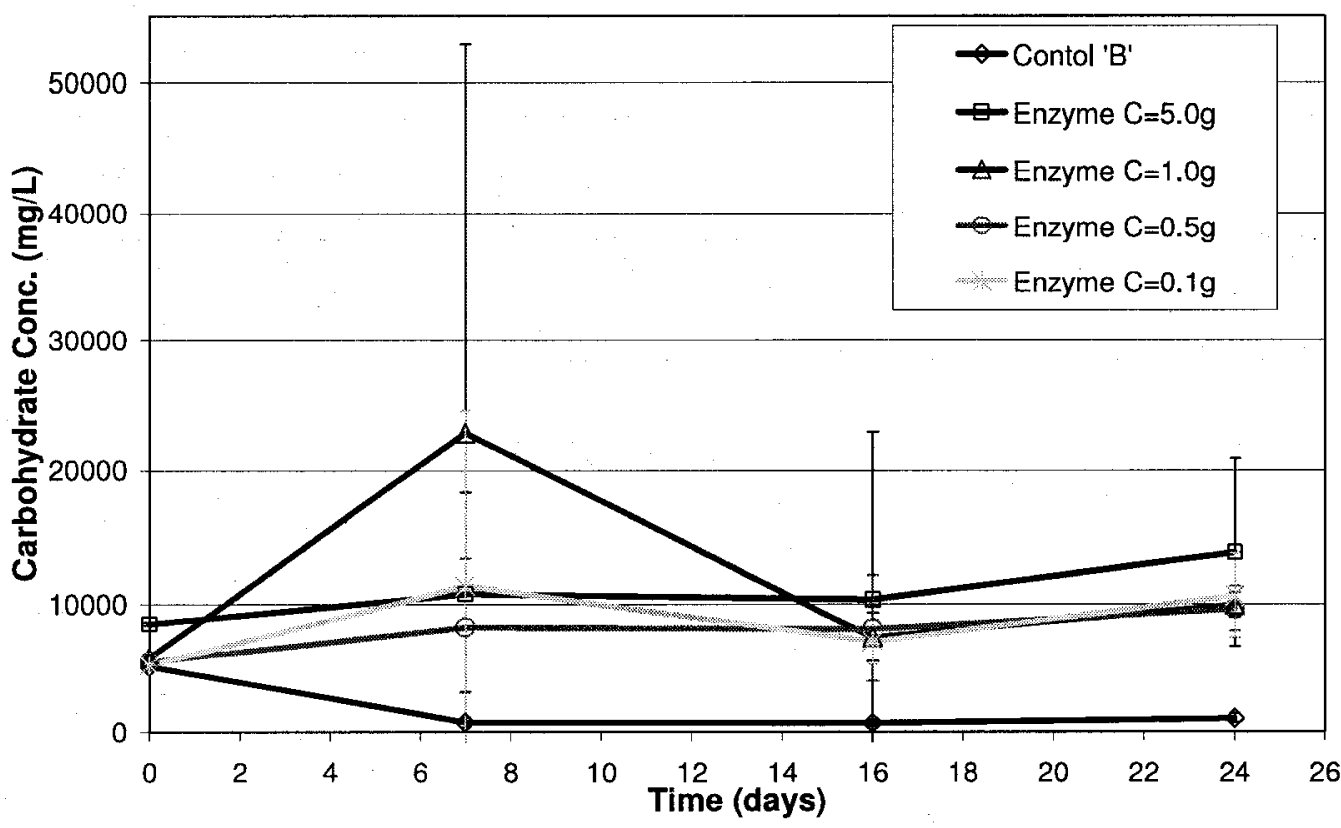

Figure 4-24(b): Profiles of the carbohydrates concentrations during the batch reactor tests with diluted primary sludge samples treated with an enzyme and bacterial additive 


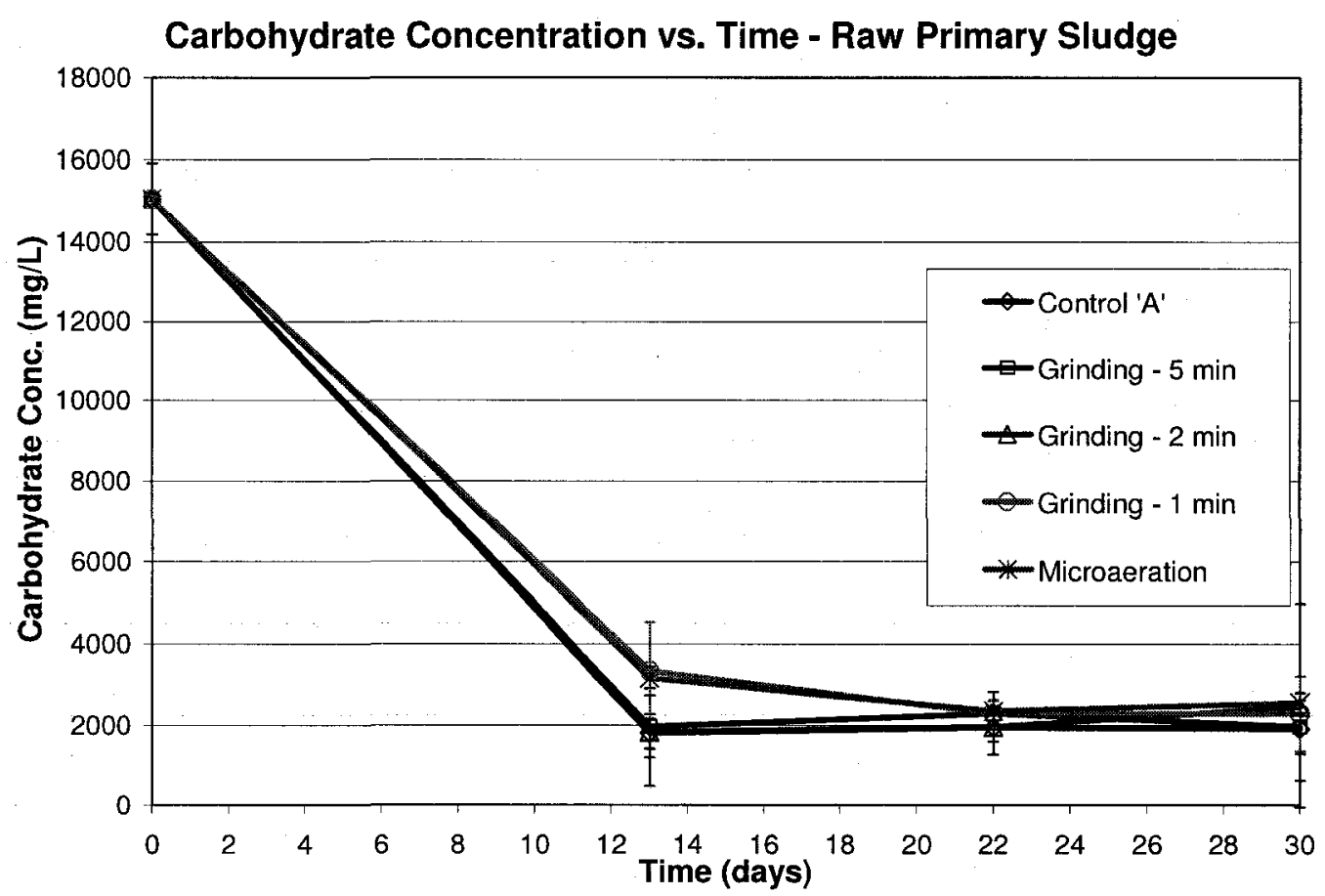

Figure 4-25(b): Profiles of the carbohydrate concentrations during the batch reactor tests with raw primary sludge treated with microaeration and an initial grinding cycle

\section{Carbohydrate Concentration vs Time - Diluted Primary Sludge}

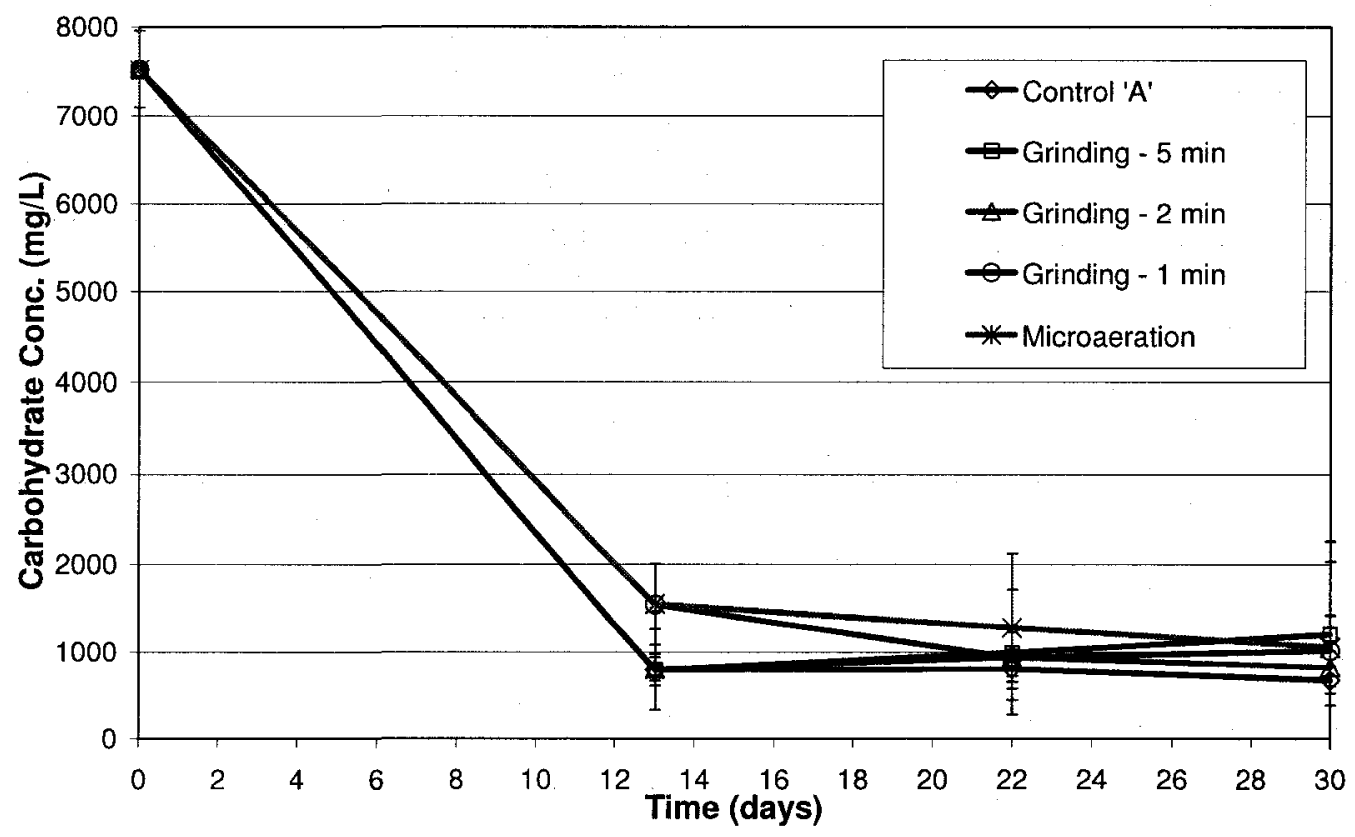

Figure 4-26(b): Profiles of the carbohydrate concentrations during the batch reactor tests with diluted primary sludge treated with microaeration and an initial grinding cycle 


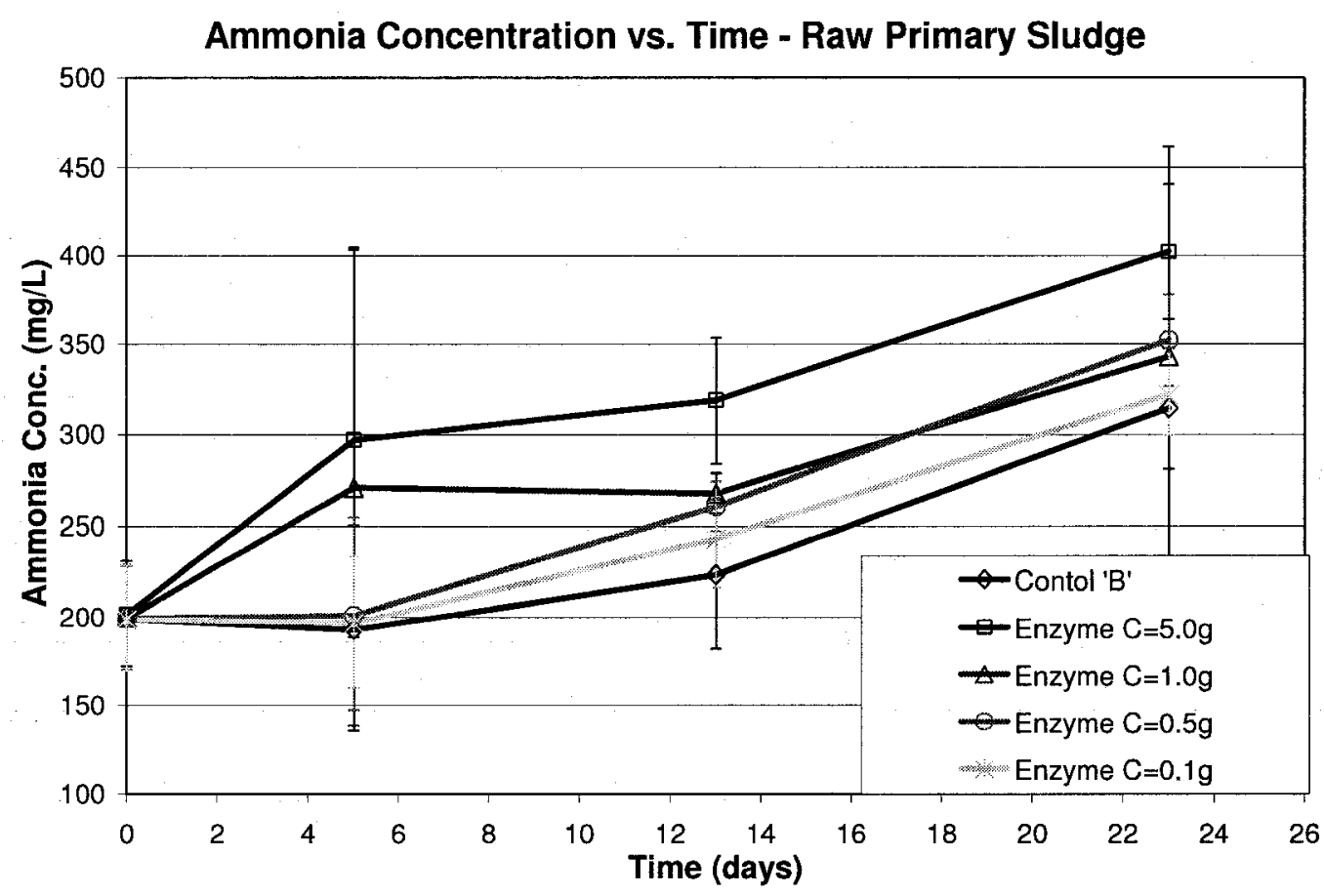

Figure 4-27(b): Profiles of the ammonia concentrations during the batch reactor tests with raw primary sludge samples treated with an enzyme and bacterial additive

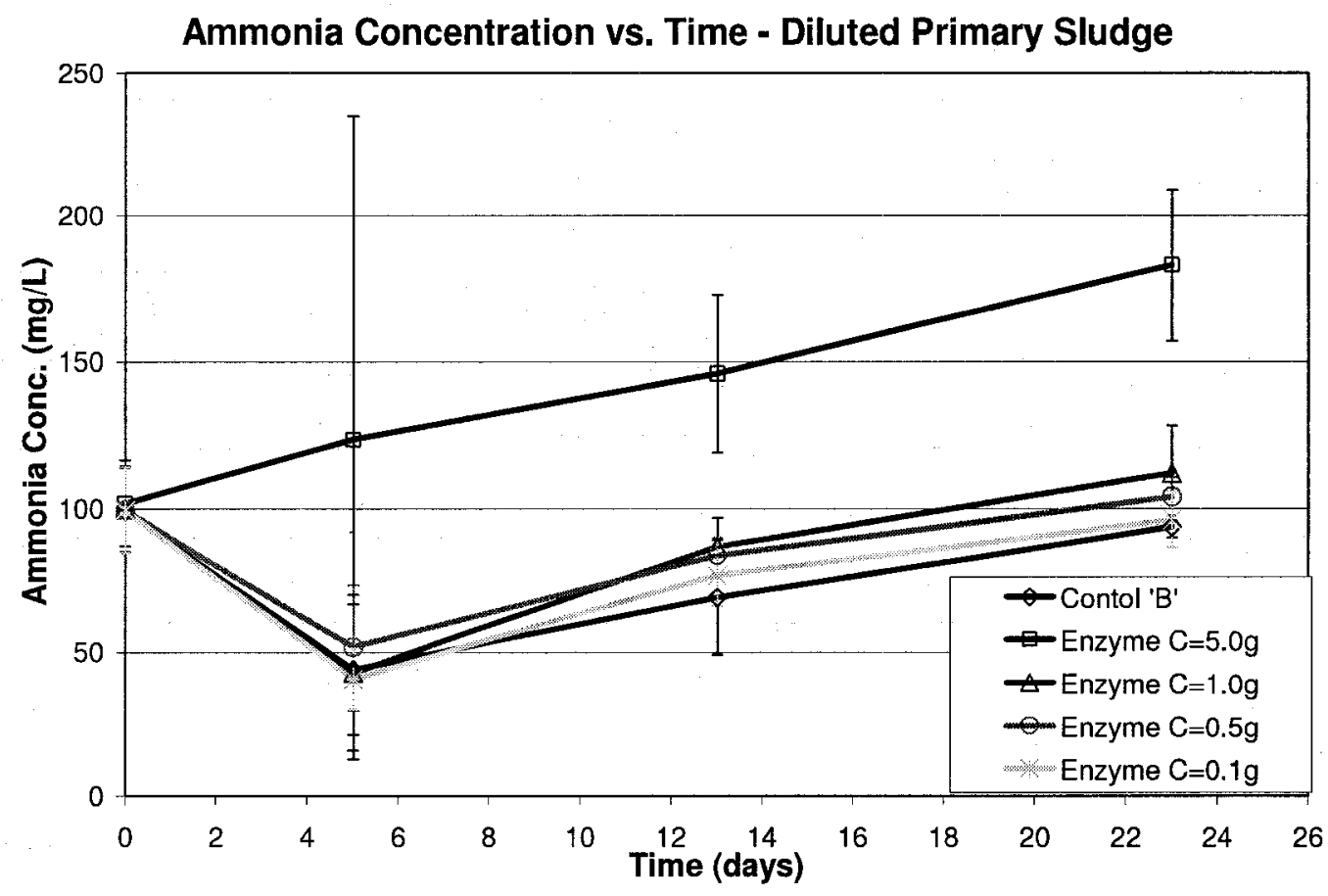

Figure 4-28(b): Profiles of the ammonia concentrations during the batch reactor tests with diluted primary sludge samples treated with an enzyme and bacterial additive 


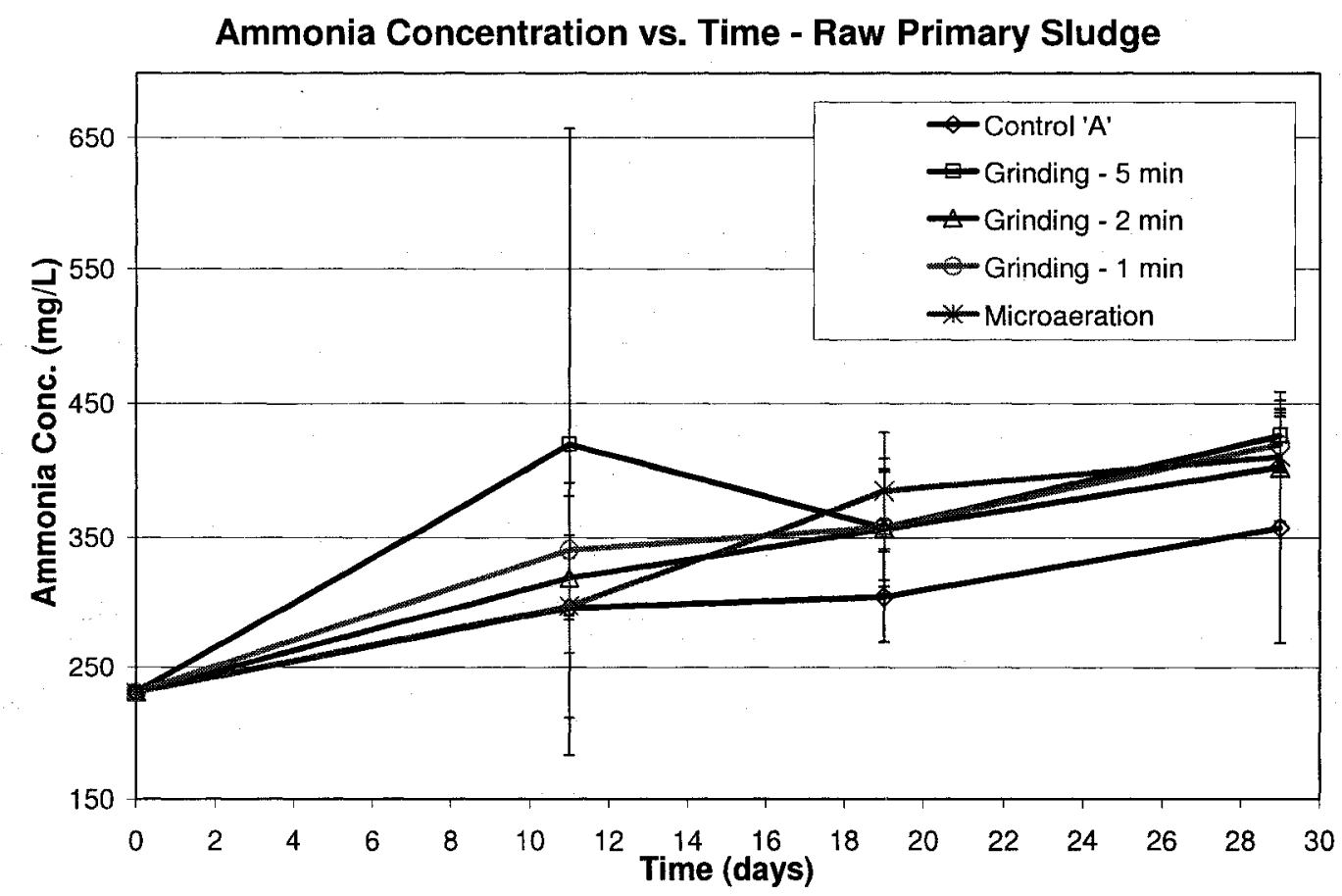

Figure 4-29(b): Profiles of the ammonia concentrations during the batch reactor tests with raw primary sludge treated with microaeration and an initial grinding cycle

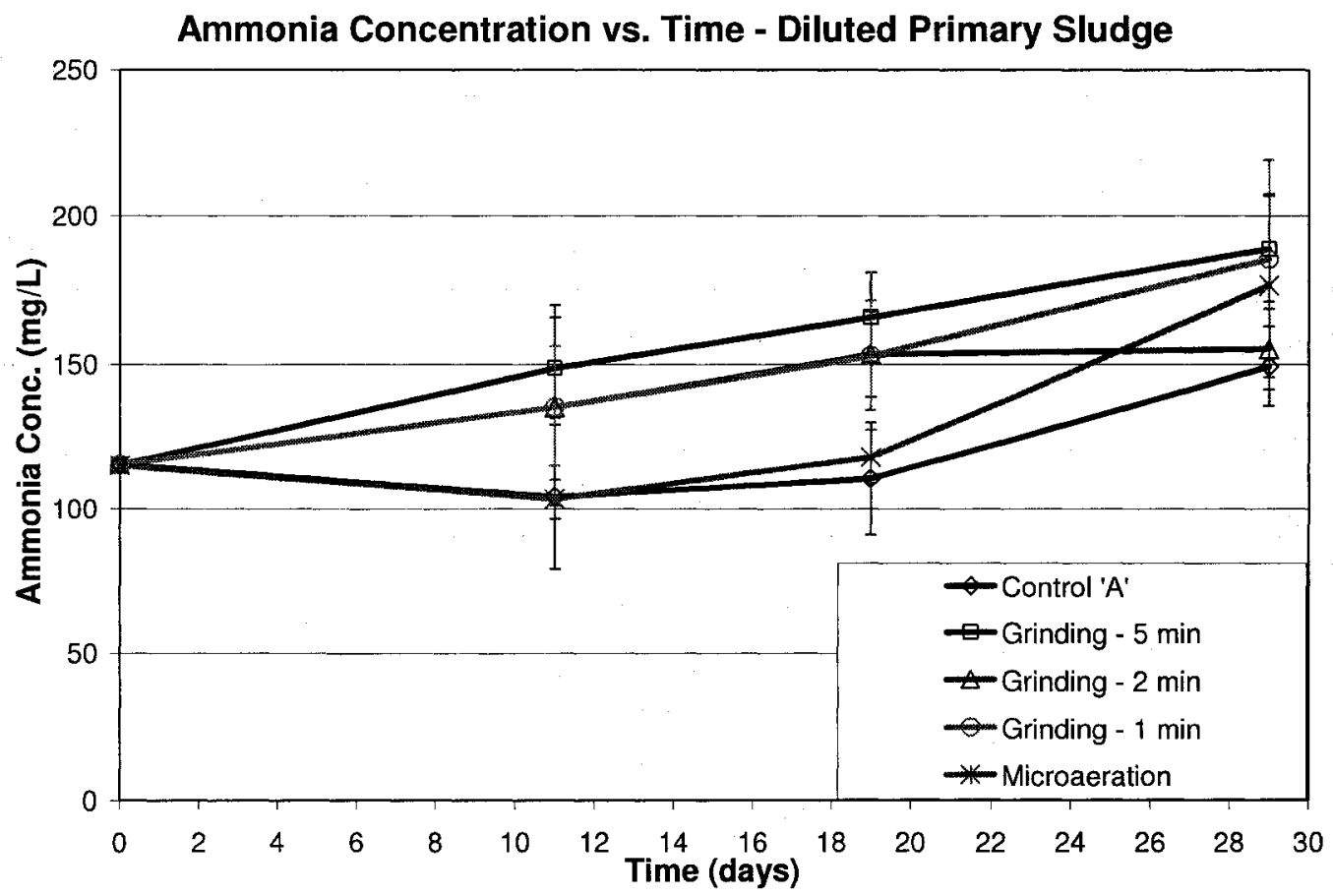

Figure 4-30(b): Profiles of the ammonia concentrations during the batch reactor tests with diluted primary sludge treated with microaeration and an initial grinding cycle 


\section{Appendix D: Volatile/Total Solids Analysis - Batch Reactor Tests}
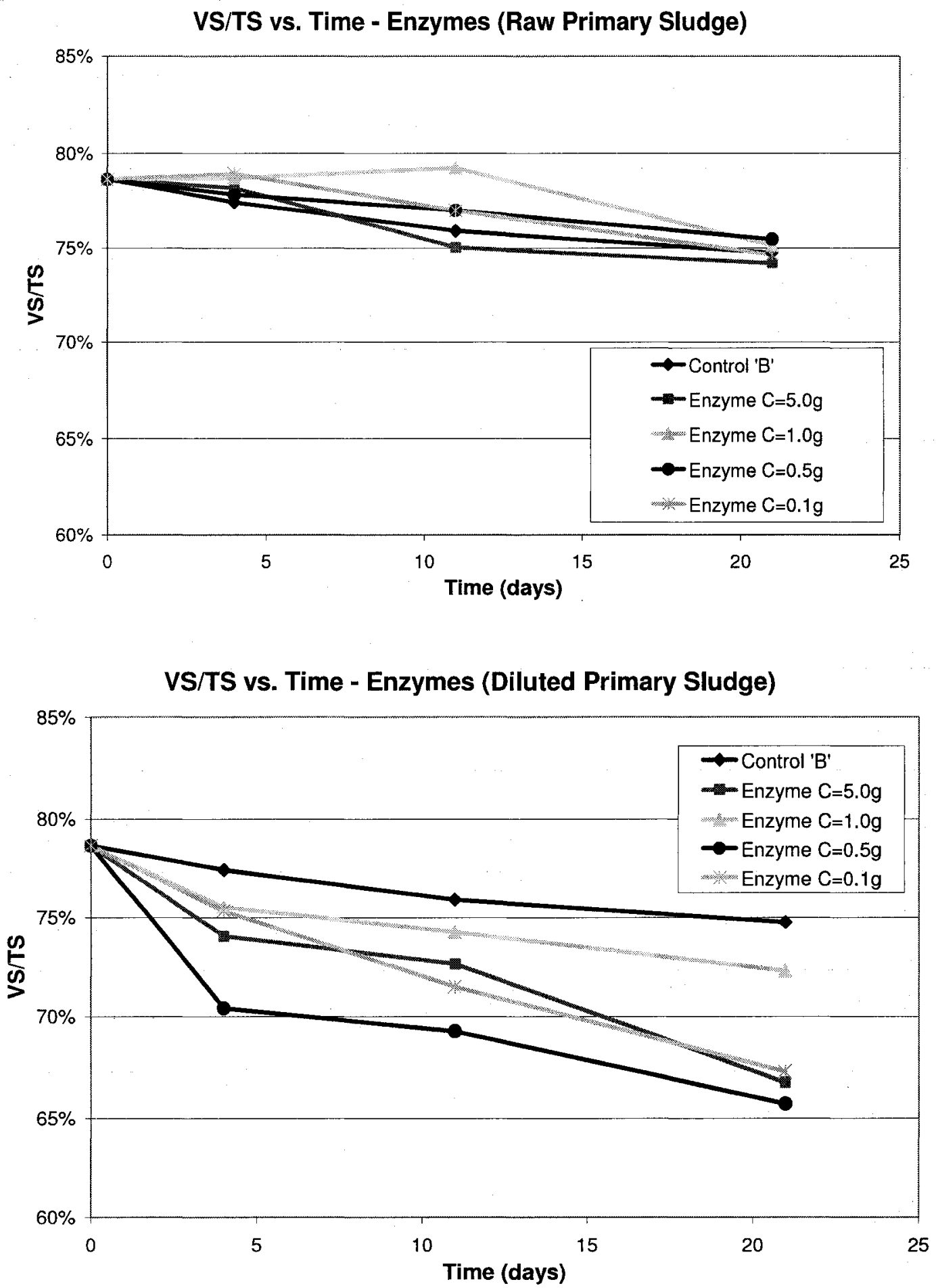

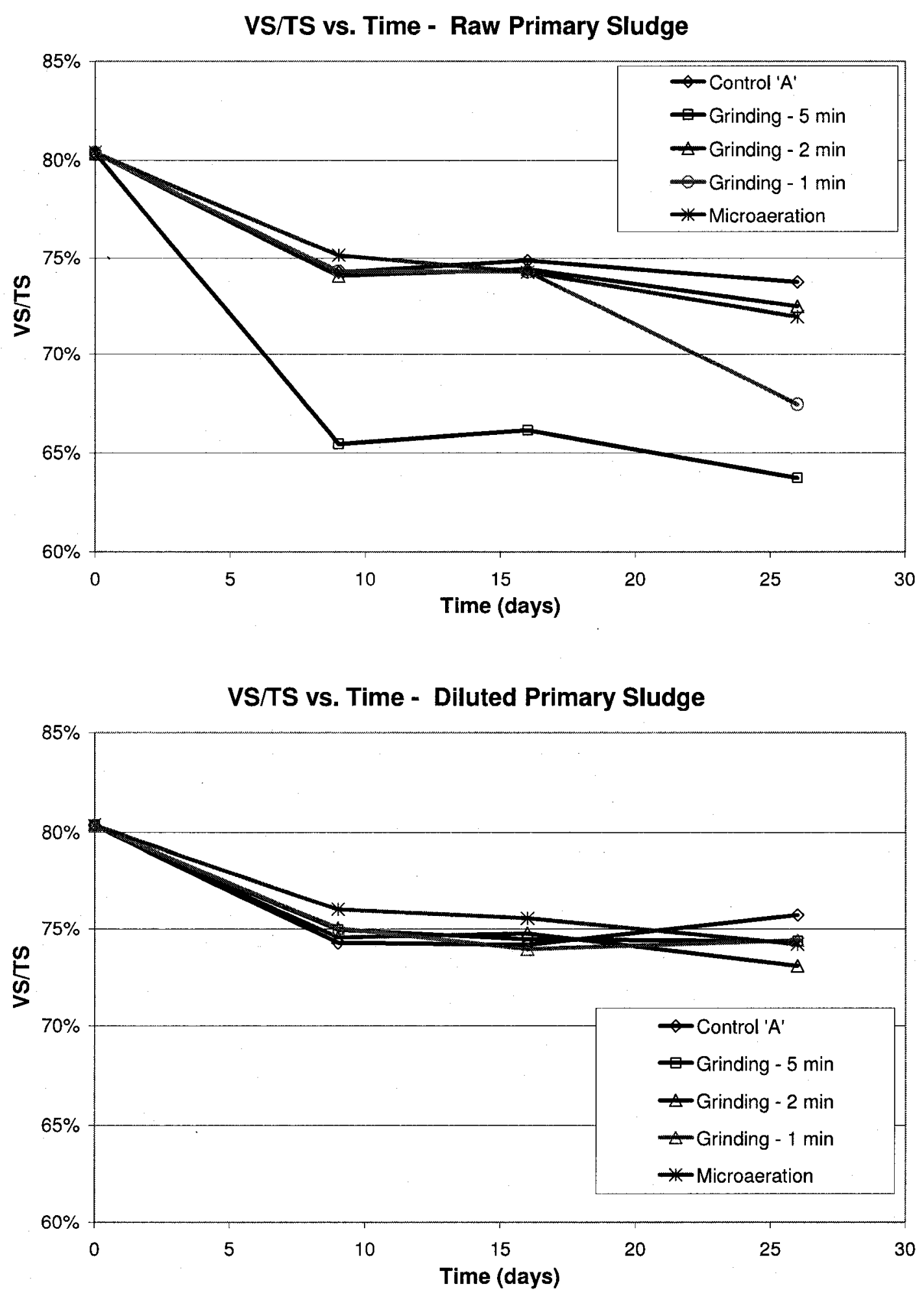


\section{Appendix E: Raw Data - Continuous Flow Reactor Tests}

\section{Appendix E1: Total Suspended Solids (TSS)}

\begin{tabular}{|lc|cc|cc|}
\hline \multicolumn{7}{|c|}{ Feed } \\
\hline \multicolumn{3}{|c|}{ Total Suspended Solids (TSS, mg/L) } \\
Test Date & Test Day & Rep.1 & Rep.2 & AVG & STDEV \\
\hline 4-Feb-2008 & 0 & 52.2 & 53.4 & 52.8 & 0.8 \\
5-May-2008 & 91 & 47.8 & 51 & 49.4 & 2.3 \\
30-May-2008 & 116 & 48.1 & 51.1 & 49.6 & 2.1 \\
\hline
\end{tabular}

\begin{tabular}{|rc|cc|cc|}
\hline \multicolumn{7}{|c|}{ Control Reactor (R1) } \\
\hline \multicolumn{7}{|c|}{ Total Suspended Solids (TSS, mgL) } \\
Test Date & Test Day & Rep.1 & Rep.2 & AVG & STDEV \\
\hline 4-Feb-2008 & 0 & 45.3 & 36 & 40.7 & 6.6 \\
12-Feb-2008 & 8 & 103.2 & 78.5 & 90.9 & 17.5 \\
3-Mar-2008 & 28 & 64.4 & 57.9 & 61.2 & 4.6 \\
19-Mar-2008 & 44 & 43.3 & 59.8 & 51.6 & 11.7 \\
3-Apr-2008 & 59 & 60.4 & 42.1 & 51.3 & 12.9 \\
17-Apr-2008 & 73 & 43.2 & 22.1 & 32.7 & 14.9 \\
5-May-2008 & 91 & 48.7 & 54.5 & 51.6 & 4.1 \\
23-May-2008 & 109 & 38.9 & 42.3 & 40.6 & 2.4 \\
30-May-2008 & 116 & 32.3 & 37.3 & 34.8 & 3.5 \\
\hline
\end{tabular}

Enzyme \& Bacterial Additives - High Dose Reactor (R2)

\begin{tabular}{|rc|cc|cc|}
\hline \multicolumn{5}{|c|}{ Tetal Suspended Solids (TSS, mgL) } \\
Test Date & Test Day & Rep.1 & Rep.2 & AVG & STDEV \\
\hline 4-Feb-2008 & 0 & 45.5 & 36.6 & 41.1 & 6.3 \\
12-Feb-2008 & 8 & 121.3 & 103.1 & 112.2 & 12.9 \\
3-Mar-2008 & 28 & 63.6 & 54.9 & 59.3 & 6.2 \\
19-Mar-2008 & 44 & 54.3 & 47.8 & 51.1 & 4.6 \\
3-Apr-2008 & 59 & 68.4 & 51.2 & 59.8 & 12.2 \\
17-Apr-2008 & 73 & 43.5 & 52.9 & 48.2 & 6.6 \\
5-May-2008 & 91 & 55.8 & 43.7 & 49.8 & 8.6 \\
23-May-2008 & 109 & 33.1 & 46.5 & 39.8 & 9.5 \\
30-May-2008 & 116 & 35.8 & 28.3 & 32.1 & 5.3 \\
\hline
\end{tabular}




\begin{tabular}{|c|c|c|c|c|c|}
\hline Enzyme \& Ba & terial Ad & ves. & osel & (F) & \\
\hline$=2$. & 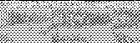 & otal Su & hideds & S(TSS & $g(1)$ \\
\hline Test Date: & Test Day & Rep.1 & Rep.2 & AVG & STDEV \\
\hline 4-Feb-2008 & 0 & 53.4 & 32.7 & 43.1 & 14.6 \\
\hline 12-Feb-2008 & 8 & 115.4 & 108.6 & 112.0 & 4.8 \\
\hline 3-Mar-2008 & 28 & 72.2 & & 72.2 & \#DIV/0! \\
\hline 19-Mar-2008 & 44 & 64.3 & 57.3 & 60.8 & 4.9 \\
\hline 3-Apr-2008 & 59 & 62.6 & 60.8 & 61.7 & 1.3 \\
\hline 17-Apr-2008 & 73 & 27.8 & 33.1 & 30.5 & 3.7 \\
\hline 5-May-2008 & 91 & 49.8 & 34.2 & 42.0 & 11.0 \\
\hline 23-May-2008 & 109 & 28.7 & 26.5 & 27.6 & 1.6 \\
\hline 30-May-2008 & 116 & 32.3 & 28.5 & 30.4 & 2.7 \\
\hline
\end{tabular}

\begin{tabular}{|rc|cc|cc|}
\hline \multicolumn{7}{|c|}{ Microaeration - High Dose Reactor (R4) } \\
\hline \multicolumn{5}{|c|}{ Total Suspended Solids (TSS, mg/L) } \\
Test Date & Test Day & Rep.1 & Rep.2 & AVG & STDEV \\
\hline 4-Feb-2008 & 0 & 44.2 & 38.6 & 41.4 & 4.0 \\
12-Feb-2008 & 8 & 185.8 & 141 & 163.4 & 31.7 \\
3-Mar-2008 & 28 & 29.1 & 32.3 & 30.7 & 2.3 \\
19-Mar-2008 & 44 & 45.2 & 54 & 49.6 & 6.2 \\
3-Apr-2008 & 59 & 35.4 & 28.1 & 31.8 & 5.2 \\
17-Apr-2008 & 73 & 22.2 & 19.6 & 20.9 & 1.8 \\
5-May-2008 & 91 & 27.2 & 35.2 & 31.2 & 5.7 \\
23-May-2008 & 109 & 19.9 & 18.9 & 19.4 & 0.7 \\
30-May-2008 & 116 & 17.6 & 18.6 & 18.1 & 0.7 \\
\hline
\end{tabular}

\begin{tabular}{|rc|cc|cc|}
\hline \multicolumn{7}{|c|}{ Microaeration - Low Dose Reactor(R5) } \\
\hline \multicolumn{7}{|c|}{ Total Suspended Solids (TSS, mg/L) } \\
\hline Test Date & Test Day & Rep.1 & Rep.2 & AVG & STDEV \\
\hline 4-Feb-2008 & 0 & 38.3 & 44.5 & 41.4 & 4.4 \\
12-Feb-2008 & 8 & 124.2 & 163.8 & 144.0 & 28.0 \\
3-Mar-2008 & 28 & 48.3 & 33.3 & 40.8 & 10.6 \\
19-Mar-2008 & 44 & 34.2 & 33.2 & 33.7 & 0.7 \\
3-Apr-2008 & 59 & 35.5 & 26.7 & 31.1 & 6.2 \\
17-Apr-2008 & 73 & 22.3 & 18.6 & 20.5 & 2.6 \\
5-May-2008 & 91 & 30.3 & 28.9 & 29.6 & 1.0 \\
23-May-2008 & 109 & 17.9 & 19.9 & 18.9 & 1.4 \\
30-May-2008 & 116 & 18.2 & 21 & 19.6 & 2.0 \\
\hline
\end{tabular}




\section{Appendix E2: Total Chemical Oxygen Demand (tCOD)}

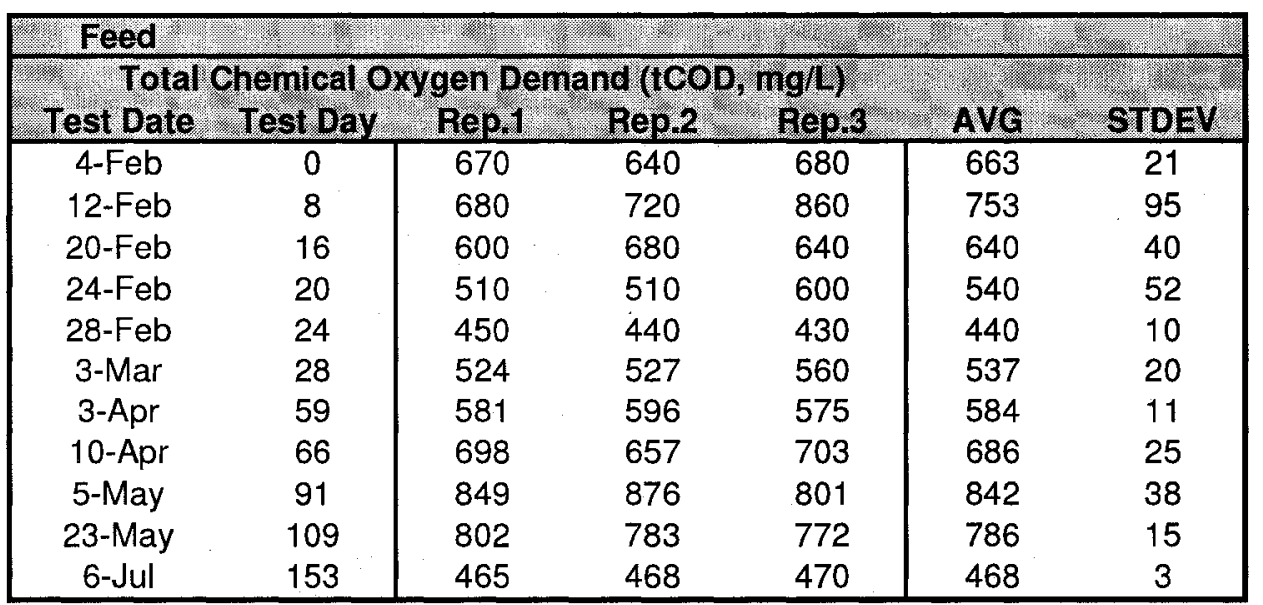

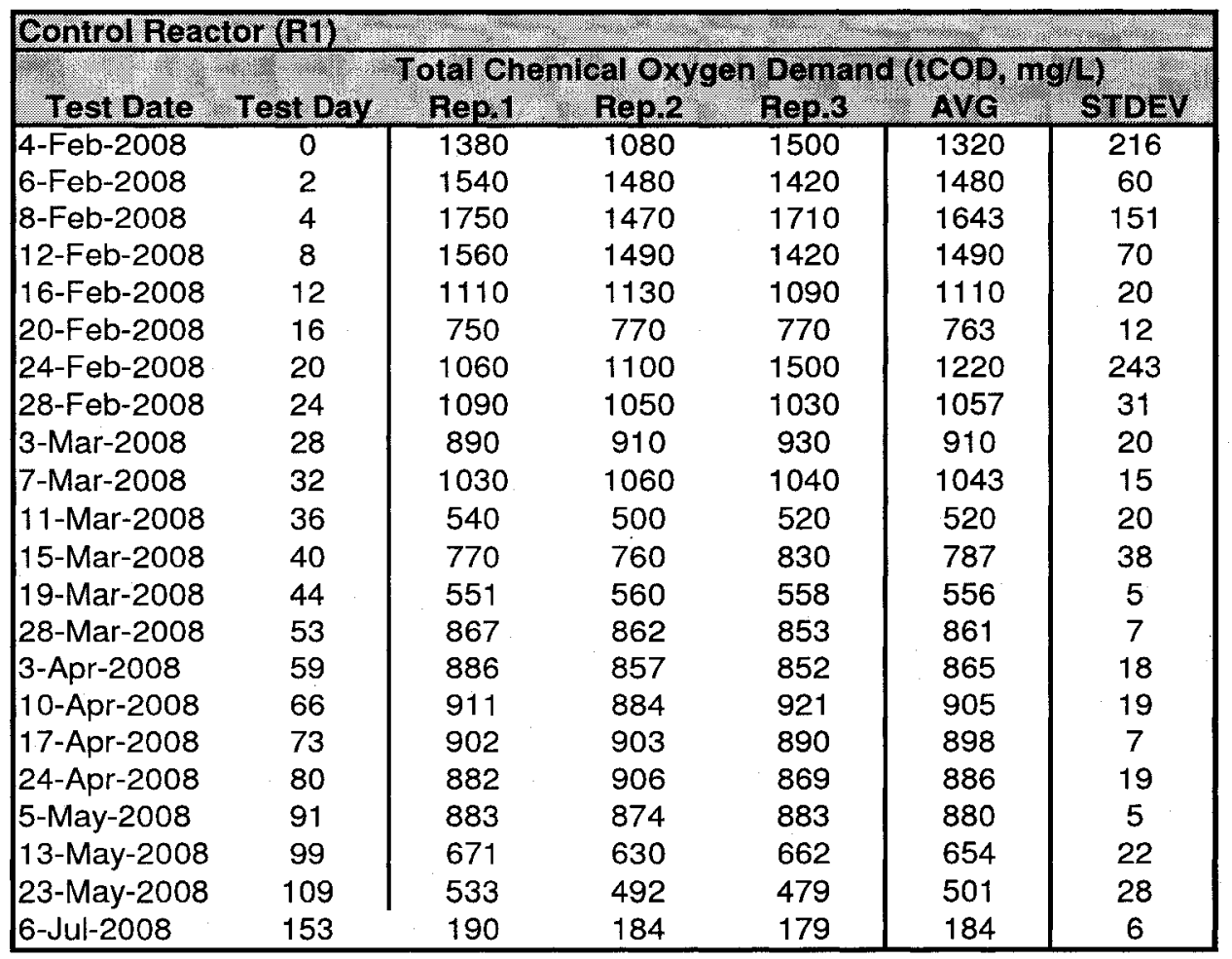




\begin{tabular}{|c|c|c|c|c|c|c|}
\hline \\
\hline \multicolumn{7}{|c|}{$\begin{array}{l}\text { Enzyme \& Bacterial Addives - Migh Dose Reactor (RD) } \\
\text { Total Chemical Oxvoen Demand (COD, moll) }\end{array}$} \\
\hline Test Date & Test Day & neopl & Rep.2 & Rep.3 & AVE & STDEVI \\
\hline 4-Feb-2008 & 0 & 1080 & 1140 & 1440 & 1220 & 193 \\
\hline 6-Feb-2008 & 2 & 1700 & 1720 & 1810 & 1743 & 59 \\
\hline 8-Feb-2008 & 4 & 2120 & 1990 & 1980 & 2030 & 78 \\
\hline 12-Feb-2008 & 8 & 1640 & 1570 & 1510 & 1573 & 65 \\
\hline 16-Feb-2008 & 12 & 1300 & 1150 & 1220 & 1223 & 75 \\
\hline 20-Feb-2008 & 16 & 930 & 860 & 900 & 897 & 35 \\
\hline 24-Feb-2008 & 20 & 940 & 900 & 1080 & 973 & 95 \\
\hline 28-Feb-2008 & 24 & 1050 & 980 & 960 & 997 & 47 \\
\hline 3-Mar-2008 & 28 & 860 & 870 & 830 & 853 & 21 \\
\hline 7-Mar-2008 & 32 & 580 & 590 & 560 & 577 & 15 \\
\hline 11-Mar-2008 & 36 & 600 & 650 & 620 & 623 & 25 \\
\hline 15-Mar-2008 & 40 & 850 & 860 & 780 & 830 & 44 \\
\hline 19-Mar-2008 & 44 & 690 & 694 & 700 & 695 & 5 \\
\hline 28-Mar-2008 & 53 & 1016 & 1010 & 1026 & 1017 & 8 \\
\hline 3-Apr-2008 & 59 & 808 & 799 & 750 & 786 & 31 \\
\hline 10-Apr-2008 & 66 & 911 & 861 & 888 & 887 & 25 \\
\hline 17-Apr-2008 & 73 & 924 & 932 & 932 & 929 & 5 \\
\hline 24-Apr-2008 & 80 & 1009 & 937 & 969 & 972 & 36 \\
\hline 5-May-2008 & 91 & 837 & 767 & 745 & 783 & 48 \\
\hline 13-May-2008 & 99 & 698 & 696 & 650 & 681 & 27 \\
\hline 23-May-2008 & 109 & 571 & 502 & 454 & 509 & 59 \\
\hline 6-Jul-2008 & 153 & 182 & 179 & 171 & 177 & 6 \\
\hline
\end{tabular}

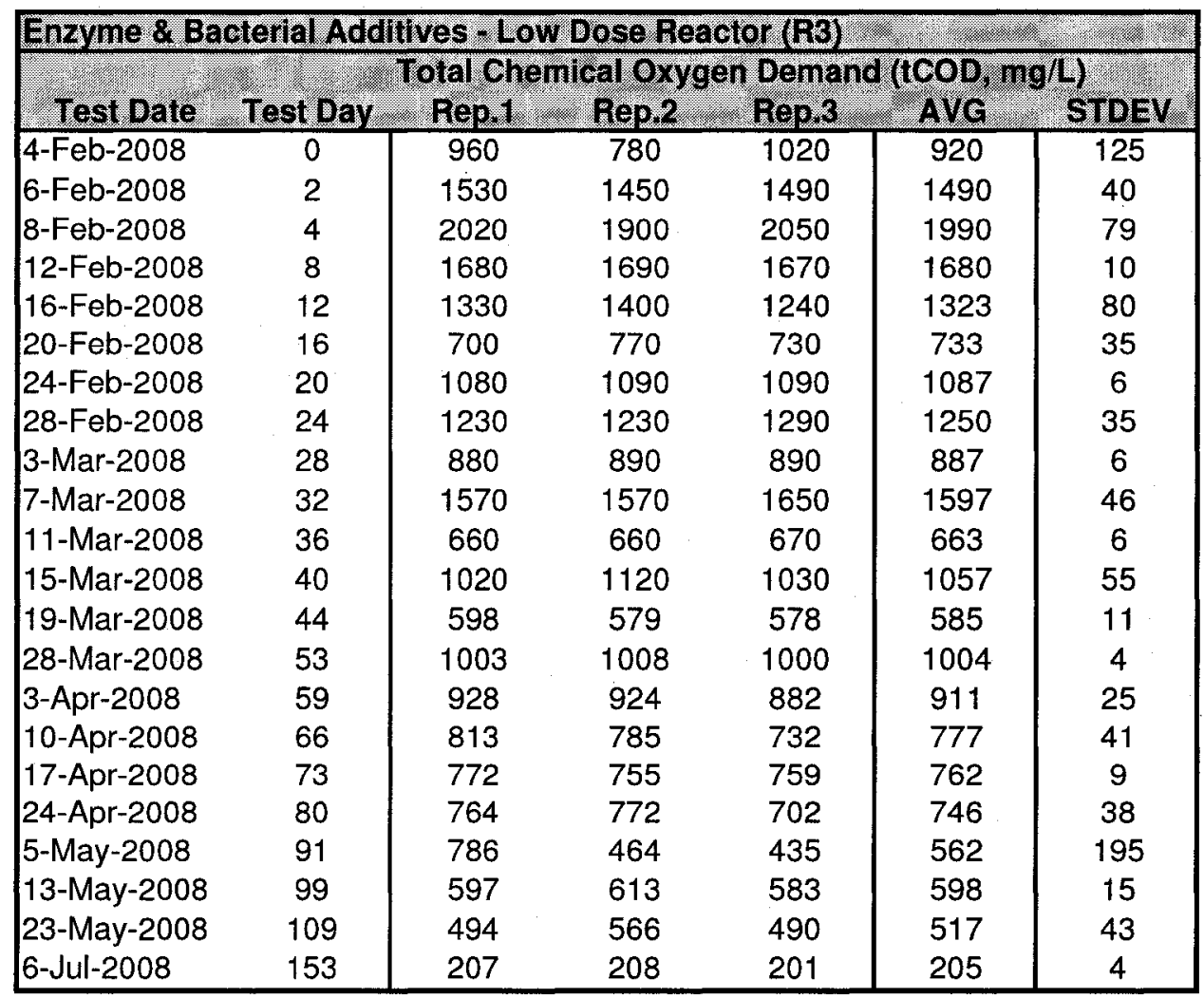




\begin{tabular}{|lc|ccc|c|c|}
\hline \multicolumn{7}{|c|}{ Microaeration - High Dose Reactor (R4) } \\
\hline \multicolumn{7}{|c|}{ Total Chemlcal Oxygen Demand (ICOD, mg/L) } \\
-Test Date & Test Day & Rep. 1 & Rep.2 & Rep.3 & AVG & STDEV \\
\hline 4-Feb-2008 & 0 & 1140 & 1020 & 1020 & 1060 & 69 \\
6-Feb-2008 & 2 & 1740 & 1700 & 1680 & 1707 & 31 \\
8-Feb-2008 & 4 & 2150 & 2050 & 2040 & 2080 & 61 \\
12-Feb-2008 & 8 & 3710 & 3610 & 3470 & 3597 & 121 \\
16-Feb-2008 & 12 & 1130 & 1170 & 1170 & 1157 & 23 \\
20-Feb-2008 & 16 & 560 & 660 & 600 & 607 & 50 \\
24-Feb-2008 & 20 & 390 & 420 & 420 & 410 & 17 \\
28-Feb-2008 & 24 & 560 & 470 & 590 & 540 & 62 \\
3-Mar-2008 & 28 & 520 & 560 & 400 & 493 & 83 \\
7-Mar-2008 & 32 & 260 & 230 & 260 & 250 & 17 \\
11-Mar-2008 & 36 & 510 & 440 & 470 & 473 & 35 \\
15-Mar-2008 & 40 & 770 & 860 & 930 & 853 & 80 \\
19-Mar-2008 & 44 & 588 & 593 & 585 & 589 & 4 \\
28-Mar-2008 & 53 & 283 & 282 & 284 & 283 & 1 \\
3-Apr-2008 & 59 & 418 & 414 & 392 & 408 & 14 \\
10-Apr-2008 & 66 & 414 & 439 & 391 & 415 & 24 \\
17-Apr-2008 & 73 & 416 & 380 & 384 & 393 & 20 \\
24-Apr-2008 & 80 & 352 & 367 & 391 & 370 & 20 \\
5-May-2008 & 91 & 728 & 583 & 540 & 617 & 99 \\
13-May-2008 & 99 & 453 & 446 & 368 & 422 & 47 \\
23-May-2008 & 109 & 362 & 328 & 339 & 343 & 17 \\
6-Jul-2008 & 153 & 181 & 189 & 179 & 183 & 5 \\
\hline
\end{tabular}

\begin{tabular}{|lc|ccc|c|c|}
\hline \multicolumn{7}{|c|}{ Microaeration - Low Dose Reactor (R5) } \\
\hline \multicolumn{7}{|c|}{ Total Chemical Oxygen Demand (tCOD, mg/L) } \\
Test Date & Test Day & Rep.1 & Rep.2 & Rep.3 & AVG & STDEV \\
\hline 4-Feb-2008 & 0 & 1140 & 960 & 1140 & 1080 & 104 \\
6-Feb-2008 & 2 & 1920 & 1920 & 1930 & 1923 & 6 \\
8-Feb-2008 & 4 & 2590 & 2460 & 2540 & 2530 & 66 \\
12-Feb-2008 & 8 & 1250 & 1210 & 1130 & 1197 & 61 \\
16-Feb-2008 & 12 & 990 & 1030 & 920 & 980 & 56 \\
20-Feb-2008 & 16 & 670 & 700 & 680 & 683 & 15 \\
24-Feb-2008 & 20 & 720 & 660 & 690 & 690 & 30 \\
28-Feb-2008 & 24 & 610 & 580 & 630 & 607 & 25 \\
3-Mar-2008 & 28 & 740 & 660 & 710 & 703 & 40 \\
7-Mar-2008 & 32 & 690 & 710 & 660 & 687 & 25 \\
11-Mar-2008 & 36 & 490 & 540 & 440 & 490 & 50 \\
15-Mar-2008 & 40 & 640 & 590 & 620 & 617 & 25 \\
19-Mar-2008 & 44 & 480 & 478 & 476 & 478 & 2 \\
28-Mar-2008 & 53 & 330 & 336 & 332 & 333 & 3 \\
3-Apr-2008 & 59 & 488 & 473 & 478 & 480 & 8 \\
10-Apr-2008 & 66 & 366 & 409 & 355 & 377 & 29 \\
17-Apr-2008 & 73 & 356 & 348 & 355 & 353 & 4 \\
24-Apr-2008 & 80 & 334 & 333 & 322 & 330 & 7 \\
5-May-2008 & 91 & 703 & 687 & 658 & 683 & 23 \\
13-May-2008 & 99 & 333 & 345 & 338 & 339 & 6 \\
23-May-2008 & 109 & 294 & 331 & 312 & 312 & 19 \\
6-Jul-2008 & 153 & 164 & 196 & 163 & 174 & 19 \\
\hline
\end{tabular}




\section{Appendix E3: Soluble Chemical Oxygen Demand (sCOD)}

\begin{tabular}{|c|c|c|c|c|c|c|}
\hline \multicolumn{7}{|c|}{1 Oxvoen Demand (sCOD. ma/l) } \\
\hline Test Date & Test Day & Rep.1 & Rep.2 & Rep. 3 & AVG & STDEV \\
\hline 4-Feb-2008 & 0 & 670 & 640 & 680 & 663 & 21 \\
\hline 12-Feb-2008 & 8 & 680 & 720 & 860 & 753 & 95 \\
\hline 20-Feb-2008 & 16 & 600 & 680 & 640 & 640 & 40 \\
\hline 24-Feb-2008 & 20 & 490 & 470 & 470 & 477 & 12 \\
\hline 28-Feb-2008 & 24 & 190 & 240 & 280 & 237 & 45 \\
\hline 3-Mar-2008 & 28 & 457 & 460 & 460 & 459 & 2 \\
\hline 3-Apr-2008 & 59 & 537 & 567 & 559 & 554 & 16 \\
\hline 10-Apr-2008 & 66 & 604 & 628 & 602 & 611 & 14 \\
\hline 5-May-2008 & 91 & 918 & 908 & 871 & 899 & 25 \\
\hline 23-May-2008 & 109 & 719 & 719 & 751 & 730 & 18 \\
\hline
\end{tabular}

\begin{tabular}{|lc|ccc|c|c|}
\hline \multicolumn{7}{|c|}{ Control Reactor (R1) } \\
\hline \multicolumn{7}{|c|}{ Soluble Chemical Oxygen Demand (sCOD, mg/L) } \\
\hline Test Date & Test Day & Rep.1 & Pep.2 & Rep.3 & AVG & STDEV \\
\hline 4-Feb-2008 & 0 & 940 & 870 & & 905 & 49 \\
6-Feb-2008 & 2 & 1260 & 1270 & & 1265 & 7 \\
8-Feb-2008 & 4 & 1420 & 1340 & & 1380 & 57 \\
12-Feb-2008 & 8 & 1180 & 1160 & & 1170 & 14 \\
16-Feb-2008 & 12 & 970 & 990 & 940 & 967 & 25 \\
20-Feb-2008 & 16 & 710 & 740 & 720 & 723 & 15 \\
24-Feb-2008 & 20 & 900 & 880 & 880 & 887 & 12 \\
28-Feb-2008 & 24 & 980 & 920 & 1050 & 983 & 65 \\
3-Mar-2008 & 28 & 790 & 840 & 800 & 810 & 26 \\
7-Mar-2008 & 32 & 800 & 970 & 840 & 870 & 89 \\
11-Mar-2008 & 36 & 380 & 400 & 410 & 397 & 15 \\
15-Mar-2008 & 40 & 830 & 760 & 780 & 790 & 36 \\
19-Mar-2008 & 44 & 486 & 482 & 482 & 483 & 2 \\
28-Mar-2008 & 53 & 800 & 798 & 800 & 799 & 1 \\
3-Apr-2008 & 59 & 768 & 796 & 781 & 782 & 14 \\
10-Apr-2008 & 66 & 842 & 880 & 855 & 859 & 19 \\
17-Apr-2008 & 73 & 908 & 880 & 880 & 889 & 16 \\
24-Apr-2008 & 80 & 933 & 893 & 928 & 918 & 22 \\
5-May-2008 & 91 & 776 & 784 & 790 & 783 & 7 \\
13-May-2008 & 99 & 540 & 572 & 563 & 558 & 17 \\
23-May-2008 & 109 & 429 & 416 & 409 & 418 & 10 \\
\hline
\end{tabular}




\begin{tabular}{|lc|ccc|c|c|}
\hline \multicolumn{7}{|c|}{ Enzyme \& Bacterlal Additives - High Dose Reactor (R2) } \\
\hline \multicolumn{7}{|c|}{ Soluble Chemical Oxygen Demand (sCOD, mglL) } \\
\hline Test Date & Test Day & Rep.1 & Rep.2 & Rep.3 & AVG & STDEV \\
\hline 4-Feb-2008 & 0 & 800 & 870 & & 835 & 49 \\
6-Feb-2008 & 2 & 1420 & 1400 & & 1410 & 14 \\
8-Feb-2008 & 4 & 1500 & 1630 & & 1565 & 92 \\
12-Feb-2008 & 8 & 1320 & 1280 & & 1300 & 28 \\
16-Feb-2008 & 12 & 1040 & 1020 & 1070 & 1043 & 25 \\
20-Feb-2008 & 16 & 750 & 800 & 770 & 773 & 25 \\
24-Feb-2008 & 20 & 810 & 780 & 800 & 797 & 15 \\
28-Feb-2008 & 24 & 980 & 890 & 910 & 927 & 47 \\
3-Mar-2008 & 28 & 790 & 850 & 770 & 803 & 42 \\
7-Mar-2008 & 32 & 260 & 260 & 280 & 267 & 12 \\
11-Mar-2008 & 36 & 520 & 630 & 600 & 583 & 57 \\
15-Mar-2008 & 40 & 740 & 790 & 780 & 770 & 26 \\
19-Mar-2008 & 44 & 633 & 624 & 622 & 626 & 6 \\
28-Mar-2008 & 53 & 941 & 926 & 923 & 930 & 10 \\
3-Apr-2008 & 59 & 774 & 721 & 700 & 732 & 38 \\
10-Apr-2008 & 66 & 793 & 901 & 844 & 846 & 54 \\
17-Apr-2008 & 73 & 866 & 878 & 874 & 873 & 6 \\
24-Apr-2008 & 80 & 905 & 893 & 899 & 899 & 6 \\
5-May-2008 & 91 & 743 & 768 & 788 & 766 & 23 \\
13-May-2008 & 99 & 564 & 599 & 560 & 574 & 21 \\
23-May-2008 & 109 & 399 & 443 & 411 & 418 & 23 \\
\hline
\end{tabular}

\begin{tabular}{|lc|ccc|c|c|}
\hline \multicolumn{6}{|c|}{ Enzyme \& Bacterial Additives - Low Dose Reactor (R3) } \\
\hline Test Date & Test Day & Soluble Chemical Oxygen Demand (sCOD, mgiL) \\
\hline Rep. & Rep.2 & Rep.3 & AVG & STDEV \\
\hline 4-Feb-2008 & 0 & 780 & 820 & & 800 & 28 \\
6-Feb-2008 & 2 & 1320 & 1290 & & 1305 & 21 \\
8-Feb-2008 & 4 & 1520 & 1460 & & 1490 & 42 \\
12-Feb-2008 & 8 & 1390 & 1310 & & 1350 & 57 \\
16-Feb-2008 & 12 & 1240 & 1210 & 1160 & 1203 & 40 \\
20-Feb-2008 & 16 & 680 & 680 & 680 & 680 & 0 \\
24-Feb-2008 & 20 & 970 & 1090 & 920 & 993 & 87 \\
28-Feb-2008 & 24 & 1150 & 1100 & 1050 & 1100 & 50 \\
3-Mar-2008 & 28 & 790 & 810 & 790 & 797 & 12 \\
7-Mar-2008 & 32 & 1320 & 1300 & 1310 & 1310 & 10 \\
11-Mar-2008 & 36 & 650 & 610 & 670 & 643 & 31 \\
15-Mar-2008 & 40 & 1010 & 910 & 1020 & 980 & 61 \\
19-Mar-2008 & 44 & 541 & 536 & 547 & 541 & 6 \\
28-Mar-2008 & 53 & 924 & 934 & 941 & 933 & 9 \\
3-Apr-2008 & 59 & 873 & 862 & 824 & 853 & 26 \\
10-Apr-2008 & 66 & 699 & 722 & 680 & 700 & 21 \\
17-Apr-2008 & 73 & 686 & 698 & 714 & 699 & 14 \\
24-Apr-2008 & 80 & 713 & 720 & 669 & 701 & 28 \\
5-May-2008 & 91 & 653 & 574 & 630 & 619 & 41 \\
13-May-2008 & 99 & 493 & 530 & 554 & 526 & 31 \\
23-May-2008 & 109 & 418 & 447 & 433 & 433 & 15 \\
\hline
\end{tabular}




\begin{tabular}{|lc|ccc|c|c|}
\hline \multicolumn{7}{|c|}{ Microaeration - High Dose Reactor (R4) } \\
\hline \multicolumn{7}{|c|}{ Soluble Chemical Oxygen Demand (sCOD, mgill) } \\
\hline Test Date & Test Day & Rep.1 & Rep.2 & Rep.3 & AVG & STDEV \\
\hline 4-Feb-2008 & 0 & 830 & 770 & & 800 & 42 \\
6-Feb-2008 & 2 & 1470 & 1450 & & 1460 & 14 \\
8-Feb-2008 & 4 & 1460 & 1480 & & 1470 & 14 \\
12-Feb-2008 & 8 & 1200 & 1210 & & 1205 & 7 \\
16-Feb-2008 & 12 & 990 & 940 & 870 & 933 & 60 \\
20-Feb-2008 & 16 & 460 & 470 & 470 & 467 & 6 \\
24-Feb-2008 & 20 & 220 & 250 & 240 & 237 & 15 \\
28-Feb-2008 & 24 & 390 & 380 & 390 & 387 & 6 \\
3-Mar-2008 & 28 & 380 & 340 & 260 & 327 & 61 \\
7-Mar-2008 & 32 & 100 & 120 & 120 & 113 & 12 \\
11-Mar-2008 & 36 & 350 & 360 & 380 & 363 & 15 \\
15-Mar-2008 & 40 & 630 & 680 & 620 & 643 & 32 \\
19-Mar-2008 & 44 & 486 & 487 & 481 & 485 & 3 \\
28-Mar-2008 & 53 & 191 & 185 & 187 & 188 & 3 \\
3-Apr-2008 & 59 & 215 & 256 & 270 & 247 & 29 \\
10-Apr-2008 & 66 & 295 & 352 & 316 & 321 & 29 \\
17-Apr-2008 & 73 & 274 & 274 & 269 & 272 & 3 \\
24-Apr-2008 & 80 & 223 & 233 & 212 & 223 & 11 \\
5-May-2008 & 91 & 639 & 563 & 584 & 595 & 39 \\
13-May-2008 & 99 & 316 & 366 & 310 & 331 & 31 \\
23-May-2008 & 109 & 198 & 199 & 258 & 218 & 34 \\
\hline
\end{tabular}

\begin{tabular}{|lc|ccc|c|c|}
\hline \multicolumn{7}{|c|}{ Microaeration - Low Dose Reactor (R5) } \\
\hline \multicolumn{7}{|c|}{ Soluble Chemical Oxygen Demand (sCoD, } \\
\hline Test Date & Test Day L) & Rep.1 & Rep.2 & Rep.3. & AVG & STDEV \\
\hline 4-Feb-2008 & 0 & 830 & 830 & & 830 & 0 \\
6-Feb-2008 & 2 & 1570 & 1600 & & 1585 & 21 \\
8-Feb-2008 & 4 & 1800 & 1790 & & 1795 & 7 \\
12-Feb-2008 & 8 & 1310 & 1260 & & 1285 & 35 \\
16-Feb-2008 & 12 & 710 & 840 & 740 & 763 & 68 \\
20-Feb-2008 & 16 & 610 & 390 & 660 & 553 & 144 \\
24-Feb-2008 & 20 & 530 & 490 & 490 & 503 & 23 \\
28-Feb-2008 & 24 & 570 & 520 & 470 & 520 & 50 \\
3-Mar-2008 & 28 & 630 & 520 & 560 & 570 & 56 \\
7-Mar-2008 & 32 & 500 & 530 & 470 & 500 & 30 \\
11-Mar-2008 & 36 & 460 & 360 & 450 & 423 & 55 \\
15-Mar-2008 & 40 & 480 & 510 & 530 & 507 & 25 \\
19-Mar-2008 & 44 & 397 & 398 & 395 & 397 & 2 \\
28-Mar-2008 & 53 & 237 & 236 & 237 & 237 & 1 \\
3-Apr-2008 & 59 & 374 & 378 & 378 & 377 & 2 \\
10-Apr-2008 & 66 & 303 & 310 & 303 & 305 & 4 \\
17-Apr-2008 & 73 & 251 & 285 & 269 & 268 & 17 \\
24-Apr-2008 & 80 & 244 & 234 & 213 & 230 & 16 \\
5-May-2008 & 91 & 633 & 621 & 448 & 567 & 104 \\
13-May-2008 & 99 & 244 & 221 & 256 & 240 & 18 \\
23-May-2008 & 109 & 270 & 251 & 265 & 262 & 10 \\
\hline
\end{tabular}




\section{Appendix E4: Volatile (Organic) Acids}

\begin{tabular}{|rc|rrr|c|c|}
\hline \multicolumn{7}{|l|}{ Feed } \\
\hline \multicolumn{70}{|c|}{ Volatile (Organic) Acids (mgL as HOAc) } \\
Test Date & Test Day & \multicolumn{1}{l|}{ Rep.1 } & Rep.2 & Rep.3 & AVG & STDEV \\
\hline 4-Feb-2008 & 0 & 64 & 41 & 28 & 44 & 16 \\
12-Feb-2008 & 8 & 186 & 173 & 176 & 178 & 9 \\
24-Feb-2008 & 20 & 164 & 164 & 155 & 161 & 0 \\
7-Mar-2008 & 32 & 38 & 24 & 28 & 30 & 7 \\
19-Mar-2008 & 44 & 107 & 92 & 102 & 100 & 8 \\
3-Apr-2008 & 59 & 155 & 154 & 176 & 162 & 12 \\
24-Apr-2008 & 80 & 154 & 138 & 131 & 141 & 12 \\
5-May-2008 & 91 & 195 & 172 & 160 & 176 & 18 \\
23-May-2008 & 109 & 87 & 37 & 52 & 59 & 26 \\
\hline
\end{tabular}

\begin{tabular}{|c|c|c|c|c|c|c|}
\hline \multicolumn{2}{|c|}{ Control Reactor (Ri) } & & & es: & $x=\frac{19}{2}$ & \multirow[b]{3}{*}{ STDEV } \\
\hline & & \multicolumn{4}{|c|}{ Volatile (Organic) Acids (mg/L as HOAc) } & \\
\hline Test Date & Test Day & Rep. 1 & Rep? & Rep.3 & $\mathrm{AVG}$ & \\
\hline 4-Feb-2008 & $\overline{0}$ & 415 & 469 & 435 & 440 & 38 \\
\hline 8-Feb-2008 & 4 & 574 & 627 & 789 & 663 & 37 \\
\hline $12-F e b-2008$ & 8 & 608 & 592 & 590 & 597 & 11 \\
\hline $16-F e b-2008$ & 12 & 420 & 439 & 430 & 430 & 10 \\
\hline $20-F e b-2008$ & 16 & 289 & 310 & 314 & 304 & 13 \\
\hline 24-Feb-2008 & 20 & 393 & 404 & 407 & 401 & 7 \\
\hline 28-Feb-2008 & 24 & 444 & 458 & 433 & 445 & 13 \\
\hline 3-Mar-2008 & 28 & 376 & 371 & 364 & 370 & 6 \\
\hline 7-Mar-2008 & 32 & 355 & 353 & 372 & 360 & 10 \\
\hline 11-Mar-2008 & 36 & 222 & 174 & 201 & 199 & 24 \\
\hline 15-Mar-2008 & 40 & 254 & 253 & 257 & 255 & 2 \\
\hline 19-Mar-2008 & 44 & 204 & 206 & 215 & 208 & 6 \\
\hline 28-Mar-2008 & 53 & 335 & 348 & 374 & 352 & 20 \\
\hline 3-Apr-2008 & 59 & 280 & 312 & 298 & 297 & 16 \\
\hline 10-Apr-2008 & 66 & 333 & 294 & 294 & 307 & 23 \\
\hline 17-Apr-2008 & 73 & 247 & 267 & 257 & 257 & 10 \\
\hline 24-Apr-2008 & 80 & 167 & 241 & 212 & 207 & 37 \\
\hline 5-May-2008 & 91 & 139 & 134 & 122 & 132 & 9 \\
\hline 13-May-2008 & 99 & 157 & 167 & 161 & 162 & 5 \\
\hline 23-May-2008 & 109 & 136 & 120 & 127 & 128 & 8 \\
\hline
\end{tabular}




\begin{tabular}{|cc|ccc|c|c|}
\hline \multicolumn{7}{|c|}{ Enzyme \& Bacterial Additives - High Dose Reactor (R2) } \\
\hline \multicolumn{7}{|c|}{ Volatile (Organic) Acids (mghL as HOAc) } \\
Test Date & Test Day & Rep.1 & Rep.2 & Rep.3 & AVG & STDEV \\
\hline 4-Feb-2008 & 0 & 483 & 392 & 427 & 434 & 64 \\
8-Feb-2008 & 4 & 853 & 720 & 967 & 847 & 94 \\
12-Feb-2008 & 8 & 801 & 812 & 830 & 814 & 8 \\
16-Feb-2008 & 12 & 506 & 471 & 489 & 489 & 18 \\
20-Feb-2008 & 16 & 358 & 336 & 312 & 335 & 23 \\
24-Feb-2008 & 20 & 398 & 436 & 362 & 399 & 37 \\
28-Feb-2008 & 24 & 415 & 422 & 419 & 419 & 4 \\
3-Mar-2008 & 28 & 376 & 363 & 358 & 366 & 9 \\
7-Mar-2008 & 32 & 159 & 150 & 145 & 151 & 7 \\
11-Mar-2008 & 36 & 253 & 322 & 252 & 276 & 40 \\
15-Mar-2008 & 40 & 276 & 285 & 283 & 281 & 5 \\
19-Mar-2008 & 44 & 292 & 277 & 282 & 284 & 8 \\
28-Mar-2008 & 53 & 410 & 414 & 423 & 416 & 7 \\
3-Apr-2008 & 59 & 258 & 237 & 272 & 256 & 18 \\
10-Apr-2008 & 66 & 287 & 264 & 275 & 275 & 12 \\
17-Apr-2008 & 73 & 256 & 251 & 242 & 250 & 7 \\
24-Apr-2008 & 80 & 201 & 229 & 238 & 223 & 19 \\
5-May-2008 & 91 & 266 & 98 & 135 & 166 & 88 \\
13-May-2008 & 99 & 173 & 155 & 132 & 153 & 21 \\
23-May-2008 & 109 & 120 & 122 & 99 & 114 & 13 \\
\hline
\end{tabular}

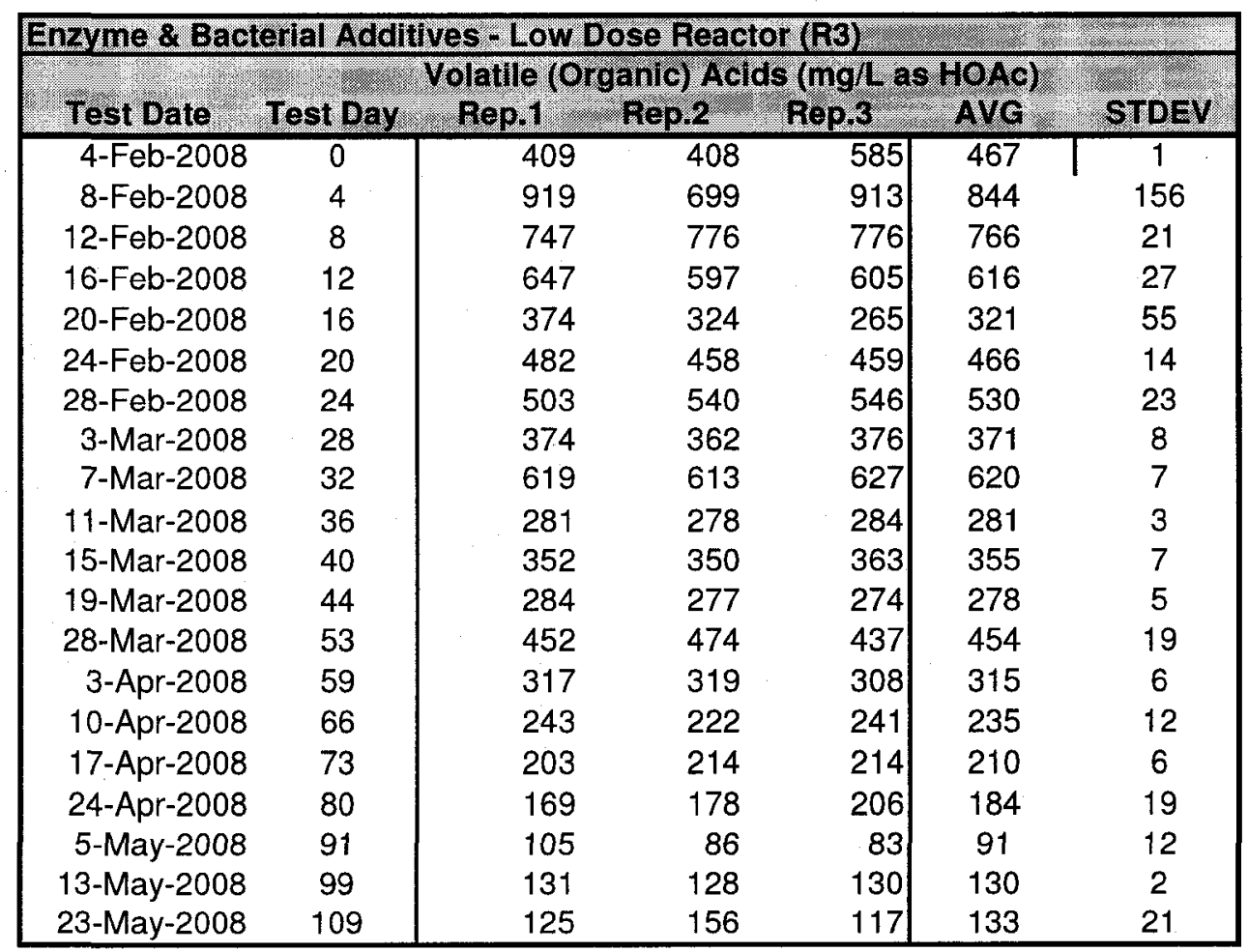




\begin{tabular}{|rr|rrr|c|c|}
\hline \multicolumn{7}{|c|}{ Microaeration - High Dose Reactor (R4) } \\
\hline \multicolumn{7}{|c|}{ Volatile (Organic) Acids (mgiL as HOAC) } \\
Test Date & Test Day & Rep.1 & Rep.2 & Rep.3 & AVG & STDEV \\
\hline 4-Feb-2008 & 0 & 439 & 436 & 421 & 432 & 2 \\
8-Feb-2008 & 4 & 920 & 749 & 979 & 883 & 121 \\
12-Feb-2008 & 8 & 781 & 828 & 789 & 799 & 33 \\
16-Feb-2008 & 12 & 466 & 496 & 459 & 474 & 20 \\
20-Feb-2008 & 16 & 313 & 246 & 208 & 256 & 53 \\
24-Feb-2008 & 20 & 116 & 112 & 122 & 117 & 5 \\
28-Feb-2008 & 24 & 205 & 167 & 173 & 182 & 20 \\
3-Mar-2008 & 28 & 129 & 142 & 129 & 133 & 8 \\
7-Mar-2008 & 32 & 14 & 19 & 15 & 16 & 3 \\
11-Mar-2008 & 36 & 132 & 151 & 136 & 140 & 10 \\
15-Mar-2008 & 40 & 210 & 216 & 213 & 213 & 3 \\
19-Mar-2008 & 44 & 224 & 202 & 205 & 210 & 12 \\
28-Mar-2008 & 53 & 65 & 86 & 60 & 70 & 14 \\
3-Apr-2008 & 59 & 62 & 48 & 52 & 54 & 7 \\
10-Apr-2008 & 66 & 86 & 57 & 59 & 67 & 16 \\
17-Apr-2008 & 73 & 48 & 46 & 55 & 50 & 5 \\
24-Apr-2008 & 80 & 23 & 45 & 38 & 35 & 11 \\
5-May-2008 & 91 & 18 & 18 & 4 & 13 & 8 \\
13-May-2008 & 99 & 103 & 90 & 84 & 92 & 10 \\
23-May-2008 & 109 & 59 & 60 & 49 & 56 & 6 \\
\hline
\end{tabular}

\begin{tabular}{|rr|rrr|c|c|c|}
\hline \multicolumn{7}{|c|}{ Microaeration - Low Dose Reactor (R5) } \\
\hline \multicolumn{7}{|c|}{ Volatile (Organic) Acids (mg/L as HOAc) } \\
Test Date & Test Day & Rep.1 & Rep.2 & Rep.3 & AVG & STDEV \\
\hline 4-Feb-2008 & 0 & 423 & 410 & 387 & 407 & 9 \\
8-Feb-2008 & 4 & 834 & 1007 & 853 & 898 & 122 \\
12-Feb-2008 & 8 & 978 & 966 & 946 & 963 & 8 \\
16-Feb-2008 & 12 & 360 & 350 & 378 & 363 & 14 \\
20-Feb-2008 & 16 & 333 & 315 & 288 & 312 & 23 \\
24-Feb-2008 & 20 & 283 & 258 & 267 & 269 & 13 \\
28-Feb-2008 & 24 & 162 & 246 & 266 & 225 & 55 \\
3-Mar-2008 & 28 & 292 & 292 & 313 & 299 & 12 \\
7-Mar-2008 & 32 & 177 & 176 & 188 & 180 & 7 \\
11-Mar-2008 & 36 & 179 & 176 & 176 & 177 & 2 \\
15-Mar-2008 & 40 & 180 & 166 & 173 & 173 & 7 \\
19-Mar-2008 & 44 & 163 & 180 & 172 & 172 & 9 \\
28-Mar-2008 & 53 & 93 & 108 & 93 & 98 & 9 \\
3-Apr-2008 & 59 & 88 & 97 & 97 & 94 & 5 \\
10-Apr-2008 & 66 & 111 & 89 & 80 & 93 & 16 \\
17-Apr-2008 & 73 & 56 & 59 & 66 & 60 & 5 \\
24-Apr-2008 & 80 & 21 & 29 & 36 & 29 & 8 \\
5-May-2008 & 91 & 20 & 22 & 28 & 23 & 4 \\
13-May-2008 & 99 & 82 & 79 & 75 & 79 & 4 \\
23-May-2008 & 109 & 108 & 87 & 67 & 87 & 21 \\
\hline
\end{tabular}




\section{Appendix E5: Proteins}

\begin{tabular}{|rc|ccc|cc|}
\hline Feed \\
\hline \multicolumn{7}{|c|}{ Protein Conc. $(\mathbf{m g}$ L ) } \\
Test Date & Test Day & Rep.1 & Rep.2 & Rep.3 & AVG & STDEV \\
\hline 4-Feb & 0 & 16 & 17 & 18 & 17 & 1 \\
8-Feb & 4 & 26 & 23 & 25 & 25 & 2 \\
12-Feb & 8 & 9 & 6 & 8 & 8 & 2 \\
24-Feb & 20 & 2 & 5 & 6 & 5 & 2 \\
7-Mar & 32 & 8 & 14 & 21 & 14 & 6 \\
19-Mar & 44 & 86 & 85 & 91 & 88 & 3 \\
3-Apr & 59 & 11 & 12 & 9 & 11 & 1 \\
24-Apr & 80 & 5 & 5 & 6 & 5 & 1 \\
5-May & 91 & 17 & 21 & 21 & 20 & 3 \\
23-May & 109 & 1 & 3 & 2 & 2 & 1 \\
\hline
\end{tabular}

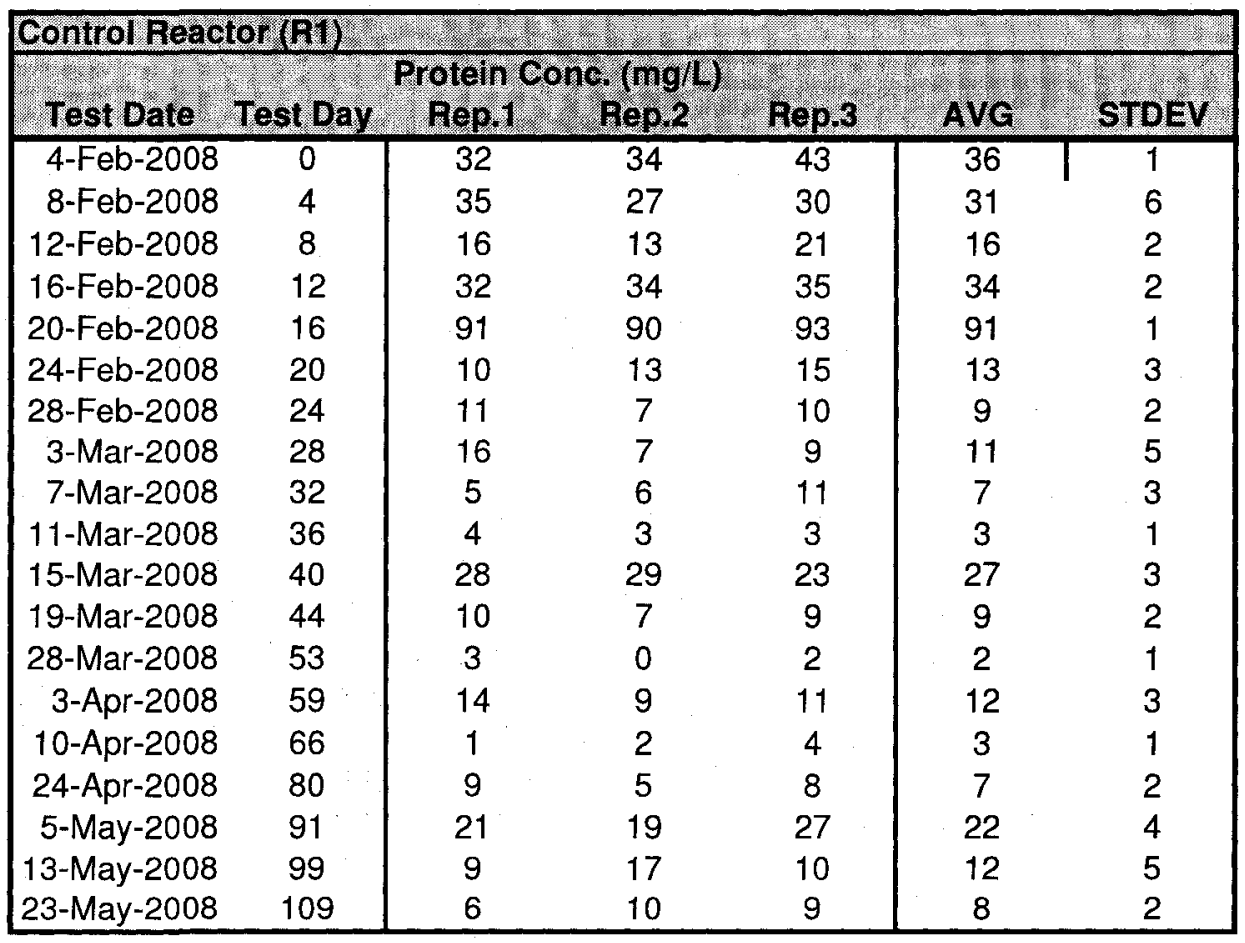




\begin{tabular}{|c|c|c|c|c|c|c|}
\hline \multicolumn{7}{|c|}{ Enzyme \& Bacterial Additives - High Dose Reactor (R2) } \\
\hline \multicolumn{7}{|c|}{ Protein Conc. $(\mathrm{mg} / \mathrm{L})$} \\
\hline Test Date & Test Day & Rep.1 & Rep.2 & Rep.3 & AVG & STDEV \\
\hline 4-Feb-2008 & 0 & 25 & 22 & 30 & 26 & 2 \\
\hline 8-Feb-2008 & 4 & 35 & 34 & 33 & 34 & 0 \\
\hline 12-Feb-2008 & 8 & 7 & 4 & 7 & 6 & 2 \\
\hline 16-Feb-2008 & 12 & 26 & 22 & 27 & 25 & 3 \\
\hline 20-Feb-2008 & 16 & 105 & 103 & 101 & 103 & 2 \\
\hline 24-Feb-2008 & 20 & 4 & 9 & 11 & 8 & 4 \\
\hline 28-Feb-2008 & 24 & 4 & -1 & 4 & 2 & 3 \\
\hline 3-Mar-2008 & 28 & 14 & 6 & 4 & 8 & 5 \\
\hline 7-Mar-2008 & 32 & 16 & 19 & 24 & 20 & 4 \\
\hline 11-Mar-2008 & 36 & 4 & 4 & 3 & 4 & 1 \\
\hline 15-Mar-2008 & 40 & 19 & 21 & 16 & 19 & 2 \\
\hline 19-Mar-2008 & 44 & 55 & 85 & 89 & 76 & 18 \\
\hline 28-Mar-2008 & 53 & -1 & -2 & 1 & -1 & 2 \\
\hline 3-Apr-2008 & 59 & 9 & 12 & 9 & 10 & 2 \\
\hline 10-Apr-2008 & 66 & 4 & 3 & 4 & 4 & 1 \\
\hline 24-Apr-2008 & 80 & 6 & 5 & 10 & 7 & 2 \\
\hline 5-May-2008 & 91 & 18 & 18 & 32 & 23 & 8 \\
\hline 13-May-2008 & 99 & 8 & 9 & 8 & 8 & 1 \\
\hline 23-May-2008 & 109 & 6 & 4 & 6 & 6 & 1 \\
\hline
\end{tabular}

\begin{tabular}{|rr|ccc|c|c|}
\hline \multicolumn{7}{|c|}{ Enzyme \& Bacterial Additives - Low Dose Reactor (R3) } \\
\hline \multicolumn{7}{|c|}{ Protein Conc. (mg/L) } \\
\hline Test Date & Test Day & Rep.1 & Rep.2 & Rep.3 & AVG & STDEV \\
\hline 4-Feb-2008 & 0 & 19 & 28 & 31 & 26 & 6 \\
8-Feb-2008 & 4 & 20 & 34 & 26 & 27 & 9 \\
12-Feb-2008 & 8 & -1 & -4 & 6 & 0 & 2 \\
16-Feb-2008 & 12 & 13 & 12 & 14 & 13 & 1 \\
20-Feb-2008 & 16 & 92 & 95 & 94 & 94 & 1 \\
24-Feb-2008 & 20 & 4 & 9 & 13 & 8 & 4 \\
28-Feb-2008 & 24 & 3 & 3 & 6 & 4 & 2 \\
3-Mar-2008 & 28 & 21 & 10 & 8 & 13 & 7 \\
7-Mar-2008 & 32 & 18 & 19 & 24 & 20 & 4 \\
11-Mar-2008 & 36 & 0 & 3 & 3 & 2 & 1 \\
15-Mar-2008 & 40 & 19 & 19 & 20 & 19 & 1 \\
19-Mar-2008 & 44 & 75 & 72 & 80 & 76 & 4 \\
28-Mar-2008 & 53 & -5 & -4 & -2 & -4 & 1 \\
3-Apr-2008 & 59 & 11 & 14 & 10 & 12 & 2 \\
10-Apr-2008 & 66 & 0 & 4 & 3 & 2 & 2 \\
24-Apr-2008 & 80 & 6 & 3 & 5 & 5 & 1 \\
5-May-2008 & 91 & 17 & 15 & 33 & 22 & 10 \\
13-May-2008 & 99 & 8 & 3 & 5 & 5 & 2 \\
23-May-2008 & 109 & 6 & 4 & 5 & 5 & 1 \\
\hline
\end{tabular}




\begin{tabular}{|rc|ccc|c|c|}
\hline \multicolumn{7}{|l|}{ Microaeration - High Dose Reactor (R4) } \\
\hline \multicolumn{7}{|c|}{ Protein Conc. (mg/L) } \\
Test Date & Test Day & Rep.1 & Rep.2 & Rep.3 & AVG & STDEV \\
\hline 4-Feb-2008 & 0 & 33 & 28 & 36 & 32 & 3 \\
8-Feb-2008 & 4 & 30 & 51 & 34 & 38 & 15 \\
12-Feb-2008 & 8 & 155 & 160 & 192 & 169 & 4 \\
16-Feb-2008 & 12 & 29 & 36 & 29 & 31 & 4 \\
20-Feb-2008 & 16 & 103 & 105 & 103 & 103 & 1 \\
24-Feb-2008 & 20 & 15 & 23 & 20 & 19 & 4 \\
28-Feb-2008 & 24 & 8 & 6 & 11 & 8 & 3 \\
3-Mar-2008 & 28 & 24 & 14 & 13 & 17 & 6 \\
7-Mar-2008 & 32 & 18 & 19 & 27 & 21 & 5 \\
11-Mar-2008 & 36 & 11 & 14 & 13 & 13 & 2 \\
15-Mar-2008 & 40 & 24 & 23 & 21 & 23 & 1 \\
19-Mar-2008 & 44 & 83 & 80 & 84 & 83 & 2 \\
28-Mar-2008 & 53 & 6 & 3 & 6 & 5 & 2 \\
3-Apr-2008 & 59 & 20 & 14 & 15 & 16 & 3 \\
10-Apr-2008 & 66 & 3 & 6 & 9 & 6 & 3 \\
24-Apr-2008 & 80 & 13 & 9 & 9 & 10 & 2 \\
5-May-2008 & 91 & 21 & 23 & 38 & 27 & 9 \\
13-May-2008 & 99 & 16 & 10 & 10 & 12 & 3 \\
23-May-2008 & 109 & 6 & 7 & 8 & 7 & 1 \\
\hline
\end{tabular}

\begin{tabular}{|c|c|c|c|c|c|c|}
\hline \multicolumn{7}{|c|}{ Microaeration - Low Dose Reactor (R5) } \\
\hline & & rotein C & c. (mg/L & & & \\
\hline Test Date: & Test Day & Rep.1. & Rep.2 & Rep.3 & Ava & STDEV \\
\hline $4-F e b-2008$ & 0 & 26 & 27 & 34 & 29 & 0 \\
\hline 8-Feb-2008 & 4 & 41 & 41 & 44 & 42 & 0 \\
\hline 12-Feb-2008 & 8 & 34 & 26 & 33 & 31 & 5 \\
\hline 16-Feb-2008 & 12 & 43 & 40 & 23 & 35 & 11 \\
\hline 20-Feb-2008 & 16 & 103 & 101 & 104 & 102 & 1 \\
\hline 24-Feb-2008 & 20 & 11 & 15 & 14 & 14 & 2 \\
\hline 28-Feb-2008 & 24 & 5 & 4 & 8 & 6 & 2 \\
\hline 3-Mar-2008 & 28 & 18 & 12 & 10 & 13 & 4 \\
\hline 7-Mar-2008 & 32 & 3 & 6 & 11 & 7 & 4 \\
\hline 11-Mar-2008 & 36 & 10 & 10 & 14 & 11 & 2 \\
\hline 15-Mar-2008 & 40 & 19 & 20 & 16 & 18 & 2 \\
\hline 19-Mar-2008 & 44 & 86 & 80 & 84 & 83 & 3 \\
\hline 28-Mar-2008 & 53 & 10 & 5 & 11 & 9 & 3 \\
\hline 3-Apr-2008 & 59 & 14 & 10 & 14 & 13 & 2 \\
\hline 10-Apr-2008 & 66 & 4 & 5 & 7 & 6 & 1 \\
\hline 24-Apr-2008 & 80 & 8 & 8 & 10 & 9 & 1 \\
\hline 5-May-2008 & 91 & 16 & 19 & 30 & 21 & 7 \\
\hline 13-May-2008 & 99 & 6 & 7 & 11 & 8 & 2 \\
\hline 23-May-2008 & 109 & 6 & 5 & 3 & 5 & 2 \\
\hline
\end{tabular}




\section{Appendix E6: Carbohydrates}

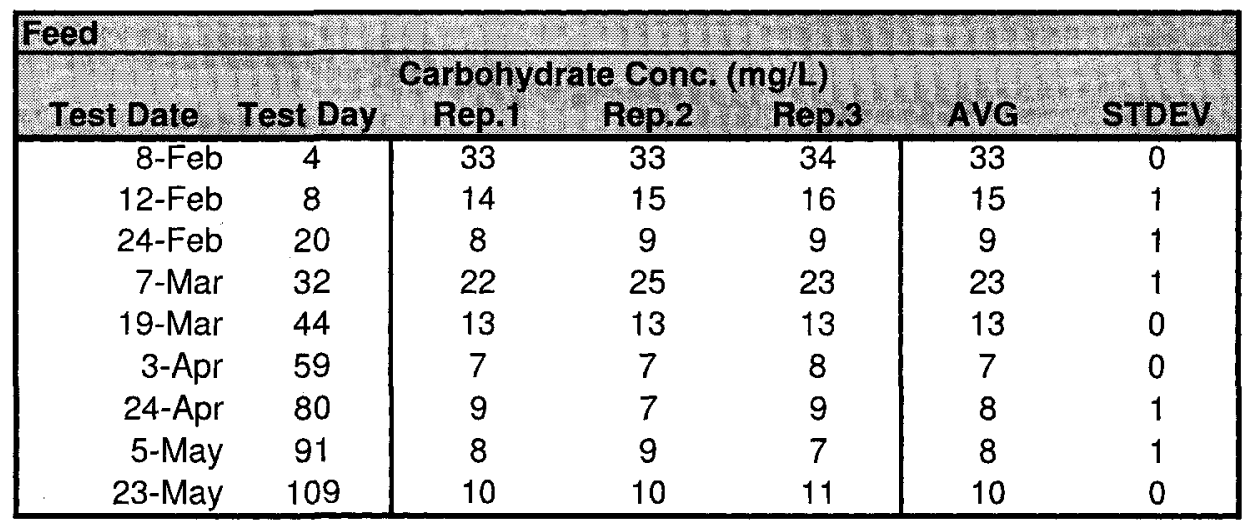

\begin{tabular}{|rc|ccc|cc|}
\hline \multicolumn{7}{|c|}{ Control Reactor (R1) } \\
\hline \multicolumn{7}{|c|}{ Carbohydrate Conc. (mg/L) } \\
Test Date & Test Day & Rep.1 & Rep.2 & Rep.3 & AVG & STDEV \\
\hline 4-Feb-2008 & 0 & 38 & 38 & 38 & 38 & 0 \\
8-Feb-2008 & 4 & 33 & 33 & 35 & 33 & 0 \\
12-Feb-2008 & 8 & 38 & 40 & 44 & 41 & 2 \\
16-Feb-2008 & 12 & 27 & 27 & 26 & 27 & 0 \\
20-Feb-2008 & 16 & 14 & 13 & 14 & 14 & 1 \\
24-Feb-2008 & 20 & 29 & 22 & 23 & 25 & 4 \\
28-Feb-2008 & 24 & 14 & 14 & 14 & 14 & 0 \\
3-Mar-2008 & 28 & 9 & 9 & 10 & 9 & 0 \\
7-Mar-2008 & 32 & 13 & 13 & 12 & 13 & 0 \\
11-Mar-2008 & 36 & 4 & 5 & 6 & 5 & 1 \\
15-Mar-2008 & 40 & 7 & 7 & 8 & 7 & 0 \\
19-Mar-2008 & 44 & 10 & 10 & 10 & 10 & 0 \\
28-Mar-2008 & 53 & 16 & 15 & 16 & 16 & 1 \\
3-Apr-2008 & 59 & 11 & 12 & 11 & 11 & 1 \\
10-Apr-2008 & 66 & 11 & 11 & 10 & 11 & 0 \\
24-Apr-2008 & 80 & 14 & 13 & 14 & 14 & 1 \\
5-May-2008 & 91 & 13 & 11 & 12 & 12 & 1 \\
13-May-2008 & 99 & 9 & 8 & 9 & 9 & 1 \\
23-May-2008 & 109 & 8 & 8 & 8 & 8 & 0 \\
\hline
\end{tabular}




\begin{tabular}{|cc|ccc|c|c|}
\hline \multicolumn{7}{|c|}{ Enzyme \& Bacterial Additives - High Dose Reactor (R2) } \\
\hline \multicolumn{7}{|c|}{ Carbohydrate Conc. (mg/L) } \\
Test Date & Test Day & Rep.t & Rep.2 & Rep.3 & AVG & STDEV \\
\hline 4-Feb-2008 & 0 & 46 & 30 & 32 & 36 & 11 \\
8-Feb-2008 & 4 & 39 & 36 & 39 & 38 & 2 \\
12-Feb-2008 & 8 & 34 & 35 & 31 & 34 & 0 \\
16-Feb-2008 & 12 & 20 & 19 & 20 & 20 & 1 \\
20-Feb-2008 & 16 & 14 & 14 & 15 & 14 & 0 \\
24-Feb-2008 & 20 & 15 & 15 & 16 & 15 & 1 \\
28-Feb-2008 & 24 & 11 & 11 & 12 & 11 & 1 \\
3-Mar-2008 & 28 & 9 & 8 & 11 & 9 & 2 \\
7-Mar-2008 & 32 & 26 & 26 & 26 & 26 & 0 \\
11-Mar-2008 & 36 & 13 & 14 & 12 & 13 & 1 \\
15-Mar-2008 & 40 & 8 & 8 & 8 & 8 & 0 \\
19-Mar-2008 & 44 & 10 & 10 & 10 & 10 & 0 \\
28-Mar-2008 & 53 & 23 & 20 & 23 & 22 & 2 \\
3-Apr-2008 & 59 & 10 & 10 & 11 & 10 & 0 \\
10-Apr-2008 & 66 & 12 & 12 & 12 & 12 & 0 \\
24-Apr-2008 & 80 & 13 & 13 & 13 & 13 & 0 \\
5-May-2008 & 91 & 13 & 13 & 13 & 13 & 0 \\
13-May-2008 & 99 & 11 & 14 & 10 & 12 & 2 \\
23-May-2008 & 109 & 9 & 10 & 9 & 9 & 0 \\
\hline
\end{tabular}

Enzyme \& Bacterial Additives - Low Dose Reactor $\left(\mathbf{R}_{3}\right)$.

\begin{tabular}{|c|c|c|c|c|c|c|}
\hline \multirow{2}{*}{\multicolumn{2}{|c|}{ Test Date }} & \multicolumn{3}{|c|}{ Carbohydrate Conc. (mg/L) } & \multicolumn{2}{|c|}{ 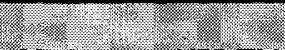 } \\
\hline & & Rep. 1 & Rep 2 & Rep.3 & & STDEV \\
\hline 4-Feb-2008 & 0 & 31 & 32 & 32 & 32 & 0 \\
\hline 8-Feb-2008 & 4 & 31 & 28 & 31 & 30 & 2 \\
\hline 12-Feb-2008 & 8 & 32 & 32 & 35 & 33 & 0 \\
\hline 16-Feb-2008 & 12 & 26 & 25 & 27 & 26 & 1 \\
\hline 20-Feb-2008 & 16 & 13 & 12 & 12 & 12 & 0 \\
\hline 24-Feb-2008 & 20 & 17 & 16 & 17 & 17 & 1 \\
\hline 28-Feb-2008 & 24 & 16 & 14 & 16 & 15 & 1 \\
\hline 3-Mar-2008 & 28 & 12 & 10 & 12 & 11 & 1 \\
\hline 7-Mar-2008 & 32 & 28 & 27 & 29 & 28 & 1 \\
\hline 11-Mar-2008 & 36 & 6 & 5 & 6 & 6 & 0 \\
\hline 15-Mar-2008 & 40 & 11 & 10 & 11 & 11 & 0 \\
\hline 19-Mar-2008 & 44 & 8 & 9 & 8 & 8 & 1 \\
\hline 28-Mar-2008 & 53 & 16 & 15 & 17 & 16 & 1 \\
\hline 3-Apr-2008 & 59 & 12 & 11 & 12 & 12 & 1 \\
\hline 10-Apr-2008 & 66 & 11 & 11 & 11 & 11 & 0 \\
\hline 24-Apr-2008 & 80 & 12 & 12 & 12 & 12 & 0 \\
\hline 5-May-2008 & 91 & 13 & 13 & 13 & 13 & 0 \\
\hline 13-May-2008 & 99 & 9 & 10 & 8 & 9 & 1 \\
\hline 23-May-2008 & 109 & 8 & 11 & 8 & 9 & 2 \\
\hline
\end{tabular}




\begin{tabular}{|rc|ccc|c|c|}
\hline \multicolumn{7}{|c|}{ Microaeration - High Dose Reactor (R4) } \\
\hline \multicolumn{7}{|c|}{ Carbohydrate Conc. (mg/L) } \\
Test Date & Test Day & Rep. & Rep.2 & Rep.3 & AVG & STDEV \\
\hline 4-Feb-2008 & 0 & 45 & 43 & 46 & 45 & 2 \\
8-Feb-2008 & 4 & 40 & 37 & 41 & 39 & 2 \\
12-Feb-2008 & 8 & 158 & 158 & 158 & 158 & 0 \\
16-Feb-2008 & 12 & 37 & 35 & 38 & 37 & 1 \\
20-Feb-2008 & 16 & 20 & 19 & 20 & 19 & 1 \\
24-Feb-2008 & 20 & 29 & 26 & 30 & 28 & 2 \\
28-Feb-2008 & 24 & 19 & 17 & 18 & 18 & 1 \\
3-Mar-2008 & 28 & 20 & 18 & 20 & 19 & 1 \\
7-Mar-2008 & 32 & 21 & 20 & 22 & 21 & 1 \\
11-Mar-2008 & 36 & 16 & 15 & 17 & 16 & 1 \\
15-Mar-2008 & 40 & 18 & 16 & 18 & 17 & 1 \\
19-Mar-2008 & 44 & 14 & 13 & 14 & 14 & 1 \\
28-Mar-2008 & 53 & 15 & 14 & 14 & 14 & 1 \\
3-Apr-2008 & 59 & 12 & 12 & 13 & 12 & 1 \\
10-Apr-2008 & 66 & 11 & 11 & 11 & 11 & 0 \\
24-Apr-2008 & 80 & 14 & 14 & 14 & 14 & 0 \\
5-May-2008 & 91 & 15 & 15 & 15 & 15 & 0 \\
13-May-2008 & 99 & 11 & 11 & 10 & 11 & 0 \\
23-May-2008 & 109 & 11 & 12 & 11 & 11 & 1 \\
\hline
\end{tabular}

\begin{tabular}{|cc|ccc|cc|c|}
\hline \multicolumn{7}{|c|}{ Microaeration - Low Dose Reactor (R5) } \\
\hline \multicolumn{7}{|c|}{ Carbohydrate Conc. (mg/L) } \\
Test Date & Test Day & Rep.1 & Rep.2 & Rep.3 & AVG & STDEV \\
\hline 4-Feb-2008 & 0 & 43 & 39 & 41 & 41 & 3 \\
8-Feb-2008 & 4 & 46 & 43 & 53 & 47 & 2 \\
12-Feb-2008 & 8 & 65 & 65 & 65 & 65 & 0 \\
16-Feb-2008 & 12 & 45 & 43 & 45 & 45 & 1 \\
20-Feb-2008 & 16 & 20 & 20 & 21 & 20 & 1 \\
24-Feb-2008 & 20 & 20 & 18 & 18 & 19 & 1 \\
28-Feb-2008 & 24 & 11 & 12 & 12 & 12 & 0 \\
3-Mar-2008 & 28 & 13 & 12 & 13 & 12 & 1 \\
7-Mar-2008 & 32 & 23 & 21 & 21 & 22 & 1 \\
11-Mar-2008 & 36 & 12 & 11 & 12 & 12 & 0 \\
15-Mar-2008 & 40 & 13 & 13 & 14 & 13 & 0 \\
19-Mar-2008 & 44 & 11 & 11 & 11 & 11 & 0 \\
28-Mar-2008 & 53 & 15 & 15 & 15 & 15 & 0 \\
3-Apr-2008 & 59 & 11 & 11 & 11 & 11 & 0 \\
10-Apr-2008 & 66 & 11 & 10 & 12 & 11 & 1 \\
24-Apr-2008 & 80 & 14 & 14 & 14 & 14 & 0 \\
5-May-2008 & 91 & 12 & 13 & 12 & 13 & 1 \\
13-May-2008 & 99 & 8 & 9 & 9 & 9 & 0 \\
23-May-2008 & 109 & 9 & 12 & 10 & 10 & 1 \\
\hline
\end{tabular}


Appendix E7: Ammonia

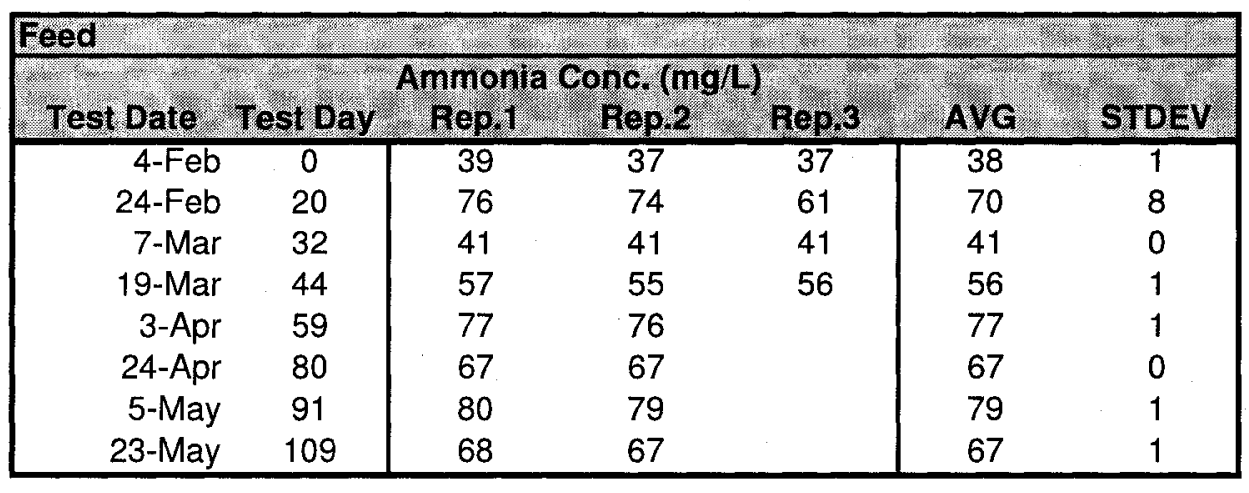

\begin{tabular}{|c|c|c|c|c|c|c|}
\hline \\
\hline \multicolumn{7}{|c|}{ Control Reactor (R1) } \\
\hline Test Date & Test Day & Rep. 1 & Rep.2 & Rep. 3 & AVG & STDEV \\
\hline $4-F e b-2008$ & 0 & 69 & 66 & 69 & 68 & 2 \\
\hline 16-Feb-2008 & 12 & 69 & 67 & 68 & 68 & 1 \\
\hline 20-Feb-2008 & 16 & 27 & 28 & 27 & 27 & 1 \\
\hline 24-Feb-2008 & 20 & 99 & 97 & 97 & 98 & 1 \\
\hline 28-Feb-2008 & 24 & 103 & 109 & 106 & 106 & 3 \\
\hline 3-Mar-2008 & 28 & 94 & 96 & 95 & 95 & 1 \\
\hline 7-Mar-2008 & 32 & 95 & 95 & 95 & 95 & 0 \\
\hline 11-Mar-2008 & 36 & 69 & 69 & 69 & 69 & 0 \\
\hline 15-Mar-2008 & 40 & 79 & 79 & 79 & 79 & 0 \\
\hline 19-Mar-2008 & 44 & 63 & 60 & 62 & 62 & 2 \\
\hline 28-Mar-2008 & 53 & 92 & 94 & & 93 & 2 \\
\hline 3-Apr-2008 & 59 & 90 & 91 & & 91 & 0 \\
\hline 10-Apr-2008 & 66 & 109 & 104 & & 107 & 3 \\
\hline 24-Apr-2008 & 80 & 114 & 117 & & 116 & 2 \\
\hline 5-May-2008 & 91 & 119 & 130 & & 125 & 8 \\
\hline 13-May-2008 & 99 & 111 & 110 & & 111 & 1 \\
\hline 23-May-2008 & 109 & 80 & 79 & & 80 & 1 \\
\hline
\end{tabular}




\begin{tabular}{|rc|ccc|c|c|}
\hline \multicolumn{7}{|c|}{ Enzyme \& Bacterial Additives - High Dose Reactor (R2) } \\
\hline \multicolumn{7}{|c|}{ Ammonia Conc. (mglL) } \\
Test Date & Test Day & Rep.1 & Rep.2 & Rep.3 & AVG & STDEV \\
\hline 4-Feb-2008 & 0 & 71 & 74 & 74 & 73 & 2 \\
16-Feb-2008 & 12 & 76 & 80 & 75 & 77 & 3 \\
20-Feb-2008 & 16 & 79 & 80 & 78 & 79 & 1 \\
24-Feb-2008 & 20 & 86 & 88 & 88 & 87 & 1 \\
28-Feb-2008 & 24 & 103 & 103 & 103 & 103 & 0 \\
3-Mar-2008 & 28 & 78 & 78 & 78 & 78 & 0 \\
7-Mar-2008 & 32 & 68 & 68 & 68 & 68 & 0 \\
11-Mar-2008 & 36 & 73 & 73 & 73 & 73 & 0 \\
15-Mar-2008 & 40 & 77 & 77 & 77 & 77 & 0 \\
19-Mar-2008 & 44 & 73 & 72 & 74 & 73 & 1 \\
28-Mar-2008 & 53 & 99 & 101 & & 100 & 1 \\
3-Apr-2008 & 59 & 84 & 83 & & 83 & 1 \\
10-Apr-2008 & 66 & 91 & 96 & & 93 & 4 \\
24-Apr-2008 & 80 & 106 & 108 & & 107 & 2 \\
5-May-2008 & 91 & 121 & 121 & & 121 & 0 \\
13-May-2008 & 99 & 88 & 87 & & 87 & 0 \\
23-May-2008 & 109 & 79 & 83 & & 81 & 3 \\
\hline
\end{tabular}

\begin{tabular}{|cc|ccc|cc|c|}
\hline \multicolumn{8}{|c|}{ Enzyme \& Bacterial Additives - Low Dose Reactor (R3) } \\
\hline \multicolumn{7}{|c|}{ Ammonia Conc. (mg/L) } \\
Test Date & Test Day & Cep.1 & Rep.2 & Rep.3 & AVG & STDEV \\
\hline 4-Feb-2008 & 0 & 81 & 78 & 75 & 78 & 2 \\
16-Feb-2008 & 12 & 31 & 33 & 30 & 31 & 2 \\
20-Feb-2008 & 16 & 27 & 27 & 27 & 27 & 0 \\
24-Feb-2008 & 20 & 93 & 97 & 98 & 96 & 3 \\
28-Feb-2008 & 24 & 116 & 117 & 117 & 117 & 0 \\
3-Mar-2008 & 28 & 90 & 84 & 87 & 87 & 3 \\
7-Mar-2008 & 32 & 70 & 70 & 70 & 70 & 0 \\
11-Mar-2008 & 36 & 65 & 65 & 65 & 65 & 0 \\
15-Mar-2008 & 40 & 77 & 77 & 77 & 77 & 0 \\
19-Mar-2008 & 44 & 44 & 42 & 41 & 42 & 2 \\
28-Mar-2008 & 53 & 85 & 88 & & 86 & 2 \\
3-Apr-2008 & 59 & 94 & 95 & & 94 & 1 \\
10-Apr-2008 & 66 & 88 & 88 & & 88 & 0 \\
24-Apr-2008 & 80 & 98 & 100 & & 99 & 1 \\
5-May-2008 & 91 & 112 & 108 & & 110 & 3 \\
13-May-2008 & 99 & 81 & 77 & & 79 & 3 \\
23-May-2008 & 109 & 74 & 76 & & 75 & 2 \\
\hline
\end{tabular}




\begin{tabular}{|cc|ccc|cc|c|}
\hline \multicolumn{7}{|c|}{ Microaeration - High Dose Reactor (R4) } \\
\hline \multicolumn{7}{|c|}{ Ammonia Conc. $(\mathrm{mg} / \mathrm{l})$} \\
Test Date & Test Day & Rep.1 & Rep.2 & Rep.3 & AVG & STDEV \\
\hline 4-Feb-2008 & 0 & 89 & 91 & 86 & 89 & 1 \\
16-Feb-2008 & 12 & 74 & 72 & 69 & 72 & 3 \\
20-Feb-2008 & 16 & 80 & 86 & 83 & 83 & 3 \\
24-Feb-2008 & 20 & 79 & 79 & 81 & 80 & 1 \\
28-Feb-2008 & 24 & 101 & 100 & 101 & 101 & 0 \\
3-Mar-2008 & 28 & 87 & 84 & 85 & 85 & 1 \\
7-Mar-2008 & 32 & 82 & 82 & 82 & 82 & 0 \\
11-Mar-2008 & 36 & 108 & 108 & 108 & 108 & 0 \\
15-Mar-2008 & 40 & 123 & 123 & 123 & 123 & 0 \\
19-Mar-2008 & 44 & 135 & 140 & 141 & 139 & 3 \\
28-Mar-2008 & 53 & 1 & 1 & & 1 & 0 \\
3-Apr-2008 & 59 & 87 & 88 & & 87 & 1 \\
10-Apr-2008 & 66 & 86 & 86 & & 86 & 1 \\
24-Apr-2008 & 80 & 99 & 94 & & 96 & 3 \\
5-May-2008 & 91 & 104 & 109 & & 107 & 4 \\
13-May-2008 & 99 & 92 & 89 & & 90 & 1 \\
23-May-2008 & 109 & 77 & 76 & & 76 & 0 \\
\hline
\end{tabular}

\begin{tabular}{|rc|ccc|c|c|c|}
\hline \multicolumn{7}{|c|}{ Microaeration - Low Dose Reactor (R5) } \\
\hline \multicolumn{7}{|c|}{ Ammonia Conc. $(\mathbf{m g} /$ l $)$} \\
Test Date & Test Day & Rep.1 & Rep.2 & Rep.3 & AVG & STDEV \\
\hline 4-Feb-2008 & 0 & 91 & 91 & 89 & 90 & 0 \\
16-Feb-2008 & 12 & 63 & 66 & 64 & 64 & 2 \\
20-Feb-2008 & 16 & 99 & 95 & 97 & 97 & 2 \\
24-Feb-2008 & 20 & 113 & 112 & 114 & 113 & 1 \\
28-Feb-2008 & 24 & 106 & 106 & 106 & 106 & 0 \\
3-Mar-2008 & 28 & 108 & 106 & 107 & 107 & 1 \\
7-Mar-2008 & 32 & 93 & 94 & 93 & 93 & 0 \\
11-Mar-2008 & 36 & 93 & 93 & 93 & 93 & 0 \\
15-Mar-2008 & 40 & 87 & 87 & 87 & 87 & 0 \\
19-Mar-2008 & 44 & 100 & 103 & 98 & 100 & 3 \\
28-Mar-2008 & 53 & 99 & 100 & & 99 & 0 \\
3-Apr-2008 & 59 & 110 & 105 & & 108 & 4 \\
10-Apr-2008 & 66 & 86 & 86 & & 86 & 0 \\
24-Apr-2008 & 80 & 90 & 93 & & 92 & 3 \\
5-May-2008 & 91 & 94 & 99 & & 97 & 4 \\
13-May-2008 & 99 & 80 & 78 & & 79 & 1 \\
23-May-2008 & 109 & 76 & 74 & & 75 & 1 \\
\hline
\end{tabular}




\section{Appendix E8: Headspace Gas Analysis}

\begin{tabular}{|c|c|c|c|c|c|c|c|c|c|}
\hline $\begin{array}{l}\text { Date: } \\
\text { days: }\end{array}$ & 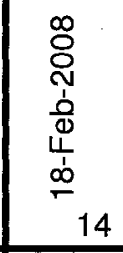 & 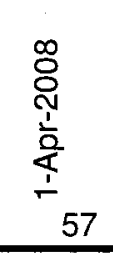 & 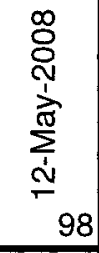 & 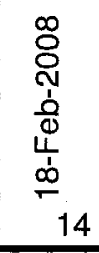 & 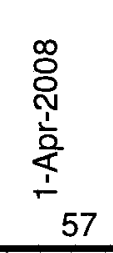 & 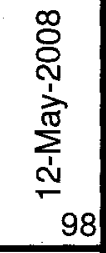 & 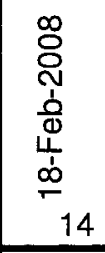 & 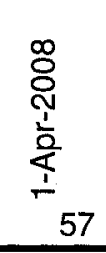 & 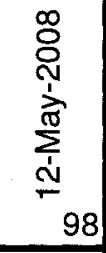 \\
\hline & $\% \mathrm{~N}_{2} \&$ & & & $\% \mathrm{CO}_{2}$ & & & $\% \mathrm{CH}_{4}$ & & \\
\hline Control & $\begin{array}{l}86.9 \\
92.5 \\
86.3\end{array}$ & $\begin{array}{l}76.3 \\
76.4 \\
78.8\end{array}$ & $\begin{array}{c}64 \\
60.1 \\
60\end{array}$ & $\begin{array}{c}11.4 \\
6.7 \\
11.3\end{array}$ & $\begin{array}{l}12.4 \\
12.3 \\
11.1\end{array}$ & $\begin{array}{c}10 \\
11.1 \\
11.2\end{array}$ & $\begin{array}{l}1.7 \\
0.8 \\
2.4\end{array}$ & $\begin{array}{l}11.3 \\
11.3 \\
10.1\end{array}$ & $\begin{array}{c}26 \\
28.8 \\
28.8\end{array}$ \\
\hline $\begin{array}{r}\text { AVERACE } \\
\text { ST DEV }\end{array}$ & 89 & $\begin{array}{l}77 \\
1.42\end{array}$ & $\begin{array}{l}61 \\
2.28\end{array}$ & $\begin{array}{r}10 \\
2.69\end{array}$ & 0.72 & $\begin{array}{l}11 \\
0.67\end{array}$ & 0.80 & 0.69 & $\begin{array}{l}28 \\
1.62\end{array}$ \\
\hline Enzymes $4 \mathrm{~g} / 2 \mathrm{wk}$ & $\begin{array}{l}91.8 \\
96.4 \\
93.7\end{array}$ & $\begin{array}{c}77.2 \\
84.1 \\
78\end{array}$ & $\begin{array}{c}41.5 \\
46 \\
47.3\end{array}$ & $\begin{array}{l}6.7 \\
2.9 \\
5.1\end{array}$ & $\begin{array}{c}10.8 \\
7.5 \\
9.8\end{array}$ & $\begin{array}{c}13.8 \\
12.6 \\
13\end{array}$ & $\begin{array}{l}1.5 \\
0.7 \\
1.2\end{array}$ & $\begin{array}{c}12 \\
8.4 \\
12.2\end{array}$ & $\begin{array}{l}44.7 \\
41.4 \\
39.7\end{array}$ \\
\hline $\begin{array}{l}\text { AVERAGE } \\
\text { ST DEV }\end{array}$ & $\begin{array}{r}94 \\
2.31\end{array}$ & $\begin{array}{c}80 \\
3.77\end{array}$ & $\begin{array}{l}45 \\
3.04 \\
\end{array}$ & $\begin{array}{c}5 \\
1.91 \\
\end{array}$ & $\begin{array}{l}9 \\
1.69\end{array}$ & $\begin{array}{r}13 \\
0.61 \\
\end{array}$ & 0.4 & $\frac{11}{2.14}$ & $\begin{array}{r}42 \\
2.54\end{array}$ \\
\hline Enzymes $2 \mathrm{~g} / 2 \mathrm{wk}$ & $\begin{array}{l}87.9 \\
92.9 \\
91.8\end{array}$ & $\begin{array}{l}77.5 \\
76.9 \\
76.7\end{array}$ & $\begin{array}{l}78.3 \\
79.9 \\
80.1\end{array}$ & $\begin{array}{l}10 \\
6.1 \\
6.9\end{array}$ & $\begin{array}{c}11.7 \\
12 \\
12.1\end{array}$ & $\begin{array}{l}9.3 \\
8.9 \\
8.8\end{array}$ & $\begin{array}{c}2.1 \\
1 \\
1.3\end{array}$ & $\begin{array}{l}10.8 \\
11.1 \\
11.2\end{array}$ & $\begin{array}{l}12.4 \\
11.2 \\
11.1\end{array}$ \\
\hline $\begin{array}{r}\text { AVERAGE } \\
\text { ST DEV }\end{array}$ & $\begin{array}{r}91 \\
2.63 \\
\end{array}$ & $\begin{array}{l}77 \\
0.42 \\
\end{array}$ & $\begin{array}{l}79 \\
0.99 \\
\end{array}$ & $\begin{array}{r}8 \\
2.06 \\
\end{array}$ & $\begin{array}{l}12 \\
0.21 \\
\end{array}$ & $\begin{array}{r}9 \\
0.26 \\
\end{array}$ & $\begin{array}{r}1 \\
0.57 \\
\end{array}$ & $\begin{array}{r}11 \\
0.21 \\
\end{array}$ & $\begin{array}{r}12 \\
0.72 \\
\end{array}$ \\
\hline
\end{tabular}




\section{Appendix F: Figures with 95\% C.I. - Continuous Flow Reactor Tests}

Figure 4-31(b): Profiles of the total suspended solids of the influent and effluents from the continuous flow reactors

Figure 4-32(b): Profiles of the total and soluble COD of the influent and effluents from the microaeration and control continuous flow reactors

Figure 4-33(b): Profiles of the total and soluble COD of the influent and effluents from the enzyme and the control continuous flow reactors

Figure 4-34(b): Profiles of the volatile (organic) acids concentrations in the influent and effluents from the continuous flow reactors....

Figure 4-35(b): Profiles of the protein concentrations in the influent and effluents from the continuous flow reactors

Figure 4-36(b): Profiles of the carbohydrates concentration in the influent and effluents from the continuous flow reactors

Figure 4-37(b): Profiles of the ammonia concentrations in the influent and effluents from the continuous flow reactors

Figure 4-38(b): Gas phase analysis of the headspace gas collected from the two enzyme and bacterial additive reactors, and the control reactor 


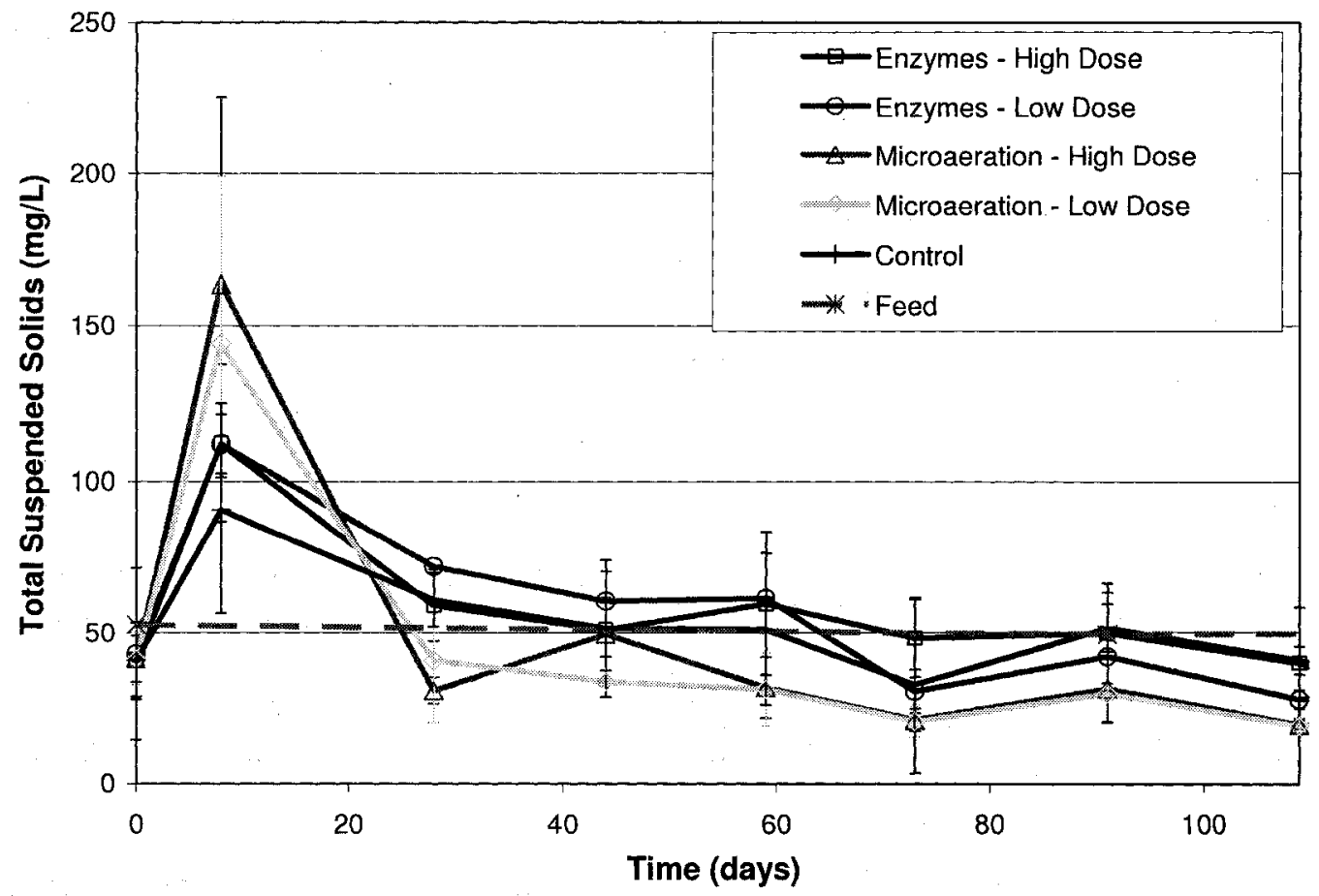

Figure 4-31(b): Profiles of the total suspended solids of the influent and effluents from the continuous flow reactors

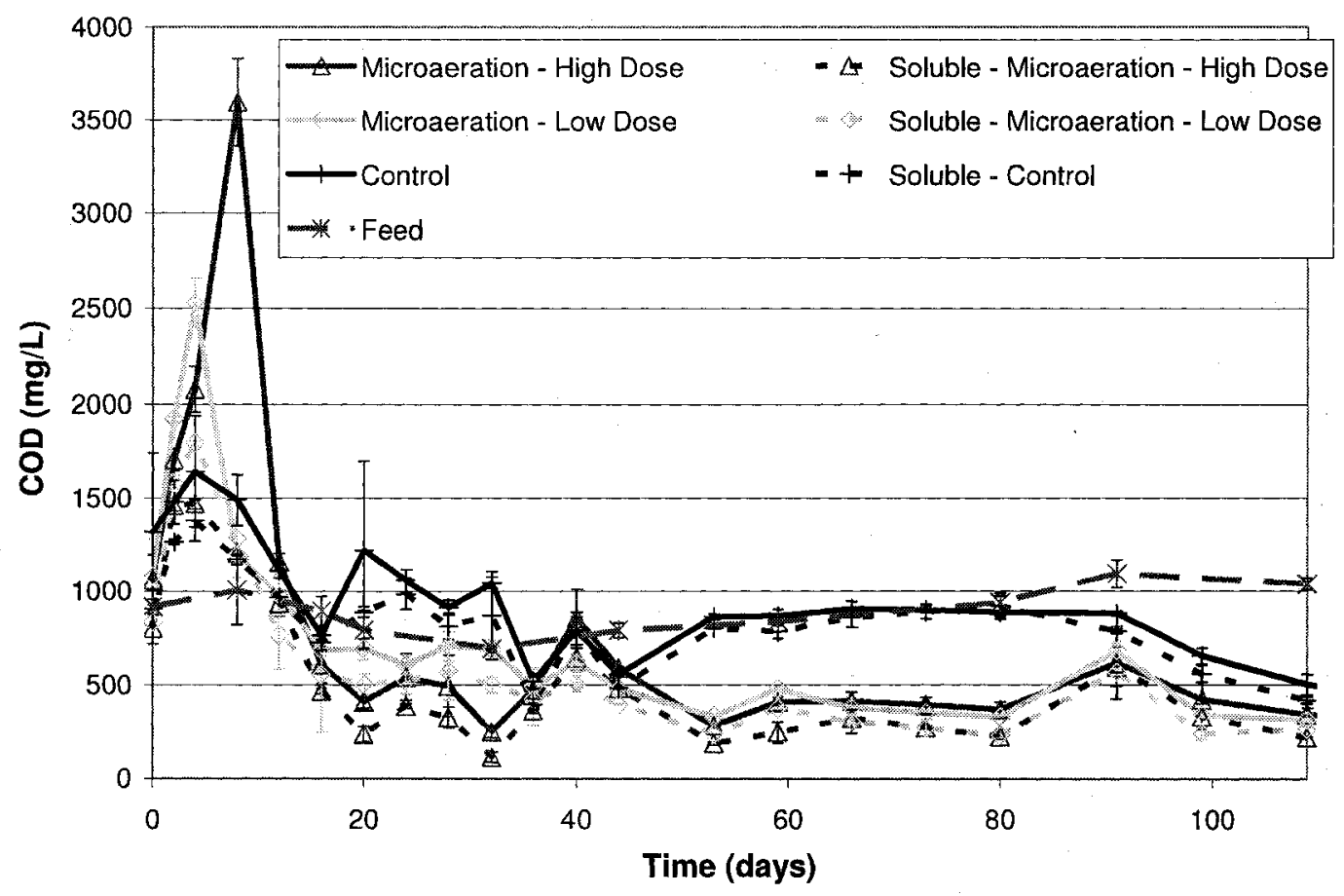

Figure 4-32(b): Profiles of the total and soluble COD of the influent and effluents from the microaeration and control continuous flow reactors 


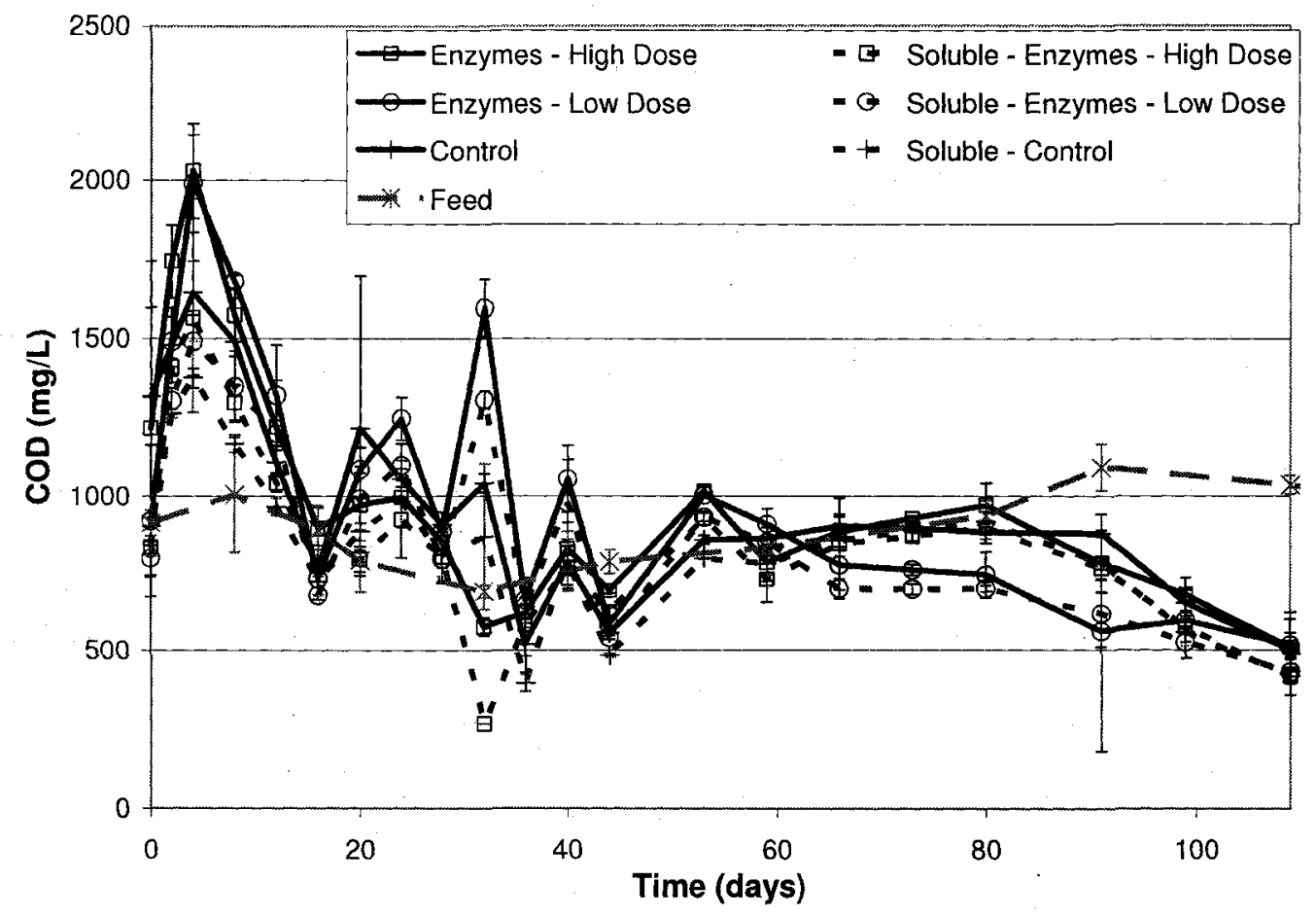

Figure 4-33(b): Profiles of the total and soluble COD of the influent and effluents from the enzyme and the control continuous flow reactors

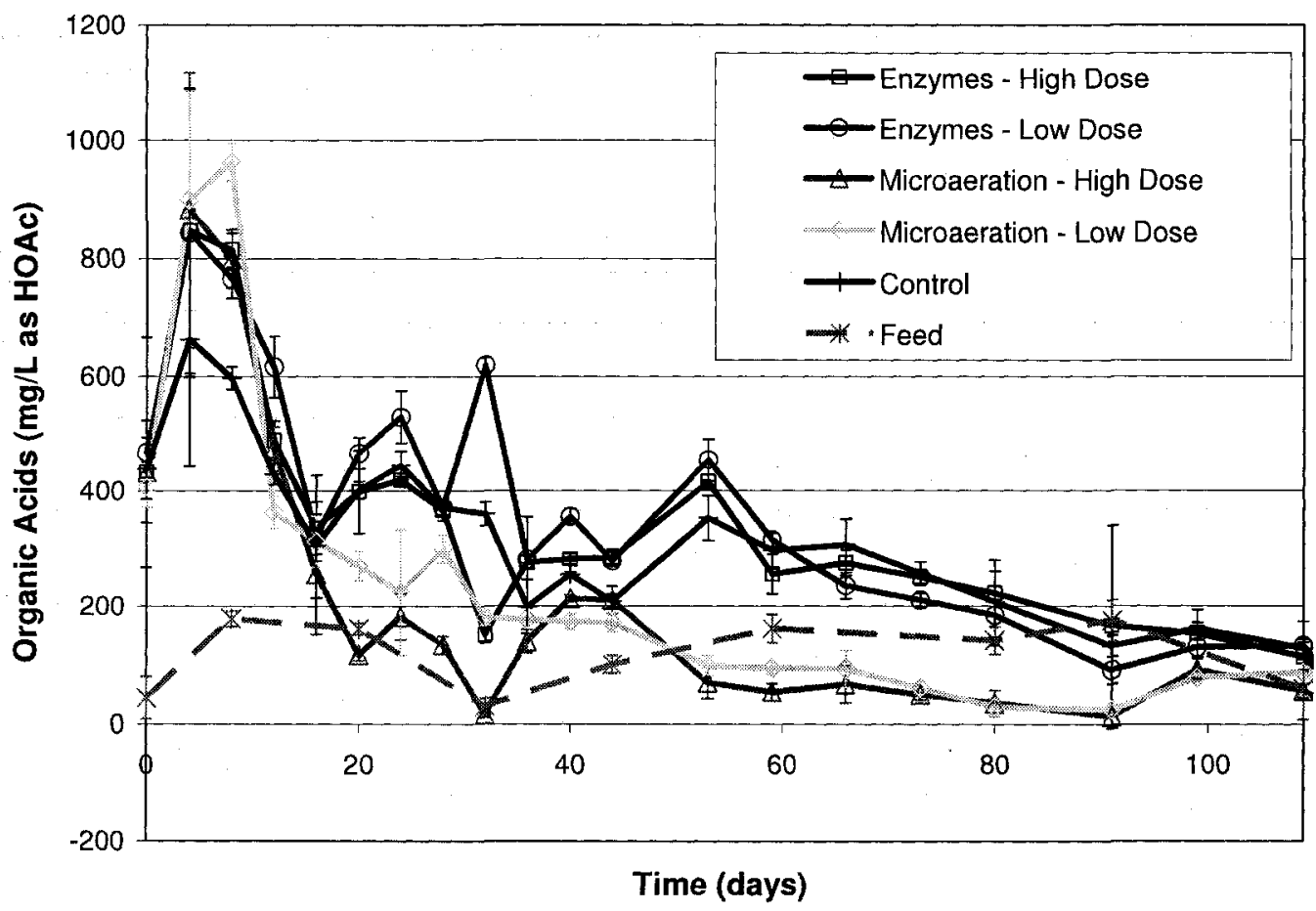

Figure 4-34(b): Profiles of the volatile (organic) acids concentrations in the influent and effluents from the continuous flow reactors 


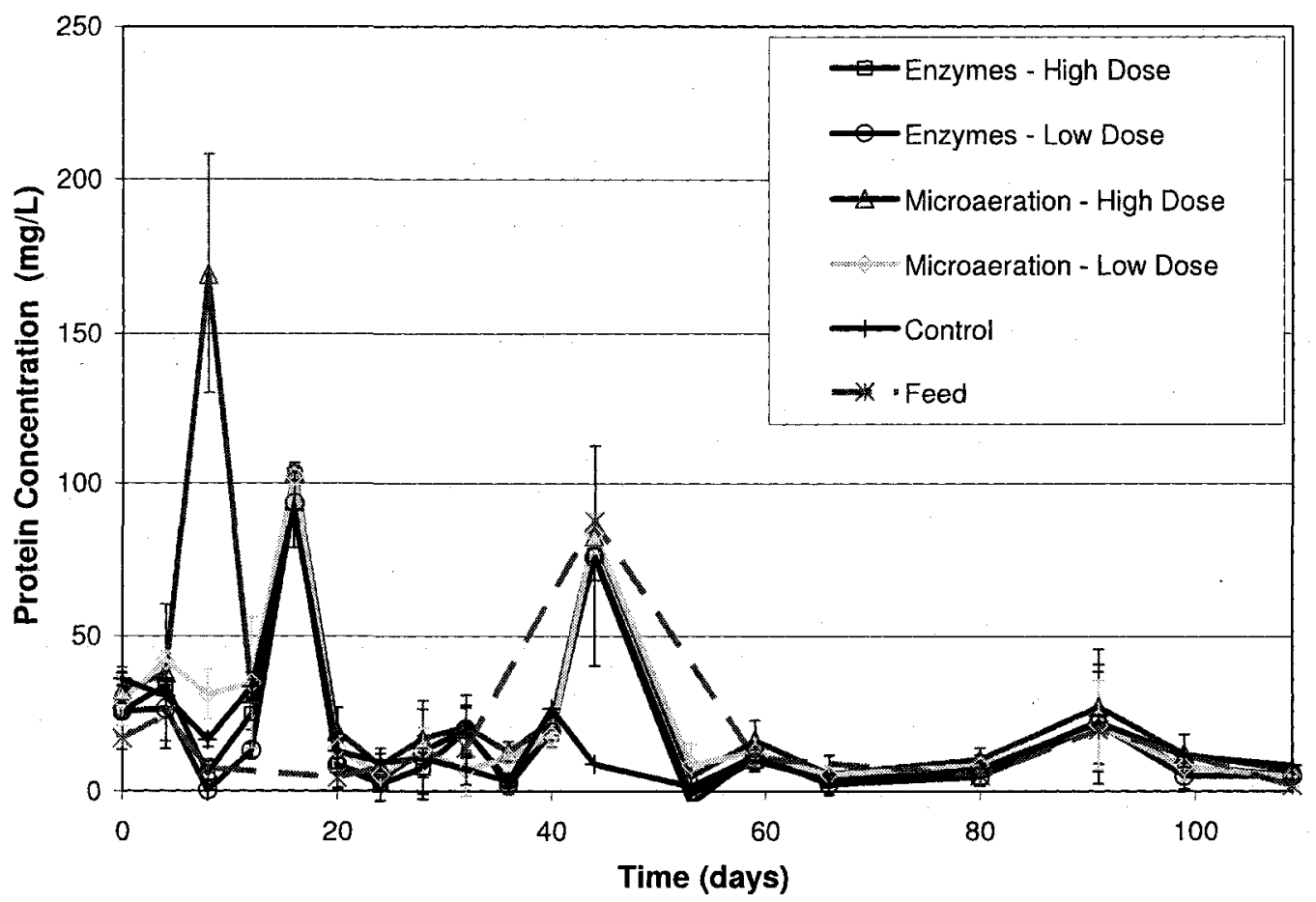

Figure 4-35(b): Profiles of the protein concentrations in the influent and effluents from the continuous flow reactors

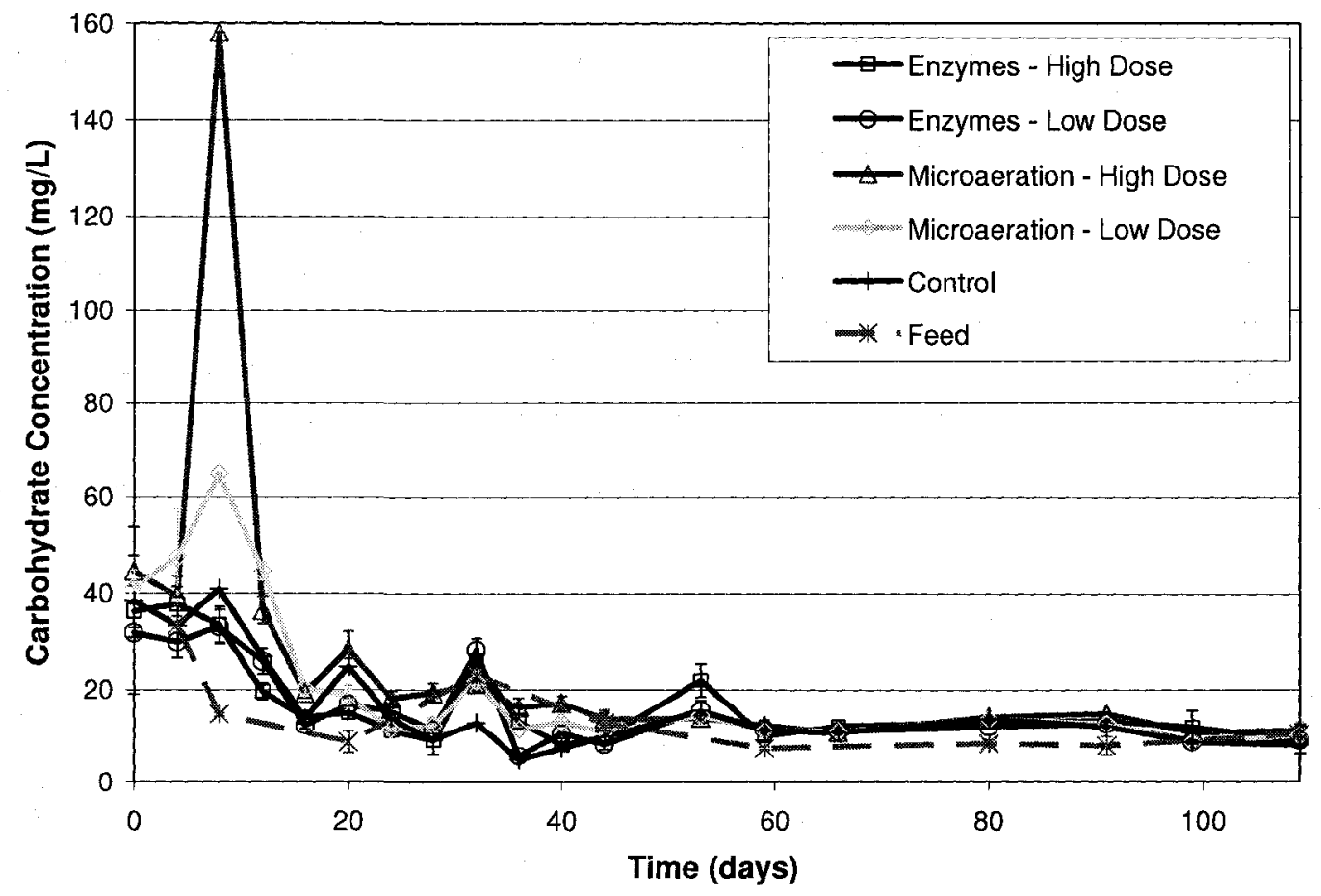

Figure 4-36(b): Profiles of the carbohydrates concentration in the influent and effluents from the continuous flow reactors 


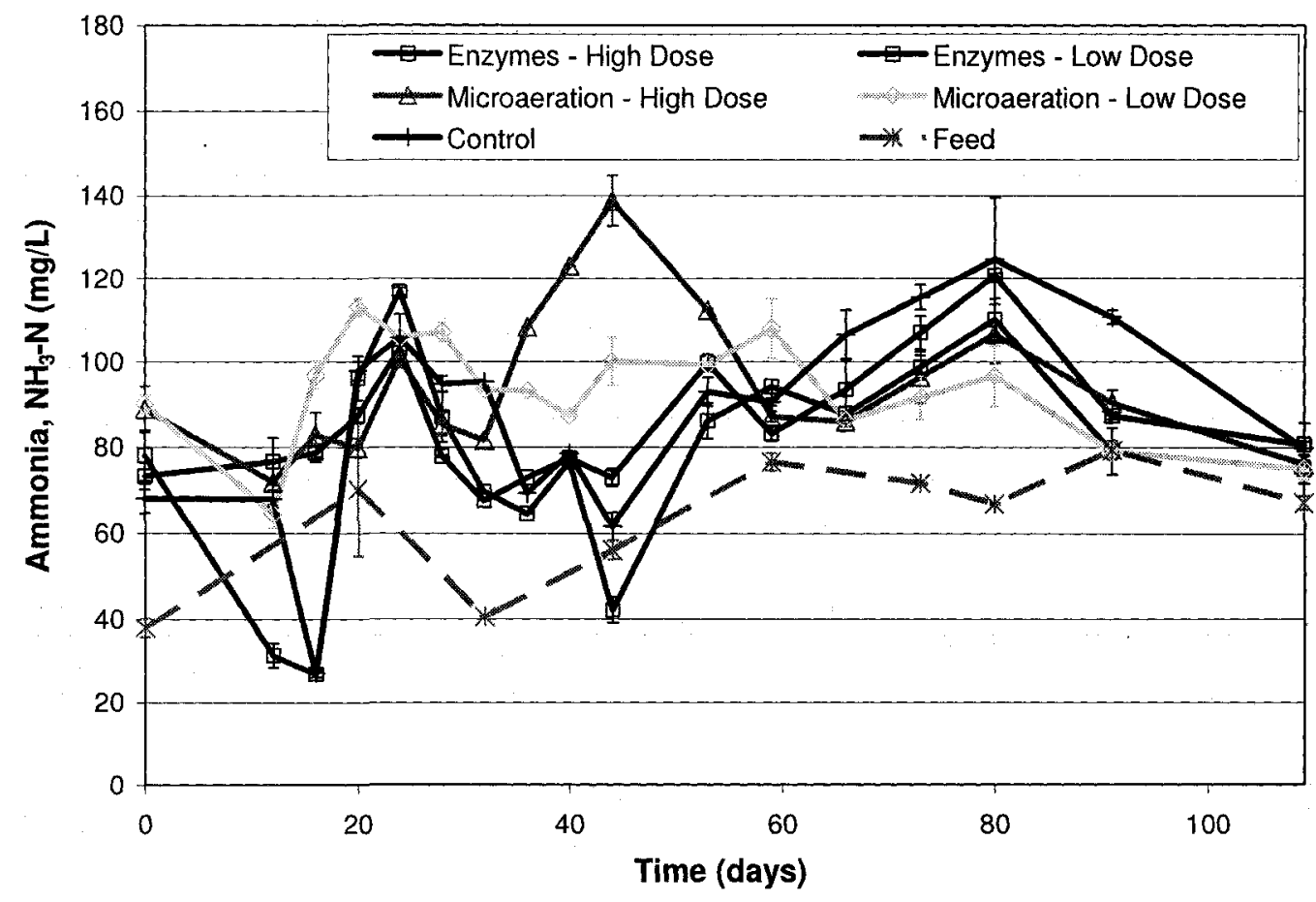

Figure 4-37(b): Profiles of the ammonia concentrations in the influent and effluents from the continuous flow reactors

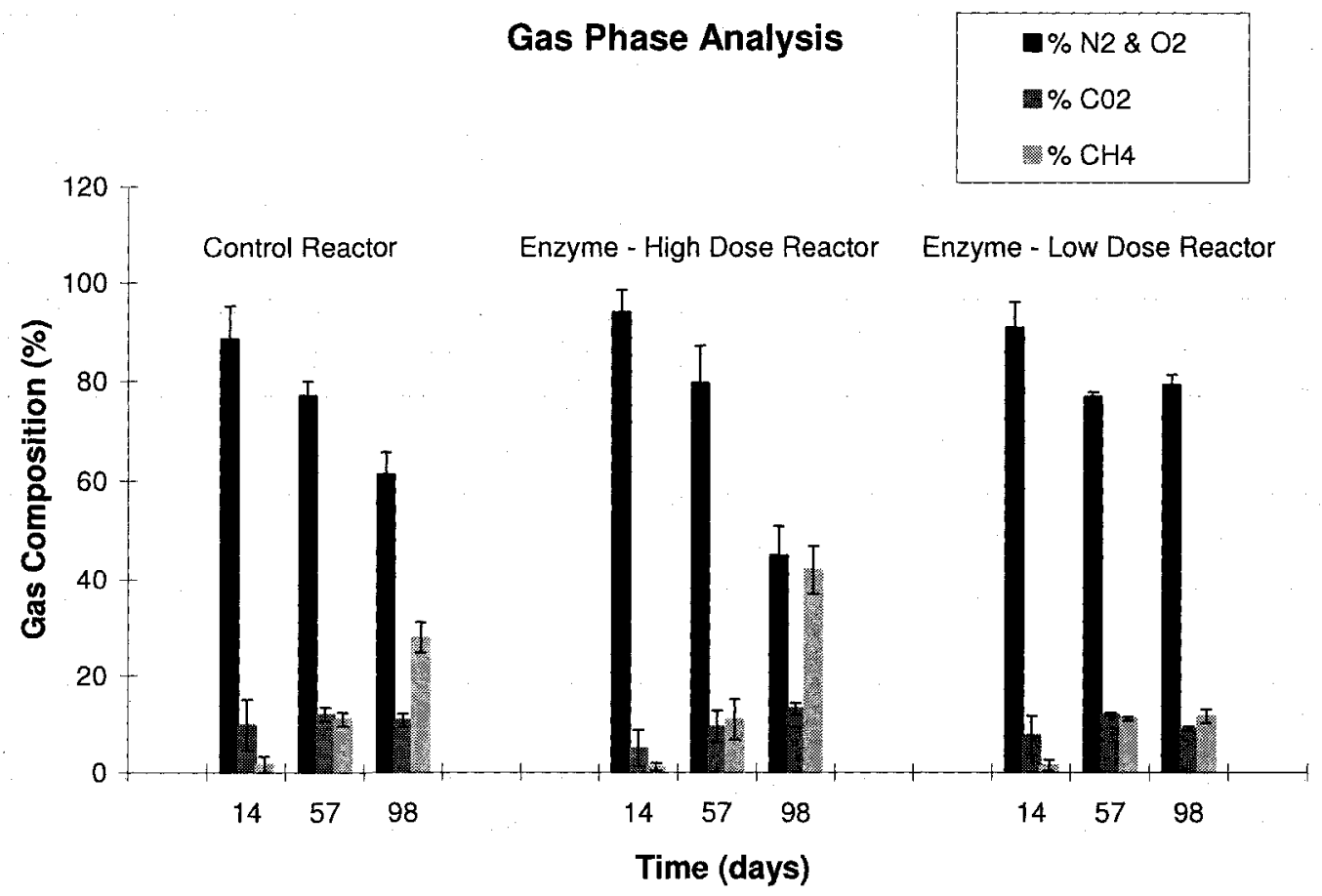

Figure 4-38(b): Gas phase analysis of the headspace gas collected from the two enzyme and bacterial additive reactors, and the control reactor 